\title{
NBSIR 77-1308
}

\section{Annual Conference on Fire Research}

Clayton Huggett, Editor

Center for Fire Research

Institute for Applied Technology

National Bureau of Standards

Washington, D.C. 20234

October 1977

Final Report

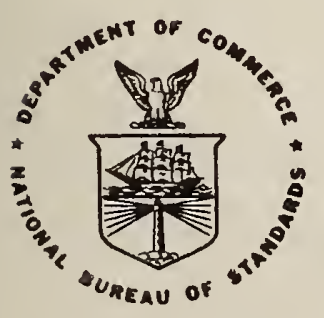

U.S. DEPARTMENT OF COMMERCE

NATIONAL BUREAU OF STANDARDS 

NBSIR 77-1308

\section{ANNUAL CONFERENCE ON FIRE RESEARCH}

Clayton Huggett, Editor

Center for Fire Research Institute for Applied Technology National Bureau of Standards

Washington, D.C. 20234

October 1977

Final Report

U.S. DEPARTMENT OF COMMERCE, Juanita M. Kreps, Secretary

Dr. Sidney Harman, Under Secretary

Jordan J. Baruch, Assistant Secretary for Science and Technology

NATIONAL BUREAU OF. STANDARDS, Ernest Ambler, Acting Director 



\section{FOREWORD}

This Conference is an important first for the fire research community. In past years there have been meetings at which grantees have described their work but NBS staff have not made presentations. On other occasions a few of the Center's staff have presented their programs to meetings attended by some of the grantees. But never before have we managed to collect in one place all of the NBS grantees and all of the NBS program chiefs and senior investigators. Indeed, the NBS program has never before been presented all at once. We are able to do this at this time because the grants and the NBS work are now all part of the same overall program.

We at NBS regard this work of our grantees as an integral part of our program, in fact an indispensable part. Despite the difficulties imposed by geographical separations we have sought to treat the work done on grants with the same concern and consideration as the work done here at NBS. After one year of work by $\mathrm{Dr}$. Huggett and the chiefs to improve grantees' understanding of our goals and objectives and to encourage our people to work more closely with the grantees, we see many encouraging signs that the efforts are paying of $f$ handsomely. Our work is stimulated and enriched by the work done elsewhere; the work of the grantees is more relevant to the National goal we all pursue. I have every confidence that this conference will give impetus to this trend and that all participants will feel the time here was well spent. 

FOREWORD

Final Program. . . . . . . . . . . . . . . . . . . . . .

ABSTRACTS OF PROGRAMS

Center for Fire Research

Program for Information and Hazard Analysis . . . . . . . . . . . . .

Program for Chemistry. . . . . . . . . . . . . . . . . . . . . .

Program for Physics and Dynamics . . . . . . . . . . . . . . . . . 12

Program for Toxicology of Combustion Products. . . . . . . . . . . . . . . 17

Program for Fire Prevention--Products. . . . . . . . . . . . . . . . . . 22

Program for Fire Control--Furnishings. . . . . . . . . . . . . . . . . 23

Program for Fire Control-Construction. . . . . . . . . . . . . . . . . . . 24

Program for Fire Detection and Control Systems . . . . . . . . . . . . . . . 29

Program for Design Concepts. . . . . . . . . . . . . . . . . . . . . 32

Contracts and Grants

Brown University

Flame Propagation and Extinction for Solid Fuels . . . . . . . . . . . .

California Institute of Technology

Convective Flow Associated with Room Fires . . . . . . . . . . . . . . .

Cornell University

Flame Spread Over Liquid Fuel. . . . . . . . . . . . . . . . . .

Georgia Institute of Technology

Properties of Combustion Products from Building Fires. . . . . . . . . . .

Georgia Institute of Technology

Effects of Ignition Sources and Fire Retardants on Material Ignition . . . . .

Georgia Institute of Technology

A Kinetics Investigation of Several Reactions Involving Bromine Compounds as

Related to Flame Initiation and Propagation. . . . . . . . . . . . . . .

Harvard University - Factory Mutual Research Corporation

The Home Fire Project . . . . . . . . . . . . . . . . . . . . . .

Full-Scale Fire Test Program . . . . . . . . . . . . . . . . .

Prediction of a Fire . . . . . . . . . . . . . . . . . . . . .

The Modeling of Fires in an Enclosure. . . . . . . . . . . . . . . .

Radiation from Flames and Smoke Layers . . . . . . . . . . . . . . . . .

The Effect of Radiation on Ignition and Fire Spread. . . . . . . . . . . . . .

The Heat of Combustion of Smoke. . . . . . . . . . . . . . . . . . 
The Johns Hopkins University

Evaluation of Toxicity of Combustion Products . . . . . . . . . . . . .

The Johns Hopkins University/Applied Physics Laboratory

Fire Casualties Study . . . . . . . . . . . . . . . . . . . . .

Combustion Research

The Pennsylvania State University

An Investigation of Fire Induced Plumes Along a Vertical Wall . . . . . . .

Portland Cement Association

Simulation of Realistic Thermal Restraint During Fire Tests of Floor and

Roof Assemblies - Phases III-V. . . . . . . . . . . . . . . . . .

Princeton University

An Experimental Investigation of Flame Spread Over Condensed Combustibles:

Gas Phase Interactions. . . . . . . . . . . . . . . . . . . . .

Princeton University, Guggenheim Laboratories

Modeling the Generation of Toxic Gases by the Smoldering Combustion of

Polyurethanes . . . . . . . . . . . . . . . . . . . . . . .

Stanford Research Institute

Application of Decision Analysis to Problems of Fire Hazard Quantification. .

Stevens Institute of Technology

Flammability Studies of Cellular Plastics . . . . . . . . . . . .

University of California at Berkeley

Fire Safety in Urban Housing. . . . . . . . . . . . . . . . . . . . .

Full-Scale Experiments and Fire Tests . . . . . . . . . . . . . . .

Flame Radiation . . . . . . . . . . . . . . . . . . . . .

Fire Modeling . . . . . . . . . . . . . . . . . . . . . . .

Polymer Combustion and Flame Chemistry. . . . . . . . . . . . .

University of California at Berkeley

Human Behavior in Institutional Fires and Its Design Implications . . . . . .

University of California at San Diego

Flame Extinction in Relationship to Fire Suppression. . . . . . . . . . . . .

University of Maryland

A Theoretical Rationalization of the Goal Oriented Systems Approach to

Building Fire Safety. . . . . . . . . . . . . . . . . .

University of Maryland

Smoke as a Determinant of Human Behavior in Fire Situations . . . . . . . . .

University of Maryland

The Examination of Selected Systemic Variables Influencing the Discharge

Distribution Pattern from Automatic Sprinkler Heads . . . . . . . . . . .

Flame Suppression by Chemical Inhibitors. . . . . . . . . . . . . . 
University of Montana

Chemistry of Cellulosic Fires . . . . . . . . . . . . . . . . . . . . . .

University of Notre Dame

Fire and Smoke Spread . . . . . . . . . . . . . . . . . . .

University of Pittsburgh

Toxicity of Plastic Combustion Products . . . . . . . . . . . . . . .

University of Utah

The Physiological and Toxicological Aspects of Smoke Produced During the

Combustion of Polymeric Materials . . . . . . . . . . . . . . . . . .

Development of Protocol for Assessment of Relative Toxicity of Materials

Upon Combustion... . . . . . . . . . . . . . . . . . . . .

Smoke 0ptical Density Studies . . . . . . . . . . . . . . . . . 163

Polymer Degradation Studies . . . . . . . . . . . . . . . . . 165

University of Washington

Development and Evaluation of Vocal Alarm Systems for Hospitals and

Convalescent Homes ... . . . . . . . . . . . . . . . . .

Integrated Systems, Inc.

Air Movement and Smoke Diffusion Simulation Programs. . . . . . . . . . . 176

APPENDIX A - ORGANIZATION CHART, CENTER FOR FIRE RESEARCH . . . . . . . . . . . . 177

APPENDIX B - FEDERAL FIRE PREVENTION AND CONTROL ACT OF 1974; PL 93-498 • • • . . 178 



\section{CONFERENCE ON FIRE RESEARCH \\ Center for Fire Research \\ Institute for Applied Technology \\ National Bureau of Standards \\ August 3, 4, 5, 1977}

\section{Wednesday, August 3}

8:15 a.m. Registration, Employee Lounge

9:15 Opening Session, Green Auditorium

Welcome

Dr. Ernest Ambler, Acting Director

National Bureau of Standards

Dr. George Suzuki, Acting Deputy Director

Institute for Applied Technology

Update on the National Fire Prevention and Control Administration Mr. David Lucht, Deputy Administrator

National Fire Prevention and Control Administration

Program of the Center for Fire Research

Dr. John Lyons, Director

Center for Fire Research

The Extramural Research Program of the Center for Fire Research Dr. Clayton Huggett, Chief

Office of Extramural Research

11:00 Coffee Break, Employee Lounge

11:30 Simultaneous Technical Sessions

Green Auditorium

Fire Modeling

Dr. John Rockett, Discussion Leader

Lecture Room D

Hazard Analysis

Mr. Benjamin Buchbinder, Discussion Leader

12:30 p.m. Lunch, NBS Cafeteria

$1: 30$

Simultaneous Technical Sessions

Green Auditorium

Fire Modeling (Continued)

Lecture Room D

Systems Design

Mr. Harold Nelson, Discussion Leader

$3: 30$

Coffee Break 
Thursday, August 4

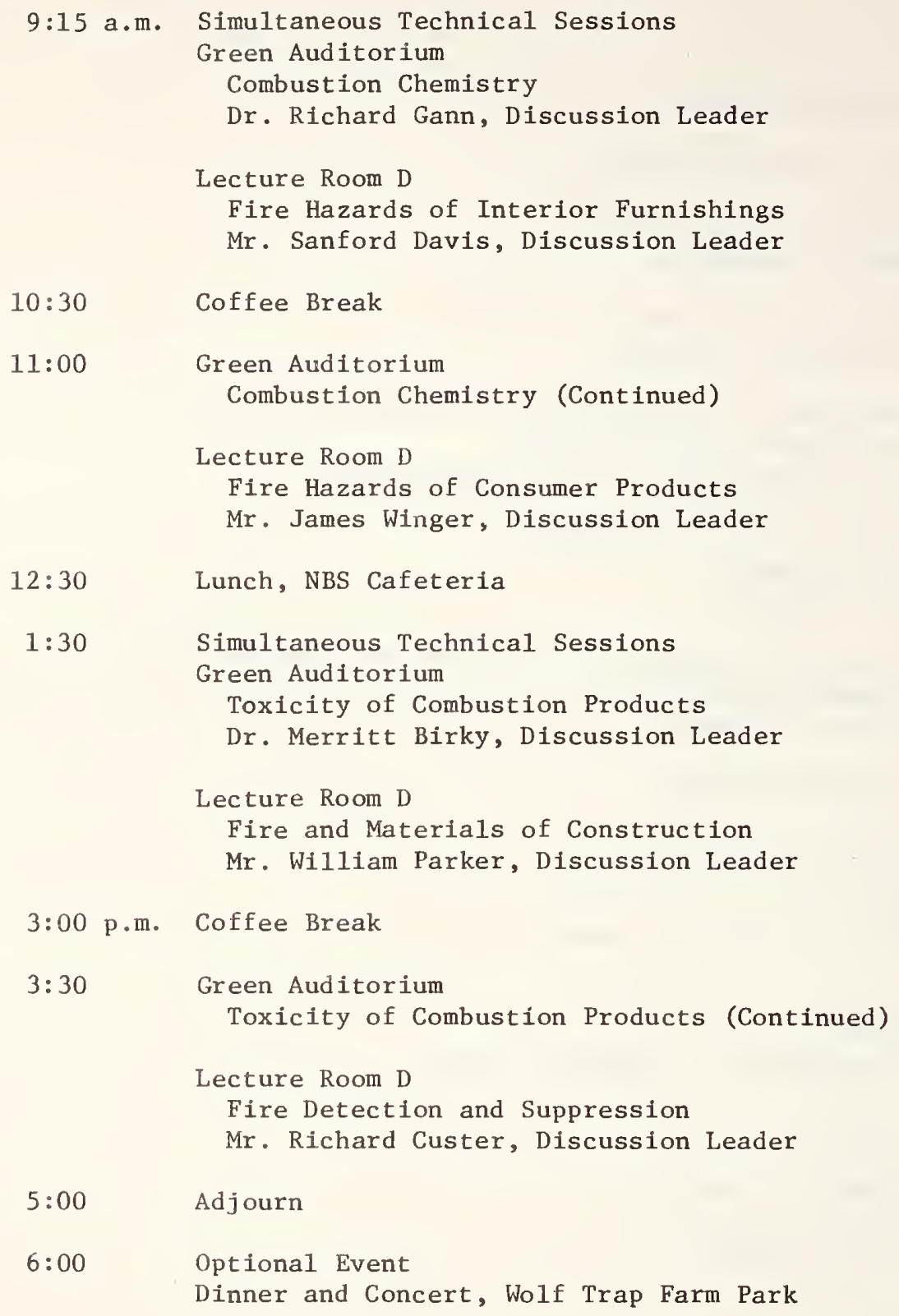


Closing Session (Continued)

Mr. Irwin A. Benjamin, Chairman

Response by Grantees - New Directions

Dr. Zoltan Annau

Dr. John de Ris

Dr. Robert Fristrom

Dr. John Keating

Closing of Conference

12:30 p.m. Lunch, NBS Cafeteria

$1: 30$

Free Time

Informal Discussions

Visits to Laboratories

Tour of Fire Research Facility (Building 205)

Tour of NBS

Transportation to Airports 


\section{PROGRAM FOR INFORMATION AND HAZARD ANALYSIS \\ FIRE SCIENCE DIVISION \\ CENTER FOR FIRE RESEARCH}

\section{$\underline{\text { Professional Personnel }}$}

Benjamin Buchbinder, Program Chief

Susan Helzer, Mathematician

Nora Jason, Technical Information Specialist

James Slater, Mathematician

Linda Miles, Research Associate (Cotton Foundation)

Kirt Smith, Research Associate (PPG Industries, Inc.)

\section{Hazard Quantification Project}

Quantitative methods are used in decision analysis framework to evaluate alternative intervention strategies for the reduction of fire losses. The choice of the best strategy is based on minimizing the cost of implementing the strategies and the associated fire losses incurred (i.e., the cost plus loss). The methodology does provide the appropriate framework for combining fire loss data, fire test results, and expert judgment to provide the technical basis for choosing among alternatives. The actual choice of a strategy rests with the policy makers. The role of hazard analysis is to provide the framework for the decision and the technical analysis, and to indicate where the policy makers need to supply value judgments. The methodology will be further applied to other problem areas such as mobile homes.

Accomplishments: A pilot decision analysis using the upholstered furniture problem as a test case; preliminary analysis of the effect of the proposed upholstered furniture standard and mandatory smoke detectors on the upholstered furniture flammability problem.

Delivery mechanisms will be reports of analyses, intervention strategies, presentations to professional organizations and contributions to standards-making organizations.

\section{General Hazard Analysis Project}

This is a study of the effect of fiber content, construction, level and type of FR finish on the ignition time of fabrics during combustion, the potential injury level and char integrity. Commercially treated apparel fabrics with varying percentages of phosphorus are tested on three different experimental devices (Mushroom Apparel Flammability Tester, Apparel Flammability Modeling Apparatus, Instrumented Mannequin) to study burning behavior of partially treated fabrics.

Accomplishments: Providing supporting data for the general apparel standard. 
Delivery mechanisms will be reports of analyses, presentations to professional organizations and supporting documentation for the general apparel standard.

\section{Plastics Hazard Analysis}

The objective is to identify and characterize those properties of plastics products which cause them to be a fire hazard in real-1ife situations; and to create an information base on fire hazards of plastics products for use in the design of appropriate test methods. Detailed investigative reports on plastic fires are obtained and analyzed, and the materials involved are identified and characterized in the laboratory. The chain of events of the fire is studied and verified when questionable. Fire performance and basic properties are determined in the laboratory and correlated with field data. The data are computerized and analyzed to assess the fire hazards of plastics.

Accomplishments: Acquisition of 175 field investigation reports, development of laboratory procedures for sample analysis, development of a computerized data base and laboratory simulations of observed fire patterns.

Delivery mechanisms will be published reports of analytical results, presentations to professional organizations, and contributions to the activities of volunteer standards organizations.

\section{Fire Research Information Services}

The objectives are to expand and maintain a techical fire literature collection, provide technical information services to the Center for Fire Research and provide information services to the fire community.

For the fire community, selected mailing lists are used to disseminate reports written by and for the Center for Fire Research; interlibrary loans are exchanged with participating institutions; and referrals are made to experts for specialized information.

Accomplishments: The collection and dissemination of information is continuous. Two reports resulting from a NASA contract will be published soon: "Fire Research Specialists: A Directory" by Nora H. Jason and "Hazard Characteristics of Combustion Products in Fires: The State-of-the-Art Report" by Merritt M. Birky. A listing of all reports written for and by the Center for Fire Research is published yearly.

Document acquisition, bibliographic searching and information services are directly related to Center for Fire Research projects and the technical interests of the fire community. 
Birky, M. M. Hazard Characteristics of the Combustion Products of Fires: The State-of-the-Art Report. National Bureau of Standards NBSIR 76-1234, May 1977. Final report. It also will be published as a National Aeronautics and Space Administration Contract report, NASA CR-135088; publication date to be announced.

Buchbinder, B. and Buchbinder, L. B. The Fire Hazard Analysis Process at the National Bureau of Standards. Fire Safety of Combustible Materials, International Symposium Proceedings, University of Edinburgh, October 1975.

Buchbinder, B., Helzer, S. G. and Offensend, F. Pilot Decision Analysis Model for Assessing Fire Losses. Presented at the NFPA Annual Meeting, Washington, D.C., May 18, 1977. It will be published in the Society of Fire Protection Engineers Seminar.

Helzer, S. Backup Report for the Proposed Standard for the Flammability of General Wearing Apparel by E. Braun, V. B. Cobble, S. Helzer, J. F. Krasny, R. D. Peacock and A. K. Stratton. National Bureau of Standards Report NBSIR 76-1072, Final Report, June 1976.

Jason, Nora H. Fire Research Publications, 1975. National Bureau of Standards NBSIR 76-1120. Final report.

Jason, Nora H. Fire Research Publications, 1976. National Bureau of Standards NBSIR to be published.

Jason, Nora H. Fire Research Speclalists: A Directory. A Contract report for the National Aeronautics and Space Administration, NASA CR-135089. Publication date to be announced.

Miles, L. Burning Behavior of Borderline Fabrics. Textile Flammability LeBlanc Symposium. Proceedings, New Orleans, April 1977.

Miles L. Extinguishability of Flammable Textiles: Part 2. Effects of Ambient Oxygen Concentration by L. Miles, G. R. Bhat, R. L. Sun, K. Yeh and S. M. Splvak. Journal of Consumer Product Flammability Vol. 3, No. 3, 166-192 (September 1976). 


\author{
PROGRAM FOR CHEMISTRY \\ FIRE SCIENCE DIVISION \\ CENTER FOR FIRE RESEARCH
}

\section{Professional Personnel}

Dr. Richard G. Gann, Acting Chief

Dr. John W. Rowen, Physical Scientist

Dr. Gerald D. Mitchell, Research Chemist

Dr. Kermit C. Smyth, Research Chemist

Dr. W. Gary Mallard, Research Chemist

Michael J. Manka, Chemist

Irene T. Cheng, Chemist

Dr. David D. Evans, Postdoctoral Research Associate

Dr. Maurice Ducloux, Research Associate, Rhone-Poulenc

\section{Affiliated}

Dr. John Hastie, Inorganic Materials Division

Dr. Michael Kurylo, Physical Chemistry Division

Dr. Wing Tsang, Physical Chemistry Division

\section{Introduction}

The Program for Chemistry is indicative of the recent rise in research emphasis in the fire program. Of the current professional staff, only half were here a year ago. The goal of the Program is to develop a better understanding of the chemical processes occurring in fires and transmit that knowledge to other fire research groups and to the technical community at large for use in developing fire resistant materials, standard test methods and building design codes.

\section{Condensed Phase Combustion Chemistry}

In this portion of our effort, we are looking at the effects of the fuel chemistry on the fuel's contribution to the fire. In addition, we consider the effects within the substrate of various fire retardants.

\subsection{Spontaneous Ignition}

In many instances fires begin" or propagate when materials are heated, smolder for a while, and then burst into flame or ignite some other substance. The Bureau of Mines has a similar problem with the ignition of low-grade coals long before they reach their eventual destination. Hence, studies on the self-heating of materials have a dual potential to reduce both fire loss and energy waste. It is our intent to develop a scientifically based susceptibility index for materials prone to spontaneous ignition and to demonstrate the validity of this index as a basis for ranking these materials for fire hazard. 
The approach taken in the first year of this project has made use of an adiabatic furnace. An updated version of the original design pioneered at NBS some 25 years ago is now operationa1, and severa1 samples, ground from a particular coal seam, have been studied. The use of coal samples reflects the partial sponsorship of the Bureau of Mines and the relative "cleanliness" of coal samples as compared to, for instance, polyurethanes. The preliminary results show thermal runaway at temperatures as $10 \mathrm{w}$ as $60^{\circ} \mathrm{C}$. The data are being used as a test for the applicability of thermal explosion theory. A further revision of the furnace, designed to ease sample handling, will be constructed this summer.

\subsection{Smoldering Combustion}

According to current statistics, at least one fourth of all fire deaths result from scenarios which include a non-flaming step. We have constructed a simple vertical flow tube to unravel the parameters which contribute to the propagation of the smoldering front. In this apparatus, a mixture of oxygen and an inert (such as $\mathrm{N}_{2}, \mathrm{Ar}$, or He) is flowed upward at various rates through a bed of granulated coconut shell char coal. This fuel was selected for the simplicity of its combustion products and its relatively high reproducibility. Five thermocouples are inserted into the bed at various heights, thus providing a means for measuring the downward rate of passage of the smoldering front. The combustion products are analyzed for $\mathrm{CO}, \mathrm{CO}_{2}, \mathrm{O}_{2}$ and $\mathrm{H}_{2} \mathrm{O}$.

We have ascertained that after the smoldering front has passed through the sample, only a nominal $6 \%$ by weight of the charcoal has been consumed. Thus, within reason, the packing of the bed is unchanged. Moreover, after one initial smoldering pass, the product gas concentrations vary little during successive passes, implying a steadiness in the chemistry. We have begun development of a one-dimensional analytical model for treating the propagation physics and gross chemistry.

The apparatus is also being used to further investigate results from two other projects. First, experiments in the Physics and Dynamics Program have shown that elemental sulfur is a general purpose inhibitor of smoldering. Preliminary results in this apparatus indicate that the addition of $10 \%$ sulfur by weight to the charcoal reduces only slightly the combustion propagation. Discovering the reasons for this anomaly will cast some light on the as yet unknown mechanism of sulfur retardance. Second, we have previously shown that $\mathrm{CO}_{2}$ is not an effective suppressant for the smoldering of cotton. In fact, it acts more like air than like nitrogen, argon or heluim. This is another anomaly to be studied.

\subsection{Extinction Phenomena}

Since its creation in the 1960's, the Oxygen Index Test has become a standard method for assigning relative flammability potential to materials. It is, however, quite clear that plastics with oxygen indices greater than 21 still burn vigorously when involved in fires. We would like to know, then, what, if any, properties of the substrate the Test is measuring. Using a conventional OI apparatus with a sample holder designed for liquids, we have measured the oxygen index of a homologous series of $\mathrm{n}$-alcohols as a function of sample pool temperature. When the results are reduced on the basis of fuel vapor pressure, the data seem to converge to a single locus. Logically, a preliminary hypothesis is that the test measures the balance of heat transfer to the fuel and heat loss to the holder. This is being further tested using more varied fuels, fuel holders and flow conditions. 


\subsection{Rate of Heat Release (RHR)}

Fortunately, when a component of a room catches fire, it generally does not burn instantaneously to completion. Rather, a gradual involvement occurs, of ten with far less heat than $\Delta \mathrm{H}$ being released over an extended time interval. Coordinating with the Program for Fire ControlConstruction, we are involved with two aspects of this phenomena. The first, recently completed, was a detailed study of the time response characteristics of the OSU calorimeter used to measure rate of heat release. This has led to a computer program to correct for the thermal lag of the instrument. The results, tested against calibration standards, have been submitted to Fire Technology.

A second project uses a RHR calorimeter to elucidate the mechanisms of polymer degradation during flaming combustion. The intent is to allow some degree of predictability for the contribution of components to room fires. This is in the development state, with the criteria for the calorimeter still being considered. Variables likely to be studied, in addition the structure of the fuel, are irradiance level, air flow, and sample orientation. Analysis of both the gaseous combustion products and polymer residue is planned.

\subsection{Polymer Combustion}

An investigation of the burning behavior of polymer rods is underway using a common oxygen index apparatus. The rods of PMMA and a cross-1inked polystyrene are ignited at the top and burned in flows containing various oxygen fractions. The mass burning rate and burning surface area are marked functions of the oxygen fraction, but the mass burning rate per unit area $\left(\dot{m}^{\prime \prime}\right)$ is independent. The external temperature and sample diameter have been varied, with $\dot{m}^{\text {" }}$ and the oxygen index decreasing slightly with increasing temperature and m $^{\prime \prime}$ varying as $\mathrm{d}^{-1 / 2}$. We have also found that as the oxygen index is approached, the cone angle of the burning rod increases until, at extinction, the top surface is flat. A model encompassing all these observations is being formulated with completion expected by early autumn.

\section{Flame Inhibition Chemistry}

Numerous studies have indicated that a major component of fire retardance occurs in the gas phase above the burning fuel. We are concerned with the specific mechanisms of fire retardant additives for the purposes of laying the groundwork for developing new suppressants and retardants, devising new chemical fire detection techniques and deciphering the effects on current detection methods, such as enhanced (or reduced) smoke formation.

\subsection{Flat Flame Burner}

Attempts to construct or test a model for flame inhibition have been hindered by the lack of a wide range of data from a single apparatus. To correct this, we have constructed a cooled, porous plug burner in a pressure-controlled housing. One purpose is to develop an analytical tool to study the heat tranfer, heat capacity and chemical changes that lead to reducing the propagation velocity of a flame. A wide range of fuels, inhibitors, inert gases, stoichiometries, pressures, gas flows and temperatures will be utilized to ald in predicting the behavior of large classes of inhibitors. 
Initially, the prime analytical tool will be a thermocouple measuring changes in the maximum flame temperature (related to changes in flame velocity) as each of the above parameters is systematically varied. Construction of the apparatus is complete, and the first experiments involve inhibition of methane flames with $\mathrm{CF}_{3} \mathrm{Br}$. There is already some detailed study of this system, thus providing some reference for the ensuing sequence.

\subsection{Laser Diagnostics}

During a recent study sponsored by the American Physical Society on the application of physics to combustion problems, the importance of enlarging our basic knowledge of combustion processes, in particular the combustion chemistry, was emphasized, as opposed to patchwork solutions to specific problems on an ad hoc basis. In this spirit the Laser Diagnostics program is exploring the utility of several optical techniques as probes for interesting atomic and molecular species in flame environments. The broad goals of this program are to investigate and develop new laser-based methods and then apply these techniques to measure temperature and species concentration profiles, which are essential input data for modeling of the flame chemistry. Four areas are now under active investigation: intracavity absorption, optogalvanic spectroscopy in flames and discharges, laser-induced fluorescence, and coherent anti-Stokes Raman Spectroscopy. All of these efforts involve collaboration with other spectroscopy groups at NBS, including the Laser Chemistry Program, the Optical Physics Division, and the Analytical Chemistry Division. To date, the effort in opto-galvanic spectroscopy has produced four papers, with Na atom detection capability in the range of $10^{10} / \mathrm{ml}$. A calibration method for laser wavelength and bandwidth has also teen demonstrated. The other three techniques are under development.

\subsection{Mass Spectrometry}

An alternative method for identifying flame species and measuring their concentration profiles is by molecular beam sampling directly into a quadrupole mass spectrometer. Studies have been carried out on retardant systems based on phosphorus, iron, molybdenum, antimony and halogencontaining species, Numerous radicals have been identified, many previously unobserved. Coordinated H-atom optical studies have shown that in different temperature regimes, phosphorus additives can either promote or reduce $\mathrm{H}$ atom formation. $\mathrm{OH}$ absorption studies are being pursued with the intent of comparing fuel-rich systems where $\mathrm{H}$-atom processes are expected to dominate with fuel-lean systems where $\mathrm{OH}$ reactions are prevalent. In addition, a new, high pressure sampling mass spectrometer apparatus is under construction. This will enable sampling of diffusion flames, flames at pressures up to $10 \mathrm{~atm}$, and flames containing particu1ates.

\subsection{Flame Inhibition Kinetics}

A recent survey of the status of measured rate data for flame inhibition reactions revealed a sorry state of affairs. Few rates had been measured and virtually none with a sufficient degree of confidence. Accordingly, we are mounting an effort to obtain data for at least some central ractions involving halogenated inhibitors. We hope that extrapolation of these results to other halons will be possible based on simple thermochemical considerations. At present, shock tube studies on the unimolecular decomposition of $\mathrm{CF}_{3} \mathrm{Br}$ are underway. In addition, a high temperature flash photolysis-resonance fluorescence system is being developed. 


\subsection{Flame Inhibition Modeling}

The culmination of all of the above efforts will be the drawing together of the results into a computer model of an inhibited flame. The model will inlcude detailed chemistry and transport and must reproduce the trends observed in the flat flame burner studies. At present, we are evaluating the status of input data and numerical schemes. The model, in its various stages of development, is to be used to highlight the important chemical and physical properties of inhibitors and thus provide predictive guidance for generating more effective use of inhibitors. 


\section{PROGRAM FOR PHYSICS AND DYNAMICS \\ FIRE SCIENCE DIVISION \\ CENTER FOR FIRE RESEARCH}

\section{Professional Personne1}

John A. Rockett, Program Chief

Howard R. Baum, Research Physicist

Margaret Harkleroad, Physicist

Takashi Kashiwagi, Material Engineer

Thomas G. K. Lee, Fire Protection Engineer

Bermard J. McCaffrey, Mechanical Engineer

Robert J. McCarter, Chemical Engineer

George W. Mulholland, Research Chemist

James G. Quintiere, Mechanical Engineer

Ronald Rehm, Mathematician

\section{Project Summary}

1. Growth and Spread of Room Fires: To predict the growth and spread of fire in a room or a set of simply interconnected rooms.

2. Turbulence: To develop calculation methods for use in buoyancy driven flows in enclosures.

3. Ignition: To identify and quantify the phenomenon related to flaming ignition of solid and liquid fuels.

4. Smoke Characterization: To develop instrumentation suitable to describe smokes and to assess the performance of fire detectors.

5. Smoldering: To identify and quantify the phenomenon related to smoldering combustion of (porous) solid fuels and to devise means of quantifying the smolder tendency of materials.

\section{Progress Report}

The Program for Physics and Dynamics of Fire currently focuses on four problem areas: modeling the growth of fire in a room, with a significant subprogram on turbulence, the physical characterization of smoke, ignition, and smoldering combustion. The largest project is the room fire modeling. This includes the work at NBS of Quintiere, and McCaffrey and of Baun and the contract/grant work of Harvard/FM, Cal Tech, Notre Dame, Penn State and parts of the work at Berkeley. Our inhouse work includes both large and small scale fire experiments with both wood and plastic fuels displayed in simple geometries and the development of a (computer based) fire behavior prediction model. The 
currently used hydraulic analogy and plume flow model seems generally satisfactory but plume entrainment (based on Taylor, Morton and Turner) is not in agreement with experiments. Although the hydraulic analogy gives excellent agreement between measured pressures and those calculated from measured temperatures, use of the model, in its present form, does not give satisfactory flow predictions, even with adjusted entrainment coefficients. Measured flows based on relatively few sampling points do not give a mass balance. For this limited data, use of orifice coefficients from Emmons and Prahl for the inflow is satisfactory but outflow data seems to imply values closer to unity.

As a part of the application of a general computer model for buoyant flows now being developed, we hope to improve our understanding of entrainment. This work is partially supported by non-fire appropriations from the NBS Director's funds. The program under development assumes inviscid (large Grashof number) strongly buoyant flow. Two approaches are being pursued: a "conventional" field equation solution and a vortex tracking system. The vortex tracking approach appears to have significant advantages for flow features which require particle following but has never been applied to this type of flow.

Our work on smoke includes that of Lee and Mulholland and the grant program of Zinn. The in-house work has centered on instrumentation to characterize aerosols and approaches to produce aerosols of known, reproducible, controllable characteristics. A set of careful experiments at NBS and the University of Minnesota has established the relative accuracy and performance limits of most of the currently available aerosol characterization instruments. Used respectively in their appropriate range it is possible to get a reasonable characterization of many real smokes. When one does, it is found that the commonly used "log normal" distribution is not a good representation of the data. The implications of this are still to be delineated but they are probably going to be important to our models of smoke formation. The development of reliable monodisperse aerosol generators greatly facilitated this instrumentation calibration work. Perhaps greater interest is the use of the monodisperse aerosols to map the response characteristics of a number of commercial fire detectors.

A simple, 1ight, portable apparatus has been developed for use in testing installed fire detectors. A reproducible, polydisperse aerosol is generated and stored in a plastic bag at a controlled concentration. This is then flushed, at a known rate, through a housing placed over the detector. Five concentrations spanning a range above and below the desired detector threshold, can be produced. The velocity across the detector is typical of that thought to be appropriate to real fire situations.

The study of ignition by $T$. Kashiwagi is an in-house program that does not currently have a grant contribution. The work is partially supported by AFOSR. Solid and liquid fuels are ignited by a powerful IR laser beam. It has been found that strong absorption of the laser energy occurs in the pyrolyzed gas colum above the sample surface. This can be related to the chemistry of the gassified fuel through its absorption spectrum. As much as $80 \%$ of the energy goes into heating the gas in this way and appears to be very important to non-piloted ignition. Ignition delay for piloted and non-piloted ignition has been measured for a range of incident energies for horizontally mounted PMMA and red oak. For some liquid fuels very little energy may be absorbed, especially when the cup has a polished surface. At low incident flux the red oak surface chars and glows (PMMA does not). The glowing appears important to ignition of the gas and may explain the relatively small difference between piloted and non-piloted ignition found for oak. 
Work here by McCarter on smoldering combustion is complemented by that of Princeton. Most of McCarter's recent effort has dealt with the use of elemental sulphur as a smolder suppressant for cotton. This material is inexpensive, easy to apply in practical configurations and effective at low dosage. U.S. and foreign patents have been applied for.

Greatest interest within the furniture industry centers on the use of sulphur in conjunction with latex backing of upholstery covering fabrics and in the bedding industry on its use with cotton padding. Currently we are exploring its practicality for cellulose loose fill insulation and on supplementing sulphur with other, compatible chemicals to obtain both flame and smolder retardancy.

Accomplishments

1. Found simple, inexpensive way to control smolder in cellulosic materials.

2. Developed practical controllable aerosol generators and applied these to the determination of fire detector performance.

3. Established the basic validity of the "hydraulic analogy" fire model and defined some limits of its validity.

4. Demonstrated possibility of using vortex tracing for buoyant flows.

5. Identified the importance of gas phase absorption in radiation stimulated ignition.

Potential Applications

1. Based on industry response and requests for patent licenses sulphur is being tested extensively as a smolder inhibitor in furniture, bedding and also blown insulation.

2. Artifical (non-fire) aerosols seem especially suited to precise determination of fire detector performance. They are being used by one manufacturer for production quality control and may be adopted for use in standard measuring apparatus.

3. Inproved analytic fire predictive systems can be used for rational fire safe design only when they are capable of making distinctions at the resolution needed by the designer. We are a step closer to making distinctions between fuel types, at least in simple situations, for both ignition and room fire development.

Milestones

1. Develop exchange of machine readable experimental data - Nov. 1977.

2. Define a conceptually satisfactory standard for smolder tendency July 1978.

3. Obtain acceptance of the concept of monodisperse spectral response for defining the performance of smoke detectors - Dec. 1978. 
4. Obtain tentative acceptance of a (portable) standard for assessment of installed fire detectors - May 1978.

5. Clarify plume entrainment models for near field - Dec. 1978.

6. Obtain reasonable, detailed room fire energy and mass balance with enough clarity to analytically model these - June 1978.

\section{Publications}

1. Baum, H.R., "Laminar Flow Induced by a Point Source of Heat," J. Res., Nat. Bur. Stand., 1977, to appear.

2. Baum, H.R., Mulholland, G.W. and Lee, T.G.K., "The Coagulation of Aerosols with Broad Initial Size Distributions," J. Colloid and Interface Sciences, 1978, to appear.

3. Baum, H.R. and Rehm, R.G., "The Equations of Motion for Thermally Driven, Buoyant Flows," submitted to Physics of Fluids.

4. Kashiwagi, T. and Newman, D.L., "Flame Spread Over an Inclined Thin Fuel Surface," Combustion and Flame, 26, p. 163, 1976.

5. Lee, T.G.K., NBSIR 77-1222 "Reproducibility of the Radiant Panel Test Method (ASTM E 162-167) Using Polyurethane Foam, Neoprene, and Hardboard Specimens," was published.

6. McCaffrey, B.J. and Rockett, J.A., "Static Pressure Measurements of Enclosure Fires," in WERB review.

7. McCaffrey, B.J. and Quintiere, J.G., "Buoyancy Driven Coumtercurrent Flows Generated by a Fire Source," presented at the 1976 International Seminar in Dubrovnik, Yugoslavia, August 30 - September 4, 1976.

8. McCarter, R.J., "Smoldering of Flexible Polyurethane Foam," Journal of Consumer Product Flamm., 3, pp. 128-140, Jume 1976.

9. McCarter, R.J., "Smoldering Combustion of Wood Fibers, Cause and Prevention," submitted to Journal of Fire \& Flamm., May 1977.

10. McCarter, R.J., "Smoldering Combustion of Cotton and Rayon," Proc. of 5th Annual Sym. on Textile Flamm., New Orleans, La., to be submitted for journal publication - May 21, 1977.

11. Mulholland, G.W., Liu, B.Y.H. and Kapadia, A., "Accuracy of the Electrical Aerosol Analyzer for Measuring Number and Volume Concentration of Polydisperse Aerosol," submitted to the Journal of Colloid and Interface Science.

12. Mulholland, G.W. and Mountain, R.D., "Calibration of Time Response of Thermometers: Concepts and Model Calculations," to be published as an NBS Tech Note. 
13. Quintiere, J.G., McCaffrey, B.J. and Rinkinen, W., "Visualization of Room Fire Induced Smoke Movement and Flow in a Corridor," in WERB review.

14. Quintiere, J.G., McCaffrey, B.J. and Kashiwagi, T., "A Scaling Study of a Corridor Subject to a Room Fire," to be presented at AIChE-ASME Heat Transfer Conference, Salt Lake City, Utah, August 15-17, 1977.

15. Quintiere, J.G., Growth of Fire in Building Compartments," Fire Standards and Safety, ASTM STP 614, A. F. Robertson, Ed., American Society for Testing and Materials, 1977, pp. 131-167. 


\section{PROGRAM FOR TOXICOLOGY OF COMBUSTION PRODUCTS \\ FIRE SCIENCE DIVISION \\ CENTER FOR FIRE RESEARCH}

\section{Professional Personnel \\ Merritt Birky, Program Chief Maya Paabo, Research Chemist James Brown, Research Chemist Sue Womble, Chemist}

\section{In-House Program Summary}

Objective I:

Develop methodology for assessment of combustion product toxicity.

Approach:

A bioassay technique is being developed for the toxicity assessment. Environmental quantification of selected toxicants is being correlated with selected biochemical toxicant levels and physiological dysfunction as determined at death or by incapacitation. 
A bioassay system for assessing combustion product toxicity has been developed and consists of 3 major parts:

1. combustion product generation system,

2. animal exposure system and

3. chemical analysis system.

Two methods of generating combustion products in the animal chamber are being explored. The first is a horizontal radiant heating system that consists of a quartz-iodide lamp. The lamp is outside the animal chamber to reduce temperature rise in the chamber. The radiation is transferred into the chamber onto the sample through a quartz window. The second system for product generation is the closed-end furnace described by Potts ( 1 ).

These two systems are being intercompared with gas data and toxicological data and with the full scale fire test data.

Two animal incapacitation models are being studied. The first involves the technique reported by Smith (2). In this system the rats are forced to exercise mildy and the method represents a whole body exposure technique. The second animal incapacitation model being explored is the hind leg flexure technique developed by Packham (3). This model represents a head-only exposure technique.

Measurements of $\mathrm{CO}, \mathrm{CO}_{2}, \mathrm{O}_{2}$ and temperature are being recorded continuously in the animal chamber. ${ }^{\circ} \mathrm{Blood} \mathrm{COHb}$ is measured on selected animals at the time of incapacitation or at the end of the experiments which is limited to 30 minutes. When a nitrogen containing polymer is degraded, environmental $\mathrm{HCN}$ is measured gas chromatographically and blood cyanide is also measured in the rats in these experiments.

The time to incapacitation is being correlated with $\mathrm{COHb}$ and blood cyanide data from various materials. Experiments have been done on wood, polyurethane (rigid and flexible) and PVC. Repeats will have to be done to verify the results. Table 1 is a summary of some urethane and wood experiments.

Animals have also been exposed to combustion products from large scale fire experiments to determine the relevance of small scale combustion techniques. 
1. W. J. Potts and T. S. Lederer, A Method for Comparative Testing of Smoke Toxicity, J. Combustion Toxicology, Vol. 4, pp. 114-162, (1977).

2. P. W. Smith, Materials Toxicological Evaluation by Direct Animal Exposures, National Academy of Sciences, International Symposium on Toxictty and Physiology of Combustion Products, Proceedings March 22-26, 1976.

3. S. Packham, Behavior and Physiology: Tools for the Assessment of Relative Toxicity, National Cellular Plastics Conference on Safety and Products Liability, 19th, Society of Plastics Industry, Washington, D.C., November 18-20, 1974. 


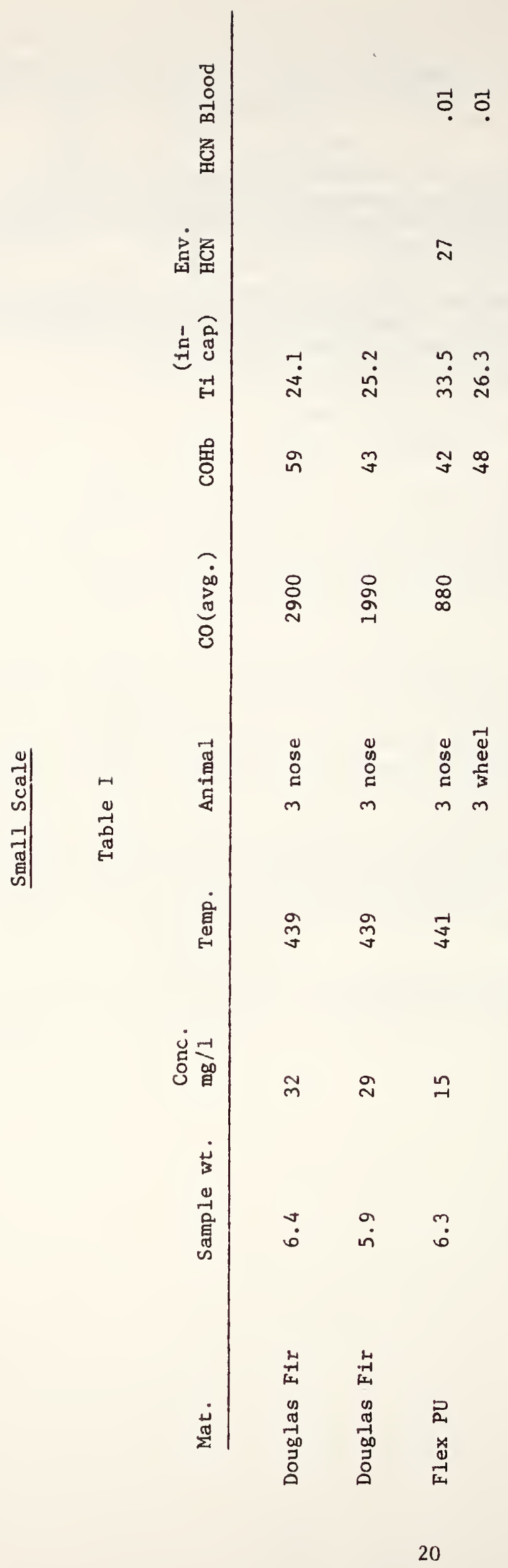


1. Merritt M. Birky, Hazard Characteristics of Combustion Products in Fires: The State-of-the-Art Review, NBSIR 77-1234, 1977.

2. Steve C. Packham, D. B. Frens, J. B. McCandless, J. H. Petajan \& Merritt M. Birky, A Chronic Intra - Arterial Cannula and Rapid Microtechnique for Carboxyhemoglobin Determination, J. Combustion Toxicology, Vo1. 3, 471-478, (1976).

3. Merritt M. Birky, Philosophy of Testing for Assessment of Toxicological Effects of Fire Exposure, J. Combustion Toxicology, Volume 3, 5-23 (1976).

4. M. M. Birky, A. W. Coats, S. E. Alderson, J. E. Brown, M. Paabo $\&$ B. Pitt, Measurement and Observations of the Toxicological Hazard of Fire in a Metrorail Interior Mock-up, National Academy of Sciences International Symposium on Toxicity and Physiology of Combustion Products, Proceedings, March 22-26, 1976. 


\title{
PROGRAM FOR FIRE PREVENTION--PRODUCTS \\ FIRE SAFETY ENGINEERING DIVISION \\ CENTER FOR FIRE RESEARCH
}

\section{Professional Staff}

\author{
James $\mathrm{H}$. Winger, Chief \\ Emil Braun, Physicist \\ Donna Hopkins, Textile Technologist \\ John Krasny, Textile Technologist \\ Joseph Loftus, Research Chemist \\ Richard Peacock, Chemical Engineer \\ Lee Smith, Physicist \\ Stephanie Wiedel, Textile Technologist
}

\section{Project Summary}

The goal of the Program for Fire Prevention--Products (PFP-P) is to reduce fire losses by reducing the probability of ignition in the environment. The Program works primarily with consumer products.

The work of the group has been concentrated in two major product areas, upholstered furniture and general wearing apparel.

The fire accident data for upholstered furniture shows that the major portion of the problem is cigarette ignition of the furniture followed by smoldering combustion which releases large quantities of combustion products resulting in death. The most important product of combustion in this scenario appears to be carbon monoxide.

A cigarette ignition test method for upholstered furniture has been developed. The test is conducted on mocked-up furniture constructions because of the unpredictable interactions of components and the cost of full-sized items of upholstered furniture. A proposed standard has been written around the cigarette ignition test method and submitted to the Consumer Product Safety Commission with the recommendation that it be published as a proposal for comment. Work in this area will continue.

The fire accident data for apparel shows that long, loose-fitting garments, such as nightgowns, are more often involved in serious burn incidents than shorter, tighter fitting garments such as shirts. Further analysis of the data, evaluation of the fabric types involved in the accidents, and laboratory accident simulations show that heat transferred from the burning fabric to a surface simulating the skin is an appropriate parameter to measure and control. From the same work and also intuitively, the probability of ignition should be reduced. The ignition probability can be reduced by controlling time to ignite under appropriate conditions and also controlling garment fit.

A proposed standard for the flammability of general wearing apparel has been prepared incorporating garment fit limitations, ease of ignition, and rate of heat transferred from the burning fabric to a surface. This standard has been submitted to the Consumer Product Safety Commission with the recommendation that it be published as a proposal for comment. Work in this area will continue.

A new area of work for the Program is fire safety in underground mines. The fire hazards in mines will be investigated and fire tests and standards developed for products and materials used in and around mines. These will be developed for the Mining Enforcement and Safety Administration. A systems analysis of the fire safety in mines will be conducted and appropriate recommendations made to MESA. 


\title{
Program for Fire Control-Furnishings \\ Fire Safety Engineering Division \\ Center for Fire Research
}

\section{Professional Personnel}

\author{
Sanford Davis, Chief \\ Vytenis Babrauskas, Fire Protection Engineer \\ Raymond C. Hess, Research Associate \\ Theodore 0. Stolz, Research Assoclate
}

The problems associated with fire have been a subject of concern to society for many years, but it has only been for the past 15 years or so that serious consideration has been given to the role played by interior furnishings in the contribution to fire losses. Code officials, fire officials, architects, and government regulators have emphasized the importance of the proper choice of materials and design factors in building the structure, but they have had little or no control of the contents brought into these structures. Although there have been efforts to control furnishings in regulated occupancies, such as hospitals and places of assembly, nothing could be done about residential occupancies. Besides, the state-of-the-art has not been able to predict how assumed safe materials and products would behave in real fire situations.

The Program for Fire Control-Furnishings has had three major projects under study for the past few years. Each of these is in various stages of progress and will be described briefly.

\section{Floor Covering Test Development}

The flooring radiant panel test for measuring the critical radiant flux of flooring systems used in corrldors and exitways was refined at NBS and has been moved forward as a standard test method. It is being processed by NFPA and ASTM as a standard test method for flooring systems and by GSA for carpets. Its adoption by regulatory agencies and codes groups has been accomplished or is in progress and our current efforts have been supportive of its broad acceptance.

\section{Full-Scale Room Fire Experiments}

We have carried out several series of experiments to evaluate the behavior of interior furnishings in full-scale room fires. Current work is in progress to analyze the results of these experiments involving Parsons tables, upholstered furniture, and mattresses. In the near future we will begin to examine the effects of interactions between two (or more) pieces of furniture such as would be found in hospital rooms or in residential occupancies.

\section{Smal1-Scale Test Development}

Based on full-scale fire experiments we expect to be able to determine the relative hazards of various furnishing materials and constructions; however, it would be desirable to be able to anticipate these hazards using small-scale predictive tests to measure inherent properties of materials and systems. Towards this end we have been working on the development of test procedures for ease of ignition, flame spread rate, and burning rate which can be applied to furnishing materials and, in particular, thermoplastic materials. In addition, measurement of heat release rates, smoke densities, and other thermal properties are being carried out. It is anticipated that we will be able to utilize inherent properties of these systems to predict the behavior of products in real world situations. 


\section{PROGRAM FOR FIRE CONTROL--CONSTRUCTION \\ FIRE SAFETY ENGINEERING DIVISION CENTER FOR FIRE RESEARCH}

\section{Professiona1 Personnel}

W. J. Parker, Chief

L. A. Issen, Research Engineer

J. B. Fang, Chemical Engineer

B. T. Lee, Fire Protection Engineer

E. K. Budnick, Fire Protection Engineer

W. D. Walton, Fire Protection Engineer

D. P. Klein, Fire Protection Engineer

J. R. Lawson, Research Associate

D. L. Chamberlain, Research Associate

J. P. Tordella, Research Associate

D. L. Sensenig, Research Associate

The overall goal of this Program is to improve the probability of preventing the spread and growth of a fire and its combustion products by materials selection and passive design concepts.

\section{Fire Test Standards (CFR)}

The objective of this project is to develop laboratory fire test methods for evaluating the potential fire hazards of construction materials. The fire properties of concern are ignitability, heat release rate, flame spread, and smoke. The approach is to participate actively in ASTM, NFPA, ISO, CIB, and government-wide committees, to develop appropriate fire test methods and standards, to perform testing, analysis and round robin coordination of such tests, to make recommendations for performance standards and test criteria, and to relate building fire standards to actual building construction fire performance.

A new heat release rate calorimeter is being constructed for research studies on heat release rate. This instrument will be capable of measuring the simultaneous heat and mass loss rates of vertical specimens $12 \times 12^{\prime \prime}$ and horizontal specimens $6 \times 12^{\prime \prime}$ at radiant fluxes up to 8 $\mathrm{W} / \mathrm{cm}^{2}$. A draft report has been completed on an ease of ignition test by flame impingement. This will be submitted as a standard test for ignitability of interior finish materials. A report on an investigation of the fire environment in the ASTM E-84 tunnel test is now at the printers. The NBS Smoke Density Chamber Test has been adopted as standard NFPA 285-1976 and the potential heat test was adopted as standard NFPA 2591976. The project leader is W. J. Parker. The professional personnel include the following research associates: J. R. Lawson, Gypsum Association; D. L. Chamberlain, National Forrest Products Association; J. P. Tordella, Society of the Plastic Industries. 
The objective of this project is to evaluate the potential for fire spread and growth in various occupancies in terms of the materials of construction, the combustible contents, the building design and the probable ignition sources. The approach consists of (a) developing analytical models of fire growth based on heat and mass balance considerations which take into account the spread of flame over the combustible interior finish materials and their heat release rates, (b) running full scale fire tests for validation of these models, (c) and conducting reduced scale fire tests, which permit verification of the model for many more combinations of parameters at considerable savings in time and money.

The work includes a cooperative effort between CFR and the National Research Council of Canada on the E-84 Tunnel Test. In order to establish the most realistic method of running and reporting on the tests of cellular plastics a set of materials with a large range of flame spread is being tested in three different configurations in the tunnel, in full scale and reduced scale rooms and corners, and in various laboratory fire tests. In another study a reduced scale model has been used to investigate the fire buildup process in a room by D. L. Sensenig, a Research Associate from the Armstrong Cork Company. As part of this task a method was developed to measure the total rate of heat production in a room from the oxygen depletion in the hot air leaving the compartment. The project leader is W. J. Parker and the other CFR investigator is $D$. Walton.

\section{Structural Fire Endurance (CFR)}

The objective of this project is to predict the fire endurance of structural building components under typical fire exposure conditions using thermal and structural analysis and to verify with full scale tests. The basic analytical approach is to combine thermal analysis and structural analysis programs which include elasto-plastic material properties, creep in concrete and steel, and local failures. Improved basic data on concrete creep at elevated temperatures will be obtained, as well as experimental data on thermal restraint due to expansion of fire-exposed concrete floors and roofs.

This project has been largely carried out through contracts with the Center for Building Technology at NBS, the Portland Cement Association, and the University of California at Berkeley. A report was published by E11ingwood and Shaver in CBT entitled "Analysis of Reinforced Concrete Beams Subjected to Fire". Reports by the other contractors will be included in their summaries. The project leader is D. Gross. Other professional personnel at CFR include: W. J. Parker and L. A. Issen.

\section{Fire Endurance of Floor Constructions (HUD)}

The objective of this project is to develop a test procedure for evaluating the structural fire resistance of floor assemblies in residences and to recommend rational performance criteria for protected and unprotected load-bearing components. The approach is to conduct full scale fire tests in a simulated basement recreation room using modern furniture with a typical fire load for that type of room. At the present time a series of 14 tests with varying room size, interior finish, and ventilation conditions is half completed. The fire is started with a newspaper on a couch with polyurethane cushions. The temperatures, heat fluxes and pressures recorded during these tests will form the basis of the new test procedure. A standard set of conditions will be selected and another series of room fire tests will be run with different floor 
constructions including cases with exposed floor joist. Finally, the time-temperature curve, and the pressures will be duplicated in a gasfired fire endurance furnace and the same types of floor constructions will be tested. An analytical prediction capability for fire growth is being developed along with the experimental testing. The project leader is J. B. Fang.

Fire Safety in Mobile Homes (HUD)

The objective of this project is to document the effect of interior finish materials on fire growth and spread and on the attainment of untenable conditions in mobile homes in order to provide a rational basis for regulating these materials. The approach is to conduct full scale fire tests on single-wide mobile homes using upholstered chairs and wood cribs as ignition sources in the livingroom and bedroom areas. The chair is a realistic source of ignition which will not lead to full involvement of the mobile home in the absence of combustible interior finish while the wood crib provides a relatively reproducible ignition source for comparison of different interior $f$ inish materials. Temperatures, heat fluxes, smoke densities, and gas concentrations are monitored throughout the mobile home. The interior finish materials are characterized by their E-84 tunnel rating, heat release rate, time to ignition in the ease of ignition test, and the smoke density in the NBS Smoke Density Chamber.

A report by E. K. Budnick, "Fire Spread Along the Mobile Home Corridor," NBS IR 76-1021 was published in July 1976. Most of the full scale testing has been completed. During the next stage of the work an attempt will be made to duplicate the essential features of the full scale test results using reduced scale modeling. This will then be followed by an attempt to deduce the results by analytical prediction techniques. The project leader is E. K. Budnick the other Fire Protection Engineer on the project is D. P. Klein.

Shipboard Fire Research (Navy)

The objective of this project is to evaluate the potential fire hazard of submarine hull insulations and to improve the application of laboratory fire tests for screening compartment lining materials. The approach is to subject the variety of submarine hull insulations, some of which are protected with fire resistant materials, to laboratory fire tests on ignitability, flame spread, rate of heat release, and potential heat. The performance of these insulations are then examined in quarter and full scale compartment fires. By comparing the time to flashover or maximum temperature in the full size compartment with the results of the laboratory fire test methods improved acceptance criteria for materials can be derived. By comparing the performance of the material between the full and reduced scale fire tests, the usefulness of the quarter scale model as a screening tool can be evaluated. The project leader is B. T. Lee.

Evaluation of Fire Loads in Residences (HUD)

The objective of this project is to provide fire and live-load data for single-family dwellings and mobile homes in order to provide a basis for establishing standard fire exposures for structural fire endurance tests of building elements in residences. The approach involves a two-phase survey of fire loads in residences using inventorying techniques for a variety of typical constructions and geometrical arrangements. A pilot (phase 1) survey will involve dwellings in the Baltimore-Washington area; this will be followed by a more extensive national survey. The assembled data will provide the fire load input to analytical models of fire growth and severity which will generate fire exposure curves for residences and mobile homes. 
The first phase of this project has been completed and a report is in the review process. No decision has been made to continue with the second phase of the project at this time. The project leader is Lionel Issen. The survey was carried out by George Washington University, the program for converting the survey data to fire and live-loads was done on contract to the Center for Building Technology at NBS. The program for producing the tables and frequency distributions was written by $W . D$. Walton.

\section{Fire Tests of Marine Construction (Coast Guard)}

The objective of this project is to furnish technical data on a flame spread test method under consideration as an international standard on marine construction and make recommendations for improvements in the test method and its application. Studies will be made of, (a) the method of securing and positioning specimens, (b) the incident heat flux distribution to several levels, (c) a suitable pilot burner for igniting the sample, and (d) the effect of air cross flow in means of controlling test variability. Samples of several materials will be tested and the results analyzed to evaluate the performance under various modifications of the existing method. The specimen can be run in either a floor, wall or ceiling orientation. Materials run in the room fire tests will also be evaluated with this test method in order to establish its validity. The project leader is W. J. Parker.

Dr. A. F. Robertson has done the most extensive work with the test to date and has made periodic reports at the ISO meetings.

\section{Fire Criteria for Solar Heating Fluid (ERDA)}

The objective of this project is to provide a technical basis for specifying the flammability standards for the heat transfer fluids used in solar heating systems. Six representative combustible heat transfer fluids will be chosen. The size and type of ignition source required for sustained ignition of these fluids will be determined. The maximum room air temperature that can be developed by burning pools and flowing leaks of the heat transfer fluid will be measured. The maximum room air temperature produced by burning selected framing and insulation materials saturated with the heat transfer liquids will also be determined. On the basis of this research, a standard test method and suggested criteria for screening combustible heat transfer fluids based on their relative fire hazard will be developed. B. T. Lee is the project leader. The project started on July 1, 1977.

Fire Hazards of Insulation in Residential Occupancies (Research Proposal)

The objectives of this proposed project are: 1) to identify and determine the magnitude of the various fire risks associated with the use of particular types of insulation, 2) to recommend, and develop where necessary, the laboratory fire tests needed to characterize insulation materials with respect to these risks and to control their use for insulation retrofit; 3 ) to provide the necessary data on fire and thermal properties for generic types of insulation considered for use in the basements, wall cavities in attics of buildings; 4) to recommend acceptance criteria suitable for adoption in the building code. 
The project would start with a review of the available fire statistics. Reduced scale model tests, based on the scaling rules developed at NBS would be run with various insulation materials to verify the important fire scenarios. The models tested would include 1) the simulated basement with exposed insulation, 2) an above grade room with insulation in the wall cavities and in the space above the ceiling, and 3) an attic space with exposed insulation. These tests would determine the effect of the insulation on 1) the maximum fire intensity (as measured by air temperature rise), 2) the time to full involvement of the space, if it occurs, and 3 ) the rate of production of the smoke and toxic gas. The role of the insulation as a site for flaming and smoldering ignition would be examined in these models. Important findings would be verified by full scale tests. A test for smoldering ignition of insulation materials will be developed. The settling and moisture absorption of the insulation in the leeching of the flame retardant chemicals will be investigated for loose fill insulation. 


\section{PROGRAM FOR FIRE DETECTION AND CONTROL SYSTEMS \\ FIRE SAFETY ENGINEERING DIVISION CENTER FOR FIRE RESEARCH}

\section{Professional Personnel}

Richard L.P. Custer, Program Chief

Richard G. Bright, Senior Research Engineer

Richard W. Bukowski, Research Engineer

Francis C.W. Fung, Mechanical Engineer

Warren D. Hayes, Fire Prevention Engineer

John O'Neill, Fire Prevention Engineer

The Program for Fire Detection and Control Systems (PFDCS) has as its objective the reduction of life and property losses through the encouragement of the use of improved fire detection, fire suppression and smoke control systems in the built environment. In pursuit of this objective PFDCS is studying the performance and installation requirements for these systems and appropriate test methods by which to judge the system capabilities. An additional goal is to develop design criteria and installation guidelines that will lead to reduced cost in the use of these systems. The program effort is divided into three specific areas: automatic fire detection, automatic fire suppression, and smoke control systems. Each of these will be discussed below.

The fire detection program has been concerned primarily with the development and evolution of residential smoke detectors. Full scale and bench tests have been used to define the performance characteristics of existing residential detection hardware. The results of these tests have led to the development of improved test methods both for the small and large scale evaluation of residential smoke detectors. Work is currently underway to develop a graded approach to the full scale evaluation of all fire detection devices (heat, smoke, and flame).

In addition to the work on test methods and device performance, considerable effort has been expended in studies relating to the siting of detection devices in residential occupancies including mobile homes. The effects of air conditioning and number of floors has been studied for dwellings and recommendations prepared regarding minimum detection requirements. Work is also underway to define the role of automatic fire detection in the overall scheme of fire protection in health care facilities. To this end a series of full scale tests in a simulated health care environment have been conducted to determine the optimum location and type of detection device that should be used for this application. 
Other important work in the detection area involves the study of the reliability of these devices both in the field and in the laboratory. Several instances of detector failures in the field have been analyzed and reports prepared for the Consumer Products Safety Commission regarding these failures.

The automatic fire suppression project has been concentrating on the generation of information relating to the performance of automatic sprinkler systems. The initial work that was done to develop design criteria for the use of automatic sprinklers in the protection of door openings in multi-family and care type facilities led to the determination that there is a need for more definitive test methods to define the performance capabilities of automatic sprinklers. Work has been completed that relates to sprinkler discharge rate to maximum cooling in the corridor sprinkler system application. The results indicate that significant differences in cooling rates exist between individual sprinklers from different manufacturers or of different design. Work is also underway studying the development of water distribution mapping techniques, factors affecting the distribution of water from sprinklers, statistical parameters of water droplet populations from sprinklers as a function of pressure and deflector design, and the use of sprinklers in health care facilities.

A special facility is being constructed in which to study the use of sprinklers for the protection of large open stairway configurations. This work will attempt to refine and build upon tests done in the mid-40's for methods which are currently in use in the NFPA sprinkler and life safety standards. In addition to this long range work, continuous effort has been made to assist in the development of both U.S. and international standards for automatic sprinkler systems and components. This work has included analysis of water distribution patterns, K-factor measurement techniques, and mechanical safety factors applied to sprinkler devices.

The smoke control project has been in operation for a number of years. During that time the work has developed along two parallel and now converging directions. Initially work was done with simple computer modeling of smoke movement in buildings. This effort built upon the work of the National Research Council of Canada and others. At the same time field tests were conducted in actual office, apartment and hospital buildings using sulfur-hexafluoride tracer gas to study the movement of simulated smoke under a variety of mechanical systems and climatic conditions. Included in the field work were several studies of buildings equipped with smoke control systems. In each case the building was evaluated both with and without the smoke control system in operation. This allowed for comparison of the relative effectiveness of the systems compared to a building without any smoke control. More recently, the output from the field survey program has been combined with a sophisticated computer program designed to predict the movement of air in a building as influenced by an air handling system. The result has been the generation of a computer-based design methodology for smoke control that allows the designer to experiment with various conceptual designs prior to development of the final plans for the building. In this way it 
is possible to optimize on the best smoke control system design in the total context of the heating/air-conditioning system. Work has also been done to compare the results of sulfur-hexafluoride smoke movement studies to actual movement of smoke in dwellings. This work showed substantial correlation between the simulated smoke and real smoke. Work is currently in progress to develop a small scale model with which to test the computer model for the movement of smoke and design of smoke control systems. The future work will involve the development of smoke control methodologies for residential application.

The primary output mechanisms for the results of this research is through additions or changes to the various voluntary standards relating to work of the Program for Fire Detection and Control systems. This includes international standards relating to detectors and sprinklers, and domestic NFPA and ASHRAE standards. 


\section{PROGRAM FOR DESIGN CONCEPTS \\ FIRE SAFETY ENGINEERING DIVISION \\ CENTER FOR FIRE RESEARCH}

\section{Professional Personnel}

Harold Nelson, Program Chief

Bernard M. Levin, Research Psychologist

A. Jeffrey Shibe, Operations Research Analyst

\section{Other Contributors}

Major contributors to the activities of the Program for Design Concepts include:

\section{A. NBS Organizations}

1. Architectural Research Section, Center for Building Technology (R. Wehrli, J. Archea, and F. Stah1)

2. Human Factors Section, Center for Consumer Product Technology (H. VanCott and V. Pezoldt)

B. Contractors and Grantees (Principal Investigators)

1. T. Waterman and R. Pape, IITRI - Room Fire Development, bibliography and model.

2. R. Fitzgerald, Worcester Polytechnic Institute, Probability Predictions of Fire Spread and Severity

3. J. Watts, University of Maryland, Goal Oriented Systems Approach

4. F. W. Fothergill, Integrated Systems Incorporated, Smoke Control Modeling

5. L. Lerup, University of California, Berkeley, Mapping and Analyzing Behavior in Fires

6. J. Bryan, University of Maryland, Post Hoc Investigations of Actions during Fire

7. J. Keating and E. Loftus, University of Washington, Emergency Voice Communication and Message Content

8. L. Bickman, Loyola University, Chicago, Assumptions Inherent in Emergency Plans, etc.

9. H. Wakeley, IITRI, Alarm System Outputs and Alarm Response 
Current funding for work undertaken by the Program for Design Concepts comes from HEW, OSHA and the CFR grants program.

\section{Program Goal and Objectives}

The objectives of the Program are to synthesize and integrate research and technology to develop technically based rational approaches towards providing safety from fire facilities; and to provide operating mechanisms for using these approaches in setting fire safety requirements in these facilities.

\section{Output Forms}

The basic characteristics of the outputs of this program will fall into five categories:

A. Management Tools. Management mechanisms for setting improved mandatory requirements.

B. Operating Tools. Technical design data and guides for architects, fire protection engineers, and others to aid them in selection of the cost effective ways of meeting requirements. These tools will permit the use of innovative and non-traditional approaches toward total system safety to a greater extent than is now permitted.

C. Short-Range Recommendations. Specific proposals based on the results of the research efforts, for revisions and other improvements in existing fire safety codes, regulations, and standards.

D. Targets of Opportunity. Serendipitous outputs that appear and indicate potentials of increased fire safety. These are pursued even though they were not in the original research where there is potential for high payoff with relatively little resources.

E. Fundamental Improvements. Advances in the state-of-the-art of applied fire protection engineering and fire technology, including the development of an improved technological base, both to support the credibility and acceptance of the other products and serve as the basis for future improvements in fire protection.

Technology Development and Technology Transfer

Inherent in the objectives of the Program are both the updating of existing technology and the delivery mechanisms useful in technology transfer between the world of research and the applied world as it actually exists and functions.

The world of technology and its uses can be divided into three basic element areas. The work of this Program is formed around these divisions. The three elements are: 
Scientific and empirical data. This ranges from physical properties such as calorific value, density, rate of heat release, and critical radiant flux to empirical values such as detection time, flame spread ratings, and sprinkler discharge capabilities. All of these involve one or more types of basic reproducible tests directed at producing data either for handbook reference or other descriptive literature. Major efforts in this program are directed at producing missing data elements particularly in areas related to detection, automatic extinguishment, and human behavior and capabilities under fire stress.

\section{Models}

Models and systems used by scientists or engineers to explain the interrelationship of two or more data elements. These can range from simple formula to complex inter-relationships. The Program has undertaken modeling efforts. Significant success and spillover has been achieved in advancing the interest and activities of the entire scientific fire research community in this area.

\section{$\underline{\text { Use }}$}

"Use systems" that are now used or can be used to govern and measure the real world. Were the technology and description of the real world perfected to an advanced level of understanding and predictability, the models developed by the scientists and research engineers could fulfill this function. The real world however is not that well described or completely understood and the practitioners must produce answers at a rate that demands relatively simple but sufficiently accurate approaches. Various types of use systems therefore govern the real world.

Use systems are frequently in the form of codes, standards, and evaluation system. There is currently no method for a direct crosswalk from scientific data and models to the use system. In each case judgment of how the technological data fits into the real world is involved. In current practice the difficulty in crossing this gap has resulted in the development of existing use systems that ignore technical bases and presume that a parliamentary concensus equates to technical accuracy.

The data and model development activities are directed at producing technologically sound outputs that will be more responsive to the needs of the use systems. Simultaneously the project points at further reducing this gap by developing use systems that are more accountable to the technological base and receptive to improved data. Professional judgment and concensus will remain a major portion of the developments of use systems for the forseeable future. Major improvements can, however, be made in the quality and accountability of these judgment and concensus activities. The end result will be both improved approaches that are more readily evaluated and accepted as rational; and a compendium of design measurements and parameters that will permit wider flexibility in the individual designs, with traceable consistency of the technological basis, the performance requirements, and the approaches from jurisdiction to jurisdiction. 
The Program contains many individual project and activity areas. This report does not identify the individual progress on these but rather gives a general overview of the most important outputs and impacts.

The pages following this section show a graphic breakdown of the general product areas in each of the three categories of use systems, models, and data development. These graphic charts lay out the areas of interest including those which the Program benefits from without necessarily active participation. The graphs are coded to indicate the degree of participation by the Program. 


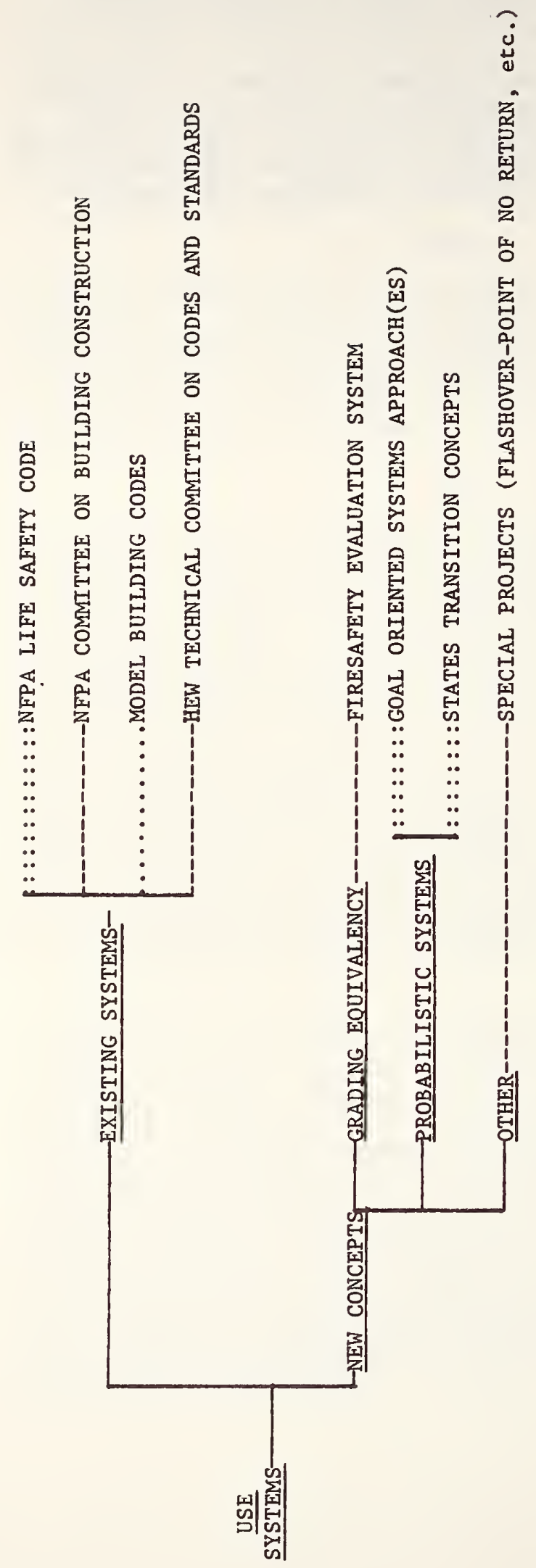

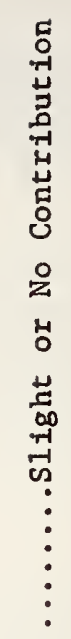

整

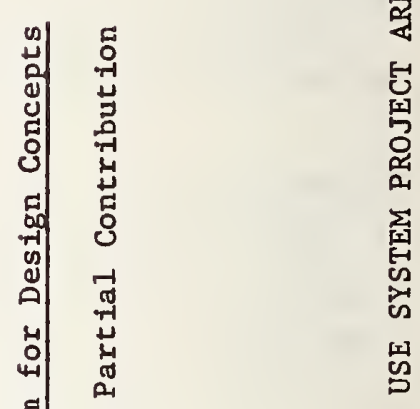

造

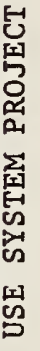

落 


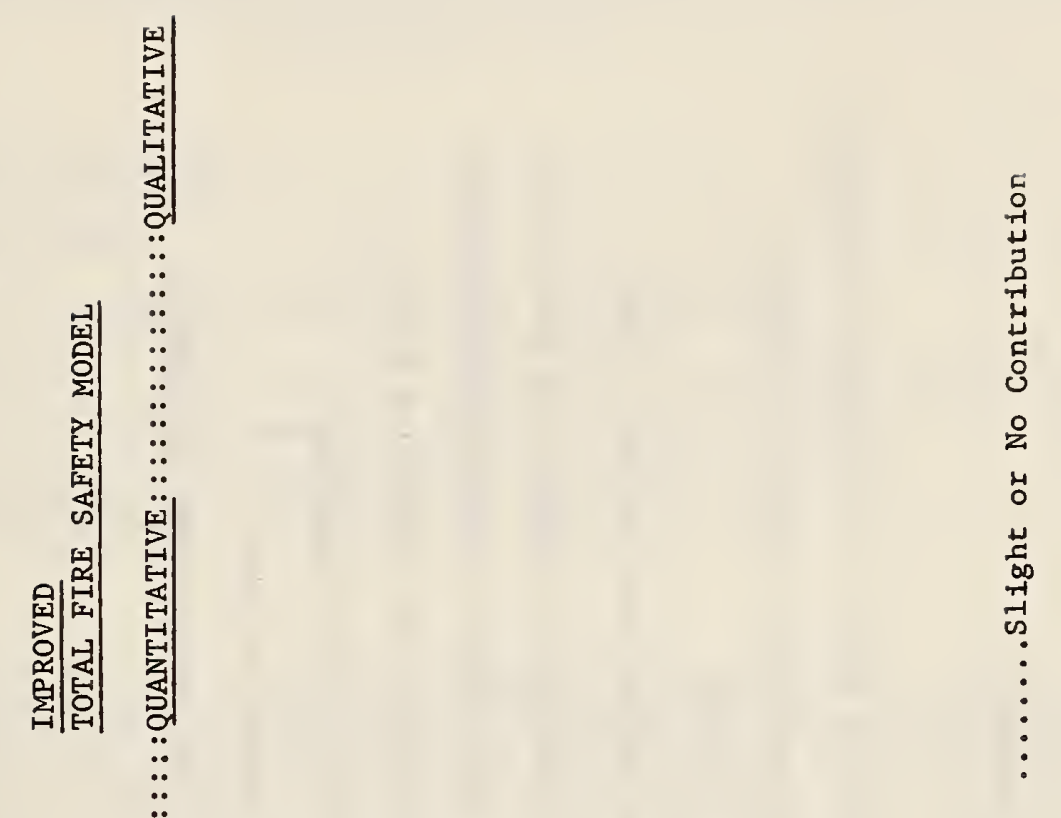

岕
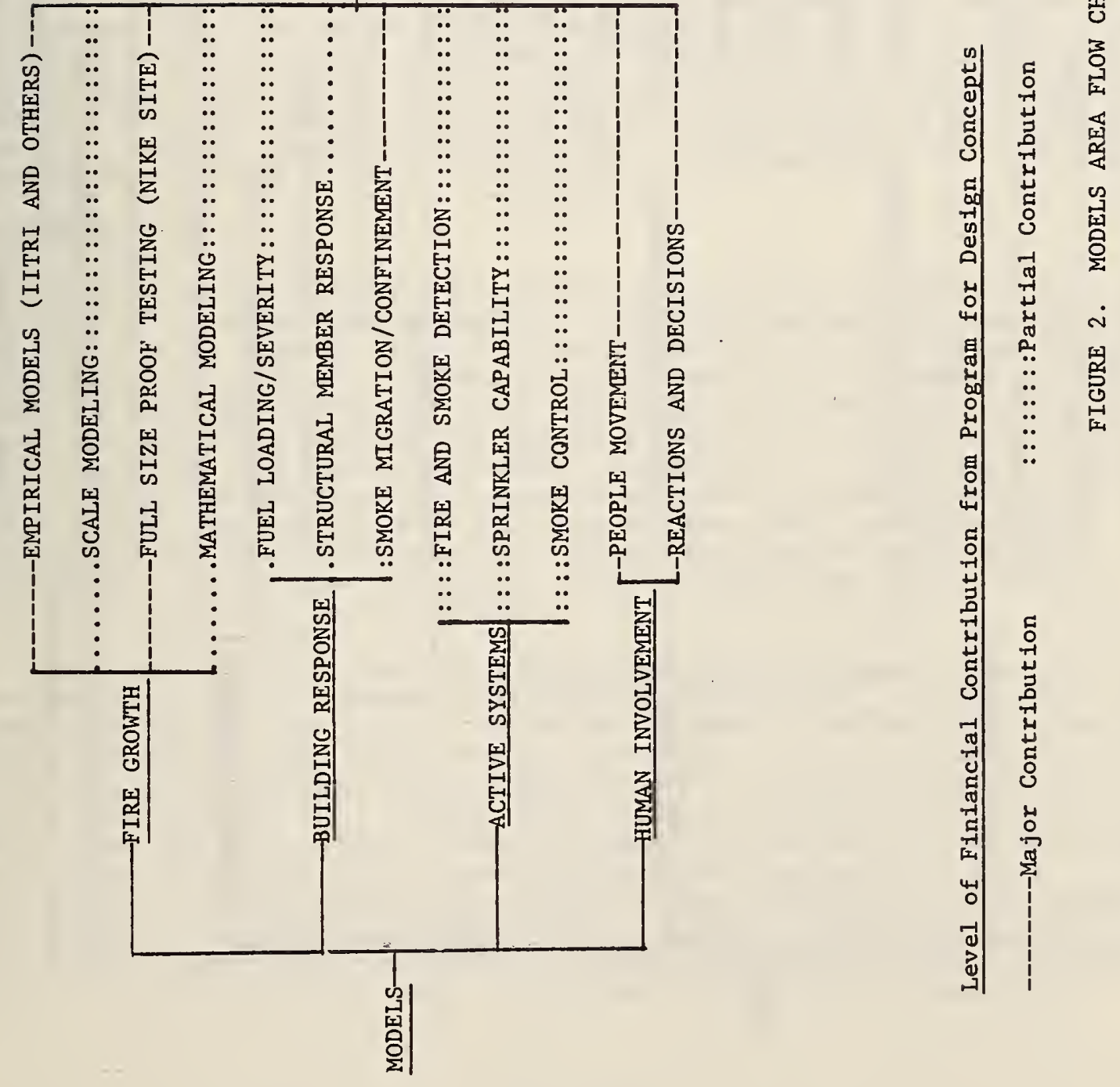


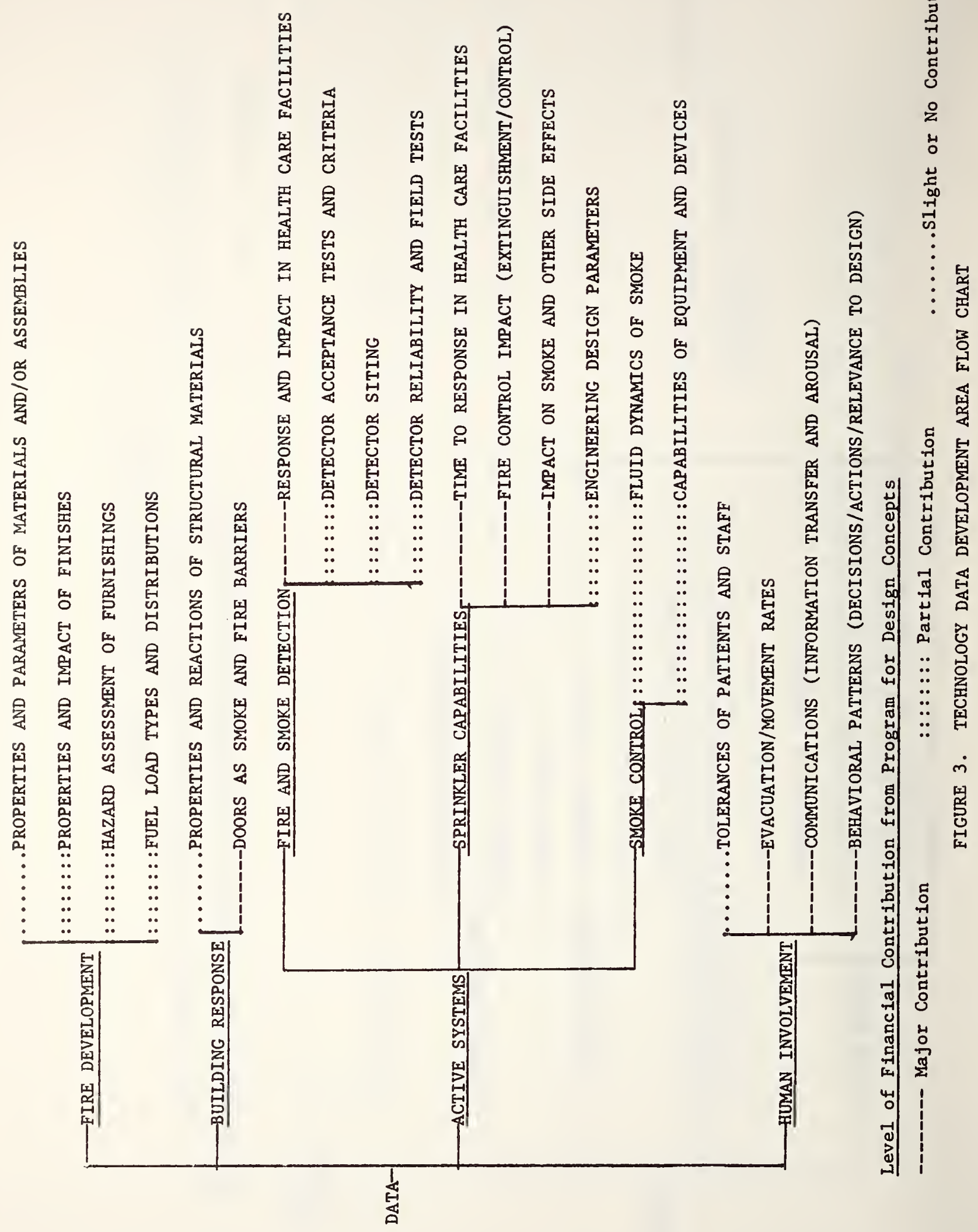


Institution: Brown University

Grant No. : $\quad$ NBS G7-9009

Grant Title: Flame Propagation and Extinction for Solid Fuels

Principal Investigator: Merwin Sibulkin, Division of Engineering, Brown University, Providence, RI $02912 \quad$ (401) $863-2867$

Other Professional Personnel: Anil Kulkarni, graduate student

\section{Project Summary:}

The objectives of this program are to advance our understanding of flame propagation and extinction for fuels involved in urban fires. An understanding of the theoretical basis of flame propagation and the ability to make quantitative predictions of flame spread rates should lead to more rational ways of testing the relative flammability of different materials. A more fundamental understanding of extinction mechanisms is desired to enable improved methods of fire suppression to be developed. The program includes both experimental and analytical tasks. Flame spread and burning rate measurements are made with solid fuels of simple geometry in controlled atmospheres of oxygen, nitrogen and extinguishing agents. Temperatures and heat fluxes are measured to obtain an energy balance for the flame-fuel system. A parallel theoretical effort is made to develop models which will predict flame spread rates and extinction conditions.

\section{Progress Report:}

Previous work in a Limiting 0xygen Index type apparatus has shown that the LOI is a limit for downward flame propagation. Extinction was shown to occur when the heat flux from the flame to the fuel is insufficient to raise the surface temperature ahead of the flame to a critical value for pyrolysis. The current work considers the comparable problem for a fuel sample ignited at the bottom. After the upward spreading flame has fully enveloped the sample, measurements of mass burning rate $\dot{m}$ are made as a function of oxygen concentration $Y_{\text {o }}$ in an $\mathrm{O}_{2}, \mathrm{~N}_{2}$ atmosphere using cylindrical samples. Polymethyl methacrylate (PMMA) was chosen as a typical noncharring material which maintains its shape while burning and gives reproducible results. Preliminary tests of charring materials were made with polycarbonate, cross-linked polystyrene, phenolic laminate and wood. Of these, wood was chosen as the least unsatisfactory of the charring materials.

Measurements with $1 / 2$ inch and 1 inch diameter PMMA cylinders showed that in decreased as $Y_{\text {ox }}$ was decreased. Extinction occurred for $Y_{0 x}<0.181$ for both diameter cylinders. Just prior to extinction the burning rate ${ }_{\text {was }}$ about 75 percent of its atmospheric value. A comparison of the effects of $Y_{\text {ox }}$ on burning rate $\dot{m}$ (current work) and downward flame propagation rate $V$ (previous work) is shown in Fig. 1. The value of $Y$ at extinction for a fully burning cylinder is significantly lower than for a downward burning cylinder. The comparison also shows that the decrease of $V$ with $Y_{\text {ox }}$ is more rapid than the decrease of $\dot{m}$ with $Y_{\text {ox }}$. Results with wood were qualitatively similar to those with PMMA but with considerably more scatter; extinction occurred for $Y_{\text {ox }}<0.205$. The next phase of the experimental program is the measurement of temperature profiles through the boundary layers of fully burning fuel slabs. Preliminary tests show that temperature 
fluctuations of considerable magnitude exist in the peak temperature region while signal averaging times are limited by regression of the sample surface. Techniques are being developed to overcome these difficulties.

\section{Accomplishments:}

Burning rates and extinction limits for fully burning samples have been measured. Comparison of these results with previous measurements on downward burning samples shows that the oxygen concentration at extinction is significantly lower for the fully burning case.

\section{Potential Applications:}

This work increases our knowledge of the factors affecting extinction which could lead to the design of improved test methods and to more effective fire suppression techniques.

\section{Future Milestones:}

Measurement of gas phase temperature profiles for fully burning fuel specimens; determination of profile changes as extinction is approached. Analysis of the effect of heat losses on extinction of fully burning fuel specimens.

\section{Publications:}

"Comparison of the effects of $\mathrm{N}_{2}$ and $\mathrm{CF}_{3} \mathrm{Br}$ on the extinction of PMMA fires," by M. Sibulkin and M. Little (under review).

"Flame propagation and extinction of downward burning fires," by M. Sibulkin and M. Little (under review). 


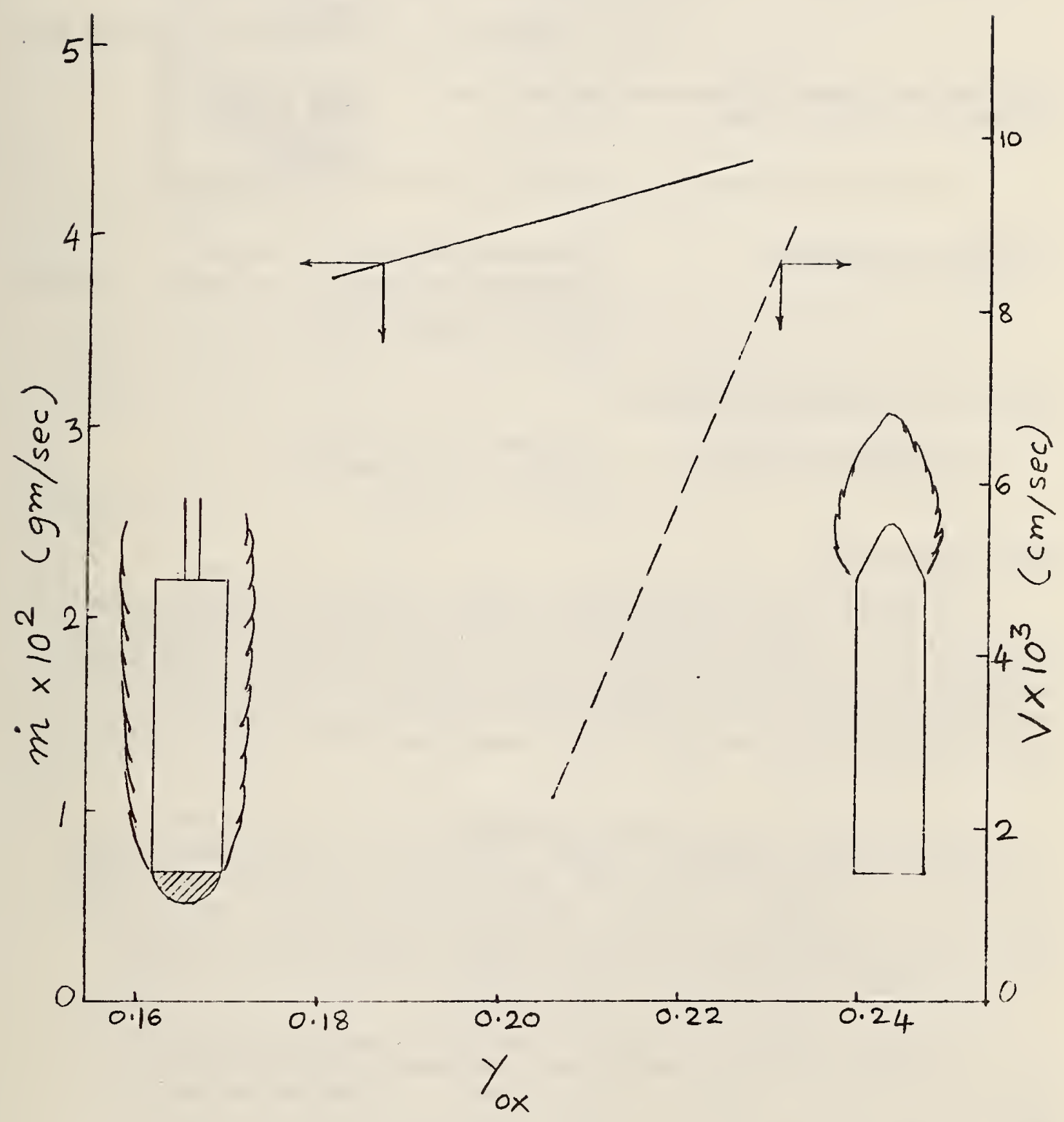

Fig. 1. Comparison of effect of oxygen concentration on burning rate and downward propagation rate. PMMA cylinders;

$1 / 2$ inch diameter. 
California Institute of Technology

Grant Title:

Convective Flow Associated with Room Fires

Experimental Study of Environment and Heat Transfer in a Room Fire
NSF Grant No.: ENV76-0660

Period:

1 June 1976 - 31 May 1977

NBS Grant No. :

NBS 5-9004

Period:

December 1976 -

30 November 1977
Principal Investigator:
Professor Edward E. Zukoski

California Institute of Technology, 301-46 Pasadena, Ca. 91125

(213) 795-6811, ext. 1785

Other Professional Personmel:

Faculty Associate: Graduate Students:

\author{
Professor Toshi Kubota \\ William S. Sargent \\ Ernst N. Tangren
}

\title{
Project Summary:
}

The flow field produced by fire within a single compartment or within a multi-compartment structure plays an important role in the development of the fire and in the spread of hot products of combustion throughout the structure. The flow field of a fire is characterized by strongly stratified regions, turbulent and buoyant plumes, and turbulent entrainment processes. Many of these processes cannot be treated analytically now.

The aim of the programs discussed here is to obtain an understanding of the fluid dynamic aspects of these flows and the convective heat transfer processes associated with them. This understanding will allow the development of rational calculation schemes which will make possible the prediction of the rate of spread of products of combustion through a complex building and will become a part of models designed to predict the complete fire spread process.

The work described here consists of two parallel programs. The first, supported by an NSF Grant, has been concerned with the use of small scale models to study the effects of various geometric and fluid dynamic parameters on the natural convective flow field set up in the early stages of a room fire. Emphasis has been placed on the study of turbulent mixing processes and stratified flow fields which cannot be treated analytically. These include the turbulent 
and buoyant plume produced by the fire, see Figure $1,(2)$ the mixing in the ceiling layer associated with the plume - ceiling interaction and (3) the stratified flows and mixing in the doorway and just inside and outside the doorway.

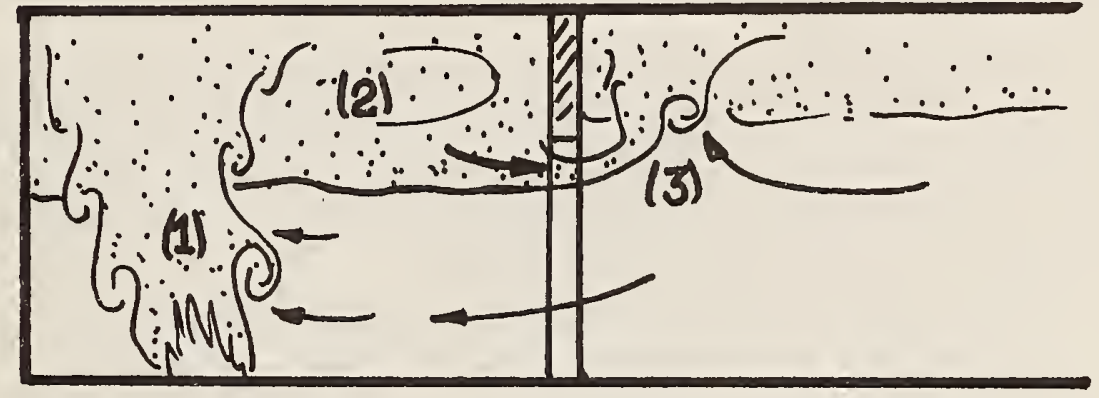

Figure 1

In this phase of the work, experiments were carried out in $1 / 5$ scale models; salt water with specific gravity in the range 1.10 to 1.002 was used to model the hot products of combustion and fresh water, to model the unheated air. Single rooms were studied with models of scale $1 / 2$ meter high by about one meter square.

This modeling work has now been completed and a final report assessing the usefulness of this type of modeling is now in preparation.

The second program, supported by an NBS Grant, concerns a study of the heat transfer and flow field produced in a single room prior to flash over. The work is carried out in a half scale room model with a natural gas fired burner to simulate a fire. The primary aim of this program is to develop scaling laws for the convective heat transfer to the room walls and to develop a better understanding of the flow field within the room and at the opening during the early stages of a fire.

Measurements of heat transfer rates, and the velocities, temperatures and concentrations of $\mathrm{CO}_{2}$ in the room are the primary experimental data. Fire heat input rate and position, and opening geometry are the primary parameters of the experiment.

In support of both of these projects, simple analytical and numerical models of the flow fields produced by a fire in a multicompartmental single story building have been constructed. These are in various stages of development and documentation. They have been used to guide the experiments and check the assumptions used in their interpretation. 
Salt Water Model: The salt water modeling work has been completed and a final report is in preparation. In this report, we will describe all the work concerning salt water modeling of convective flows in building fires, which we have carried out under this and previous NSF Grants.

During the past year we have studied the effects on a fire plume in a single room of a number of parameters. These include fire strength and fire geometry, fire location within the room and its vertical location with respect to the floor, opening geometry, and an examination of the density gradient set up in the ceiling layer during the development of that layer.

The result of this work will be available in September as a progress report and several results are discussed here.

In the case of an exisymmetric fire geometry, the dependence of the flow field on fire strength and a range of opening variations can be predicted by the simplest models. However, once the ceiling layer interface reaches the lower edge of the opening (e. g., the bottom sill of a window) considerable contamination of the incoming cold flow occurs and our simple models fail. We are currently studying this mixing process and the corresponding mixing process which occurs when the hot door jet impinges on the ceiling outside the opening. See (3) Figure 1.

The effect of fire geometry have been studied by comparing axisymmetric fire with rectangular fires of aspect ratio $2: 1$ and $5: 1$, and a line fire. The axisymmetric and line fire cases agree with simple models. The effect of the door jet, (the jet produced at the opening by the inflow of cold air), on fire plume has been studied. For fires located near the opening the entrainment can be increased and in all cases, the impingement point of the fire plume on the ceiling is effected. Appreciable swirl can be produced in the plume by off-centerline fire locations.

Finally, when an axisymmetric fire is placed in a corner, it behaves as if it were 1/4 of a fire of strength four times larger. That is, it entrains cold air as if it were one quadrant of a fire 4 times larger. In contrast, the entrainment rate of a line fire placed against a wall is greatly reduced.

Heat Transfer Model: The one-half scale room (1.22xl.22x $2.44 \mathrm{M}$ long) is constructed of $12.7 \mathrm{~mm}$ thick marinite walls which are cooled on the outside by a flow of air in a cooling passage. Local heat transfer rates are measured by using the wall it elf as a heat transfer gage. Temperatures are measured with 175 pairs 
of thermocouples imbedded in the inside and outside surfaces of the marinite sheets. The overall heat transfer rate to each wall is determined by measuring the heat input to the cooling air stream.

A rotating-translating probe allows gas temperature and composition samples to be obtained throughout the room. The local concentration of $\mathrm{CO}_{2}$ is obtained from six sampling tubes attached to the probe. The opening is instrumented with a separate array of thermocouples.

The premixed-natural gas burner used to simulate the fire can be moved around within the room and the fire strength can be varied over a wide range (at least 10 to $200 \mathrm{KW}$ ).

Preliminary results obtained with this apparatus indicate that a previously developed heat transfer prediction scheme will give a reasonable estimate of the maximum convective heat transfer rates.

Model Development: Several solutions have been obtained to describe the motions of gas (in a room or two rooms) during the early progress of a room fire. These solutions deal with gas motion alone; the fire is treated as a known source of heat and heat loss to walls is added in an ad hoc manner.

(i) Nearly-Closed Room. When heat is added to an ideal gas in a fixed volume, the pressure must increase in response to the temperature rise since the average density must remain fixed. In a room fire situation, the pressure rise is often kept very small due to gas leaks through openings in the walls of the room such as cracks around windows and doors. Under these circumstances we are interested in the time required for the gas remaining in the room to be contaminated and heated by mixing with the products of combustion from a fire of given heat input.

We have examined this problem for a simple example: the fire treated as a point source of heat with a specified strength and our examination is restricted to a volume composed of a single room with a horizontal ceiling layer of hot gas formed under the ceiling. This layer may contain a non-uniform temperature distribution. However, we can solve for a position of the interface between the hot and cold regions as a function of time without knowing the details of this temperature distribution due to the interesting results that in a constant pressure room fire the enthalpy of the gas remaining in the room is constant regardless of the temperature distribution. During the progress of the fire, the thickness of the ceiling layer grows in time and we are interested in predicting when the lower boundary will reach the floor level because this time is related to the time available for escape from the room. Analytic solutions have been found for this problem and are reported in a Progress Report.

Our purpose was to illustrate the general order of magnitude of the time involved and the manner in which various parameters influence this time by looking at cases which are mathematically very simple. This problem is a special case of a room fire and a numerical solution for the more general problem is described below. 
(ii) Two-Room Fire Model. A building, in most cases, is a combination of rooms, halls, and corridors, and it is desirable to have a simple method for estimating the movement of hot air, smoke and noxious gases throughout the building. For this purpose, a mathematical model for multi-room convective flow has been constructed by combining a simplified description for the fire plume, ceiling layer, and flow through openings.

Dependent variables are the ceiling layer height, the gas densities in the ceiling layer and below the ceiling layer, and the pressure in each room. By applying the conservation of mass and energy in each region, we obtain a necessary and sufficient number of differential equations from which time evolution and dependent variables may be computed for any time-dependent energy input $Q$ from the fire. The exchanges of mass and energy between two rooms and outdoors through openings are formulated by using the counter-current orifice flow assumption reported in Semiannual Progress Report, June 1975. The size of openings are functions of time, so that the affects of openings or closing of doors during fire may be computed. A program incorporating these approximations has been written and documentation of the program is in progress.

\section{Accomplishments}

(1) Completion of salt water modeling work; effects of a range of parameters on fire plume have been examined.

(2) Completion of $1 / 2$ scale test rooms; heat transfer data collection started.

(3) Development of one and two room convective flow models completed.

\section{Potential Applications}

Results will be used in development of fire spread models which will lead to better codes.

\section{$\underline{\text { Reports }}$}

E. E. Zukoski, "Development of a Stratified Ceiling Layer in the Early Stages of a Closed-Room Fire." Progress Report, February 1, 1977, National Bureau of Standards, Grant No. 5-9004. 
Institution:

Grant Title:

Principal Investigator:

Other Personne1:
Corne11 University

Grant No: NSF ENV74-15253 $\mathrm{A} 01$
FLAME SPREAD OVER LIQUID FUEL

Kenneth E. Torrance

Grumman Hall

Corne 11 University

I thaca, New York 14853

(607) 256-6253

E. Martin Remick

Graduate Research Assistant

Project Summary:

The object of this research is to determine in a quantitative way the range of physical parameters which will allow a flame to spread over the surface of a liquid fuel when the fuel is at a temperature below its flashpoint. The research to date has focused on the development and evaluation of a theoretical-numerical model for the liquid phase and, more recently, on the extension of such a model to the coupled gas-liquid combustion problem.

\section{Progress Report:}

A physical model has been developed for flame spread over a liquid fuel. The equations governing time dependent fluid motion in two dimensions are approximated by stable and explicit numerical methods. The physical model consists of a liquid fuel layer with an overlying oxygen-nitrogen atmosphere. The layer is at a sub-flash temperature. Although global reaction kinetics of a fairly general nature are permitted for the gas phase, only results for infinite-rate kinetics using Schvab-Zeldovich variables have been obtained with reasonable computing economy. The model includes detailed balances of mass, heat, and shear at the fuel surface, as well as forces due to buoyancy and surface tension effects.

Studies on two fuel geometries have been completed. One geometry is that of a shallow fuel pool of finite length burning in a cross wind. The effects of several parameters have been documented; such as shear rate, surface tension, buoyancy, fuel temperature, fuel type, gaseous inert concentration, and radiation models. Results indicate that surface tension effects dominate the liquid fuel behavior, and that buoyancy effects trigger timeperiodic motions in the gas phase.

The second geometry which we have considered is that of a moving flame propagating over a shallow fuel layer of infinite horizontal extent. The parameters considered for the aforementioned pool burning problem have also been considered for the moving flame problem. Moving flames have been obtained for fuel depths of $0.4 \mathrm{~cm}$ and $5.0 \mathrm{~cm}$ and the results compared with laboratory experiments at Princeton University. A representative moving flame solution for the shallower fuel depth is shown in Figure 1. The various graphs display mass fraction $(Y)$, streamline $(\psi)$, and temperature $(T)$ contours for a steadily propagating flame at $2.4 \mathrm{~cm} / \mathrm{sec}$. The fuel is $n$-decane 
and the oxidizer is air. The surface-tension-driven eddy and its influence are clearly apparent in the streamline and temperature fields. Although several factors are important for the flame spread process, it appears that flame radiation and flame unsteadiness are closely coupled and in many cases may be much more important than previously thought.

Results of the moving flame and pool burning studies are currently being written up as part of the doctoral thesis of E.M. Remick. Corresponding reports are also in preparation.

Accomplishments:

A. numerical model for the coupled gas/liquid phases has been formulated and validated. Parametric studies have been completed for the case of pool burning and for the case of a moving flame.

\section{Potential Applications:}

The research is relevant to activities involving the use, handling, or production of flammable liquids, and will provide fundamental information on the physical mechanism of fire spread over liquids. Such information will be useful for the design and control of industrial combustion processes, and for the engineering design of storage facilities and fire prevention and extinguishment systems. The results are also relevant to the successful burning of oil or hydrocarbon spills.

\section{Future Milestones:}

Future work will include study of buoyancy-driven flames and comparison of results with physical experiments. 

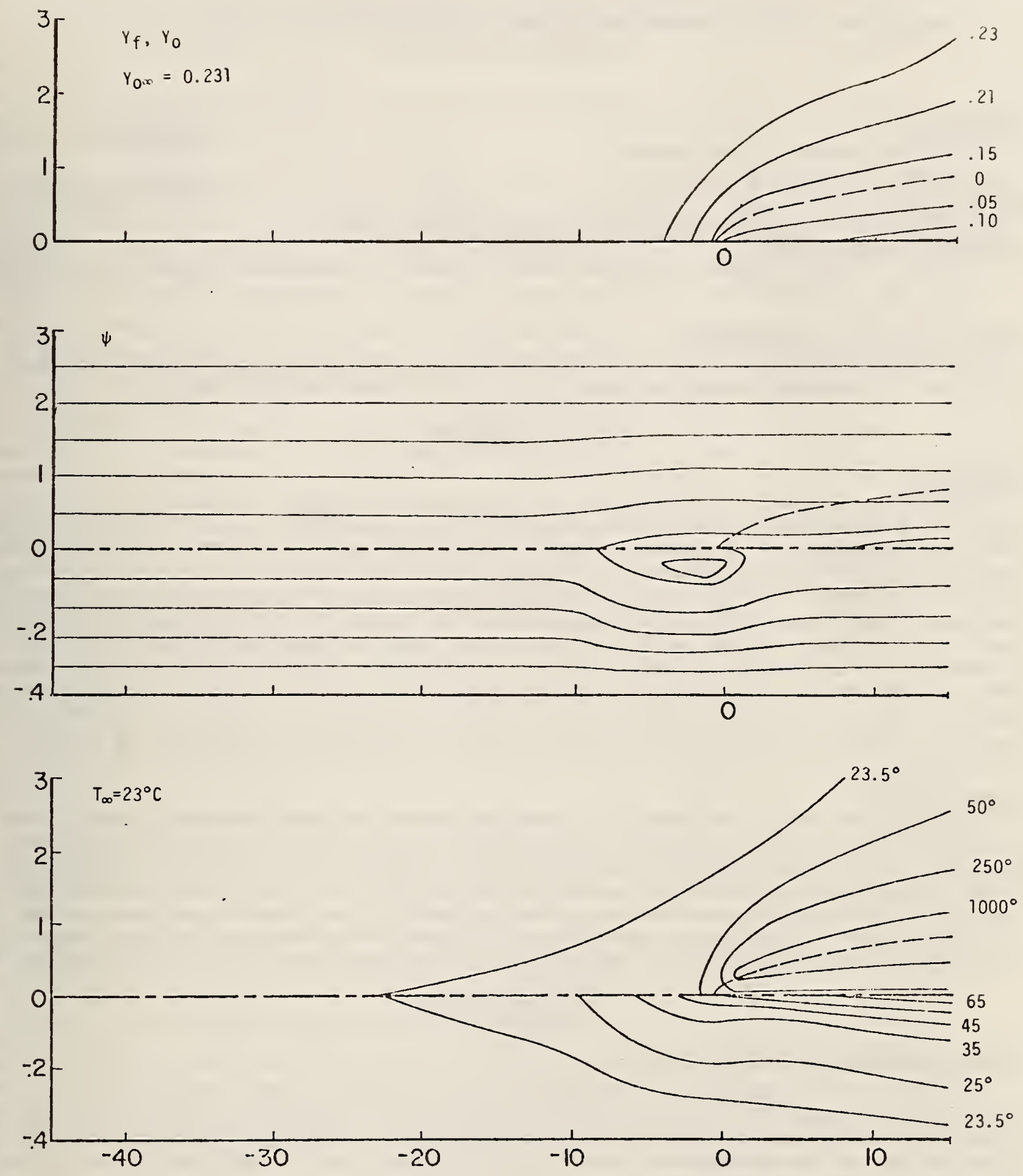

Figure 1. Mass fraction contours (oxidizer, $Y_{0}$; fuel, $Y_{f}$ ); streamlines $(\psi$ ) and isotherms $\left(\mathrm{T}\right.$, in ${ }^{\circ} \mathrm{C}$ ) for flame spread over a $0.4 \mathrm{~cm}$ layer of $\mathrm{n}$-decane. Origin of coordinate system coincides with leading edge of flame. Computed flame speed, $\mathrm{V}_{\mathrm{f}}$, is $2.4 \mathrm{~cm} / \mathrm{sec}$. 
INSTITUTION

School of Aerospace Engineering

Georgia Institute of Technology

GRANT TITLE

"Properties of Combustion Products from Building Fires"

PRINCIPAL INVESTIGATORS

Dr. Ben T. Zinn, Regents' Professor and Dr. Robert A. Cassanova, Sr. Research Engineer,

School of Aerospace Engineering, Georgia Institute of Technology, Atlanta, Ga. 30332,

404-894-3033.

OTHER PROFESSIONAL PERSONNEL

Dr. Eugene A. Powell, Assistant Professor; Dr. C. Perry Bankston, Research Engineer;

Dr. R. F. Browner, Assistant Professor; Dr. J. U. Rhee, Research Chemist.

\section{PROJECT SUMMARY}

Objectives

The objectives of this program are: (1) continued development and utilization of facilities and experimental techniques required for the determination of particle size distributions and particulate mass concentrations, the chemical properties of both smoke and gaseous products, and the optical properties of smoke produced by burning various building materials; (2) determination of the dependence of the properties of smoke generated by the combustion of various materials on the temperature and composition of the chamber atmosphere, the type of burning, the radiant heat flux to the sample in non-flaming combustion, the orientation of the sample, and the amount of ventilation; (3) determination of the dependence of smoke and gaseous products generated by burning synthetic polymers on the type and amount of chemical additives found in those polymers; and (4) utilization of small-scale test data with related theoretical models to predict the smoking properties of various materials.

\section{Research Plan}

To pursue the objectives outlined above, the efforts of this research project can be divided into three major categories or tasks. Task $I$ is concerned with the continued improvement of and modifications to the experimental capabilities of the fire research facility. Task II deals with the actual determination of the detailed characteristics of the products generated during the combustion of materials in a ventilated, small-scale Combustion Products Test Chamber under carefully controlled conditions. Finally, Task III is concerned with the theoretical modeling of smoke producation from burning materials.

\section{PROGRESS REPORT}

\section{Task I - Experimental Capabilities}

Facilities which have been previously developed in this research project are: (1) a ventilated Combustion Products Test Chamber (CPTC); (2) a Combustion Products Sampling System; (3) an Optical Aerosol Measurement System; and (4) a Chemical Analysis System. Modifications and improvements to these facilities that have been carried out during the past year are reviewed below.

Further development of the optical system. The in situ optical system is presently being modified in order to determine the imaginary part of the complex refractive index of the smoke particles. Two additional detectors will be incorporated into the present system to measure $90^{\circ}$ - scattering intensities both parallel to $\left(I_{11}\right)$ and perpendicular to ( $\left.I_{1}\right)$ the plane of polarization of the incident light beam. A data reduction procedure has been developed to determine the complex refractive index (m=n-ik) from the measured ratio $I_{11} / I_{\perp}$ considered along with the ratio of optical densities at two wavelengths and the mean par- 
ticle size $\mathrm{D}_{32}$ determined from the forward scattering measurements. These improvements of the optical system will allow the determination of volume concentrations for smokes which absorb as well as scatter light.

Computerized Data Acquisition. On-line data acquisition and data reduction system utilizing a Hewlett-Packard 2100 mini-computer has been implemented for all optical and sampling measurements taken during CPTC smoke tests.

Addition to the Chemical Analysis System. During the past year a Hewlett-Packard 5722A Gas Chromatograph has been added to the Chemical Analysis System. This gas chromatograph is a single column model equipped with a thermal conductivity detector and is utilized in the analysis of gaseous and other low molecular weight combustion products generated during tests run in the CPTC.

Task II - Determination of the Characteristics of Combustion Products

High Temperature Studies. A series of high temperature tests conducted with samples of Douglas fir and a rigid PVC have been completed. For both nonflaming and flaming combustion, the vertically mounted samples were tested at ventilation gas (air) temperatures of $100^{\circ} \mathrm{C}$, $200^{\circ} \mathrm{C}$ and $300^{\circ} \mathrm{C}$, while exposed to a radiant flux of $5 \mathrm{~W} / \mathrm{cm}^{2}$. In addition, flaming tests were conducted at $400^{\circ} \mathrm{C}$ without the radiant heater. As previous $1 y$ reported, the data indicated changes in smoke optical densities and particle size characteristics due to changes in ventilation gas temperature for both flaming and nonflaming conditions. Figures 1 and 2 provide examples of these results; where optical densities are plotted for wood burning (flaming) at $200^{\circ} \mathrm{C}$ and $300^{\circ} \mathrm{C}$, and the average particle size behavior is given for flaming PVC at $300^{\circ} \mathrm{C}$ and $400^{\circ} \mathrm{C}$. In general for the tests of wood, smoldering samples produced smaller particles and lower optical densities at higher ventilation gas temperatures, while under flaming conditions larger particles and greater optical densities were evident as temperature increased. For nonflaming PVC tests, higher temperatures produced larger particles and lower optical densities. Under flaming conditions PVC samples again generated larger particles as temperature increased, while temperature did not have a strong effect upon the measured optical densities.

Tests of PVC and Different Additives. Tests were conducted to determine the effects of several different, commonly used PVC additives on the smoke production and the physical characteristics of the smoke particles. PVC samples which contained a lead stabilizer, two different plasticizers, lubricants, $\mathrm{CaCO}_{3}, \mathrm{Al}_{2} \mathrm{O}_{3} \cdot 3 \mathrm{H}_{2} \mathrm{O}$ and $\mathrm{MoO}_{3}$ were tested under nonflaming combustion conditions. In general, the samples with the least amount of additives produced the highest concentration of smoke and the largest smoke particles. The samples which contained the fillers, $\mathrm{CaCO}_{3}$ or $\mathrm{Al}_{2} \mathrm{O}_{3} \cdot 3 \mathrm{H}_{2} \mathrm{O}$, produced the least concentration of smoke and the smallest smoke particles. Data is available on smoke particles size distributions, mean particle size and optical density variations during the sample combustion, sample weight loss during combustion and smoke mass concentration. Tests are continuing for samples exposed to flaming ignition and high temperature ventilation gases.

Tests of Polypropylene with Different Additives. A series of tests of polypropylene samples containing various commercial fire retardant additives has been initiated. To date, seven formulations have been tested under nonflaming conditions in the horizontal sample mount at a radiant heat flux of $5 \mathrm{w} / \mathrm{cm}^{2}$ (in air). Figures 3 and 4 give typical results for three of the samples tested. Figure 3 shows cascade impactor data from tests of a pure polypropylene polymer and two fire-retarded polypropylenes. These data indicate that more smoke (by mass) was generated by the pure polymer than by the particular fire-retardant formulations tested, although the particle size distributions peak near the same particle size in all three cases. Time resolved optical density measurements presented in Figure 4 show nearly the same behavior for all three samples tested. Analysis of data from tests of the remainder of the polypropylene samples show varying effects on smoke characteristics as other fire retardant formulations are considered. Measured quantities for all samples include particle size distribution, average particle size, particulate mass concentration and smoke optical density. Tests of the same samples under flaming conditions will be initiated during August of 1977. 
Chemical Analysis of Particulates. The chemical analysis efforts have focussed on two primary objectives: (i) the analysis of compounds important because of their high toxicity, and (ii) the analysis of compounds important to aid modeling studies of the combustion process. In the first category, compounds of prime interest are the low molecular weight compounds absorbed onto the particulates which are known to possess high acute toxicity (such as $\mathrm{HCl}, \mathrm{HCN}$ and certain aldehydes). The general analytical scheme involves the thermal desorption of these compounds from the particulates into a stream of dry $\mathrm{N}_{2}$, collection and concentration of the released volatile compounds onto a packed trap and subsequent release of these compounds for analysis by gas chromatography. Identification is by g.c. retention time and by g.c./m.s. Methodology is currently under development for quantification of this analysis, and recovery experiments using standard atmospheres of certain known mixtures are underway.

The chemical analysis of high and intermediate molecular weight compounds, necessary for incorporation into analytical models of the combustion process, has been continued. For the high molecular weight compounds, pre-separation by high pressure liquid chromatography, followed by g.c./m.s. of the collected fractions has been used successfully to achieve a high degree of resolution and make identification of many compounds possible.

Recently, work has begun on a micro-preparative g.c. scheme for the pre-separation of low molecular weight compounds, prior to identification by g.c. retention time and g.c./m.s. By this means, it is hoped to achieve effective "clean-up" of the complex mixture of organic compounds in the approximate molecular weight range 44-120. In all phases of the chemical analysis program, the emphasis has been on obtaining thorough pre-separation of the complex particulate material prior to the analytical step, in order to obtain reliable compound assignments, and considerable progress has been made in this area.

\section{Task III. - Theoretical Efforts}

Development of an analytical model capable of describing certain "smoking" characteristics of different solid materials is underway. Specifically, a one-dimensional model describing the smoldering decomposition with charring of a slab of polymeric material of finite thickness has been considered. The fact of the "sample" is subjected to a known incident heat flux and both solid and gas phase properties are described. Initially, fundamental equations have been formulated to account for solid decomposition, solid/gas phase energy and the transport of the volatile, condensable products of thermal degradation. The material sample is characterized by regions which range from the primary solid decomposition reaction zone to a very porous char structure closest to the sample surface. A computer program which utilizes an implicit finite differencing scheme has been written to obtain solutions to the developed governing equations. The program includes a block tri-diagonal matrix inversion routine and presently calculates gas density, solid porosity, gas velocity and gas/solid temperature. Debugging of the program has recently been completed and calculations of the above-mentioned quantities for selected thermally decomposing materials have been initiated. Once the present model is found to be yielding acceptable results, particulate formation and growth processes such as nucleation, condensation, agglomeration, etc., will be added on a stepwise basis. It is expected that these "smoke" formation processes will begin to be included in the model in September of 1977.

\section{ACCOMPLISHMENTS}

The following is a list of accomplishments under NSF Grant AEN 73-03168 A02 and NBS Grant No. G7-9001 during the period July 1, 1976 - June 30, 1977.

(1) Experimental facilities have been enhanced by the addition of (i) on-line computerized data acquisition and data reduction for all optical and sampling measurements taken during CPTC smoke tests, and (ii) a new gas chromatograph to utilized in the analysis of gaseous and low molecular weight combustion products.

(2) High temperature smoke tests of wood and a rigid PVC plastic in air have been completed and results show variations in smoke characteristics as ventilation gas temperatures are increased for both nonflaming and flaming conditions. 
(3) Tests designed to determine the effects of various additives on the smoke production of burning PVC have continued. Results show that samples with the least amount of additives produced the highest concentration of smoke and the largest smoke particles for the formulations studied under nonflaming conditions.

(4) Tests designed to characterize and determine the effects of various additives on smoke production from burning polypropylene have been initiated. Results show that for nonflaming conditions measured smoke characteristics are directly dependent upon the fire-retardant formulation utilized.

(5) The chemical analysis of high and intermediate molecular weight compounds has continued. Utilization of high pressure liquid chromatography with g.c./m.s. techniques have provided for more accurate identifications of additional compounds in smoke particulates.

\section{POTENTIAL APPLICATIONS}

Data obtained in this research program will aid in the evaluation of hazards resulting from smoke produced during building fires. Furthermore, these data can be of use in determining what environmental conditions and material additives most affect smoke production, and thus aid in the development of safer commercial materials. Finally, correlation of measured smoke properties with theoretical predictions will provide detailed information on the mechanisms of smoke production which has not previously been available.

\section{FUTURE MILESTONES}

The following milestones have been established for the coming year: (i) High temperature and flaming tests of PVC + additives will be completed by December, 1977; (ii) Flaming tests of polypropylene samples will be completed by September, 1977; (iii) Low temperature tests of polyethylene will begin in September, 1977 and should be completed by February, 1978; (iv) Cataloging of all physical property measurements obtained in CPTC tests wil1 begin in July, 1977 and be completed by the end of December, 1977; (v) Design and construction of a new. small-scale, low-pressure test chamber will begin in October, 1977 and should be completed by the end of March, 1978; (vi) Microprobe and in situ optical measurements in the near-sample region will begin in April, 1978; (vii) Development of the theoretical model for smoke production will continue with the addition of particulate formation processes to the model during the Fall of 1977.

\section{REPORTS AND PUBLICATIONS}

1. Cassanova, R. A., Powe11, E. A., Bankston, C. P. and Zinn, B. T., "The Effects of PVC Additives on the Properties of Smoke Produced During Nonflaming Combustion," presented at the Combustion Institute Meeting (Western Section) on Combustion Diagnostics and Fire Research, La Jo1la, Ca., October 18-19, 1976.

2. Bankston, C. P., Powe11, E. A., Cassanova, R. A. and Zinn, B. T., "Detailed Measurements of the Physical Characteristics of Smoke Particulates Generated by Flaming Materia1s," presented at the Combustion Institute Meeting (Eastern Section) on Chemical and Physical Processes in Combustion, Philadelphia, Pa., November 18-19, 1976 (Submitted for publication).

3. Zinn, B. T., Powe11, E. A., Cassanova, R. A. and Bankston, C. P., "Investigation of Smoke Particulates Generated During the Thermal Degradation of Natural and Synthetic Materia1s," Fire Research, Vo1.1, March 1977, p. 23. 

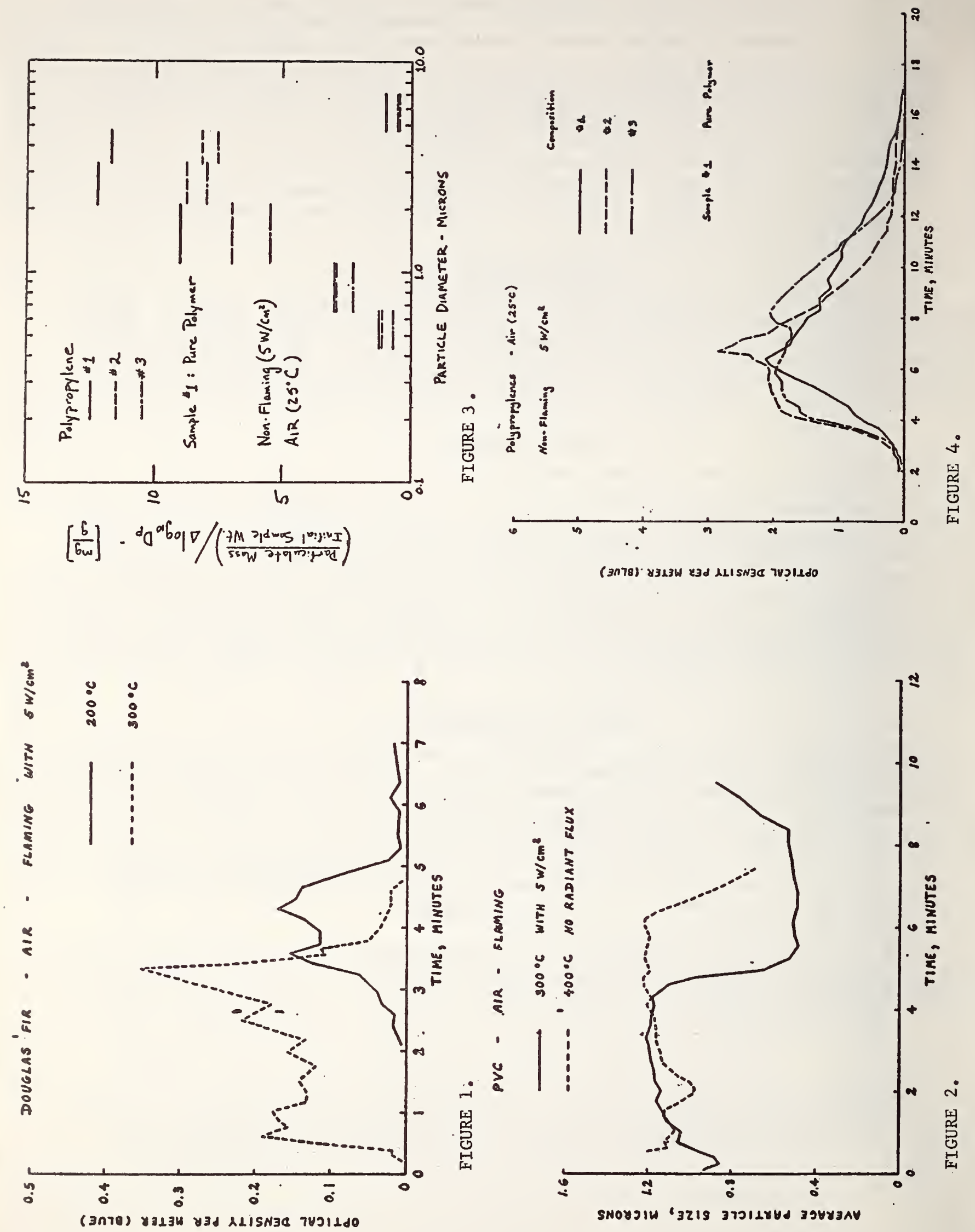
Proceedings of a Conference Held at NBS, Gaithersburg, Md., August 3-5, 2977, (Issued October 2977)

\section{INSTITUTION}

Fire Hazard and Combustion Research Laboratory

School of Mechanical Engineering

Georgia Institute of Technology
GRANT NO. NBS G7-9003

Grant Title: Effects of Ignition Sources and Fire Retardants on Material Ignition

\section{Principal Investigator}

Professor P. Durbetaki

Fire Hazard and Combustion Research Laboratory

School of Mechanical Engineering

Georgia Institute of Technology

Atlanta, Georgia 30332

(404) 894-3282

Other Professional Personnel

Professor W. C. Tincher, Faculty Associate

Mr. H. Chang, Graduate Research Assistant

Mr. L. R. Lloyd, Graduate Research Assistant

Mr. R. P. Lowery, Graduate Research Assistant

Mr. C. C. Ndubizu, Graduate Research Assistant

Mr. M. L. Teague, Graduate Research Assistant

Mr. W. J. Tingle, Graduate Research Assistant

Mr. V. L. Wolfe, Jr., Graduate Research Assistant

Project Summary

The objective of the research program has been (i) to provide modeling rules and experimental data for the prediction of thermally thin and thermally thick material ignition, (ii) to measure ignition time, ignition frequencies and evaluate the necessary parameters which describe the probability of ignition under given exposure $\mathrm{P}(\mathrm{I} / \mathrm{E})$, for single and pairs of fabrics, and for building materials, (iii) to measure material thermophysical properties which characterize the material behavior during the preignition processes, (iv) to develop universal ignition criteria for thermally thick and thin media, and establish constitutive descriptions required for the modeling analysis, (v) to establish the relationship between laboratory and actual exposure conditions, and (vi) to assess the effects of geometry and material combinations on ignition.

The program currently in progress is divided into the following tasks:

Ignition Characteristics of Flame Retardant Fibers and Fabrics

Ignition/Destruction Characteristics of Unrestrained Fabrics

Effect of Convective Source Type and Size on the

Ignition Time of Thermally Thin Materials

\section{Progress Report}

Thermal radiative properties have been measured both on original and charred samples of cellulosic and thermoplastic materials. The charring was carried out both under quasi-steady and under transient heating conditions. The method of charring has shown significant difference in the absorptance of the material tested. 
Ignition time measurements have been carried out on plane-parallel pairs of thermally thin materials under convective and radiative mode of heating. The ignition time measurements on similar and dissimilar fabric pairs have shown that under convective heating the ignition time of the front fabric is completely independent of the presence of the back material. The ignition time measurements under radiative heating using fabric number 5 ( $100 \%$ cotton) for the similar pair, and fabric number 18 ( $100 \%$ cotton) front with fabric number 3 ( $100 \%$ polyester) back for the dissimilar pair are shown in Figures 1 and 2 . These measurements have shown no apparent chemical interaction between the fabric layers but strong thermal interaction has been observed as the figures indicate.

Ignition frequency measurements have been carried out using the Convective Ignition Time Apparatus (CITA) on thermally thick materials to determine the median self-sustaining ignition time, the standard deviation, and the probability of ignition given laboratory exposure. The self-sustaining ignition process which leads to the material destruction consists of two stages: the pyrolyzate ignition and the post-pyrolyzate heating to establish self-sustaining ignition. Each stage has its characteristic time where the pyrolyzate ignition time is strongly dependent on heating intensity and weakly dependent on material thickness. The self-sustaining ignition time is strongly dependent on both heating intensity and material thickness. Figures 3,4 and 5 give the representative ignition probability under laboratory exposure for some of the material tested. The standard deviation which accounts for the stochastic variation of thermally thick material properties ranges between 0.93 and $5.65 \%$ of the median self-sustaining ignition time for the material tested. These materials included wood veneer, polymethyl metharcylate (PMMA) and polyethylene.

The effect of sample size and convective ignition source size on the ignition time measurements of thermally thin and thick materials has been investigated under convective heating mode. In the range of ignition source size used $(12.5 \mathrm{~mm}-37.0$ $\mathrm{mm}$ diameter burners) and the range of thermally thin material sample size used $(63.5 \mathrm{~mm}-120 \mathrm{~mm})$, pyrolyzate ignition times and solid ignition times have been found to be independent of source size and sample size.

The Lower Ignition Temperature and Concentration Apparatus (LITACA) was designed and built with a resistance heater furnace which provided a heating rate of 20-25 $\mathrm{c} / \mathrm{min}$ for the sample to be pyrolyzed. While the level of heating is comparable to those rates used in DTA/TGA analysis, it does not establish heating rates on the same order as those encountered in actual fires and in laboratory ignition studies. Therefore, a major change in the apparatus was carried out with the replacement of the resistance heater furnace by a radiant heater furnace. This new furnace is capable of pyrolysis heating rates in excess of $6000 \mathrm{c} / \mathrm{min}$. Measurements were carried out with pyrolyzate gases generated using different heating rates. The pyrolyzate gases were used to determine their minimum self-ignition temperature as a function of concentration in a mixture with air. The results of these measurements using pyrolyzate gases generated from $100 \%$ polyester and $100 \%$ cotton materials are shown in Figures 6 and 7 respectively. Pyrolyzate gases have also been generated from a flame-retarded $100 \%$ cotton at two heating rates and the minimum self-ignition temperature measurements on these gases are presented in Figure 8. The results at the high heating rate are also compared in Figure 9 with those of the unt reated $100 \%$ cotton fabric. Minimum self-ignition temperatures of pyrolyzateair mixtures have been found to depend on the heating rate during the pyrolysis of the material. The ignition temperatures decrease with increasing heating rates.

\section{Accomplishments}

Experimental techniques and apparatus have been developed to measure ignition times and ignition frequencies on small and large samples of thermally thin and thermally thick media under time invariant radiative heating.

Experimental techniques and apparatus have been developed to measure ignition times and ignition frequencies on thermally thin and thermally thick media at various orientations and under time invariant convective heating. 
Experimental techniques and apparatus have been developed to pyrolyze materials at heating rates ranging from $20 \mathrm{c} / \mathrm{min}$ to an excess of $6000 \mathrm{c} / \mathrm{min}$ and to measure the minimum self-ignition temperatures on pyrolyzate-air mixtures as a function of pyrolyzate concentration.

Modeling analysis has been developed to describe the ignition process along with the associated preignition stages for thermally thin materials under convective and radiative heating.

Potential Applications

The ignition times measured and the modeling analysis developed serve to assess the relative ease of ignition for thermally thin and thermally thick materials.

The investigations with flame retardant material serve to assess the effect of the treatment and level of treatment on the ignition process.

The investigations on the self-ignition temperatures of pyrolyzate-air mixtures serve to describe the ignition of materials as well as flashover in a room fire.

Future Milestones

Experimental efforts are directed at:

(i) Measurement of ignition of materials and self-ignition temperatures of pyrolyzate-air mixtures to determine the effect of flame retardant treatment and level of treatment on the ignition process.

(ii) Measurement of ignition and ignition statistics to determine the effect of convective source size and type on the ignition process of thermally thin materials.

Analytical efforts are directed at:

(i) Modify the modeling analysis developed for the prediction of ignition times of single fabrics and assembly of fabrics under radiative heating.

(ii) Develop a model for the description of the preignition processes of thermally thick materials under convective heating.

\section{Reports and Papers}

1. P. Durbetaki, "Measurement and Prediction of Fabric Ignition Time and Its Relation to Fire Hazard", Fire Retardants: Proceedings of 1976 International Symposium on Flammability and Fire Retardants, Technomic Publishing Co., Inc., Westport, CT, 1977, Pp. 88-98.

2. P. Durbetaki, L. R. Lloyd, and W. C. Tincher, "Ignition Probability of Thermally Thin Media Subject to Convective Heating: Effect of Orientation", Coatings and Plastics Preprints of Papers Presented at the 172nd Meeting, 36, No. 2, American Chemical Society, 1976, pp. 185-190.

3. K. Annamalai and P. Durbetaki, "Ignition of Thermally Thin Porous Pyrolyzing Solids Under Normally Impinging Flames", Combustion and Flame, 27, pp. 253-266, 1976.

4. P. Durbetaki, W. Wulff, G. L. Matson, W. P. Ryszytiwskyj, and P. T. Williams, "Ignition of Pyrolyzing Solids in Air", Fall Technical Meeting, Eastern Section, The Combustion Institute, Drexel University, Philadelphia, PA, 18-19 November 1976.

5. P. Durbetaki, "Fundamental Studies on Fabric Ignition", Proceedings of the Tenth Annual Meeting, Information Council on Fabric Flammability, Galveston, TX, 1976, pp. 243-254.

6. V. L. Wolfe, Jr., and P. Durbetaki, "Ignition of Thermally Thick Media Under Convective Heating", Spring Meeting, Central States Section, The Combustion Institute, NASA Lewis Research Center, Cleveland, OH, 28-30 March 1977.

7. P. Durbetaki, and C. Thorn-Andersen, "Effect of Heat Flux Level and Exposure Time to a Radiant Heat Source on the Thermal Radiative Properties of Cellulosic and Thermoplastic Materials", Seventh Symposium on Thermophysical Properties, National Bureau of Standards, Gaithersburg, MD, 10-12 May 1977.

8. P. Durbetaki, "Effects of Ignition Sources and Fire Retardants on Material Ignition", Quarterly Progress Report No. 7, NBS Grant No. G7-9003, Fire Hazard 
and Combustion Research Laboratory, School of Mechanical Engineering, Georgia Institute of Technology, Atlanta, GA, 11 January 1977.

9. P. Durbetaki, W. C. Tincher, L. R. Lloyd, R. P. Lowery, W. J. Tingle, and

V. L. Wolfe, Jr., "Prediction of Fire Hazard from Fabrics and Building Materials", Fifth Research Report, NSF Grant No. AEN72-03359 A04, Fire Hazard and Combustion Research Laboratory, School of Mechanical Engineering, Georgia Institute of Technology, Atlanta, GA, 28 February 1977.

10. P. Durbetaki, "Effects of Ignition Sources and Fire Retardants on Material Ignition", Quarterly Progress Report No. 8, NBS Grant No. G7-9003, Fire Hazard and Combustion Research Laboratory, School of Mechanical Engineering, Georgia Institute of Technology, Atlanta, GA, 11 April 1977.

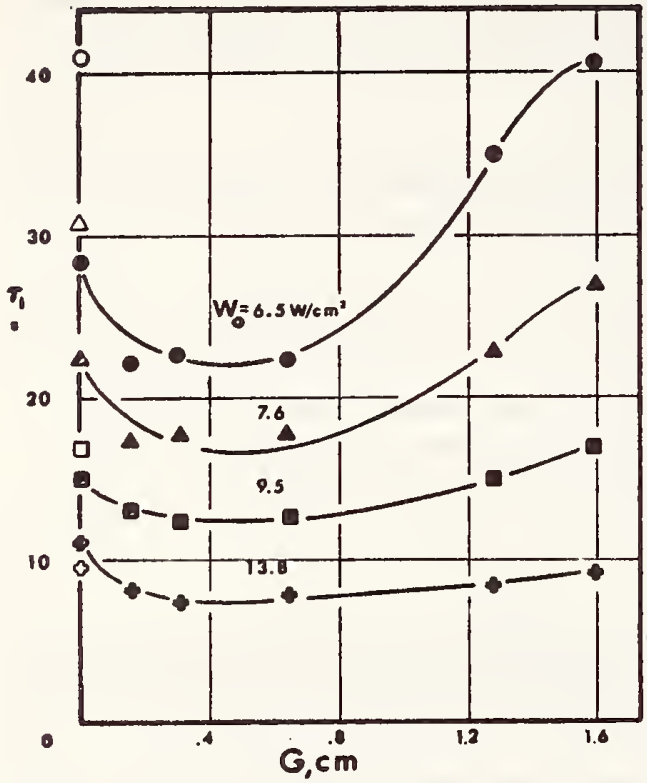

Figure 1. Ignition Time of Front Fabric as a Function of Spacing and Heating Intensity; Fabric No. 5 (100\% Cotton) Front and Back; Open Points Denote Single Fabric Ignition Times.

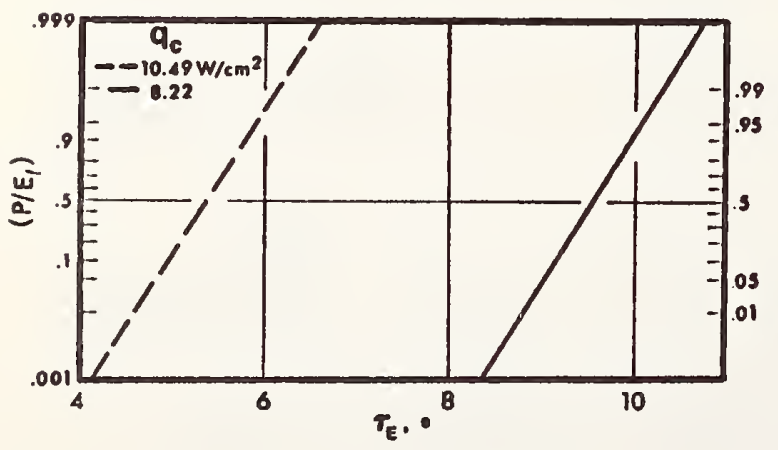

Figure 3. Self-Sustaining Ignition Probability as a Function of Exposure Time and Convective Heating Intensity; Material No. 1, Red Oak Veneer, $0.91 \mathrm{~mm}$ Thick.

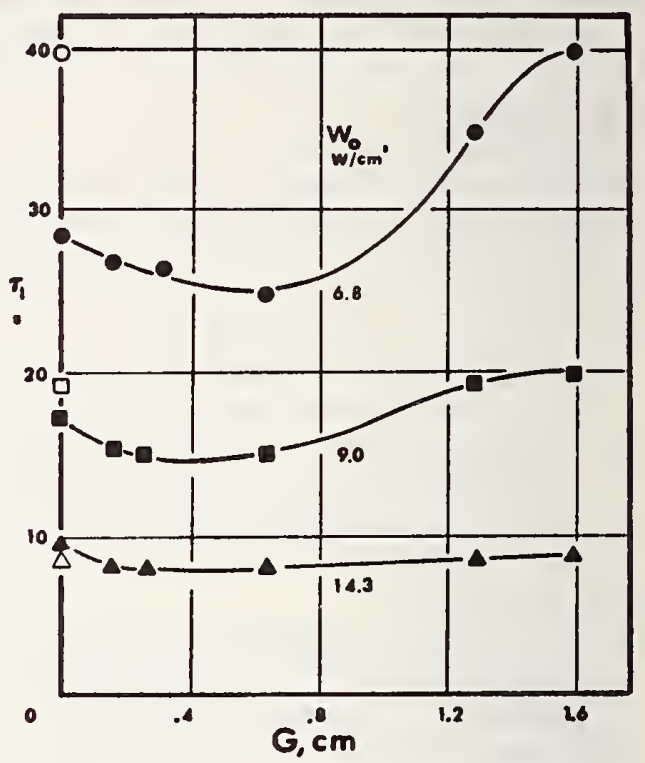

Figure 2. Ignition Time of Front Fabric as a Function of Spacing and Heating Intensity; Fabric No. 18 (100\% Cotton) Front with No. 3 (100\% Polyester) Back; Open Points Denote Single Fabric Ignition Times.

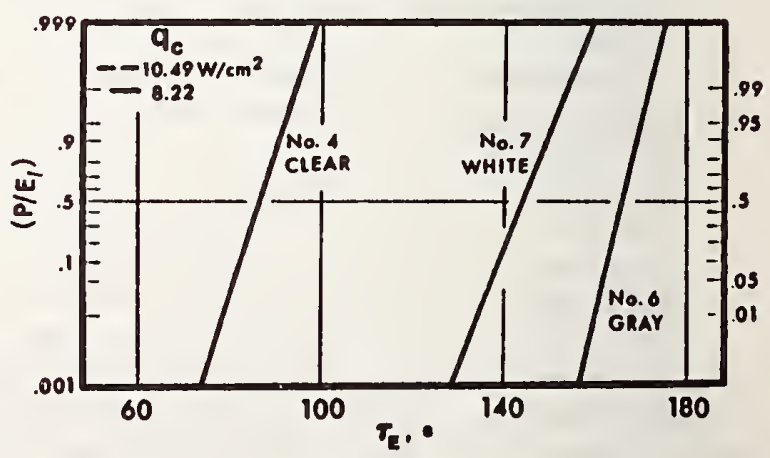

Figure 4. Self-Sustaining Ignition Probability as a Function of Exposure Time; PMMA, $3.18 \mathrm{~mm}$ Thick. 


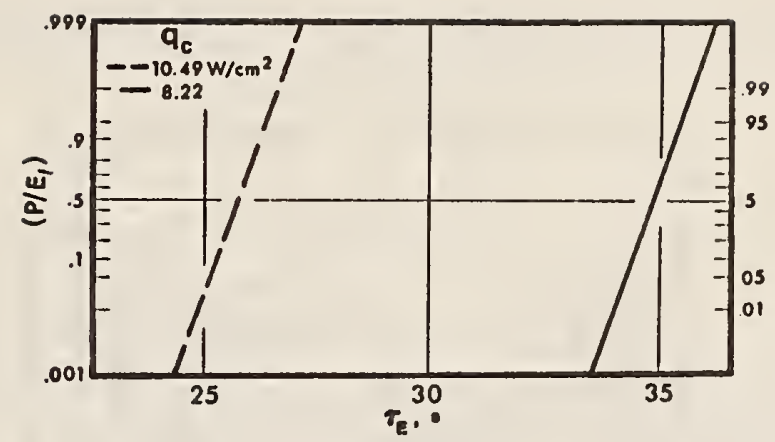

Figure 5. Self-Sustaining Ignition Probability as a Function of Exposure Time and Convective Heating Intensity; Material No. 12, High Density Polyethylene, $1.65 \mathrm{~mm}$ Thick.

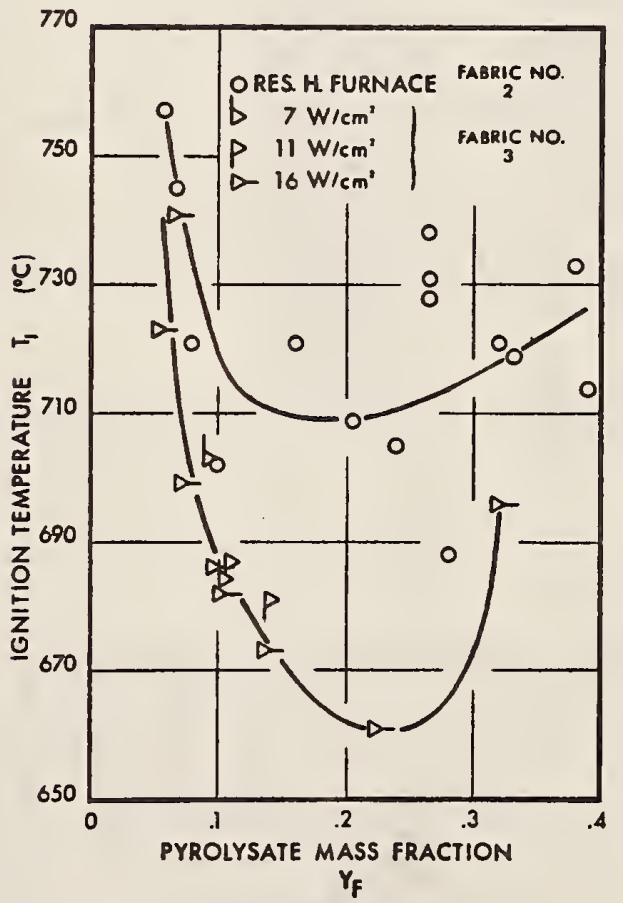

Figure 6. Minimum Self-Ignition Temperatures of Pyrolyzate Gases Generated at Four Different Heating Rates from $100 \%$ Polyester Fabrics. 


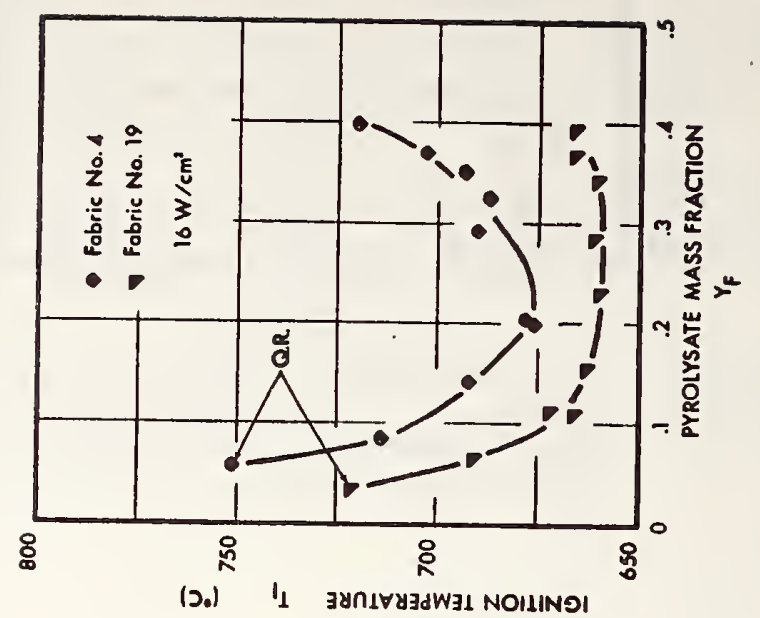

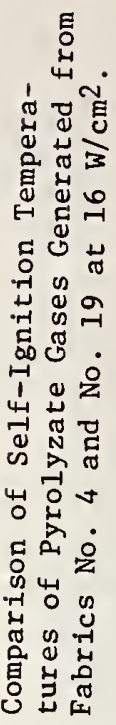

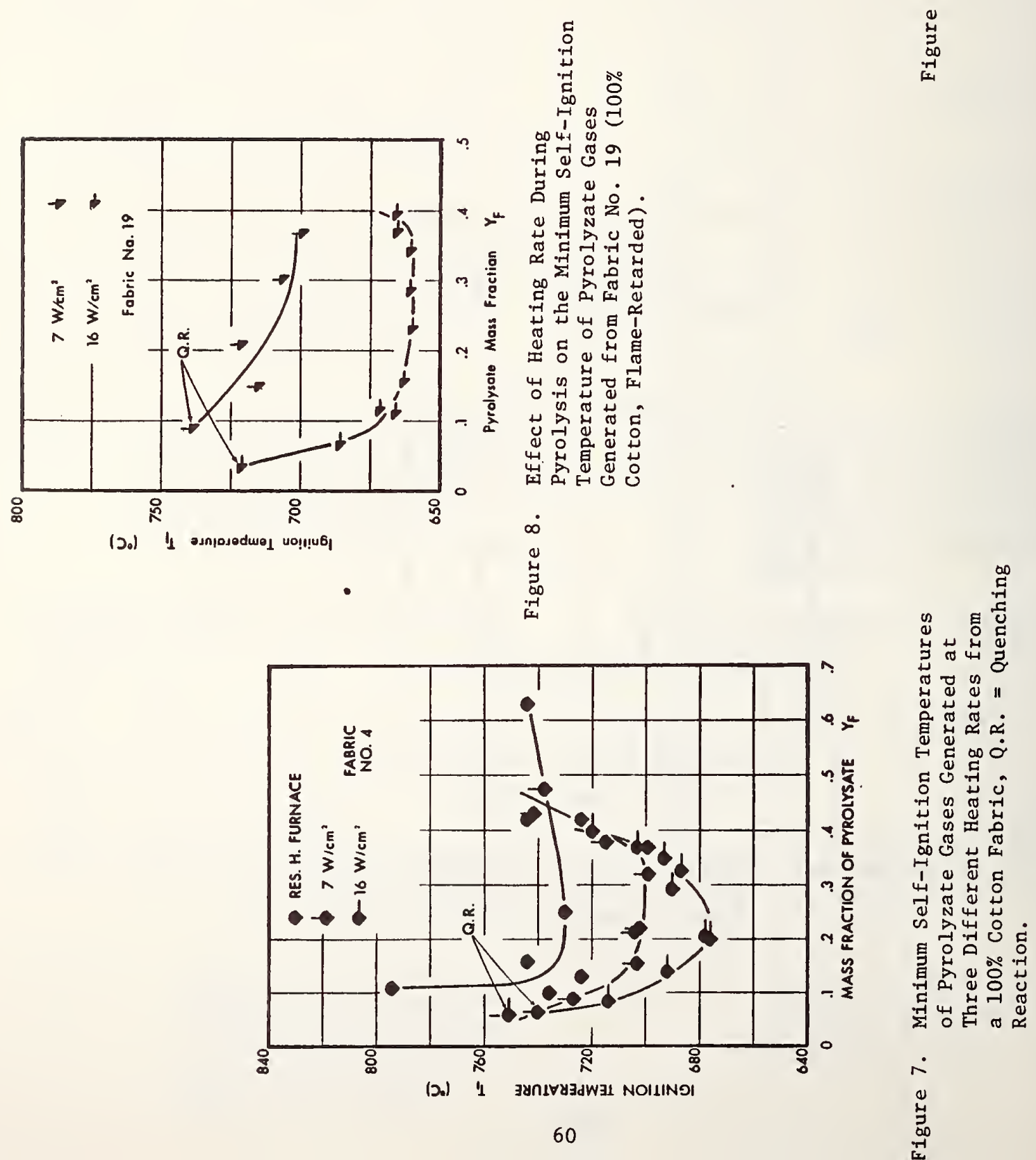




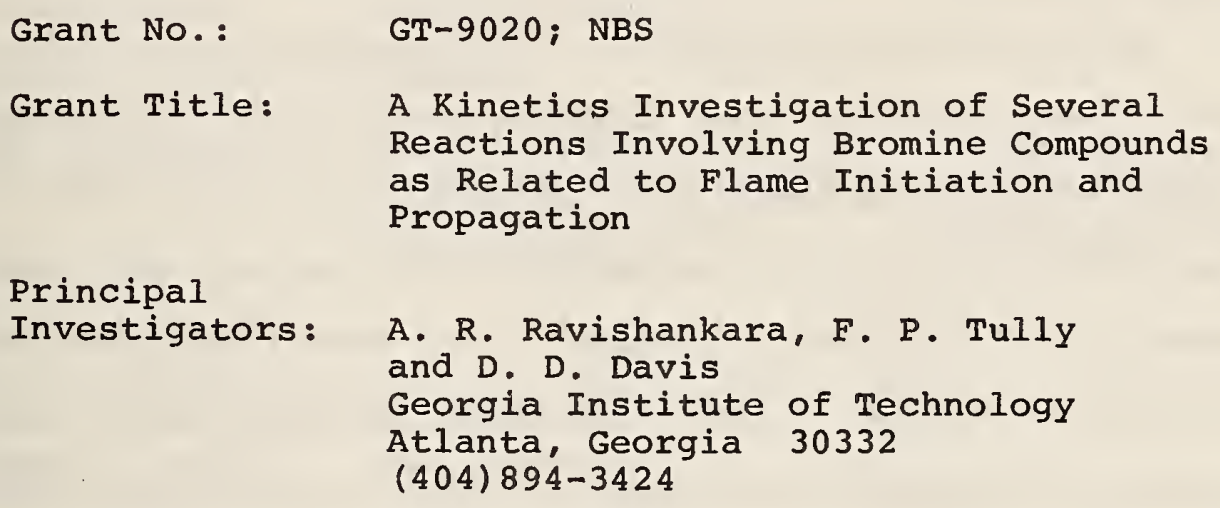

Grant No.:

Grant Title:

Investigators:

GT-9020; NBS
A Kinetics Investigation of Several Reactions Involving Bromine Compounds as Related to Flame Initiation and Propagation

\author{
A. R. Ravishankara, F. P. Tully \\ and D. D. Davis \\ Georgia Institute of Technology \\ Atlanta, Georgia 30332 \\ (404) 894-3424
}

\section{Project Summary:}

Knowledge of the rate constants for the reactions of hydroxyl radicals with constituents of both uninhibited and inhibited flames is essential to the understanding and modeling of flame dynamics. Under the present grant, we are measuring the rate constants for the reactions of $\mathrm{OH}$ with the test fuels $\mathrm{CH}_{4}$ and $\mathrm{H}_{2}$ and with several halon fire inhibiting agents.

our experimental approach is to study these reactions under pseudo-first order kinetic conditions; $\mathrm{OH}$ is formed upon flash photolysis of water, and is always maintained at a lower concentration than the stable reactant. The decay of the $\mathrm{OH}$ concentration with time is monitored by either the conventional resonance fluorescence method or the more recently developed laser induced fluorescence technique. By obtaining the time dependent concentration profiles at different stable reactant (i.e., $\mathrm{CH}_{4}, \mathrm{H}_{2}$, halons, etc.) concentrations, the bimolecular rate constants are determined. These bimolecular 
rate constants are then measured at different temperatures to obtain the activation energy for the reactions.

\section{Progress Report:}

We are presently completing the installation and testing of a new stainless steel reaction cell which will be capable of reaching temperatures of $1200 \mathrm{~K}$. In the near future, we will be interfacing a frequency doubled tunable dye laser (pumped by a C.W. Argon ion laser), with this high temperature kinetics system. Using a previous reaction cell, and resonance fluorescence detection, we have measured the rate constants for the reactions of $\mathrm{OH}$ with $\mathrm{CH}_{4}$ and $\mathrm{H}_{2}$ up to $700 \mathrm{~K}$. 
Proceedings of a Conference Held at NBS, Gaithersburg, Md., August 3-5, 2977, (Issued October 2977)

Institutions: Harvard University and Factory Mutual Research Corporation

NFPCA Grant \#76-024

PRC Grant 非P-77-3-4

Grant Title: The Home Fire Project

Principal Investigators: Howard W. Emmons

Raymond Friedman

Pierce Hall, Harvard University Factory Mutual Research Corp.

Cambridge, Mass. 02138

(617) $495-2847$

Norwood, Massachusetts 02062

(617) 762-4300, Ext. 570

Other Professional Personnel:

H. U. Research Fellows: Henri Mitler, Kun Min, Phiroz Bhagat, A. Fernandez-Pello Research Associate: Richard Land

Graduate Students: Jana Backovsky

Undergraduates: L. Trefethen, B. Chang, M. Fedorchak, P. Barth, H. T. Sung L. Healy

FMRC: Task Leaders: J. deRis, R. Alpert, P. Croce, G. Markstein

Other Scientists: A. Modak, L. Orloff, F. Tamanini, A. Tewarson

Project Summary: The broad objective is to make predictable the growth of fire in a home. The project consists of eight tasks-the most important of which are the development of the Computer Fire Code for the prediction of fire growth and the closely coupled full scale fire tests.

Task Progress Reports:

Full-Scale Fire Test Program

- Ronald L. Alpert

Most of this work was sponsored by NFPCA. Its continuation is sponsored by P.R.C.

We are currently performing a series of about eight full-scale fire tests to evaluate Harvard's fire development computer model. The present test series principally focuses on the effects of enclosure geometry on the development of the fire to flashover. The computer-model predictions are based on measurements of the initiating item burning in the open (outside the 8-foot by 12-foot enclosure). The series of fire tests includes variations in the following parameters: (1) maximum size of initiating item; (2) distance from top of doorway to ceiling; (3) addition of window; (4) location of fire relative to window; (5) door half-closed, no window; (6) elevation of base of fire. We have also made a very broad set of basic laboratory-scale flammability measurements for the polyurethane foam being used for both the initiating and target items. As the year progresses, we intend to predict the fire development in terms of the foam's basic flammability properties.

$$
\text { Prediction of a Fire - H. Mitler, H. W. Emmons, B. Chang, L. Trefethen }
$$

The fire in an enclosure is viewed in modular form: a burning object, a plume, a hot gas layer, flow out a vent, radiation heat transfers, toxic gas production and distribution, etc. The appropriate transient equations are written for each module including all important interactions; e.g. radiative feedback. These equations ( 40 or more) are solved for the time history of the fire growth given an initial ignition. Approximate equation systems have been solved analytically or through a time-constant formalism. Such solutions while fair are not good 
enough for general fire prediction. When solved on a computer, however, the predictions are beginning to be in acceptable agreement with our former full scale bedroom tests.

Sub-routines of greater precision and generality are being prepared and used and will be further tested by predicting before the actual burns, the full scale fires to be run this summer.

The Computer Fire Code has been devised in such a way that anyone - anywhere can prepare a subprogram for some module which will run with the main program without having to rewrite any other subprogram. The program needs further development and we would welcome the participation of others in subprogram development.

\section{(3) The Modeling of Fires in an Enclosure}

\section{(3.1) Pressure Modeling of Fire Growth in Enclosures- R. L. Alpert}

Precise measurements of the radiative properties of PMMA flames at elevated pressures are currently being obtained to investigate the practicality of pressure modeling radiation-dominated fires. Both narrow angle (radiance) and wide angle (irradiance) instruments have been used with simultaneous burning-rate measurements at ambient pressures from 14 to 28 atmospheres. Preliminary results of the irradiance measurements for a 12.7-cm-high wall show that the radiant fraction, $X$, is from $22 \%$ to $28 \%$, compared to about $33 \%$ for a 360-cm-high wall at one atmosphere. Radiance measurements at angles of incidence of $0^{\circ}$ (wall normal to radiometer axis) and $60^{\circ}$ yield calculated flame temperatures of about $1500 \mathrm{~K}$, compared to a 1400-K-flame temperature at $1 \mathrm{~atm}$. These results, which are self-consistent, will be further refined with additional measurements at $0^{\circ}, 30^{\circ}$ and $75^{\circ}$ angles of incidence.

$$
\text { Modeling of Enclosure Fires at Atmospheric Pressure - P. A. Croce }
$$

After a demonstration of the usefulness of this modeling method for quasisteady crib fires within an enclosure, the method has been applied to transient, non-spreading fires using PMMA slabs as the primary fuel. Geometrically similar full-and quarter-scale enclosures were utilized, with ventilation provided through a doorway-like opening; doorway width was a parameter. Quantities such as burning rate (weight loss), gas and wall temperatures, gas species concentrations and radiation escaping through the opening were monitored continuously during a test. General overall agreement was obtained between large-and small-scale results. Currently, the method is being applied to spreading transient enclosure fires, using foamed polyurethane as the primary fuel.

$$
\text { Radiation from Flames and Smoke Layers -- G. H. Markstein }
$$

Studies of fire radiation have concentrated on two areas: (1) measurements of radiative properties of plastics fires and (2) measurements on smoke layers. Both studies are performed with equipment of intermediate scale so that results applicable to full-scale tests can be obtained.

In the work on plastics fires, narrow-beam radiometry with blackbody background combined with photographic determination of flame geometry has been used for characterizing steady pool fires of various materials by their radiation temperature $\mathrm{T}_{\mathrm{f}}$ and their absorption coefficient $\alpha_{\mathrm{f}} \cdot$ Recently, the method has 
been extended to charring plastics that cannot support a steady pool fire, by working instead with fires spreading over elongated rectangular fuel beds. Measurements performed by this technique on a polyurethane foam gave results

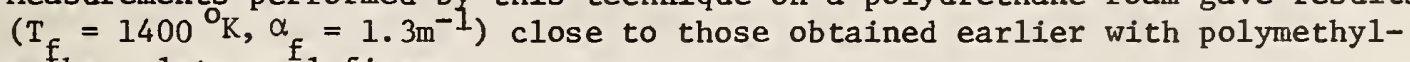
methacrylate poôl fires.

In the smoke layer study, measurements are performed on the combustion products of plastics pool fires flowing along a $0.6 \mathrm{~m}$ wide, $0.6 \mathrm{~m}$ deep and $3.6 \mathrm{~m}$ long channel open at the bottom. The instrumentation includes one absorption meter employing a blackbody source $\left(600^{\circ} \mathrm{C}\right)$ and one with an infrared-emitting diode source, a flow velocity probe and a thermocouple arranged for vertical traverse in the channel, a probe for sampling particulate products, and mass loss measurement of the pool fire. This study not only will provide data to be used in the analysis of full-scale tests, but the absorption meters also serve as prototypes of devices incorporated in the current FMRC full-scale test program.

Continuation of these studies, and development of a method for two-dimensional scanning of fire radiance is planned.

The Effect of Radiation on Ignition and Fire Spread -A.C. Fernandez-Pello, J. Backovsky

Upward flame spread velocity over vertical sheets of Polymethylmethacrylate (PMMA) and downward flame spread velocity over vertical sheets of PMMA, Filter Paper and White Pine wood were measured under the influence of externally applied radiant fluxes ranging from 0 to $2.0 \mathrm{w} / \mathrm{cm}^{2}$. The flame spread rate was found to be dependent on the surface temperature of the fuel prior to flame arrival. For both modes of fire spread a power law correlation exists between the flame spread velocity and the difference between the vaporization temperature of the fuel and its surface temperature prior to flame arrival. An approximated theoretical model for upward laminar flame spread was developed and present theoretical models for downward flame spread were extended to account for the additional effect of external radiation. It is shown that the predictions of the theoretical models agree qualitatively with the experimental observations.

The theory of free convective burning under external radiation has been developed in various degrees of approximation. A careful study is being made of these and more exact theories of steady, laminar, free convective burning of a vertical fuel surface including fuel surface and flame radiative properties. The degree to which similarity solutions can be found is being examined.

(6) The Heat of Combustion of Smoke - Kun Min

A catalytic sensor in the form of a heated platinum wire is being tested to measure the heat of combustion of smoke generated in a fire.

Calibration of the sensor with different fuel gases shows that its sensitivity, defined as the ratio of the sensor output to the heat of combustion per unit volume of the fuel-air mixture, varies by a factor of about two. Effort is being made to design a sensor with less variation in sensitivity.

In preparation for its use in the forthcoming full scale fire tests, the sensor was tested with gases from a small enclosure fire - a crib fire inside a 6" $\times 6$ " $\times 6$ " enclosure with a door opening. Tests showed that the sensor responds negatively to the moisture produced by the fire. This behavior is presently under study. 
The fuel gases in smoke are measured by removing the particles by a filter. However some low accuracy data on the heat of reaction of the particles per unit volume of smoke is obtainable by measuring the whole smoke with an open wire and then the filtered smoke with a second wire. A first use of such a combined instrument will be made in the full scale tests this summer.

\section{(7) Extinguishment - P. M. Bhagat}

The top end of a vertically positioned charcoal cylinder is burnt in a stagnation air flow. Water is introduced into the air stream by injecting steam upstream of the air blower and by spraying water at a point just downstream of the blower. This method permits close control and accurate measurements of the amount of moisture introduced. Several experiments were conducted to measure the moisture content in the airstream, and the rate of water being deposited on the stagnation plane, for various air and water flow rates. The heat transfer coefficient at the stagnation plane was measured for various conditions.

Tests were run to determine the burning characteristics of charcoal for various air and water flow rates. A very small amount of liquid water causes an increase in burning rate by the removal of the ash which normally adheres for a while on the burning surface. An analytical model was developed in an attempt to understand the ash removal mechanism. Ash is also blown off more easily if the fire crosses the grain from the center of the tree outward rather than inward; suggesting a ring structure which inhibits inward burning.

Experiments have been conducted in the water flow range where extinguishment occurs at the edges and the extinguished zone encroaches on the burning region, leading to total extinguishment.

At present, the burning data for various air and water flow rates is being analyzed.

\section{Special Test Burns of Mattress and Bedclothes - R. Land}

Our full scale tests begin with fire on the bed. The growth of the fire on bedding is sensitive to many parameters. If the ignition technique is not controlled carefully, a large uncertainty in starting time for the burn results. In comparison with dry tests $(40 \% \mathrm{RH})$, when the bedding has been subjected to high relative humidity before the test, the rate of spread and mass pyrolized is reduced by about one-third and the foam has less char on its surface after extinguishment. Lab tests under dry conditions produced results similar to early data in the full scale bedroom test of 1975.

\section{A Special Senior Project - The Breaking of Window Glass by Fire - P. Barth,}

Windows are usually broken in a fire. Uneven heating, sudden cooling by water, or some mechanical event is sufficient and one gets the impression that the breaking is a random event. When heated by radiation, free standing small glass sheets $3^{\prime \prime} \times 3^{\prime \prime}$ to $6^{\prime \prime} \times 6^{\prime \prime}$ break only at high heating rates. If the edge of the glass is shielded from the radiation (as when installed in a window frame) they break easier but reproducibly in a time which depends upon the radiation intensity and the size of the glass sheet. The break always starts at an edge away from the corners, never in the middle. The stress relieving crack moves, at very high speed, through the cool edge then divides into two (or sometimes more) cracks, two of which run along the hot-cool boundary for some distance before turning up symmetrically through the main sheet. At a heating rate of .1 watt $/ \mathrm{cm}^{2}$ the break occurs at 1 minute. 
Alpert, R. L., "Pressure Modeling of Fires Controlled by Radiation," Sixteenth Symposium (International) on Combustion, Combustion Institute, MIT, Aug. 1976.

Croce, P. A., "Modeling of Vented Enclosure Fires," Presentation to 5th International Fire Protection Seminar, Karlsruhe, West Germany, September 22-24, 1977.

Croce, P. A., "A Method for Improved Measurement of Gas Concentration Histories in Rapidly Developing Fires," Combustion Science and Technology, Vo1. 14, 1976.

Croce, P. A. and Modak, A. T., "Flame Radiative Feedback and the Burning of Horizontal Plastic Slabs," Sixteenth Symposium (International) on Combustion, MIT, August 1976.

de Ris, J., "Buoyant Diffusion Flames," Presentation to International Heat and Mass Transfer Seminar, Dubounik, Yugoslavia, August 1976.

Emmons, H. W., "Computer Fire Code (II)," Home Fire Project Technical Report No. 20, January 1977 .

Emmons, H. W., "The Home Fire - Viewed as a Scientific System," Home Fire Project Report No. 21, April 1977, to be published in SFPE Journal.

Emmons, H. W., "The Modeling of Fires," Presentation to the U.S.-Japan Cooperative Program on Natural Resources, Fire Research Subcommittee, Tokyo, Japan, Oct. 19-23, 1976.

Emmons, H. W., "Physics of Fire - A Review," Presentation to the Gordon Conference, Wolfboro, N.H., August 22-26, 1977.

Evans, D. and Emmons, H. W., "Combustion of Wood Charcoa1," Fire Research, Vo1. 1, January 1977.

Fernandez-Pello, A. C., "Fire Spread over Vertical Fuel Surfaces under the Influence of Externally Applied Thermal Radiation," Home Fire Project Technical Report No. 19, January 1977.

Fernandez-Pe1lo, A. C., "Downward Flame Spread Under the Influence of Externally Applied Thermal Radiation," Combustion Science and Technology, 1977.

Friedman, R., "Ignition and Burning of Solids," Symposium on Fire Standards and Safety, ASTM, STP 614, January 1977.

Land, R. I., "Ful1-Scale Fire Tests," Presentation to the Borehamwoods Fire Research Station, London, England, April 5, 1976.

Markstein, G. H., "Radiative Energy Transfer from Turbulent Diffusion Flames," Combustion and Flame, Vol. 27, No. 1, 1976.

Markstein, G. H., "Scaling of Radiative Characteristics of Turbulent Diffusion Flames," Sixteenth Symposium (International) on Combustion, MIT, August 1976.

Min, Kun, "Vapor Phase Thermal Analysis of Pyrolysis Products from Cellulosic Materials," Combustion and Flame.

Mitler, H. E., "The Harvard Home Fire Project," Presentation to the National Bureau of Standards Conference on Fire, Washington, D.C., January 10-11, 1977.

Modak, A. T. (Editor), "The Third Full-Scale Bedroom Fire Test of the Home Fire Project (July 30, 1975): Vol. II - Analysis of Test Results," FMRC Technical Report, Serial No. 21011.7, November 1976 .

Modak, A. T. and Mathews, M. K., "Radiation-Augmented Fires within Enclosures," Presentation to the Seventeenth National Heat Transfer Conference, Salt Lake City, Utah, August 1977.

Modak, A. T., Alpert, R. L. and Orloff, L., "Burning of Large-Scale Vertical Surfaces," Sixteenth Symposium (International) on Combustion, MIT, August 1976. 
Institution: IIT Research Institute

Grant or Contract No.: T-9023

Grant Title: Fire Alarms and Responses to Alarms

in Health Care Institutions

Principle Investigator: Harold Wakeley

IIT Research Institute

10 West 35 th Street

Chicago, Illinois 60616

$312 / 567-4757$

Other Professional Personnel:

Thomas Waterman, Engineering Advisor; Howard Schechter, Research

Engineer; Joe Koeberl, Graduate Student; Kenneth Brown, Summer

Student Assistant

Project Summary:

The objective of the study is to determine the effectiveness of various fire alarm and evacuation systems in nursing homes. The initial problem is determining the noise levels in nursing homes and the signal characteristics of existing alarm systems. Information is desired on the attenuation characteristics of the room, corridors, and area ways as well as the response of the patients and staff to fire alarms.

Objective measures of sound intensity and spectral distribution are obtained by recording information at the site and processing the material later with a third octave band analyzer. Complete descriptions of the recording and sound source and the configuration of the building are obtained plus photographic records. Staff responses to fire alarms are recorded by questionnaires.

Progress Report:

A substantial amount of information has been obtained from a complete range of nursing homes. Preliminary evaluations have been performed and data collection is being completed.

\section{Accomplishments:}

A satisfactory method of reliably obtaining noise/fire alarm sound measurements in nursing homes and its evaluation has been achieved. Methods for obtaining access to nursing homes and the performance of fire alarm tests and drills have been developed. Some specific problems with existing fire alarm systems have been identified.

\section{Potential Applications:}

Improved fire alarm systems will improve communications during actual fires, substantially reduce stress and confusion during drills and fires, and improve human responses to fire alarms.

- Future Milestones:

Summarize questionnaire and objective data to identify improved fire alarm characteristics. 
Proceedings of a Conference Held at NBS, Gaithersburg, Md., August 3-5, 2977, (Issued October 2977)

\section{INSTITUTION:}

The Johns Hopkins University

GRANT (or Contract) NO. :

NBS Grant Number GT-9019

GRANT (or Contract) Title:

Evaluation of Toxicity of Combustion Products

\section{PRINCIPAL INVESTIGATOR(s):}

Zoltan Annau, Ph.D. and William F. Sette, Ph.D.

The Johns Hopkins University

Department of Environmental Health Sciences

School of Hygiene \& Public Health

615 North Wolfe Street

Baltimore, Maryland 21205

(301) 955-3029

\section{PROJECT SUIMARY:}

\section{OBJECTIVES}

1. To provide a sensitive, reliable, and valid behavioral baseline for evaluating the toxicity of smoke.

2. To characterize and compare the effects of smoke from different materials by constructing concentration response curves.

These objectives will be attained by: a) exposing animals to smoke during large scale burns and measure a variety of physical, physiological and behavioral variables; b) exposing animals trained on a behavioral task to small controlled combustion experiments and measure quantitatively changes in the rate of ongoing behavior, as well as physiological parameters.

\section{PROGRESS REPORT:}

We have participated in room scale burns in cooperation with other personnel at NBS. In the last series, four sizes of wood and polyurethane cribs were burned. Products were drawn through a teflon coated stovepipe 
to a 125 liter plexiglass exposure chamber equipped with a tumblecage and

3 nose exposure ports. Measurements were made of temperature, oxygen, carbon monoxide, carbon dioxide, and cyanide concentrations in the chamber during each burn.

Three tumble cage and three nose exposure rats were used in each burn. Two rats from each exposure condition were subjected to several behavioral tests immediately after each exposure. These measures were: posture, 60 seconds of open field activity, breathing rate, corneal reflex, tail pinch response, and righting reflex. This cluster of tests provides a simple screen for disruptions in the central nervous system and is a derivation of tests common in pharmaceutical laboratories. Blood was drawn from these animals and analyzed for carboxyhemoglobin and cyanide levels. For some burns, we also examined body weight, food and water intake, and daily wheel running activity before and after exposure.

Figures 1 and 2 show the data from a representative polyurethane and wood burn. In the polyurethane burn, there were slight postural changes and some inhibition of response to the tail pinch in some animals, but these are small effects and not consistent in all subjects. The other burns presented a similar picture, that is, relatively low blood values and small, inconsistent behavioral changes.

These exposures led us to the conclusion that large scale burns are not viable or economic means for evaluating toxicity. While the problems encountered are not insurmontable, we feel that the greater control that can be achieved over temperature and FAS concentrations in laboratory scale exposures outweighs the presumed greater relevance of a genuine mattress burn to fire toxicity.

The major behavioral technique used to study the effects of drugs on on the functioning of the central nervous system is the schedule of reinforcement. Animals are trained to perform a response such as pressing a 
lever to obtain a rewarding stimulus or to avoid an aversive stimulus. By specifying the relationship between the lever press and its consequences, we can produce a reliable rate and pattern of responding. The drug effect is then measured as a change in this controlled rate of lever pressing. Our experience with the large scale burns described in this report indicates that during the combustion of plastics, in particular, the animals inhale large quantities of particulates, which during autopsies can be seen in the oral cavities and the upper respiratory tract. For this reason, we have chosen as our behavioral model the lever press avoidance of mildly aversive electric shock rather than responding for food.

On this schedule, each lever press postpones this delivery of a shock by 30 seconds. If there is no response, brief shocks are delivered every five seconds. After about two weeks of training, the rats will respond at a steady rate for several hours and receive few shocks. This schedule is widely used in drug houses as a simple, yet sensitive, CNS screen. It has been used to characterize the effects of hundreds of drugs (Cook and Catania, 1964).

Male Long-Evans rats, are serving as subjects. There are four plexiglass chambers which measure $12.5 \times 20.5 \times 21 \mathrm{~cm} \cdot$ with stainless steel grid floors and a lever at one end. The grid floor and lever of each chamber is wired so that brief scrambled shocks ( 2 mamps, 0.5 seconds) may be delivered. The avoidance schedule now is controlled by convential electro-mechanical equipment which will soon be replaced by a small digital computer programmed in a language (SKED) designed for behavioral experiments.

The stainless steel exposure chamber (Wahmann) is approximately a $53 \mathrm{~cm}$ cube and has a volume of 200 liters. This chamber is now being interfaced at the bottom to a conductive heat furnace provided by Dow Chemical Company. Within the chamber, we will monitor concentrations of $\mathrm{O}_{2}, \mathrm{CO}, \mathrm{CO}_{2}, \mathrm{CN}$ and temperature. 
Rats will be exposed under static conditions for 30 minutes to products decomposed at both pyrolysis and combustion temperatures. Concentrations will be varied by weight and each subject will be exposed to four concentrations at least twice in an ascending - descending order. Blood samples will be drawn from subjects prepared with chronic arterial cannulae and the blood analyzed for carboxyhemoglobin and cyanide.

Cook, L. and Catania, A.C. Effects of drugs on avoidance and escape behavior. Proceedings of Federation of American Societies of Experimental Biology, 23: 818-835, 1964. 


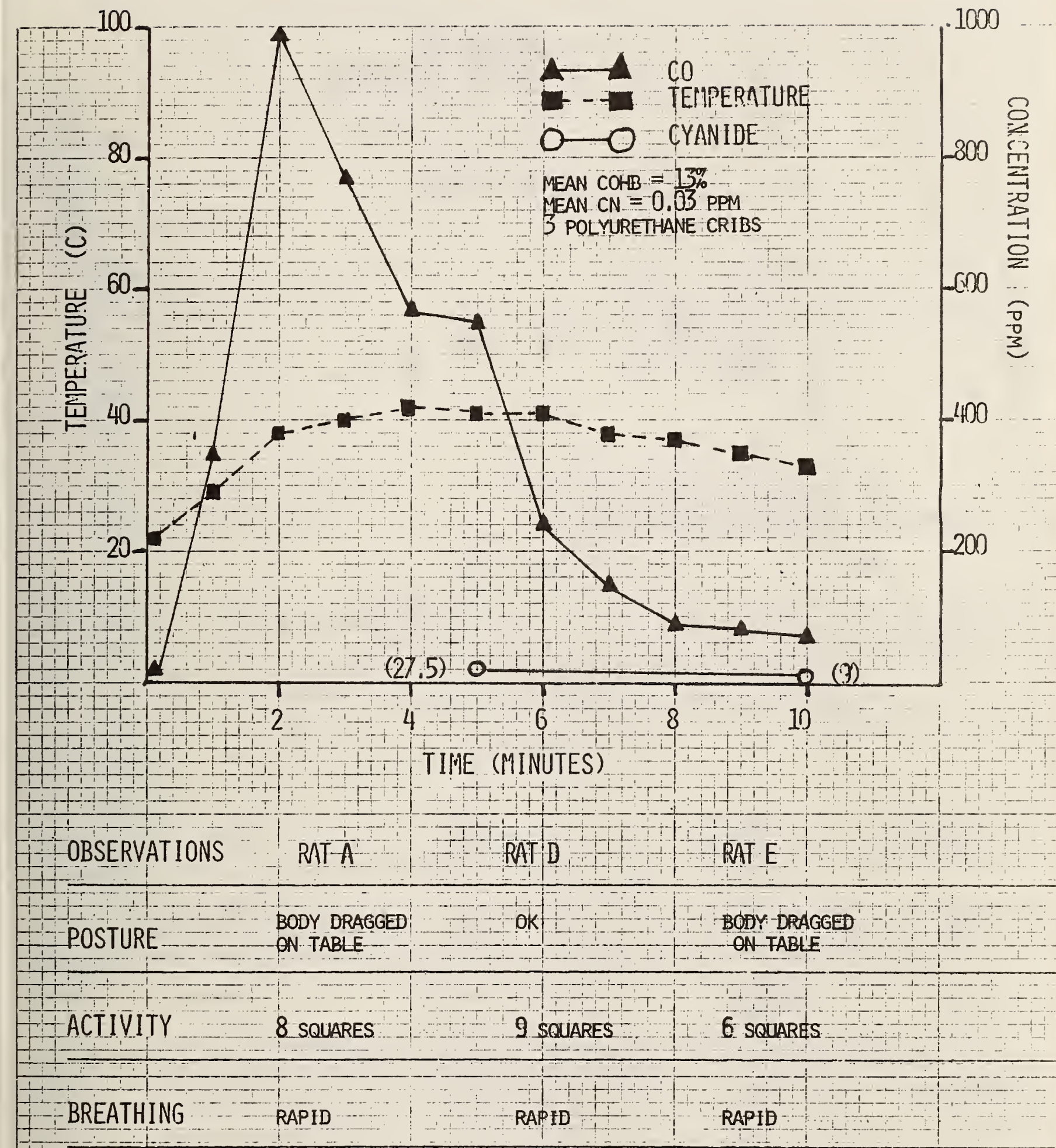

CORNEAL-REFLEX - OK

SLIGHTLY SLOVED OK

TAIL PINCH $\quad$ OK 1 MUTED MUTED

RIGHTING REFLEX SPLAYING

SPLAYING

SPLAYING 


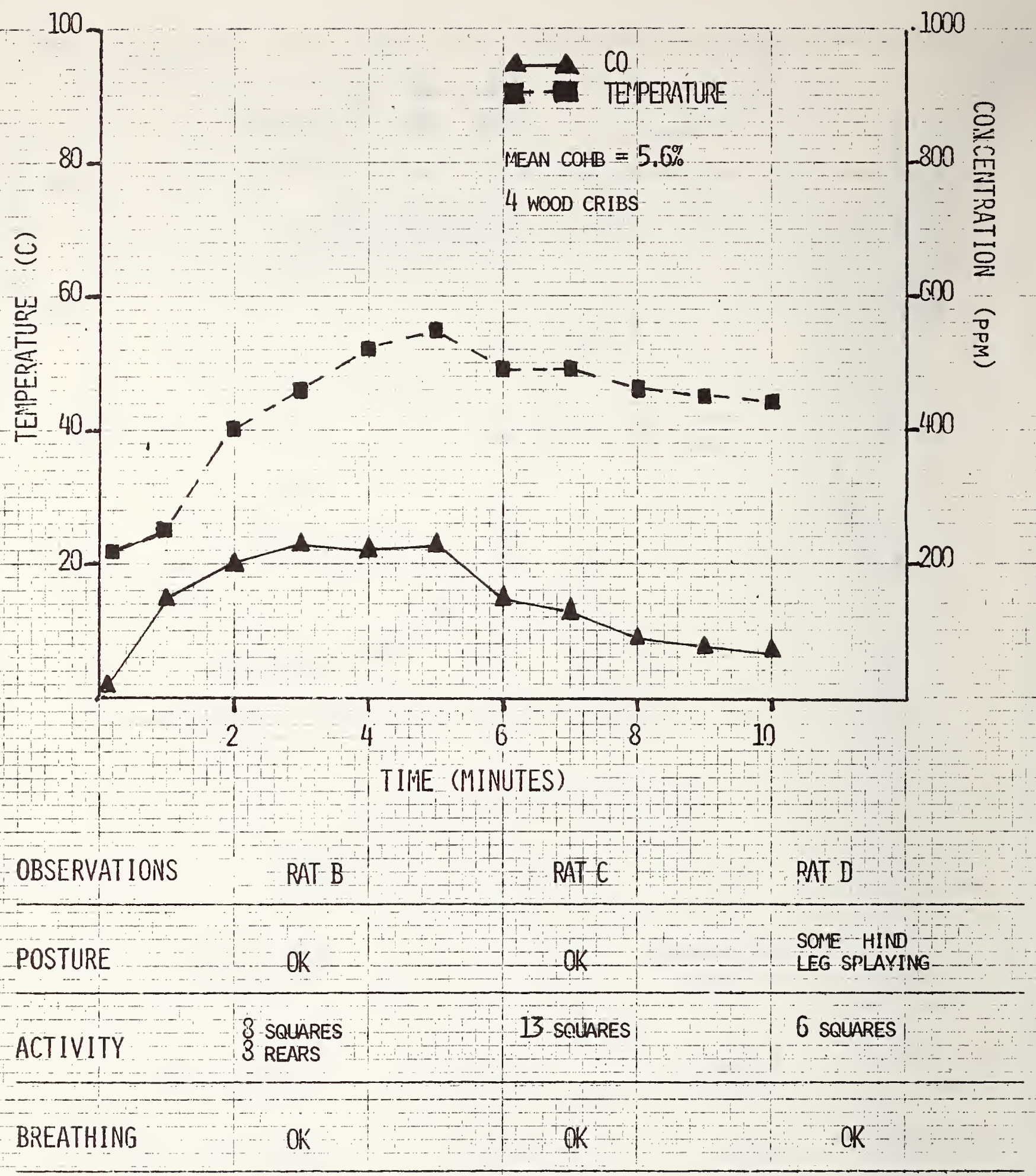

CORNEAL REFLEX

OK

OK

TAIL PINCH ... EXAGGERATED

EXAGGERATED

OK

RIGHTING REFLEX SOME SPLAYING 
Institution: The Johns Hopkins University/Applied Physics Laboratory

Grant Title: Fire Problems Program

NBS Grant No. 4-9022

Principal Investigators:

Robert M. Fristrom; Walter G. Berl Applied Physics Laboratory

The Johns Hopkins University

Johns Hopkins Road

Laure1, Md. 20810

(301) $953-7100$
NFPCA Grant No. 76-033

Othèr Professional Personnel:

Y. M. Caplan (Toxicology)*
O. J. Deters (Mathematics)
R. S. Fisher (Pathology)
C. Grunfelder (Physics)
N. deHaas (Physics)*
Marshal S. Levine The Johns Hopkins University School of Hygiene and Public Health 615 Wolfe Street Baltimore, Md. 21205 (301) $955-3295$

Overal1 Project Summary: The objectives of the APL-directed Fire Problems Program, supported since 1970 by the National Science Foundation (IRPOS and RANN) and more recently by the Center for Fire Research of the National Bureau of Standards (1974) and by the National Fire Prevention and Control Administration (1975) are two-fold:

1. To quantify the medical and biochemical effects of fires on humans,

2. To investigate the physical and chemical principles of fuel ignition and extinction.

These topics are reported on separately as subtasks.

\section{FIRE CASUALTIES STUDY}

Project Summary: The objective of the program is to obtain rellable in-depth information about people exposed to the fire atmosphere. The two project areas are:

A. The Fire Fatalities Project is an on-going program initiated in 1971 under the RANN Program and transferred to NBS in 1974. Case studies are made of exposures to the fire atmosphere resulting from respiratory system insult. The study does not include fatalities occurring more than 6 hours after fire exposure. This eliminates most "burn" cases.

B. "Project Smoke" began in October of 1973. It is being conducted by the School of Hygiene and Public Health/JHU in cooperation with the Baltimore City Fire Department. The current series of investigations includes both the acute and chronic effects of inadvertent exposure, and the effects of the occupational exposure to the fire atmosphere.

\section{Progress Report:}

A. Fire Fatalities Project: This project has four major sub-efforts that involve cooperation among APL, the State Medical Examiner, the State Fire Marshal and other local fire department jurisdictions. The four tasks are: (1) Case Histories, (2) Cyanide Study, (3) Heart Study in Fire Victims, and (4) Analysis of Soots. 
(1) Case Histories: Four hundred twenty-one fatalities have been studied through December 1976. The victim had to have died within 6 hours after the fire and an autopsy had to be performed with a detailed evaluation of the coronary system. A review of the circumstances at the fire scene is also included.

The fatalities occurred in 315 fires with 293 of them in a residence. For the time period there were 1.3 deaths per fire with 254 single fatality fires.

"Smoking" was considered to be the cause of the fire in $50 \%$ of the cases, and the human element was quite apparent in the overall fire problem from ignition to casualty. Alcohol played a significant role in the majority of the "smoking" caused fires with other drugs as a very minor problem.

Carbon monoxide poisoning was considered to be the primary cause of death in approximately one-half of the fatalities. Pre-existing heart disease in combination with carbon monoxide has been implicated in another $30 \%$ of the cases (see heart study). Approximately $10 \%$ of the cases require better definition of the cause of death.

A larger fraction of the residences in which the fatal fires occurred have had more synthetic materials in furnishings than in the first years of this study. The synthetics are found in all classes of furnishings for the homes as well as clothing, etc.

(2) Cyanide Study: A study has been underway to investigate factors in the analysis and interpretation of cyanide concentrations so that its role could be evaluated. A gas chromatograph with electron capture detector is used to determine blood cyanide levels.

The distribution of the measured blood cyanide levels for 152 cases shows that $33 \%$ of the victims had a normal level. The normal level is considered to be $0.25 \mu \mathrm{g} / \mathrm{ml}$ of $\mathrm{blood}$. That means that $67 \%$ had a raised level of blood cyanide. Thirty-two percent of the cases had levels considered to be in the possibly toxic and probably toxic ranges. The range of measured values are 0.0 to $4.3 \mu \mathrm{g} / \mathrm{ml}$.

In those fires where cellulosic materials were involved normal levels of blood cyanide were measured. When synthetic materials were involved that might have produced cyanide during the fire, raised levels of blood cyanide were also measured in the victims.

There is no direct evidence that cyanide was either the incapacitating or lethal agent in the fatalities studied. In general a high level of blood cyanide is accompanied by a high level of blood carboxyhemoglobin.

(3) Heart Study: This study was initiated to explore the relationship between pre-existing heart disease and blood carbon monoxide levels inasfar as lethality is concerned. Persons with pre-existing heart disease would be expected to survive for a shorter period of time in a CO contaminated atmosphere than healthy individuals. This premise is based on the assumption that heart disease already jeopardized the myocardial oxygen supply in a normal atmosphere.

A measurable and quantifiable parameter of pre-existing heart disease is the degree of coronary stenosis. In addition, it is the most important and prevalent form of heart disease.

The study includes those individuals who die in a "typical" house fire while eliminating flash fires, automobile collision fires, immolations, etc. Further, those who survived for some period of time after the incident were excluded. This provided a data base of 119 cases for comparative analysis.

Using a scoring system based on the amount of stenosis and the distance from the heart that the stenosis occurs, the relationship between blood carbon monoxide level and coronary artery stenosis can be examined. No constant relationship could be seen between the two parameters. This leads one to believe that the pre-existing heart disease contributes to early incapacitation in a fire atmosphere. This premise would explain the high incidence of heart disease in our series since the heart disease would "select" those individuals to be fatalities. 
(4) Analysis of Soots: Chemical and instrumental analyses are performed on the "internal" soots that can be isolated from the tracheobronchial trees of fire victims and of "external soot deposits collected at the fire scene. The former will not give evidence for compounds readily dissolved by body fluids (such as hydrochloric acid). The latter presents a total cross-section of the particles that are deposited during the course of the fire.

The results of the autopsies indicate the sooty deposits are found in the total respiratory system of nearly all fire casualties. The analysis of the soots shows that a number of inorganic metals frequently in large amounts are present. Some of the metals found are $\mathrm{Pb}, \mathrm{Sb}, \mathrm{Cd}, \mathrm{Zn}, \mathrm{Mn}, \mathrm{Cu}$ and $\mathrm{Cr}$. There were 20 "external" soot samples of sufficient quantity to analyze for both HCl adsorption and organic metals. In 11 of those 20 anitmony was found. Lead and cadmium were found in all 20 samples. The C1 was found in $84 \%$ of the "external" soot samples analyzed in quantities up to $20 \%$ by weight of the sample.

The soot analyses raise unresolved questions concerning the clinical significance of the findings, particularly in those instances when a person is injured and is not a fatality. Other questions raised relate to the possible treatments for those persons exposed to the toxic fire atmospheres.

B. Project Smoke: "Project Smoke" is the name given to investigations being conducted by The Johns Hopkins School of Hygiene and Public Health and the Applied Physics Laboratory with the cooperation of the Baltimore City Fire Department. This grew out of and is a logical extension of the Fire Fatalities study being conducted by The Johns Hopkins Applied Physics Laboratory and the School of Hygiene and Public Health.

Project Smoke deals with the acute and chronic effects of exposure to the fire atmosphere, both in accidently exposed civilians, and in occupationally exposed firefighters. The range of these activities includes the investigation of the medical outcomes of civilian fire casualties, the acute exposures of firefighters to toxic gases, epidemiological studies of long-term chronic pulmonary and cardiac disease in firefighters, and the mortality experience of Baltimore firefighters.

Baltimore firefighters have been extensively investigated to evaluate the presence of chronic pulmonary and cardiac disease. Volunteers complete a detailed questionnaire expanded from the standard British MRC questionnaire to include cardiac and general medical history, as well as smoking and fire exposure history. Pulmonary function studies including FVC, FEV, and MMEF are performed on a Stead-Wells spirometer. Resting electrocardiograms and blood pressure readings complete the examination. To date 900 men have completed this examination, and the data have been computerized. We anticipate a total sample of approximately 1000 men when this study is completed. Preliminary findings to date have shown that for all parameters, FVC, FEV, and MMEF firefighters are somewhat below the standard. This deficit remains constant when regression curves are plotted for increasing age.

As more data are collected and analyzed, we hope to be able to determine the separate effect of smoking, urban environment, and firefighting on pulmonary function, and on cardiac status.

Mortality studies of the Baltimore Fire Department are also underway. We have collected death certificates of all deceased firefighters for the ten year period 1963-1973. These death certificates have been coded by ICDA cause of death and transferred to computer tapes. A preliminary examination of causes of death indicate that accidental deaths may occur more frequently among firefighters. This finding will be tested by on-going studies.

Accomplishments: The framework of cooperation of the Fire Fatalities Studies is functioning smoothly. The special study areas such as heart, cyanide and soot analyses are providing some interesting results and procedures. The foundations for expanded effort in all areas of study has been established, and important data are being obtained.

Potential Applications: Knowledge of the physical and medical causes and complications resulting in fire casualties can be used to suggest the direction for care of patients who are "overcome," designs of "fire safe" materials for use in residences, building design, and the need for more intense public education and effective detection and warning devices. 
Future Milestones: Fires which have significant interest to the fire community will be included in the study. These will include special materials fires and fires in which fire detection or suppression systems have been involved.

The epidemiological studies of long-term pulmonary and cardiac disease in firefighters, and the mortality experience of Baltimore City firefighters will be continued. Protocols will be established and published for the various segments of the Fire Casualties Program. These will include protocols for the investigation, post-mortem, and toxicological phases of the program.

\section{REFERENCES}

1. W. G. Berg and B. M. Halpin, "Fire Related Fatalities: An Analysis of Their Demographic, Physical Origin, and Medical Causes in Fire Standards and Safety. ASTM STP 614, pp. 2654, A. F. Robertson (Ed.) American Society for Testing and Materials (1977).

2. B. M. Halpin (Ed.), Proceedings of the Fires Conference and Workshop on Fire Casualties, May 28-29, 1975, APL/JHU FPP B76-1 (April 1976).

3. B. M. Halpin, R. S. Fisher, Y. H. Caplan, "Fire Fatality Study" in Internationa1 Symposium on Toxicity and Physiology of Combustion Products, March 22-26, 1976 (to be published).

4. B. M. Halpin, J. Dinan, and 0. Deters, "Assessment of Hypothetical Fire Protection Systems' Impact on Actual Fire Incidents" (Preliminary Report), APL/JHU Topical Report, FPP TR29 (April 1977).

5. E. P. Radford and M. S. Levine, "Occupational Exposures to Carbon Monoxide in Baltimore Fire Fighters," J. Occup. Med., 18 628-632 (1976).

6. M. S. Levine, "Fire Victims: Medical Outcomes and Demographic Characteristics," Am. J. Public Health (to be published).

\section{COMBUSTION RESEARCH}

Staff and Collaborators: L. W. Hunter, R. M. Fristrom, C. Grunfelder, C. H. Hoshall, A. A. Westenberg, N. Dehass, N. Brown (Un. of Calif., Berkeley), R. Sawyer (Un. of Calif., Berkeley), P. van Tiggelen (Un, of Louvain, Belgium).

\section{A. POLYMER FLAMMABILITY}

Progress: Polymer combustion is an important fire problem because fires commonly involve such fuels. We have developed the Moving Wire Technique (MWT) for studying polymer combustion (Fig. 1). In the MWT, the polymer is coated on a supporting metal or fiberglass strand and then moved at a controlled speed through a heat source. The MWT determines reproducibly (better than $5 \%$ ) the minimum surface temperature at ignition (Refs. 1 and 2). This quantity is independent of scale (Ref. 2). The technique, in its present state of development, also determines the qualitative chemical composition of the pyrolyzate gases and their evolution sequence as a function of surface temperature (Ref. 3 ).

The heat transfer characteristics of the heat source in the MWT are important to the analysis and interpretation of the polymer combustion studies. In the past year, we demonstrated a new technique (Refs. 4 and 5) for measuring forced convection heat transfer (Fig. 2) and are presently extending it to the measurement of radiant heat transfer. The technique is potentially applicable in practical fire plumes.

Two theoretical papers (Refs. 5 and 6) were prepared on the MWT. One application is the calculation of the surface temperature of the polymer coating on the moving wire. Scaling laws were developed to predict the position and wire speed at which the polymer surface attains a given temperature, such as the gasification point. 
Development of a low pressure MWT apparatus is nearly complete. Preliminary results indicate that the ignition transition is sharp. A new feature is that flammable pyrolyzate can survive even in the presence of $\mathrm{O}_{2}$. The ignition point no longer coincides with the onset of flammable gas evolution. A goal of our MWT studies is a polymer flame structure analysis for the determination of reaction mechanisms and rates. The low pressure apparatus expands the polymer flame as required but so far the concentration profiles have not been sufficiently reproducible.

Potential Applications: The MWT is applicable as a flammability test, but also provides insights into the chemical and physical mechanisms of polymer combustion.

Future Milestones: We are presently investigating the possibility that polymer pyrolysis is intrinsically unstable. The wire geometry is convenient for exploratory studies at low pressure but other geometries, such as a ribbon, may allow us to study a wider range of polymers. We hope to demonstrate that ignition is well defined in other moving polymer geometries.

\section{$\underline{\text { References }}$}

1. R. M. Fristrom, L. W. Hunter and C. Grunfelder, "Exploratory Studies in Polymer Ablation, Ignition and Extinction by the Moving Wire Technique," Combustion and Flame 27, 33 (1976); ibid.

2. L. W. Hunter, H. Schacke, C. Grunfelder, and R. M. Fristrom, "Surface Temperature Measurements in the Moving Wire Technique," Combustion Science and Technology $\underline{15}, 41(1976)$.

3. H. Schacke, L. W. Hunter, C. Grunfelder, and R. M. Fristrom, "Combustion of Poly (viny1 chloride) Studied by the Moving Wire Technique," Sixteenth Symposium International on Combustion (The Combustion Institute, 1977).

4. L. W. Hunter and C. Grunfelder, "Moving Wire Technique Measurements of Heat Transfer in F1ame Gases," to be submitted to Combustion and Flame.

5. L. W. Hunter, "Theory of the Moving Wire Techniques for Measuring Heat Transfer and Studying Polymer Combustion," submitted to J. Heat Transfer.

6. L. W. Hunter and S. Favin, "Steady State Temperature Distribution in a Solid Cylinder Moving in the Direction of Its Axis Through a Cross-Flow of Hot Gas," submitted to $\mathrm{J}$. Heat Transfer.

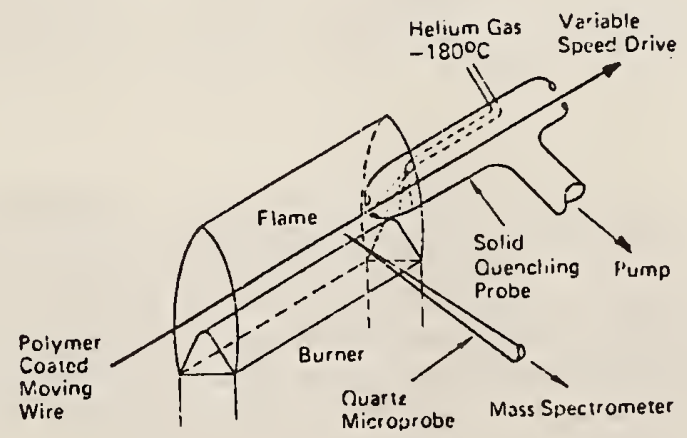

Figure 1. The moving wire apparatus. A gas sampling probe and a heat extractor for solid sampling are shown. 


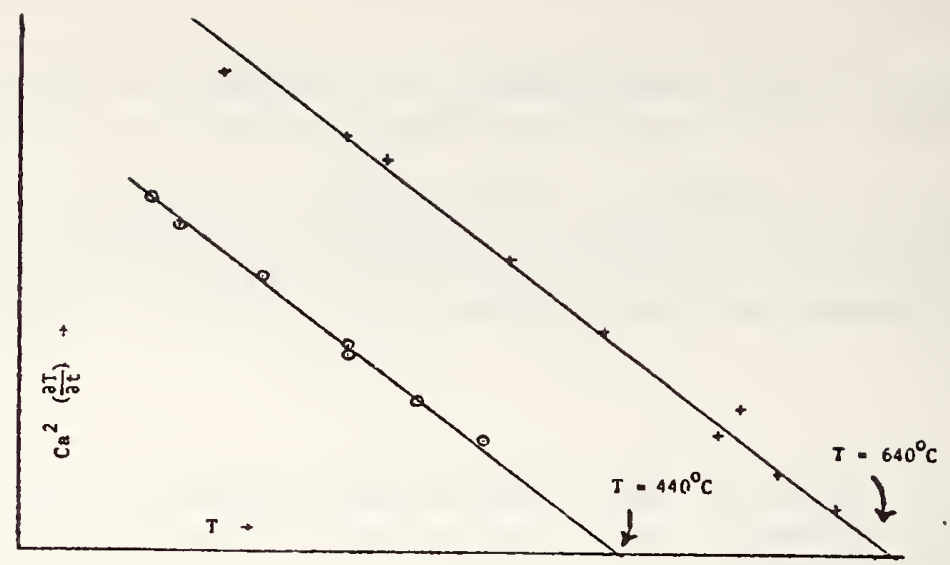

Figure 2. Validation of a new technique for measuring heat transfer. A chrome1alumel thermocouple was drawn through a cross-flow of hot $\mathrm{N}_{2}$ at temperatures $440{ }^{\circ} \mathrm{C}$ (lower plot) and $640^{\circ} \mathrm{C}$ (upper plot). C is the heat capacity of the wire, a is the wire diameter, and $\frac{\partial T}{\partial t}$ is the rate at which the thermocouple temperature (T) rises. The slope is the product $k_{\text {gas }} \mathrm{Nu}$ of the thermal conductivity, $\mathrm{k}_{\text {gas }}$, and the Nusselt number, Nu. This product characterizes the heat transfer. The successful comparison between theory (solid lines) and data (points) validates the formula

$$
k_{\text {gas }} \mathrm{Nu}=a^{2} \mathrm{C} \frac{\partial \mathrm{T}}{\partial \mathrm{t}} \quad\left(\mathrm{T}_{\text {gas }}-\mathrm{T}\right)
$$

which may be applied to the measurement of $\mathrm{kgas}_{\mathrm{gu}}$ in other systems.

\section{B. INHIBITION CHEMISTRY}

Project Summary: The objective of the Inhibition Chemistry studies has been to develop an understanding of the chemical inhibition of flames so that predictions could be made of the effect of an inhibitor based on its chemistry in flames. This would have the two-fold value of suggesting promising candidates for inhibition and extinction and provide an upper collision limit for the effectiveness for such processes. Comparison between this limit and existing inhibitors would indicate whether much improvement can be expected from new inhibitors.

Progress Report: Progress was made in three areas of the program. (1) The rates of two reactions involving inhibitors with $\mathrm{H}$ atoms were measured using a new technique Flash Photolysis-Resonance Fluorescence. A paper reporting the work has been published, (2) In collaboration with the University of California Fire Research Group, a paper applying a two-zone model to the hydrogen oxygen flame inhibited by $\mathrm{HCl}$ was prepared for publication (Fig. 1), and (3) In collaboration with the University of Louvain la Neuve (Belgium), a compilation of the inhibition literature is being prepared to test the generality of the observation of additivity of atomic contributions to inhibition. The F-S inhibition index has been reinterpreted to allow separation of the effects of fuel system, scavenging reactions, and catalytic radical recombination on inhibition (Fig. 2). 
Development of a low pressure MWT apparatus is nearly complete. Preliminary results indicate that the ignition transition is sharp. A new feature is that flammable pyrolyzate can survive even in the presence of $\mathrm{O}_{2}$. The ignition point no longer coincides with the onset of flammable gas evolution. A goal of our MWT studies is a polymer flame structure analysis for the determination of reaction mechanisms and rates. The low pressure apparatus expands the polymer flame as required but so far the concentration profiles have not been sufficiently reproducible.

Potential Applications: The MWT is applicable as a flammability test, but also provides insights into the chemical and physical mechanisms of polymer combustion.

Future Milestones: We are presently investigating the possibility that polymer pyrolysis is intrinsically unstable. The wire geometry is convenient for exploratory studies at low pressure but other geometries, such as a ribbon, may allow us to study a wider range of polymers. We hope to demonstrate that ignition is well defined in other moving polymer geometries.

\section{$\underline{\text { References }}$}

1. R. M. Fristrom, L. W. Hunter and C. Grunfelder, "Exploratory Studies in Polymer Ablation, Ignition and Extinction by the Moving Wire Technique," Combustion and Flame 27, 33 (1976); ibid.

2. L. W. Hunter, H. Schacke, C. Grunfelder, and R. M. Fristrom, "Surface Temperature Measurements in the Moving Wire Technique," Combustion Science and Technology $15,41(1976)$.

3. H. Schacke, L. W. Hunter, C. Grunfelder, and R. M. Fristrom, "Combustion of Poly (vinyl chloride) Studied by the Moving Wire Technique," Sixteenth Symposium International on Combustion (The Combustion Institute, 1977).

4. L. W. Hunter and C. Grunfelder, "Moving Wire Technique Measurements of Heat Transfer in Flame Gases," to be submitted to Combustion and Flame.

5. L. W. Hunter, "Theory of the Moving Wire Techniques for Measuring Heat Transfer and Studying Polymer Combustion," submitted to J. Heat Transfer.

6. L. W. Hunter and S. Favin, "Steady State Temperature Distribution in a Solid Cylinder Moving in the Direction of Its Axis Through a Cross-Flow of Hot Gas," submitted to $\mathrm{J}$. Heat Transfer.

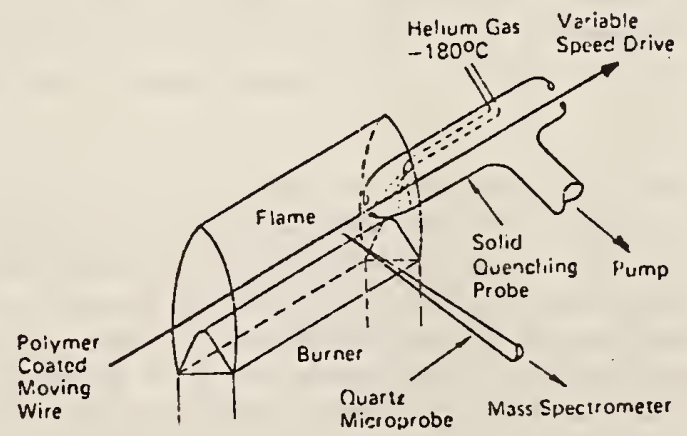

Figure 1. The moving wire apparatus. A gas sampling probe and a heat extractor for solid sampling are shown. 


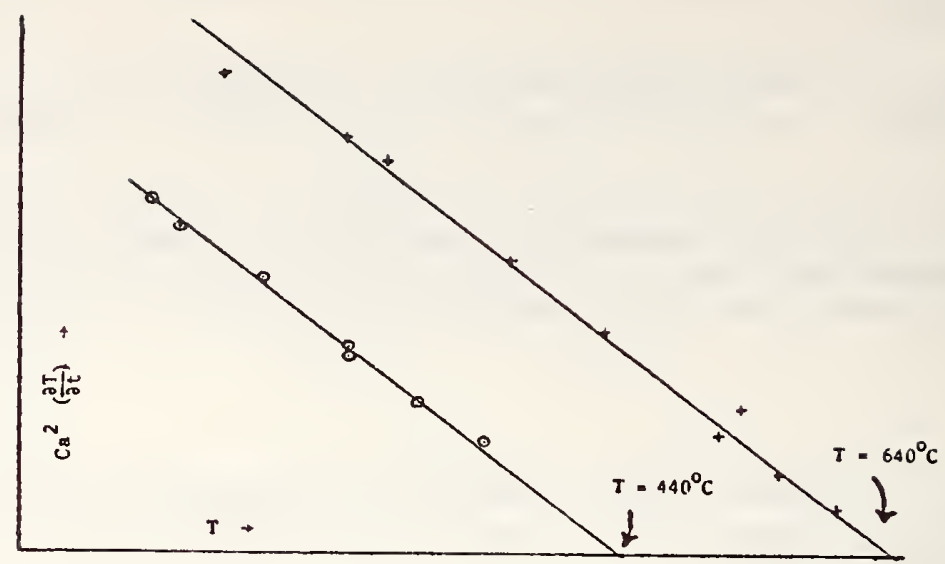

Figure 2. Validation of a new technique for measuring heat transfer. A chromelalumel thermocouple was drawn through a cross-flow of hot $\mathrm{N}_{2}$ at temperatures $440{ }^{\circ} \mathrm{C}$ (lower plot) and $640^{\circ} \mathrm{C}$ (upper plot). C is the heat capacity of the wire, a is the wire diameter, and $\frac{\partial T}{\partial t}$ is the rate at which the thermocouple temperature $(\mathrm{T})$ rises. The slope is the product $k$ gas $\mathrm{Nu}$ of the thermal conductivity, kgas, and the Nusselt number, Nu. This product characterizes the heat transfer. The successful comparison between theory (solid lines) and data (points) validates the formula

$$
k_{\text {gas }}{ }^{N u}=a^{2} \mathrm{C} \frac{\partial T}{\partial t}\left(T_{\text {gas }}-T\right)
$$

which may be applied to the measurement of $\mathrm{kgas}_{\mathrm{gu}}$ in other systems.

\section{B. INHIBITION CHEMISTRY}

Project Summary: The objective of the Inhibition Chemistry studies has been to develop an understanding of the chemical inhibition of flames so that predictions could be made of the effect of an inhibitor based on its chemistry in flames. This would have the two-fold value of suggesting promising candidates for inhibition and extinction and provide an upper collision limit for the effectiveness for such processes. Comparison between this limit and existing inhibitors would indicate whether much improvement can be expected from new inhibitors.

Progress Report: Progress was made in three areas of the program. (1) The rates of two reactions involving inhibitors with $\mathrm{H}$ atoms were measured using a new technique Flash Photolysis-Resonance Fluorescence. A paper reporting the work has been published, (2) In collaboration with the University of California Fire Research Group, a paper applying a two-zone model to the hydrogen oxygen flame inhibited by HC1 was prepared for publication (Fig. 1), and (3) In collaboration with the University of Louvain la Neuve (Belgium), a compilation of the inhibition literature is being prepared to test the generality of the observation of additivity of atomic contributions to inhibition. The F-S inhibition index has been reinterpreted to allow separation of the effects of fuel system, scavenging reactions, and catalytic radical recombination on inhibition (Fig. 2). 
Future Milestones: During the next year the program will include application of the zonal model to fuels other than hydrogen, and general halogenated compounds and to illustrate compatability of the additive concept for inhibitors with this model. Experimental studies will center on the development of the modulated point source technique and its application to measurement of inhibition kinetics. Reactions which are planned for study are: the three body recombination reactions $H+X+M H X+M^{*}$ and scavenger reactions of the type $\mathrm{RX}+\mathrm{H} \quad \mathrm{HX}+\mathrm{R}$.

\section{Reports:}

1. A. A. Westenberg and N. DeHaas, "A Flash Photolysis-Resonance Fluorescence Study of the $0+\mathrm{C}_{2} \mathrm{H}_{2}$ and $\mathrm{O}^{\mathrm{C}} \mathrm{C}_{2} \mathrm{H}_{3} \mathrm{Cl}$ reactions," J. Chem. Phys. 664900 (1977).

2. N. J. Brown at the University of California, Berkeley, R. M. Fristrom, and R. F. Sawyer at the University of California, Berkeley, "A Two Zone Model of Flame Propagation Applied to $\mathrm{H}_{2}+$ Air Flames and $\mathrm{HCl}$ Inhibited Flames," prepared for submission to Comb: and Flame. 


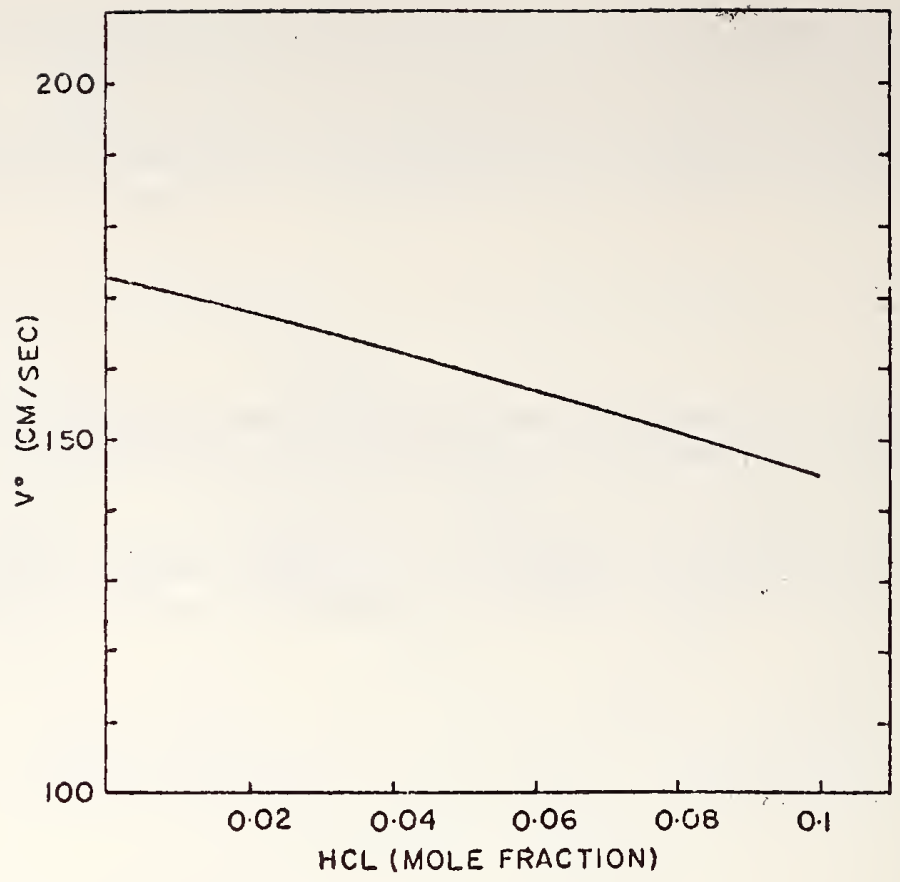

Figure 1. Dependence of burning velocity of stoichiometric hydrogen-air flame on added HCl (Ref. 2).

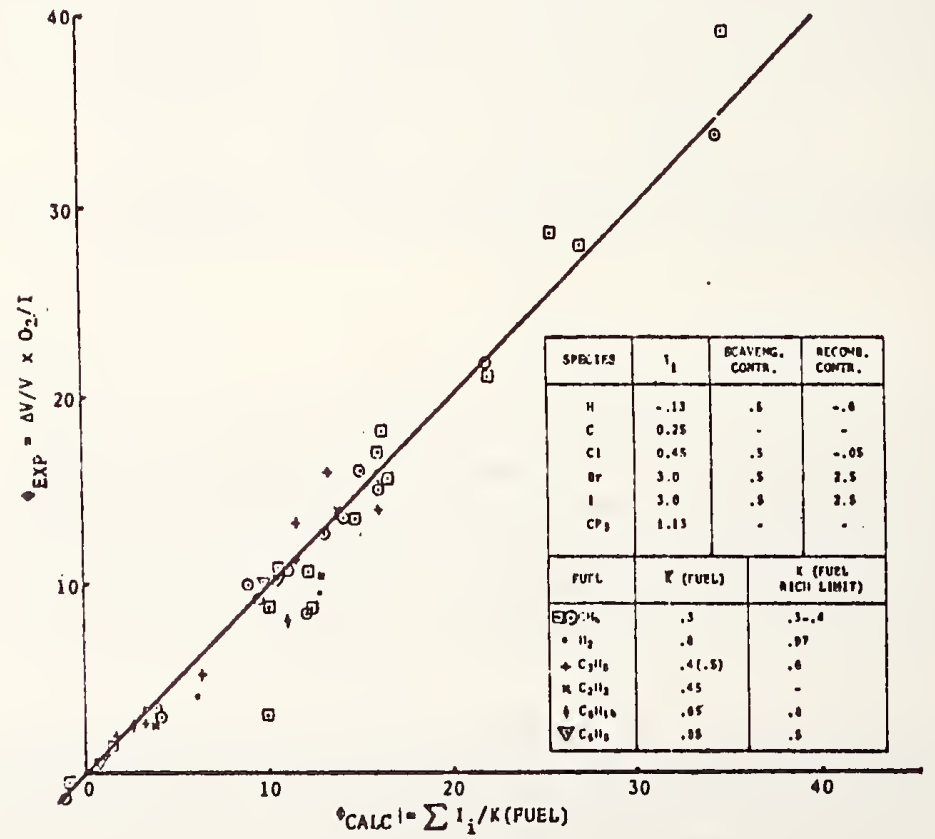

Figure 2. Comparison of calculated and experimental inhibition indices. 
Proceedings of a Conference Held at NBS, Gaithersh' r. Md., August 3-5, 2977, (Issued October 2977)

The Pennsylvania State University

NBS Grant No.: 5-9020

Grant Title: An Investigation of Fire Induced Plumes Along a Vertical Wall

Principal Investigator:

Gerard M. Faeth

214 Mechanical Engineering Building

University Park, Pennsylvania 16802

(814) $865-3743$

Other Professional Personnel:

J. A. Liburdy, Graduate Student

T. Ahmad, Graduate Student

A. Lau, Undergraduate Student

Project Summary:

Objectives: Wall plumes are generated by fires burning both on and near upright surfaces. Heat transfer between the hot gases within the plume and the surface governs both flame spread rates and the general heating of a structure by fire. The plume also provides a mechanism for transporting smoke and toxic materials throughout a structure, thereby affecting fire hazards and fire detection. The aim of the present investigation is to study fire induced wall plumes, with the following specific objectives:

1. Non-Flaming Turbulent Wall Plume. Measure heat transfer rates between the plume and the wall, and profiles of mean and turbulent quantities within the plume (velocity, temperature, Reynolds stress, etc.). Correlate the measurements with a simple integral model which can be readily used within comprehensive models of fires within structures.

2. Flaming Laminar Wall Plume. Measure wall heat transfer rates and flame shapes. Compare the measurements with a detailed theoretical model based on exact, variable property solutions of the boundary layer equations. Determine criteria for transition to turbulent flow.

3. Flaming Turbulent Wa11 Plume. Measure radiative and convective wall heat transfer rates and profiles of mean velocity and temperature. Correlate the measurements with a simple integral model which can be readily used within comprehensive models of fires within structures (the extension of this model to laminar flow, Part 2, is also to be considered).

Approach: The investigation began with the study of nonflaming wall plumes and continued with successive consideration of the flaming region for laminar and turbulent flow conditions. The approach employed in each of these phases may be summarized as follows:

1. Nonflaming Turbulent Wall Plume. The test wall plume was generated by a linear array of small gas flames along the base of a water-cooled wall, $1.22 \mathrm{~m}$ wide and $2.44 \mathrm{~m} \mathrm{high}$. Heat transfer rates were measured 
with various combinations of hot wire probes and fine wire thermocouples.

2. Flaming Laminar Wall Plume. The fire source was simulated by burning liquid fuels from a wick mounted flush with the front surface of the wall. Wall heat flux was measured by transient heating of a segmented copper wall. Flame shapes were determined from dark field photographs, the onset of turbulence was determined from shadowgraphs.

3. Flaming Turbulent Wall Plume. Heat flux measurements were made using an apparatus similar to the laminar study. A trip at the base of the wall insured fully turbulent flow. Radiation effects were evaluated by using gold-plated low emissivity surfaces as well as high emissivity black-painted surfaces. Profiles of mean quantities are obtained with a water-cooled wall using fine wire thermocouples and a pitot-static probe system. Radiation from the flame to the ambient environment was measured with a radiation transducer.

\section{Progress Report:}

Nonflaming Turbulent Wall Plume: Work in this area has been largely completed and detalls of the results may be found in Items 1-4 under Reports and Papers. Integral analysis suggested that the flow should exhibit local similarity, based on the local thermal energy flux in the plume and height above the source, if the wall friction factor and Stanton number were slowly varying. Figures 1 and 2 illustrate that local similarity is approximately satisfied for the present measurements of temperature and velocity profiles. The measurements for an isothermal wall plume fall between earlier results for free-line plumes and adiabatic wall plumes. Surprisingly, the wall plumes have higher velocities and temperatures than the free-line plume for comparable conditions, in spite of direct losses to the wall. This behavior is due to the wall stabilizing the large scale meandering observed with free-line plumes. The stabilizing effect is also reflected in lower values of the entrainment constants for wall plumes than for free plumes.

Figure 3 illustrates the correlation of measurements of heat flux between the plume and the wall. Through the Colburn analogy, the results can also be used to infer wall friction factors. The integral theory yields a simple expression for the wall heat flux, which can also be used to estimate the variation in the thermal energy flux of the plume with distance above a fire.

Profiles of turbulent quantities were also measured ( $u^{\prime}, v^{\prime}, w^{\prime}, \overline{u^{\prime} v^{\prime}}$,

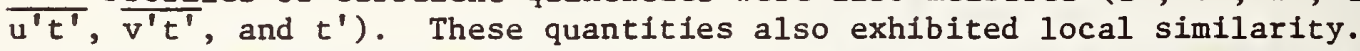
The measurements provide more detail than is required by an integral model, however, the findings are of value in developing more complete turbulence models of buoyant processes along surfaces.

Flaming Laminar Wall Plume: Work in this area has been largely completed and the details of the results may be found in Items 5 and 6 under Reports 
and Papers. In order to reduce radiation from soot, various alcohols were used as test fuels. The theory for the flaming plume region involves extension of earlier boundary layer analysis developed for the zone of active combustion.

Figure 4 illustrates a typical comparison between measured and predicted wall heat fluxes for different pyrolysis zone lengths, $x_{0}$. The comparison between theory and experiment is reasonably good, particularly in view of the difficulties in estimating physical properties for flames. The presence of the flame maintains an extended region of high wall heat flux, followed by a rapid decrease in the heat flux beyond the tip of the flame. Transition to turbulence beyond the flame tip did not result in a marked variation in heat flux. Similar results were obtained for ethanol and 1-propanol. Radiation effects were found to be small in the laminar region for these fuels.

Figure 5 illustrates measured and predicted flame shapes for a number of alcohols. The theoretical predictions are quite good, except near the tip of the flame where quenching of the reaction by the cool wall causes the combustion process to terminate somewhat sooner than the predictions.

Conditions for transition to turbulence in this flow were not fully resolved, although laminar flow was generally observed for Grashoff numbers less than $.5-2 \times 10^{8}$. The Grashoff number does not completely describe transition requirements; effects of fuel type, presence or absence of combustion, pyrolysis zone length, and wall angle were also observed.

Flaming Turbulent Wall Plume: With work completed on the turbulent nonflaming and laminar flaming wall plumes, efforts are now concentrating on the completely turbulent flaming wall plume. In order to simplify interpretation of the results, alcohols are also being used in these tests to reduce radiation from soot.

In terms of normalized distances, $x / x_{0}$, flame lengths are shorter for turbulent flow than for laminar flow. Aside from radiation contributions from the thicker turbulent flames, the maximum heat flux values in the flaming region are not very different from the values measured for laminar flow. Similar to the findings of nonflaming plumes, the results indicate that turbulent mixing with the ambient gas has the strongest influence on flame propertles, while wall effects are secondary. This behavior simplifies the task of data correlation.

For wall heights up to $0.66 \mathrm{~m}$, using alcohol fuels, the effect of radiation is not large, comprising ten to twenty percent of the total heat flux to the wall. The radiative heat flux from the flame to the ambiance is somewhat greater than the flux to the wall, agreeing with earlier findings obtained at Factory Mutual Research. This effect appears to be due to absorption of radiation by the fuel and product-rich region between the flame zone and the wall.

Work in progress includes completion of measurements of profiles of mean temperature and velocity. These measurements will provide a basis for 
an integral model of the flow in both the pyrolysis zone and the flaming plume region. This model will also be applied to the laminar results in order to provide a more convenient treatment of wall heat transfer than the complete boundary layer analysis.

\section{Accomplishments:}

1. Measurements of wall heat flux and profiles of mean and turbulent quantities were completed for turbulent, nonflaming wall plumes. The results were correlated by an integral model to allow use of the results in more comprehensive models of fires within structures.

2. Wall heat flux and flame shape measurements were completed for laminar flaming wall plumes. The measurements compared favorably with a laminar boundary layer analysis of the process. Preliminary criteria for transition to turbulent flow have been developed.

3. Radiative and convective heat flux measurements have been completed for turbulent flaming wall plumes. An apparatus has been constructed for measurements of mean velocity and temperature profiles in this flow.

\section{Potential Applications:}

The theoretical and experimental results obtained during this investigation can be applied as a part of room fire models. The results provide simple expressions for heat transfer rates between fire plumes and surfaces which are also useful in modeling and interpreting flame spread data for both laminar and turbulent upward fire spread on surfaces. In addition to direct application to fire research, the measurements also serve to expand the data base for turbulent buoyant flows along surfaces, and should prove to be helpful in the development of more sophisticated models of turbulent buoyant flows along surfaces.

\section{Future Milestones:}

Measurements of mean profiles of temperature and velocity in turbulent flaming plumes will be completed. The results will be correlated using an integral model of the process, including both the pyrolysis and plume regions. The model will also be applied to results already generated for the laminar flaming plume.

\section{Reports and Papers:}

1. Liburdy, J. A. and Faeth, G. M.: "Theory of a Steady Laminar Thermal Plume Along a Vertical Adiabatic Wall", Letters in Heat and Mass Transfer 2, 407-418 (1975).

2. Liburdy, J. A.: "Investigatons of Thermal Plumes Along Vertical Wa1ls", Ph.D. thesis, The Pennsylvania State University, University Park, PA (1976). 
3. Liburdy, J. A. and Faeth, G. M.: "An Experimental Investigation of a Turbulent Thermal Plume Along an Isothermal Wall", proceedings of the Symposium on Turbulent Shear Flows, Vol. 1, pp. 6.51-6.59, The Pennsylvania State University, University Park, PA (1977).

4. Liburdy, J.A. and Faeth, G. M.: "Heat Transfer and Mean Structure of a Turbulent Thermal Plume Along a Vertical Isothermal Wall", submitted to ASME, Heat Transfer Division, 1977 Winter Annual Meeting.

5. Liburdy, J. A., Ahmad, T., and Faeth, G. M.: "An Investigation of the Overfire Region of Wall Fires", presented at the Fall Technical Meeting, Eastern Section, The Combustion Institute, Philadelphia, PA (1976).

6. Ahmad, T. and Faeth, G. M.: "An Investigation of the Laminar Overfire Region Along Upright Surfaces", ASME/AIChE 17th National Heat Transfer Conference, Salt Like City, Utah, (August, 1977). 


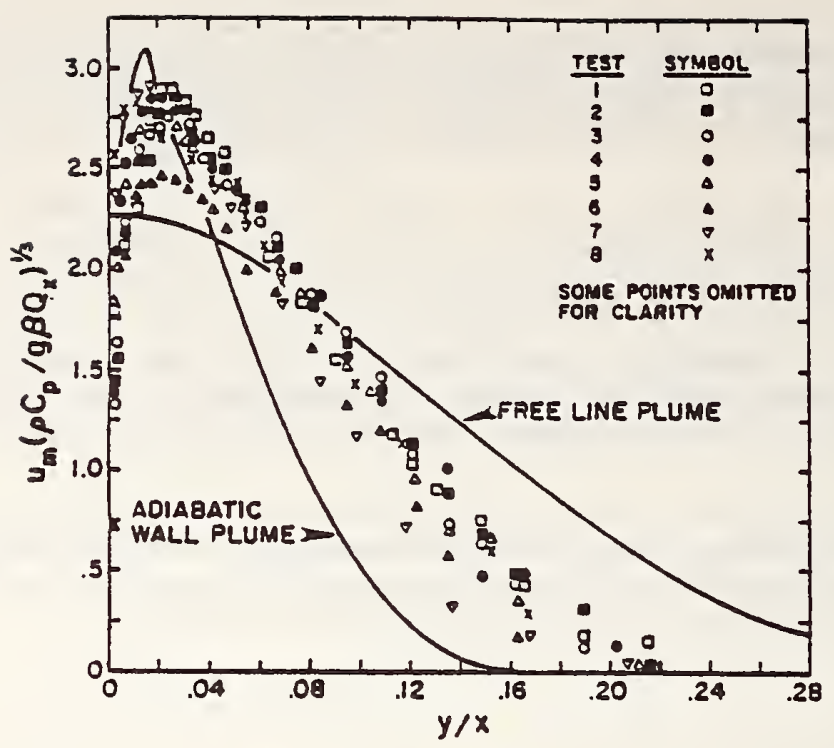

Figure I Isothermal wall plume velocity profiles compared with results for adiabatic wall plumes and free line plumes.

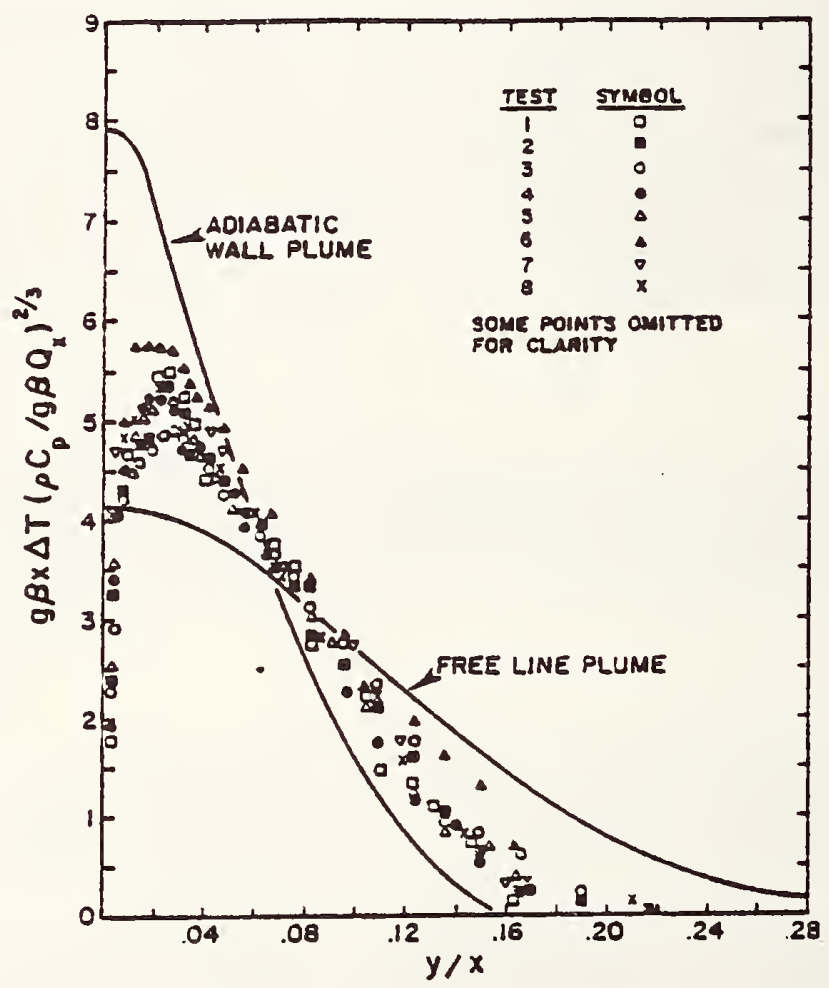

Figure 2 Isothermal wall plume temperature profiles compared with results for adiabatic wall plumes and free line plumes. 


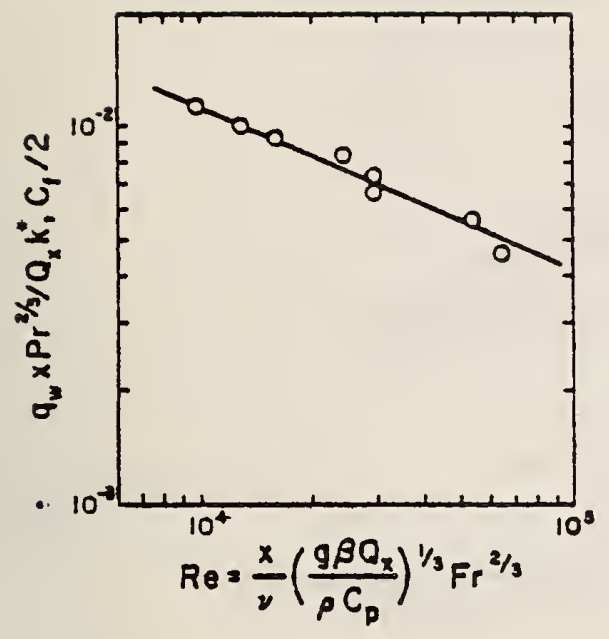

Figure 3 Wall heat flux for the isothermal wall plume.

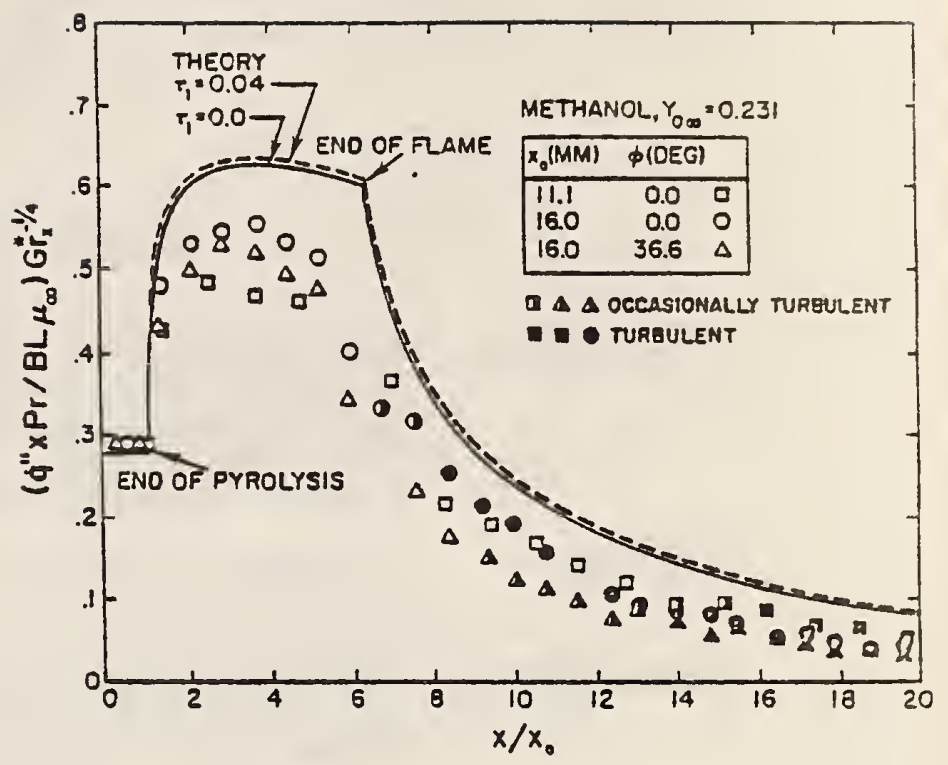

Figure 4 Wall heat flux for the laminar flaming plume region of a wall Eire.

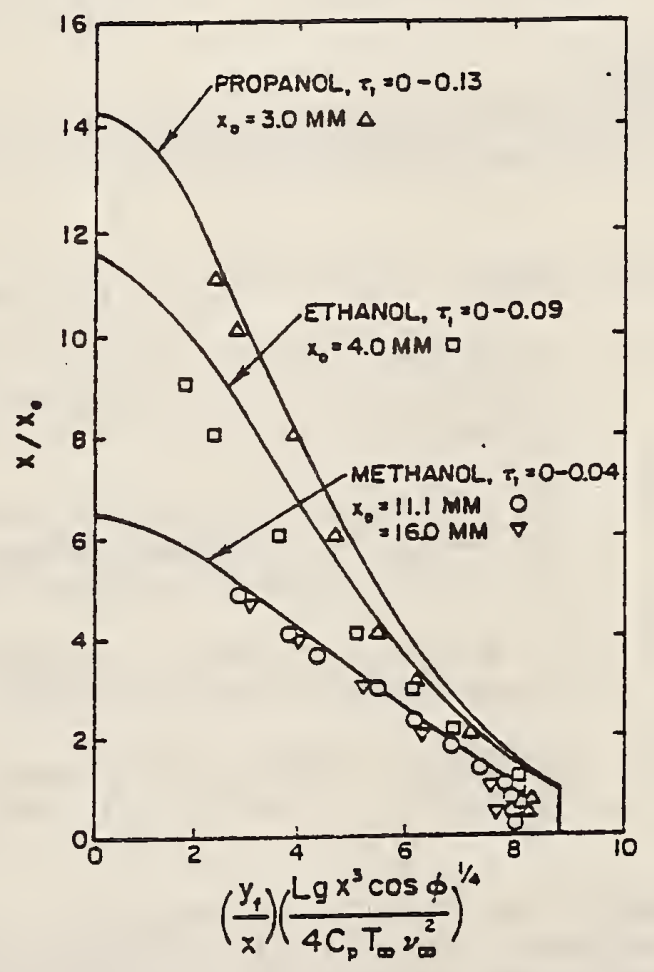

Figure 5 Flame shapes for the laminar wall plume. 


\section{PROJECT SUMMARY}

Institution: Portland Cement Association

Research and Development

Construction Technology Laboratories

old Orchard Road

Skokie, Illinois 60076

Grant No.: National Bureau of $S$ tandards

Grant No. G4-9011

Grant Title: Simulation of Realistic Thermal Restraint

During Fire Tests of Floor and Roof

Assemblies - Phases III-V

Principal

Investigator: Melvin S. Abrams

Manager, Fire Research Section

5420 Old Orchard Road

Skokie, Illinois 60076

(312) $966-6200$

Other Professional

Personnel:

Dr. T. D. Lin

Senior Research Engineer

Fire Research Section

Project

Summary:

The major objectives of the research program are:

1. To develop analytical procedures for calculating thermal restraint that occur in floor and roof assemblies.

2. To obtain experimental information from tests of carefully designed slabs that will serve to verify calculated restraints.

3. To develop method to simulate these tests in fixed frame floor furnaces.

4. To verify these procedures for fixed frame furnaces by full scale tests.

Progress Report:

Based on results of Phases I and II of the overall program, analytical procedures were developed to calculate expansion-time relationships and axial forces to simulate behavior of floor systems in actual structures. Tests were conducted on full 
scale flat slab, pan joist, and waffle floor specimens to verify the validity of the analytical programs. Further analytical studies were made to study the use of certain compressible materials to reproduce expansiontime relationships in fixed frame furnaces. These furnaces are not normally equipped to control expansion of the specimen and, consequently, the restraint forces that develop. Tests of full scale floors using compressible materials to simulate realistic restraint conditions will be conducted soon. Flat slab, pan joist, and waffle floor types are involved. Tests will be made to simulate interior and exterior slabs in the structure.

Accomp lishments:

Analytical methods have been developed and verified by tests to simulate in fire tests of floor assemblies the realistic behavior of concrete floors in concrete buildings exposed to fire.

Potential

Applications: Information developed in this research program should result in more realistic building code requirements for concrete structures that are more economical to build, and that provide safer structures for the protection of life and property.

Reports and Paper:

Progress and final reports submitted to National Bureau of Standards 


$\begin{array}{ll}\text { Institution: } & \text { Princeton University } \\ \text { Grant No.: } & \text { NBS 7-9004 } \\ \text { Grant Title: } & \text { "An Experimental Investigation of Flame Spread Over } \\ & \text { Condensed Combustibles: Gas Phase Interactions" }\end{array}$

Principal Investigators:

F. L. Dryer and I. Glassman

Dept. of Aerospace and Mechanical Sciences

Engineering Quadrangle, Princeton University

Princeton, New Jersey 08540

(Telephone No. 609 452-5206)

Other Professional Personnel

R. J. Santoro, Research Staff

C. Fernandez-Pello, Research Staff

J Newman, Graduate Student

Project Summary:

Princeton University has had a continuing effort on fire safetyrelated research with particular emphasis on the problem of flame spreading over combustible materials. Of primary concern to date has been development of a physical understanding of the mechanism controlling flame spread over liquids. With major emphasis on high-flash-point temperature materials, both analytical and experimental research have been conducted in the past.

The present research is a continuation of the experimental endeavors of the previous program in order to resolve what we consider to be one of the remaining critical factors with respect to the mechanism of flame spreading - the importance of induced (and forced) convective gas phase flow to the flame spread mechanism. In the case of flame spread over highflash-point liquids, this question is the one remaining area which has not been investigated previously. Measurements of other parameters, particularly surface temperature distribution has led us to postulate the existence of a gas phase recirculation or separation region near the flame front. Of more importance, the fundamental insights gained through previous research have led us to postulate that gas phase phenomena may play a significant role in flame spread over solid materials, a fact completely neglected by existing flame spread theories.

The resolution of these questions can only be made through precise experimental measurement of the gas phase flow fields. With this goal in mind, this laboratory has undertaken construction of a two-dimensional laser-doppler velocimetry facility for conducting time and spatially resolved flow field measurements on bench-scale fires. With the completion of the LDV facility, liquid and gas phase flow field measurements over high-flash-point materials are being completed and measurements of the gas phase flow field over solid materials are to follow. 
During the current grant period the laser-doppler velocimetry (LDV) facility has been made operational. Verification of the operation of the optical, electronic signal processing and computer data acquisition subsystems has been achieved. The complete IDV facility has been tested and optimized using well-defined liquid flows to determine the importance of particle seeding, laser power, shielding from rf noise, stray light and signal processing threshold.

The reduction of $\mathrm{rf}$ noise pick-up proved to be critical for optimum performance of the LDV electronics. The Bragg cell frequency shifting and beam splitter technique utilized in the facility was the source of the rf signal. Careful shielding of the components and elimination of ground loops were responsible for the major reduction in this rf pick-up. Seed particle size and concentration also proved to be important for obtaining optimum results. The importance of seeding is, of course, well documented in the literature, nevertheless for any LDV application the proper seeding requirements for an experiment must be ascertained on an individual basis.

Once the IDV operation had been verified using a well-defined flow, measurements of the liquid flow field resulting from surface tension induced convective flow were undertaken. A binary mixture of ethanol-water ( 90 proof), the mixture generally used for the studies in this laboratory, was chosen as the fuel. In fact, velocity profiles using hydrogen bubble techniques had previously been determined. Thus a comparative data set existed. Velocity profiles were taken with the LDV as close as $0.5 \mathrm{~cm}$ from the surface. Large concentration gradients in the region near the surface due to the binary nature of the fuel made it impractical to obtain measurements closer to the surface. The results of these experiments are in good agreement with past hydrogen bubble technique results.

The LDV has also been applied to measuring a well-detined gas phase flow. As in the liquids case the goal was to examine seeding requirements and optimization of the LDV optics and electronic subsystems. This work is now being extended to measure gas flow velocities above the liquid surface. As mentioned previously the objective of this study is to determine the importance of gas phase recirculation, and perhaps separation, on the flame spread mechanism for both liquid and solid combustibles.

\section{Accomplishments:}

Specific achievements during the current grant period include:

1. A LDV capable of measuring a two-dimensional velocity field including flow reversal has been completed.

2. The operation of the LDV has been proven using well-defined liquid and gas flows.

3. Seeding requirements for the liquid and gas phase LDV measurements of the velocity fields generated by flames spreading over a combustible surface have been examined.

4. Velocity measurements for the liquid phase have been made for a binary mixture of ethanol and water. The results have been compared with earlier work using a hydrogen bubble technique and yielded good agreement. 
A thorough understanding of the flame spread process over condensed fuels will provide a basis for the application of measures to avoid or control fire hazards. Potential applications of the studies of flame spread over liquid fuels include fighting of large scale fuel tank fires, oil spill clean up problems, and design of aircraft runaways. For the case of solid fuels applications include flammability ratings of materials, flashover times for room fires and better evaluation of fire hazards of wood and plastics.

\section{Future Milestones:}

Future efforts will concentrate on measuring the gas phase velocity for flames spreading across liquid and solid combustibles. These experiments will be aimed at elucidating the importance of gas phase recirculation on the mechanism of flame spread.

\section{Reports and Papers:}

1. Dryer, F. L. and Newman, J. S., "Flame Spread over Liquid Fuels The Mechanism of Flame Pulsation," Paper No. 76-48, Fall Meeting of the Western States Section of the Combustion Institute, La Jolla, California, 18-19 October 1976.

2. Glassman, I., Santoro, R. J., and Dryer, F. L., "A Review and Some Recent Results of the Princeton Program on Flame spread over Condensed Phase Combustibles," Paper No. 76-29, Fall Meeting of the Western States Section of the Combustion Institute, La Jolla, California, 18-19 October 1976.

3. Glassman, I., "Some Perceptions on Condensed Phase Flame Spreading and Mass Burning," Session IVB Paper No. 1, Spring Meeting of the Central States Section of the Combustion Institute, NASA Lewis Research Center, Cleveland, Ohio, 28-30 March 1977. 
Institution: Princeton University, Guggenhelm Laboratories

Grant No.: G4-9026

Grant Title: Modeling the Generation of Toxic Gases by the Smoldering Combustion of Polyurethanes

Principal Investigator: M. Summerfield

Guggenheim Laboratories

Princeton University

Princeton, New Jersey

Other Professional Personnel: T. J. Ohlemiller and F. E. Rogers

\section{Project Summary:}

Toxic gases arising from smoldering combustion of bedding and upholstery materials are implicated in a large fraction of residential fire deaths. Flexible polyurethane cushioning materials, in combination with cellulosic fabrics, have been found to smolder and, thereby contribute strongly to this hazard situation. This research is aimed at an understanding of the mechanism of smolder in these permeable polyurethanes by means of experimental and modeling studies as an aid in eliminating it and other potential smolder problems.

Smolder in polyurethanes can conveniently be studied in materials which, while they can self-sustain the process, are still qualitatively similar to the majority of formulations requiring some weak heat source (e.g., fabric smolder) to sustain them. Such studies have shown the smolder to be drastically different from the more familiar flaming combustion. The smolder wave is thick (few $\mathrm{cm}$ ), very low in temperature $\left(300-500{ }^{\circ} \mathrm{C}\right.$ ), and orders of magnitude slower than flames $\left(\simeq 10^{-2} \mathrm{~cm} / \mathrm{sec}\right)$. It is also extremely incomplete in its oxidation of the polymer, requiring only a few percent of the stoichiometric air supply. The wave is essentially oxygen-limited in all of its characteristics and as more oxygen is supplied, all of these characteristic numbers change; the wave speeds up and its output of carbon monoxide is sharply increased. In the absence of some external pilot source, transition to flaming is surprisingly difficult, requiring more than $50 \% \mathrm{O}_{2}$ in the permeating gas (pilot sources do, however, easily ignite smoldering upholstery).

The transitions taking place in the polyurethane as the smolder wave overtakes it are very complex, both physically and chemically. In a gross sense, one finds the wave gasifies about half of the polymer and leaves behind a high surface area, porous, and char-like residue retaining varying degrees (depending on formulation) of the original foam cell structure. The polymer degradation process can be followed crudely by $\mathrm{C}, \mathrm{H}, \mathrm{O}, \mathrm{N}$ analyses of successive layers across the wave; the end product is far from being pure carbon. Infrared studies of these layers suggest that the charforming reactions involve formation of amide and/or isocyanurate linkages. Charring is important to smolder for two reasons: it provides a high surface area fuel and, by leaving a residue, provides an insulation layer 
around the reaction zone. This latter fact, coupled with its versatility, accounts for the surprising stability and tenacity of an established smolder wave despite its seemingly weak, marginal character as a combustion process.

When an open-celled polyurethane foam is subjected to heating in an inert atmosphere it goes through successive stages of depolymerization which eventually lead to a tarry residue. During the first stage the individual struts, which surround the cells of the foam, lose their elasticity and become progressively weaker. Continued heating causes further depolymerization of the polymer chain, presumably at the urethane bonds, and the struts become gel-like in appearance. At this point, they are very weak and yield to slight pressure. Collapse of the structure follows soon after the appearance of the gel structure. In a typical foam the transition from a cellular structure to tar takes place with a 20-30\% weight loss. In the presence of air, oxidation reactions may intercept this process and convert the weakened struts to a stronger char-like structure. Formation of the charry struts give the cellular structure new strength and impedes the collapse due to pyrolysis. The balance of these two competing processes will determine whether smolder can take place. If the oxidation reactions are fast enough to intercept the structure destroying pyrolysis process a cellular char results which has the necessary surface area (and insulative properties) to permit smolder. If the oxidation reactions are too slow then the structure collapses and no smolder is possible. Any physical, structural, or chemical varlable in the foam or its environment that alters this competition will influence the potential for smolder in the foam. The addition of fire retardants may or may not inhibit smolder. In certain formulations the common retardant called TRIS actually promotes smoldering. It does this by slowing down the tar forming reaction and accelerating the oxidative char forming step. Other polymeric chlorophosphate retardants are fairly effective smolder inhibitors and some even inhibit smolder in a cellulosic fabric atop the foam. Certain components in the original foam formulation can alter the polymeric structure to give varying smolder potential. The presence of water in the formulation promotes the formation of urea blocks in the polymer. These blocks are less thermolabile than the usual urethane bond and seem to be nuclei for char formation. When the water content is decreased in a particular formulation, smolder potential is reduced. The molecular weight and nature of the pendant groups (grafting) in the polyol moiety of the foam also play an important but less characterized role.

On the basis of the above observations of the character of smolder in flexible polyurethanes, a simplified mathematical model of the process has been developed. The model employs the overall chemistry of the polyurethane degradation described above, coupled with a description of the important thermophysics. The resultant set of nine differential equations is solved by computer. By this means the parameters influencing the initiation and propagation of one-dimensional smolder wave, can be studied. The model confirms the oxygen-limited nature of established smolder and, under these circumstances, the chemical behavior of the 
polyurethane is of secondary importance. It is of primary importance, however, in the smolder initiation process. Parametric studies show that suppression of self-sustained smolder is not excessively difficult. However, fabric-assisted smolder is the more usual problem in practice and it appears unavoidable if (1) the fabric-smolder is not suppressed, and (2) the char-forming character of the polyurethane is not altered. Some promising leads on (2) have been formulated. McCarter at NBS has been successful with (1).

With the above studies as a basis for understanding smolder in one rather limited application, future work will branch out to other configurations. The intent is to first look at a variety of organic materials in a standardized test. These results, coupled with thermal analyses of the materials should provide a basis for rating relative smolderability of materials. The influence of physical configuration variables will then be examined with the intent of obtaining guidelines for reliable testing of potential smolder hazard. 
Institution:

Contract Number:

Contract Title:

\section{Stanford Research Institute}

7-35756

Application of Decision Analysis to Problems of Fire Hazard Quantification

Principal Investigator: Fred L. Offensend

Project Objectives:

The principal objective of this project has been to test the utility of the decision analytic approach in quantifying fire hazard and in evaluating alternative intervention strategies for improving fire safety. The profect is a joint effort between the Decision Analysis Group, Stanford Research Institute and the Program for Information and Hazard Analysis, Center for Fire Research. Project Accomplishments:

As a vehicle for testing the utility of the decision analytic approach to problems of fire safety, this project has focused on evaluating a small set of alternatives for reducing upholstered furniture fire 10sses. A simple probabilistic model has been developed to assess the costs and losses that would occur under each intervention strategy. The model addresses such factors as the type of ignition source, whether anyone was home at the time of Ignition, whether there was a functional smoke detector, time of discovery, and extent of flame damage. Over 500 sets of possible conditions under which upholstered furniture fires can burn are defined by the model. Expected levels of loss (measured in terms of personal and property loss) are assigned to each set of five conditions, and once likelihoods of each of the Individual fire conditions are assigned, the model calculates the range and likelihood of possible fire losses under the intervention strategy in question. The 
output of the analysis gives a probability distribution on the cost plus loss for the alternative in question, reflecting the uncertainties on the Individual input factors to the analysis.

The project is actively underway at the time of this writing. It Is anticipated that three principal alternatives will be analyzed and evaluated by the time of the CFR Extramural Research Conference. Those alternatives are 1) a proposed upholstered furniture ignition standard, 2) a possible federal requirement requiring installation of smoke detectors in all U.S. residences and 3) no action at all. Reports:

It is anticipated that a detalled report outlining the decision analytic approach and 1 ts application to the upholstered furniture fire problem w1ll be avallable in fall, 1977.

\section{Potent1a1 Applications:}

Both the Decision Analysis Group and the Program for Information and Hazard Analysis are convinced that the decision analytic approach has widespread application, far beyond the upholstered furniture problem. The decision analytic approach provides for a systematic structuring of the many complex factors and relationships that affect a fire safety decision problem and thereby provides a vehicle to explicitly address uncertainty and carry out a systematic evaluation of alternatives. 
Institution Stevens Institute of Technology

Grant No. NSF ENV 76-07136

Grant Title "Flammability Studies of Cellular Plastics"

Principal Investigator Prof. Richard S. Magee

Department of Mechanical Engineering

Stevens Institute of Technology

Hoboken, N.J. 07030

(201) $792-2700 \times 580$

Other Professional Personnel

Angelo A. Volpe* - Faculty Associate Salvatore S.Stivala* - Faculty Associate Jean Marie Dineen* - Graduate Student John Vigliotta - Graduate Student

* Department of Chemistry and Chemical Engineering

Project Summary

The overall objective of this investigation is to correlate the results of fundamental polymer characterization studies and fundamental fire dynamic studies on a variety of cellular plastic materials with 1) the ratings or values assigned to these materials by various laboratory test standards and procedures (e.g., E-84 and rate of heat release tests), and 2) their performance in full-scale geometry tests.

In support of this generally stated objective, the specific objectives of this investigation are:

1. To determine the physicochemical characteristics of the cellular plastics under study. This involves an in-depth polymer characterization study. (A frequent criticism of many fire dynamic flammability studies is lack of characterization of the materials tested.)

2. To perform a fundamental fire dynamic investigation of the burning intensity of these cellular plastics. The response of these materials (mass loss, mass burning rate, self-ignition) is determined as a function of radiant heat input. Thus, the "fire response" of each material is determined. 
3. To collect the performance of these materials in standard tests from continuing or completed studies.

4. To obtain the contribution of these materials to early fire development and early fire growth under a variety of building enclosure geometries.

5. To analyze and compare the data from the fundamental chemical and fire dynamic studies with results from standard tests and large-scale tests to determine those material physicochemical properties which are most critical in determining the level of fire hazard.

6. To obtain a series of curves for the mass burning rates of these materials over a sufficient range of realistic fire conditions so that i) designers, architects and fire protection engineers will have a basis on which to evaluate the potential fire hazard of a given material in a specific application and ii) fire dynamic specialists concerned with predicting temperature-time and concentration-time curves in a burning enclosure will have the necessary boundary condition data.

The following experimental program was undertaken. Polymer Characterization

The major objective of this phase of the research effort is to determine the physicochemical characteristics of the cellular plastics under study and to identify those properties which are characteristic of and related to the level of fire hazard.

Analytical procedures used have included solubility tests, elemental analysis, KBr pellet infrared analysis, thermogravimetric analysis (TGA), and analysis of TGA decomposition products by gas chromatography and chemical ionization mass spectrometry. Burning Intensity

Single slabs of the materials (7" wide $x 14 "$ high) are subjected to burning as a vertical wall. Electrical radiant heaters, directed at the burning surface, are employed to simulate real fire conditions. Radiant heat fluxes to the fuel surface up to 4 watts $/ \mathrm{cm}^{2}$ have been 
employed. A water-cooled transducer and load plate assembly measured the response of the plastics to the externally applied radiant flux. Tests were conducted with and without a pilot flame. Quantities measured included: 1) minimum radiant flux levels to cause thermal decomposition, 2) weight loss versus time at various external fluxes, and 3) minimum radiant flux levels to cause self-ignition. Quantities determined included burning rate versus time curves as a function of radiant flux.

\section{Progress Report}

The investigation was initiated with five specimens: two polyurethanes, two polyisocyanurates and one carbodiimide. These materials and the manufacturers ASTM E-84 flame spread classifications are shown below.

\begin{tabular}{|c|c|}
\hline SPECIMEN & ASTM E-84 FSC \\
\hline Urethane-A & 75 \\
\hline Urethane-B & $75^{*}$ \\
\hline Isocyanurate-A & 25 \\
\hline Isocyanurate-B & 25 \\
\hline Carbodiimide & 20 \\
\hline
\end{tabular}

*Listed as a class II

Obviously these specimens offer a limited variation of flammability behavior, as measured by $E-84$, and there is also some uncertainty to the correct flame spreading classification assigned urethane B. Nevertheless, these specimens formed the starting point for our investigation. Unfortunately, the performance of these materials in full-scale geometry tests was not available. Consequently the results from this study could only be compared with performance in laboratory and standard tests.

These specimens have been subjected to the above mentioned polymer characterization and burning intensity studies.

\section{Accomplishments}

Test results from TGA carried out in a helium atmosphere indicate some correlation of percent residue of samples remaining at $500^{\circ} \mathrm{C}$ and $800^{\circ} \mathrm{C}$ with the E-84 flame spread classification (FSC) for these materials. 
The slopes of the mass loss versus time curves were obtained and these burning rates plotted versus time. These results are extremely encouraging, indicating a maximum burning rate which occurred generally within the first ten seconds of external heating. The order and magnitude of these values correlated extremely well with the ASTM E-84 ratings, including the polyurethane-B (75 FSC) discrepancy discussed earlier.

By multiplying the mass burning rate curves by the specimen's corresponding heat of combustion, as measured in a Parr oxygen bomb calorimeter, maximum potential rate of heat release curves were obtained. These were then compared with measured rate of heat release curves. These results seem to indicate a strong correlation between maximum burning rate and maximum heat release rate. However, the potential rate of heat release may in fact be 3-4 times larger than anticipated.

Potential Applications

This burning intensity study seems to indicate that the maximum burning rate is a good indication of fire hazard; it correlates well with the ASTM E-84 flame spread classification. More testing, employing a wider range of materials, is required to confirm this finding. This laboratory test method must also be tested against the behavior of these materials in large scale room and corner tests. However, it is hoped that since the burning rate involves a more sensitive measurement than the.E-84 FSC, it may be a better indication of actual hazard, and thus be able to identify materials that will burn in a very hazardous manner in the real world. The E-84 test has not been able to consistently identify hazardous materials.

If successful, this approach will offer a simple and inexpensive method for assessing the fire hazard potential from a particular material. While it will not eliminate the ineed for "real geometry" largescale fire tests, a good predictive test would greatly reduce the number of full scale tests required to insure an acceptable level of fire safety. Future Milestones:

This program was only funded for one year.

Reports and Papers:

Vigliotta, J.J. "Flammability Studies of Cellular Plastics" Masters Thesis, Department of Mechanical Engineering, Stevens Institute of Technology, May 1977.

Final report and paper in progress. 
Institution: University of California at Berkeley

Grant No.: NBS Grant-G7-9006

Grant Title: Full Scale Experiments and Fire Tests

Principal Investigator: Robert Brady Williamson, Civil Engineering Department, University of California, Berkeley, California 94720 .

Telephone: (415) 642-5308

\section{Other Professional Personnel:}

V. Babrauskas (now at National Bureas of Standards)

R. Draemel (Ass istant Specialist)

F. Fisher (Principal Engineering Aid)

H. Hasegawa (Assistant Specialist)

W-C. Ling (Research Assistant)

D. Van Valkinburg (Research Assistant)

C. Warbington (Research Assistant)

A. Weatherly (Assistant Programmer)

P. Wolf (Sr. Electronic Technician)

Project Summary:

This project is focused on the correlation between full scale fire experiments, laboratory scale fire tests and actual fire conditions. It has been divided into two parts (1) pre-flashover fire growth and (2) post-flashover fire endurance. The objective of the first part is to establish methods for evaluating the contribution of room furnishings and finishing materials to fire development. This study will concentrate on the evaluation of experimental results and the comparison of different test methods. The objective of the second part is to more clearly define the relationship between requirements for post-flashover fire endurance and the fire resistance of building components. This involves producing an improved description of expected fires as well as constructing a rational set of criteria for judging fire test performance of building components. The emphasis in the last six months has been to develop techniques of translating the results of fire tests (such as ASTM E-119 and E-162) into probabilistic framework.

The approach has been to analyze fire growth and fire endurance within the context of the current knowledge of fire. In fire growth situations, one is often faced with the identification of a possible causal-chain-of-events that either did or could lead to a serious fire situation. There are a large number of cases in which this is reduced to evaluating the contribution of an isolated specimen to the rate of fire propagation; but for the presence of a given specimen, it is clear that the fire would not have spread. Thus, intervention strategies can be visualized to prevent such fires in the future. A state transition model has been proposed for fire growth experiments and this has been coupled with fault tree analysis in order to interpret the role of specific laboratory fire test methods. 
In the post-flashover regime the unexposed faces of walls, floors, doors and other fire containment building components become the potential source of fire spread to the adjacent areas. The existing criteria for failure of fire endurance tests are being analyzed in the fire growth context described above. The pressure differentials across assemblies and the production of excess pyrolysis products in the fire compartment have not been duplicated in the standard test procedures and this will necessitate certain changes in the test standards before meaningful criteria can be introduced.

Progress Report:

In the area of fire growth, our efforts have concentrated in reviewing previous compartment and corner wall experiments and further developing the state transition techniques. The State Transition Model of fire growth has been generalized and it has been coupled with fault trees and/or success trees in each transition event. It is planned to send a summary of our thoughts to other investigators who have conducted fire growth experiments. The assistance of these investigators will be solicited in supplying experimental data and suggestions for application of the analysis. As part of this summary, the method has been applied to a number of research projects which included fire growth experiments. It is hoped that a new subcommittee on full-scale fire tests of the combined E5/39 Committee of ASTM will be a focus for this activity.

The new burn-out module has been designed and constructed and a series of experiments are in progress to simplify full-scale fire trials. It is designed so that specimens can be easily mounted and so that the experiments can be conducted with a minimum of set-up time. Some additional improvements have been planned which will make the set-up and clean-up even easier. This is one aspect of compartment tests which has made them more expensive than small scale tests.

In the post-flashover fire tests area, the description of end-point criteria has been studied for door tests. Two door tests were conducted with side-by-side doors in one hour fire walls. Hoods were placed above the door to trap the flames and hot gases that were forced through some doors. Special features were added to certain doors to prevent the penetration of the flames and these were completely successful in one case and partially successful in another. A fault tree analysis will now be made of the door tests and recommendations will be prepared for new criteria.

\section{Accomplishments:}

There is definite progress toward quantitative methods of correlating full-scale fire experiments with many laboratory scale experiments and test methods. Corner-wall compartment fire trials are being used to evaluate the contribution of many materials, products and assemblies. This research project has been involved with many progressive steps in the area. It is hoped that we can continue to contribute. 
In the post-flashover area, Dr. Vytenis Babrauskas finished his doctoral work. He developed methods of calculating the gas temperatures in fully involved compartments with known ventilation, fuel load, and wall properties or with the worst possible (i.e., pessimized) choices of these factors. He reviewed the history of fire testing for fire endurance and this historical review has allowed a more rational assessment of the limitations of our current post-flashover fire tests. The lack of scientific knowledge severely limited many of the possible choices for the early fire test standards and codes.

Potential Applications:

The improvement of fire tests and the closer regulation of the actual fire behavior of materials are now within the grasp of the fire research community. ASTM, NFPA and Building Code groups are taking notice of our research as well as that of other organizations. This represents an indirect area of application.

\section{Publications:}

1. Vytenis Babrauskas, Fire Endurance in Buildings, Doctora1 Dissertation, November 1976, University of California, Berkeley.

2. V. Babrauskas and R. B. Williamson, "Post-Flashover Compartment Fires: Part I A Theoretical Model," submitted to Fire and Materials.

3. V. Babrauskas and R. B. Williamson, "Post-Flashover Compartment Fires: Part II Application of the Mode1" in preparation.

4. R. B. Williamson, "Fire Performance Under Full Scale Test Conditions - A State Transition Model," presented at the 16th. International Symposium on Combustion 15-21 August 1976. To be published in the proceedings.

5. R. B. Williamson, "Wide-Span, Fire-Rated Automatic Fire Barriers," presented at 1977 NFPA Annual Meeting 16-19 May 1977.

6. R. B. Williamson, "Installing ABS and PVC Drain Waste and Vent Systems in Fire-Resistive Buildings," presented at the 1977 NFPA Annual Meeting 16-19 1977. 
ANNUAL CONFERENCE ON FIRE RESEARCH, NBSIR 77-2308

Proceedings of a Conference Held at NBS, Gaithersburg, Md., August 3-5, 2977, (Issued October 2977)

Institution: University of California at Berkeley

Grant No.: NBS Grant-G7-9006

Grant Title: Flame Radiation Section in "Fj.re Safety in Urban Housing"

Principal Investigator: Chang-Lin Tien, Mechanical Engineering Department

University of California, Berkeley, California 94720

Telephone: (415) 642-0877

Other Professional Personiel (all graduate research assistants)

L. C. Chow (now, Engineer at General Electric)

G. L. Hubbard

G. S. Shiralkar

W. W. Yuen (now, Assitant Professor, UC-Santa Barbara)

Project Summary

To characterize flame radiation in a simple, realistic manner constitutes the major objective of the present research program. In the past few years, fundamental studies have been conducted on the overlapping of both continuous and band spectra due to soot and gaseous combustion products, as well as the effect of nonhomogeneity due to temperature and species distributions. Specific recent contributions include flame radiation measurements and data interpretation of plastic fuels, a simple scheme to calculate flame emissivities, and the characterization of infrared mean (or gray) absorption coefficients for luminous flames and smoke. Further research is planned on the radiation mean beam length calculation, radiation interaction with combustion, and combined radiation and convection in enclosures.

Progress Report

Flame radiation is being recognized as a critical factor in many physical and transport phenomena in fires. In flames and smoke, both gaseous and particulate matters emit, absorb and scatter radiation in a significant way in the visible and infrared. In the past, however, little systematic and fundamental information on flame radiation was available to provide a better basic understanding or a simple, quantitative characterization for practical fire-radiation calculations. The purpose of this research program has been to devèlop a sound physical basis as well as a simple calculation for flame radiation.

Analytical studies have been performed on the various important factors in characterizing flame radiation, including scattering and absorption of soot and conglomerated particulates, overlapping gaseous bands and its interaction with soot radiation, and nonhomogeneous temperature and species distributions. Most of these results are contained in the FRG publications during the period of 1975-76. Low-resolution spectroscopic measurements on flames of polymer fuels (polystyrene, plexiglass and Delrin) have generated 
fundamental information regarding various pertinent parameters in flame radiation (Buckius and Tien, 1977).

Significant progress made during the past year include establishing a simple calculation scheme for the luminous-flame emissivity and developing a method to calculate the mean (or gray) absorption coefficient of flames. The emissivity calculation scheme is based on a physical model of gray soot and nongray gases. In particular, the model allows a comparative analysis of soot emission characteristics in flames produced by fuels of different chemical composition. In most applications, however, the mean absorption coefficient is a more fundamental and convenient parameter to work with than the total emissivity, which depends on the optical pathlength. Based on the physical model of a homogeneous nongray flame, the coefficient can be conveniently expressed as a function of temperature, the volume fraction of soot and the partial pressures of $\mathrm{CO}_{2}$ and $\mathrm{H}_{2} \mathrm{O}$. The mean-coefficient concept is particularly useful because the Planck mean for the optically thin limit and the Rosseland mean for the optically thick limit do not deviate much from each other.

Further research on the radiation mean beam length for flames of different goemetric shapes is planned. Continuing effort has been spent on the development of a more efficient computation technique for elliptic convection equations as applied to enclosures. Exploratory work on interaction between radiation and combustion processes in flames has also been initiated.

\section{Accomplishments}

On the basis of the fundamental information obtained for the gaseous and particulate radiation contributions in flames in the past few years, two simple, realistic methods of calculation have been developed for the total emissivity and the mean (or gray) absorption coefficient of luminous flames. Results for common gaseous and solid fuels have been tabulated or graphically presented.

\section{Potential Applications}

Radiation of flames and smoke is an important concern in all practical fire problems such as fire detection, ingnition, spread, plume convection, and modeling. Radiation assumes an even more prominent role in fires in an enclosure such as in urban housing fires because of the restricted high-side walls. Emissivity and mean absorption coefficient calculations developed in this study have already been used by other groups in their related studies and calculations.

\section{Future Milestones}

Further measurements and data interpretation for flame radiation from burning polymeric materials in both open and confined systems. Refinement of analytical techniques in calculating radiation from flames of complex geometries. Development of a computational analysis for flame and smoke plume spread in a confined system, including convection, combustion and radiation. 
Refereed Publications

1. Tien, C. L., Doornink, D. G., and Rafferty, D. A., "Attenuation of Visible Radiation by Carbon Smokes," COMBUSTION SCI. TECH., 6, 55-59 (1972).

2 Felske, J. D., and Tien, C. L. "Calculation of the Emissivity of Luminous Flames," COMBUSTION SCI. TECH., 7, 25-31 (1973).

3. Felske, J. D., and Tien, C. L., "Infrared Radiative Transfer from non-Homogeneous Gas Mixtures Having Overlapping Bands," J. QUANT. SPECT. RADIAT. TRANSFER, 14, 35-38 (1974).

4. Felske, J. D., and Tien, C. L., "A Theoretical Closed-Form Expression for the Total Band Absorptance of Infrared Radiating Gases," INT. J. HEAT MASS TRANSFER, 17, 155-158 (1974).

5. Dayan, A., and Tien, C. L., "Radiant Heating From a Cylindrical Firé Column," COMBUSTION SCI. TECH., 9, 41-47 (1974).

6. Tien, C. L., Felske, J. D., and Dayan, A., "Analytical Basis For Fire Radiation," LETTERS HEAT MASS TRANSFER, 1, 79-80 (1974).

7. Felske, J. D., and Tien, C. L., 'Wide-band Characterization of overlapping Band Radiation," COMBUSTION SCI. TECH., 11, 111-117 (1975).

8. Dayan, A., and Tien, C. L., "Heat Transfer in a Planar Medium with Anisotropic Scattering," J. HEAT TRANSFER, 97, 391-396 (1975).

9. Ilayan, A., and Tien, C. L., "Radiative Transfer with Anisotropic Scattering in an Isothermal Slab," J. QUANT. SPECT. RADIAT. TRANSFER, 16, 113-125 (1976).

10. Yuen, W. W., and Tien, C. L., "A Simple Calculation Scheme for the Luminous-Flame Enissivity," 16th International Symposium on Combustion (1976).

11. Buckius, R. 0., and Tien, C. L., "Infrared Flame Radiation," INT. J. HEAT MASS TRANSIER, 20, 93-106 (1977).

12. Felske, J. D., and Tien, C. L. "The Use of the Milne-Eddington Absorption Coefficient for Radiative Heat Transfer in Combustion System,"

J. HEAT TRANSFER, 99, (1977).

Papers in Preparation

13. Hubbard, G. L. and Tien, C. L., "Infrared Mean Absorption Coefficients for Luminous Flames and Smoke." 
Institution: University of California at Berkeley

Grant No.: NBS Grant-G7-9006

Grant Title: Fire Modeling Section in "Fire Safety in Urban Housing"

Principal Investigator: Patrick J. Pagni, Mechanical Engineering Department University of California, Berkeley, California 94720 Telephone: (415) 642-0729

\section{Other Professional Personnel}

T.M. Shih (Postdoctoral Research Engineer)

M.S. Sahota (now at Aerojet General)

R. Toossi (Graduate Research Assistant)

S. Bard (Graduate Research Assistant)

C.M. Kinoshita (Graduate Research Assistant)

S.T. Wang (Graduate Research Assistant)

K. Kayayan (Graduate Research Assistant)

\section{Project Summary}

The overall goal of the Fire Modeling Group is to develop analyses of fire growth within the compartment of origin and propagation throughout the structura. These physical and mathematical models permit prediction of the consequences of specific designs, materials and strategies. They also provide the bases for development of meaningful test methods to evaluate real fire material and configuration hazards. The following problem areas are under consideration: 1. Extensions of Excess Pyrolyzate: Several new flow fields have been considered. An analysis of mixed mode, forced and free, laminar boundary layer combustion has been completed. Turbulent flames in forced flow downstream of a burning fuel slab have been described. New techniques for extracting explicit variables from probability density functions for the Shvab-Zeldovich variables have evolved. Preliminary studies on excess pyrolyzate in laminar opposed flow diffusion flames have been completed. 2. Combustion of Urethane Foams: Empirical histories of flame shape, temperature, and specie concentrations as well as mass loss rates have been obtained. Good agreement is achieved with analytic calculations of mass loss. 3. Flame Spread, Porous Media, Particulates: These programs are in the process of being completed. Final flame spread experiments are under way. The analyses of temperature fields and water vapor fields in wet porous concrete will be published shortly. A flame apparatus has been designed and constructed which may become a standard apparatus for research on flame chemistry and structure.

\section{Progress Report}

1. Extention of Excess Pyrolyzate: The work begun in Reference 1 has been extended to combired mode laminar flames (Ref. 8) and to turbulent flames (Ref. 6). In the process some useful general techniques for describing flame variables with Gaussian distributions were developed (Ref. 7). In conjunction with the sub-program sub-committee of the Ad Hoc Group of Mathematical Fire Modeling, these developments have been prograrmed and documented (Ref. 9). Additional 
details may te found in the cited publications. Further research will be directed tc calculating excess pyrolyzate and flame neights for these mixed mode and turbulent flanes. Radiation effects will be included and the crucial variation of ambient oxygen, as found in a burning compartment, will be studied in detai1.

2. Combustion of Urethane Foams: In coordination with the Harvard-FMRC series of full scale room fire tests, small scale studies of urethane combustion were undertaken. The now completed experiments provided empirical histories describing early fire growth. Calculations of the radiant heat transfer to the surface, using measured iemperatures, geometries, and specie concentrations were performed. Good agreement was obtained between the observed mass loss rate and that predicted on the basis of the radiation calculation. (Ref. 4 ). The soot volume fraction is a crucial parameter in such a calculation. Indeed, the gas phase contribution to the radiation was less than $10 \%$. Techniques were developed using laser absorption which permit direct measurement of the soot volume fraction in any flame. A report of giving volume fraction measurements for a wide variety of typical fire fuels is in preparation.

3. Flame Spread, Porous Media, Particulates: During this past year a graduate course in flame spread taught jointly with Prof. de Ris and with Profs. Sirignano and Williams as invited lecturers was offered. A preliminary report on laminar flame spread has been published (Ref. 6). Additional experiments and anaiytic work stimulated by the above course are under way. The work on heat and mass transfer in wet concrete has been completed (Ref. 3). Further work on postflashovers structural consequences of internal heat and mass transfer has been postponed to the next grant period. Study of particulate generation in premixed flames led to the development of a cooled flat flame burner wrich has potential application as a standard apparatus. A detailed report is in preparation.

Accomplishments

Much progress has been made on quantifying excess pyrolysis in systems which approach real fires. While much remains to be done, the extension to turbulent flames was a crucial step. The experimental study of urethane combustion may prove useful input to other fire modelers. It was shown that radiation very quickly ( $60 \mathrm{sec}$.) dominates convection as the major heat transfer mechanism in this pool-like fire. A simple accurate techrique to measure the soot volume fraction in a flame was developed. The flame spread course generated considerable enthusiasm among our graduate students. The heat and mass transfer in concrete study developed a relatively simple procedure to incorporate water vapor effects in structural elements subject ro fires; indeed, in many cases these effects are of secondary import.

Potential Applications

The study of excess pyrolyzate explains why fires fueled by synthetic plastics propagate so much more rapidly through structures than do those fueled by natural polymers. It also suggests the ability to rank polymers according to this specific hazard on the basis of flame height tests. A slight adaptation of the ASTM E-84 tunnel test might speed the practical use of these results. Radiation has been shown to be an often dominant mode of energy exchange in fires, however its quantification requires knowledge of the amount of soot in the flame. No theory to predict soot formation is currently avaiiable, consequently the experinientai techniques developed here 
may prove of important utility. The application of the heat and mass transfer study is that water vapor effects in concrete structural elements do not appear to be essential.

\section{Future Milestones}

Compartment fire applications of excess pyrolyzate remain to be quantified. The effects of flame radiation and external radiation on full scale burning fuel slabs will be incorporated in the near future. A more general analysis including variable ambient oxygen is also under way. The combustion process in the ceiling layer is of crucial import to the spread of the fire throughout the structure. Physical and mathematical models for this phenomena will be developed. Final reports will be forthcoming shortly on empirical histories of urethane combustion, flame spread experiments and analysis, heat and mass transfer in wet concrete and particulate formation in premixed flames.

\section{Publications}

1.) Păgni, P.J. and Shih, T.M., "Excess Pyrolyzate" Sixteenth Symposium (Int'1.) on Combustion. The Comb. Inst., in press.

2.) Pagni, P.J., "Flame Spread Over Thin Solid Fuels", Journal of Heat Transfer, 97c:1, 153, 1975.

3.) Sahota, M.S., "Heat and Mass Transfer in Porous Concrete Structures Subject to Fires" Report UCB-FRG-76-15, Fire Research Group, University of California, Berkeley, September 1976.

4.) P.J. Pagni, K.H. Clow, S. Bard and G. Heffner, "Observations on the Burning of Urethane Mattresses" Western States Section of the Combustion Institute, Paper No. 76-35. Also Report UCB-FRG-76-2, October 1976.

5.) C. K-Y. Chan and P.J. Pagni, "Flame Spread in Laminar Opposed Flow" Report UCB-FRG-76-8, Fire Research Group University of California, Berkeley, December 1976.

6.) T.M. Shih and P.J. Pagni, "Wake Turbulent Flames" American Society of Mechanical Engineers Paper No. 77-HT-97 to be presented at the AIChE -ASME Heat Transfer Conference, Salt Lake City, Utah, August 15-17, 1977. A7so Report UCB-FRG-77-4, April, 1977.

7.) T.M. Shih and P.J. Pagni, "Analytic Incorporation of Probability Density Functions in Turbulent Flames", submitted to the International Journal of Heat and Mass Transfer. Also Report UCB-FRG-77-3, April 1977.

8.) T.M. Shih and P.J. Pagni, "Laminar Mixed-Mode, Forced and Free, Diffusion Flames" submitted to the Journal of Heat Transfer. Also Report UCB-FRG-77-6, June, 1977.

9.) T.M. Shih and P.J. Pagni, "Excess Pyrolyzate from Diffusion Flames", Fire Research Group, University of California, Berkeley, Report UCBFRG-77-7, June, 1977. 
Institution: University of Calffornia, Berkeley

Grant No.: NBS Grant-G7-9006

Grant Title: Fire Safety in Urban Housing

Polymer Combustion and Flame Chemistry Task

Principal Investigator: Professor Robert F. Sawyer

Department of Mechanical Engineering

University of California

Berkeley, CA 94720

415-642-5573

Other Professional Personnel: Dr. Nancy J. Brown

William J. Pitz, Ph.D. Candidate

LInda Doppleb, M.S. Candidate

Project Summary: Experimental and theoretical studies of polymer combustion, flame inhibition, and flame chemistry are being pursued. Fundamental parameters (burning rates, extinction limits, mass transfer numbers, and flame structure data) have been obtained under well-controlled and reproducible conditions. These data have contributed toward a better understanding of polymer combustion mechanisms and the physical and chemical polymer properties which control flamability.

The flame inhibition research has been directed toward gaining an improved understanding of the inhibition mechanism(s) which prevails in different combustion environments. Experimental and theoretical flame chemistry studies have been concerned with providing chemical descriptions of various levels of complexity for premixed laminar flame systems.

Progress Report: The opposed flow diffusion flame has proven a useful laboratory tool for the study of the combustion of both liquids and solids. Quarititative determinations of burning rates, extinction limits, mass transfer numbers, polymer thermal diffusivity, and flame structures have been obtained under well-controlled and reproduceable conditions. The temperature and composition structure of the flame is of particular interest as detailed knowledge should yield a better understanding of the mechanisms of polymer combustion, physical and chemical polymer properties which control flammability, and approaches for polymer flame retardacion. The nature of the flame composition near the polymer surface should prove decisive in the resolution of the controversy over the importance of surface oxidation reactions in the combustion of polymers.

Since spatial resolution on the order of $100 \mu$ is desirable in extractive methods, assessment of the disturbance introduced by the microprobe is essential. Deflection mapping has been found to be a convenient means for deternination of probe influence. Interferograms of the flame without the presence of a sampling probe, in the presence of a sampling probe but without sample extraction, and in the presence of a sampling probe with sample extraction were obtained by the method of deflection mapping using a helium-neon laser light source. From the 
records produced, maximum fringe deflection contours were obtained, which Indlcate flame height changes due to probe effects.

Modelling studies of chemical flame inhibition in a hydrogen/oxygen tlame are underway. The kinetics of the hydrogen/oxygen systems have been extensively reviewed and a thirteen step reaction mechanism with approprlate rate data has been constructed to describe the systen. Flames are being studied at equivalence ratios of $0.5,1.0$ and 1.5, at 1.0 and .01 atmospheres. Blow out curves for the peraecty stirred reactor environment are being computed for the case of hydrogen chloride and hydrogen bromide inhibition. A plug flow, adlabatic reactor calculation is also underway to investigate the effiects of chemical inhibitors on peak radical concentrations, Individual radical concentration and mean spectes residence times. The use of an approximate code to describe premixed laminar flames is under consideration.

Work assoclated with the construction and demonstration of a two zone flame model has been completed and reported. The model allows for the computation of flame propagation velocity and average properties in the radical generation and fuel attack regions of a flame. The approach is sultable for inhibition calculations. A study of low pressure hydrogen/oxygen flames has also been completed and reported. This involved the careful analysis of flame structure to examine the branching mechanism, water formation mechanism and partial equllibriun approximarion. In addition various approximations for estimating radical concentrations in flames were compared. The flame model work and hydrogen/oxygen flame study were performed in collaboration with Dr. R. M. Fristrom of JHU/APL.

Accomp 11shments: A shear interferrometric optical system was developed and applied to the opposed flow diffusion flame for visualization of the disturbance caused by sampling probes. It was concluded that probe samples can be extracted without unacceptable affects on the flame structure and burning rate.

Much progress has been made in understanding flame chemistry and flame tnhibition. A zonal approach to flame structure has been devised which is useful for computing average properties of the radical generation and fuel attack reglons, flame propagation velocity and for treatment of flame inhibition. A review of hydrogen/oxygen kinetics has been accomplished. Branching and product formation mechanisms, partial equilibrium approximations, and techniques for estimating radical concentrations have been examined in low pressure hydrogen/oxygen flames. A fruitful collaboration has been malntalned with investigators from JHU/APL and the combustion research group at Gottingen.

Potential Applications: Determination of the mechanisms of polymer combustion will provide a foundation for the design of materials with low flammability characteristics. An improved understanding of flame inhibition will have useful applications in the development of flame retarded materials and in fire suppression methods. The work also applies to the development ard understanding of unambiguous test procedures.

Future Milestones: Flane structure measurements (temperature and composition) will be obtained with a polymer not containing oxygen to determine importance of oxygen diffusion to polymer surface to the burning process. The study of halogen inhibition in the opposed flow diffusion flame configuration will be pursued to determine the mechanism of inhibition. 
Reports and Papers:

Brown, N.J., Eberius, K.H., Fristrom, R.M., Hoyermann, K.M. and Wagner, H.Gg., "Low Pressure Hydrogen/Oxygen Flame Stud1es" (In press).

Brown, N.J., Fristrom, R.M., Sawyer, R.F., "A Two-Zone Model of Flame Propagation Applied to $\mathrm{H}_{2}+\mathrm{Alr}$ Flames and HCl Inhibited Flames" (in press).

Pitz, W.J. and Sawyer, R.F., "Deflection Mapping in the Study of Polymer Burning," Western States Section/The Combustion Inst1tute, Paper No. 77-21; also Un1versity of California Report UCB-FRG-77-5. 
Inst1tution: Department of Architecture, College of Environmental

Design, University of California, Berkeley

Grant Number: NBS Grant No. 6-9013

Grant Title: Human Behavior in Institutional Fires and Its Design Imp11cations

Principal Invest1gator: Lars Lerup, Architecture Life Safety Group, Center for Planning and Development Research, College of Environmental Design, University of Cal1fornla, Berkeley, 94720, Telephone 642-4942 (415)

Other Professional Personnel: David Cronrath, John K. C. LIu, Zahava Sternberg, and Harold Bexton (consultant)

Profect Summary:

Objectives

The goal of this project 18 to gain further understanding of the complex Interrelationships between human emergency actions and physical settings. The specific objective is to derive design Implications from the in-depth analysis of behavior in institutional settings under fire. The context and the data for this pursult are drawn from ten case studies of significant nursing home fires which occurred in the United States between 1970 and 1974 .

Approach

A working model describing the interaction of people and fire is developed. The method of analysis of the case studies is qualitative, based on a mapping technique developed specifically to facilitate the 
understanding and description of behavior in fires. The basic unit of analysis is human behavior in the form of behavioral eplsodes, the fire development in the form of diatinct states, and the interaction between the two in the context of a defined set of 11fe-saving actions. Progress Report: completed February 28, 1977 Accomplishments: The analysis of recurrent sequences of human actions Is inconclusive, only suggesting a repetition of certaln behavior patterns. However, recurrent types of behavior are distinct and do warrant further study. These are:

1. The tendency for staff to call the fire department even when it has already been notified.

2. The apparent need to investigate face-to-face and verify the existence and severity of the fire emergency.

The analysis of the ten case studies generated seven design implications concerning fire doors, holding and releasing systems, alarm systems, location of nurse statlons, egress systems, smoke detectors, and defense of nonambulatory patients.

An environmental approach to life safety and fire protection 1s suggested, in wh1ch knowledge, behavior and f1re-directed solutions are intimately connected.

Potential Applications: Although largely methodological, the study suggests that an environmental approach to life safety and fire protection In Institutional facilities would in its focus on simultaneous attention to education and the safety features of a facllity improve the potential of avolding a fire incident as well as improve life safety in case of an emergency. 
Other Related Work: The theoretical work undertaken in this study and the previous one has resulted in an exploratory primer for teaching architects about the fire phenomena: Learning From Fire: A Fire Protection Primer for Architects, Architecture Life Safety Group, 1977 (NrPCA Grant) Two papers have been prepared:

"Mapp1ng F1re and Behav1or" EKISTICS: The Problems and Science of Human Settlement8, July 1977

"Mapplng Fire: A Technique for Deplcting Dynamic Aspects of Environment and Behav1or", FIRE RESEARCH, July 1977 
Institution:

Grant Title:

Grant No. :

Principal Investigator

Other Professional

Personnel
University of California, San Diego

Flame Extinction in Relationship to Fire Suppression

NSF A EN-75-20997

Professor Forman A. Williams

Department of Applied Mechanics and Engineering Sciences

University of California, San Diego

La Jolla, California 92093

(714) 452-3172

K. Seshadri (Graduate Student)

Bernard Bregeon (Postdoctoral Fellow)

Alvin S. Gordon (Adjunct Professor)

\section{Project Summary}

The objective of this work is to develop an improved understanding of mechanisms of fire suppression by studying flame extinction in the presence of suppressive agents. Main suppressants considered are nitrogen, $C_{3} F_{3}$ and water. Principal configuration studied is the counterflow diffusion flame produced by directing an oxidizing gas stream, containing suppressant, downward onto the burning surface of liquid or solid fuel. Data include concentration profiles (obtained by sampling and gas chromatographic analysis), temperature profiles (measured with thermocouples) and extinction conditions (in terms of suppressant content and flow rate of oxidizer). Results are interpreted on the basis of theory which specifies a critical Damköhler number for extinction. Plan is to apply the theory to extract overall chemical kinetic information under conditions near extinction, to attempt to relate such information to chemical kinetic mechanisms underlying suppression, to ascertain differences in the thermal, flow and kinetic aspects of extinction by the different agents and to consider theoretical prediction of suppression under nonideal conditions.

\section{Progress Report}

During the past year work on ignition theory, on extinction theory and on theory of the structure of diffusion flames has been published, and progress has been made in experimental studies of near-limit phenomena in premixed systems and of extinguishment of diffusion flames above solid and liquid fuels. Since the theoretical work has been discussed previously, only references to the publications will be given here. The following discussion is restricted to experimental work.

Measurements were completed on nitrogen concentrations required to prevent downward propagation of hydrogen-oxygen and methane-oxygen flames in open tubes of 2.5 and $5.1 \mathrm{~cm}$ diameter. Limits plotted as functions of the fuel-oxygen ratio showed that quenching is most difficult on the fuel-lean side for hydrogen flames and near stoichiometric for methane flames. Cellular patterns were observed near 
flammability limits, and near-limit flame speeds were measured. Results have been interpreted mainly in terms of conductive losses from cellular flames since alternative mechanisms appear to produce qualitatively inconsistent predictions. Support for the interpretation is provided by Figure 1, in which the product of the flame speed and the cell size, divided by the thermal diffusivity of the mixture, is shown to be independent of the hydrogen-oxygen ratio at extinction, within the accuracy of the data. This independence is predicted by the model of conductive losses from cellular flames. Incidentally, the measurements definitely showed that the flame speed at extinction does not remain constant, independent of the hydrogen-oxygen ratio. This work was reported at a meeting of the Western States Section of the Combustion Institute.

Since polymethylmethacrylate is known to depolymerize largely to its monomer when heated, the chemical kinetics in the gaseous diffusion-flame produced by this polymer in a fire may coincide with that of burning liquid methylmethacrylate. To test this hypothesis, flat diffusion-flames were probed and extinguished adjacent to surfaces of each of these fuels. Profiles of temperature and of concentrations of stable chemical species were obtained - as were gas velocities of approach flow required to produce extinction, for various oxygen-nitrogen ratios of the stream. Results revealed structural differences attributable to differing thermal properties of the fuels. Many fuel species were observed in the gas phase, their profiles being partially rationalized on the basis of a suggested decomposition mechanism for gaseous methylmethacrylate. Representative concentration profiles for the polymer are shown in Figure 2. Overall kinetic parameters for gas-phase combustion, obtained by use of extinction results in a previously developed theory, as illustrated in Figure 3, are nearly the same for the polymer and monomer but appear to differ by amounts exceeding experimental uncertainties. It appears that this may be traced to small differences in fuel species leaving the condensed phase which, for the polymer, is covered by a thin, two-phase region. This work will be published in the Journal of Polymer Science.

Additional experimental work that has been completed includes extinction measurements for cellulosic fuels in the diffusion-flame apparatus and extinction of methanol and of heptane by application of water sprays in oxygen-nitrogen mixtures. The cellulose behaves in a relatively complex manner which differs for different types of materials (e.ge, Douglas fir differs from birch). Time-dependent effects are of paramount importance for these fuels. The water-application results appear to be consistent with the previous results, within the accuracy of the data, if it is hypothesized that the fine sprays employed vaporize prior to reaching the flame and merely act as diluents to the gas stream. These results are still being analyzed and will be reported more fully at a later time.

Accomplishments

1. Some clarification has been obtained for the influence of cellular-flame phenomena on extinguishment of downwardly propagating premixed flames in tubes.

2. The relationship between diffusion-flame combustion of polymethy1methacrylate and of its liquid manner has been clarified, it having been demonstrated that these fuels burn by gas-phase combustion mechanisms that have similar but not identical kinetics. 
Long-term applications of these results consist mainly in possible improvements in techniques for fire suppression. If developed through the present program these improvements will be derived from increased understanding of mechanisms of flame extinction, taking into account interactions between chemical kinetics, fluid flow and heat transfer. The work affords the possibility of extracting basic information on both the fluid mechanics and the chemical kinetics of combustion near extinction, which may be useful in analyzing extinctions under widely different conditions of burning and of suppressive action.

\section{Future Milestones}

The main milestone planned for the future is theoretical explanation of data on extinctions effected by application of halogenated suppressants. All other major aspects of the program either have been completed or are nearly completed.

The halon suppression work is largely theoretical and possesses an uncertain probability of success. Techniques that have been useful in extracting overall kinetic data from experiments on extinction by nitrogen addition will continue to be studied for possible application to data on extinction by halon addition, including further exercise of equilibrium chemistry routines for estimating ideal flame temperatures. If peculiar results persist, explanations will be sought through more detailed considerations of chemical kinetics. Experimentally, use of halons to extinguish solid fuels will be investigated for purposes of comparison with liquid fuels.

\section{$\underline{\text { Reports }}$}

1. L. Krishnamurthy, F. A. Williams and K. Seshadri, "Asymptotic Theory of Diffusion-Flame Extinction in the Stagnation-Point Boundary Layer", Combustion and Flame 26, 363-377 (1976).

2. L. Krishnamurthy, "On Gas-Phase Ignition of Diffusion Flame in the Stagnation-Point Boundary Layer", Acta Astronautica 3, 935-942 (1976).

3. R. W. Bilger, "The Structure of Diffusion Flames", Combustion Science and Technology $13,155-170$ (1976).

4. B. Bregeon, A. S. Gordon and F. A. Williams, "Near-Limit Downward Propagation of Hydrogen and Methane Flames in Oxygen Nitrogen Mixtures", WSS/CI Paper Number 76-51, Fall Meeting, Western States Section, the Combustion Institute, University of California, San Diego, La Jolla, Calif., October 18, 1976.

5. K. Seshadri and F. A. Williams, "Structure and Extinction of Counterflow Diffusion-Flames above Condensed Fuels: Comparison between Polymethylmethacrylate and its Liquid Monomer, both Burning in Nitrogen-Air Mixtures. Journal of Polymer Science, to appear.

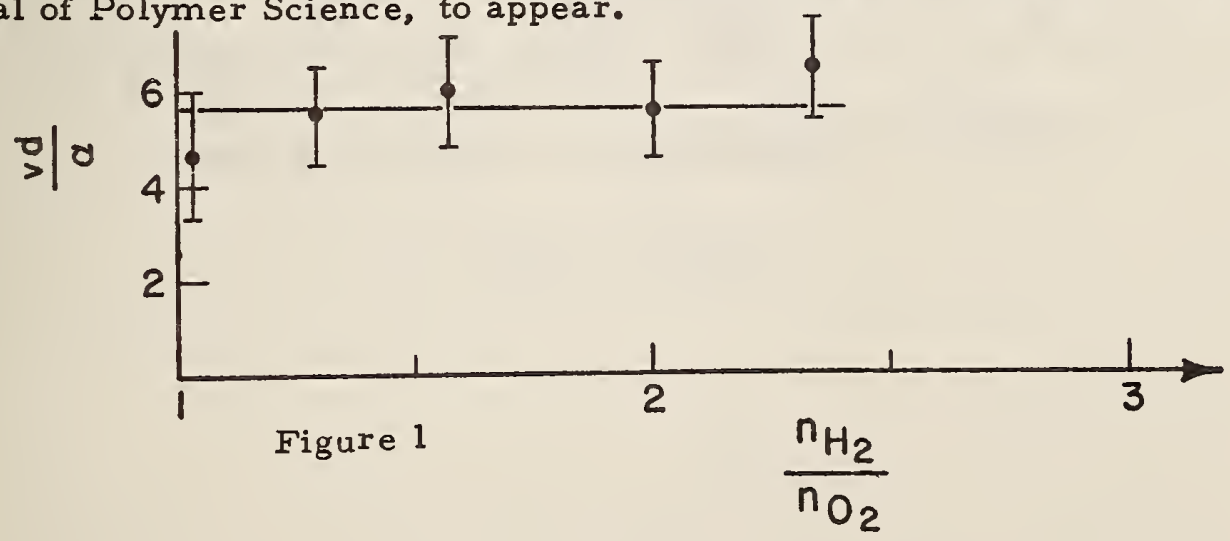


Polymethylmethacrylate

$$
\begin{aligned}
\mathrm{N}_{2} & \text { in } \mathrm{O}_{2} \\
Y_{\mathrm{O}_{2}} & =0.178 \\
U & =0.315 \mathrm{~m} / \mathrm{s}
\end{aligned}
$$

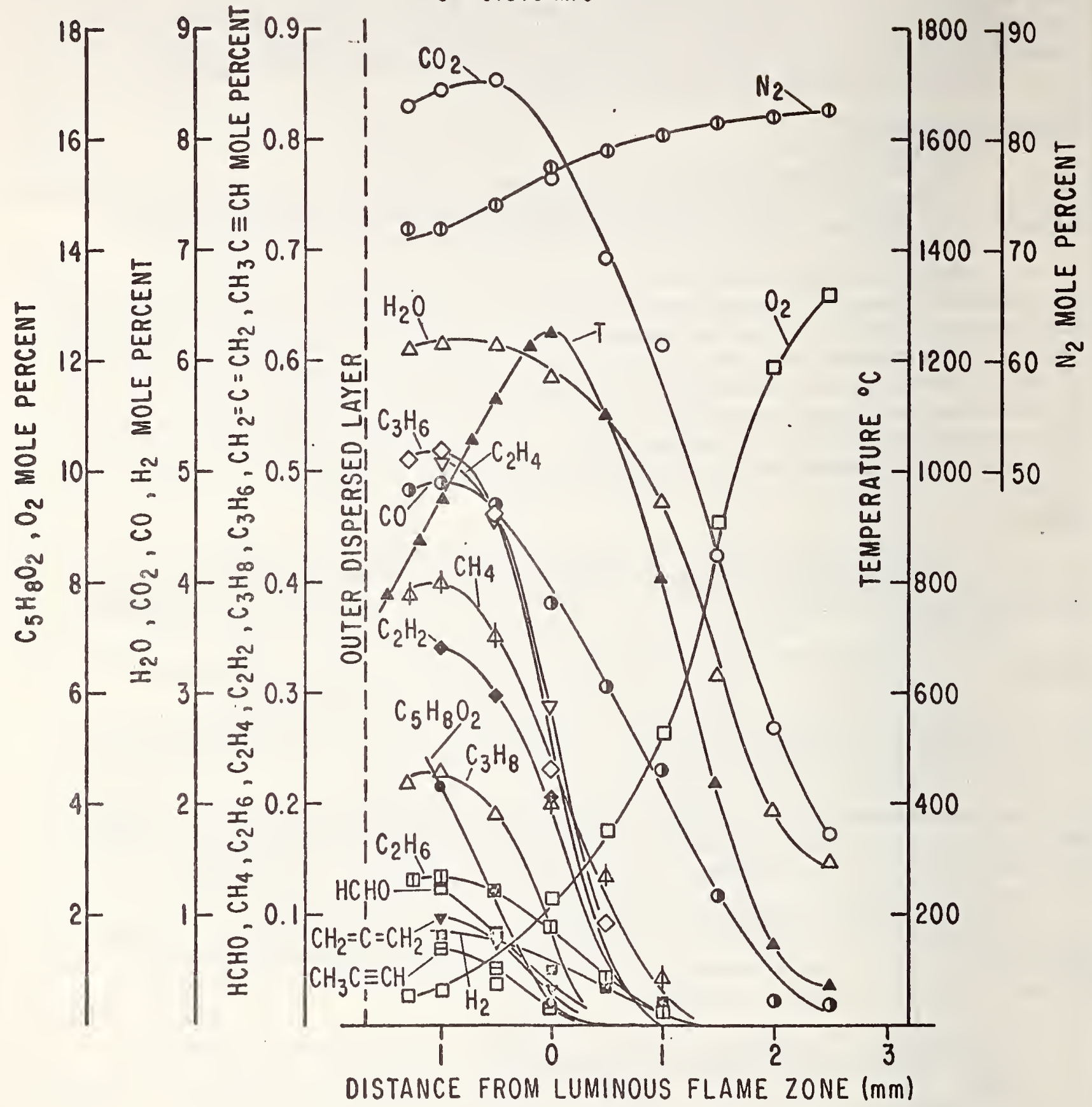

Figure 2 


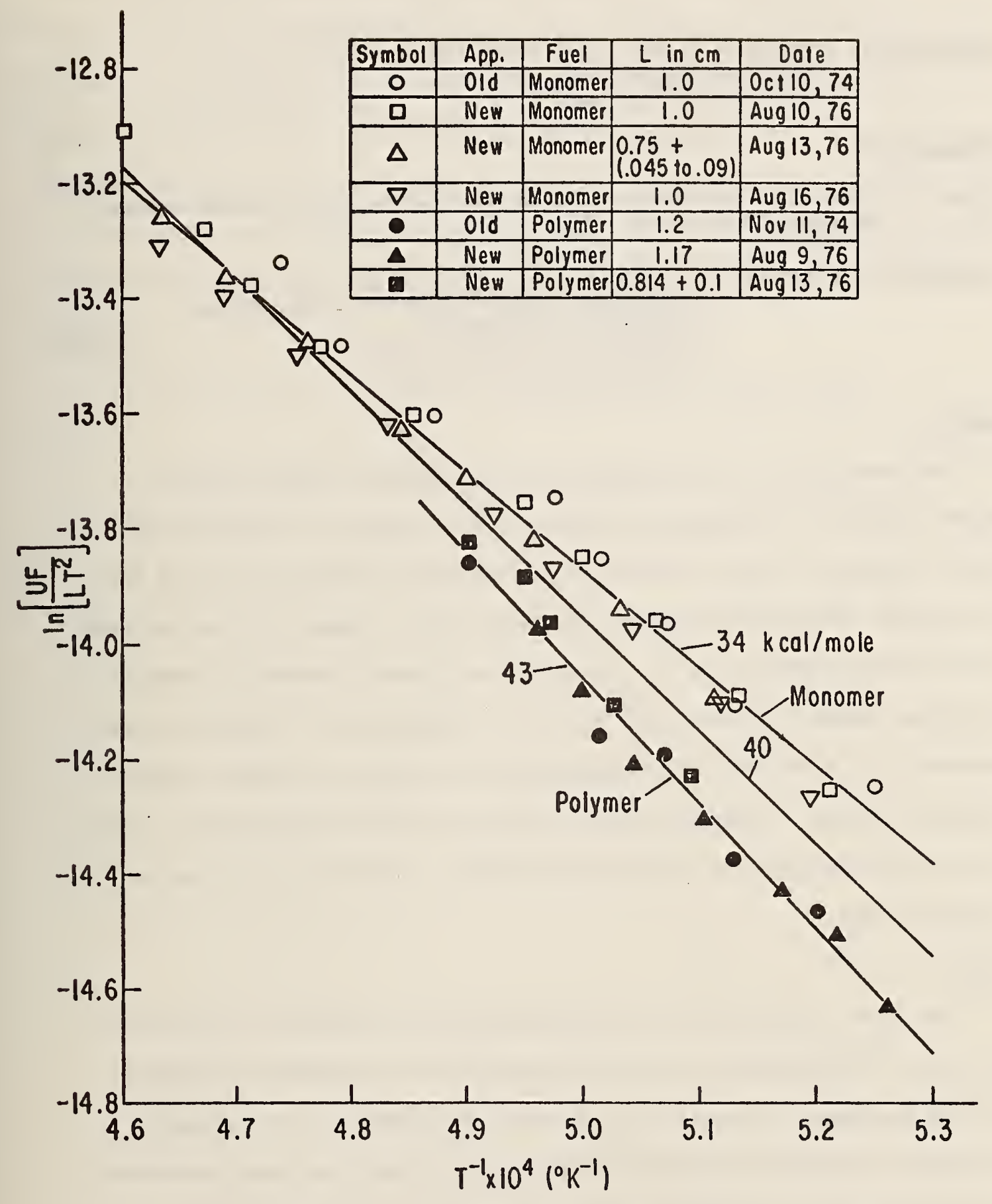

Figure 3 
Institution: Department of Fire Protection Engineering

College of Engineering

University of Maryland

NBS Grant No:

Title: A Theoretical Rationalization of the Goal Orlented Systems Approach to Building Fire Safety.

Principal Investigator: Jack Watts

Department of Fire Protection Engineering

University of Maryland

College Park, Maryland 20742

(301) $454-2424$

Summary:

The objective is to reformulate the GSA version of a Goal Oriented Systems Approach to Building Fire Safety. The research is being carried out in 5 phases. Phase I consists of a literature review and state of the art analysis of the Goal Oriented Systems Approach. Phase II is an analysis of the problem addressed by the Goal Oriented Systems Approach in terms of objectives, scope, the variables and their relationships. Phase III is the formulation of a revised Goal Oriented Systems Approach employing a sound theoretical basis. Phase IV is the evaluation of the revised model in terms of the avallable data and Phase $V$ will present a summary and conclusions of the research.

\section{Status:}

Four basic components of the problem have been identified in Phase II. These are: Pre-flashover fire, post-flashover fire, automatic sprinklers and fire barriers. In Phase III, the model will require a two parameter probability distribution for each of these components. The scale parameters will be calculated by deterministic relationships of the significant variables and the shape parameters will be derived by subjective evaluation 
of rellability features. A stress/strength rellability model w1ll then be applied to appropriate pairs of probability distributions to derive fallure probabilities for each spatial module in a fire scenario. Finally, a modification of the GSA combinatorlal model will compute the spatial probabilities of the limitation of fire spread.

Application:

This research will ascertain the theoretical validity of a new approach to fire protection design which is in current use.

\section{Reports:}

The Phase I report is being published by NBS as a grant report. 
Institution: Fire Protection Curriculum

College of Engineering

University of Maryland

NBS Grant No: 4-9027

Title: Smoke as a Determinant of Human Behavior in Fire Situations. (Project People)

Principal Investigator: John L. Bryan

Fire Protection Curriculum

College of Englneering

University of Maryland

College Park, Maryland 20742

(301) $454-2424$

Other Professional Personnel: David J. Icove, Harold D. Hicks, James A. Milke,

William P. Wheeler, and Jamie E. Weaver, Student Research Assistants, Fire Protection Curriculum.

Profect Sumary:

This study involved the interviewing of 584 participants by fire department officials at the scene of the fire incident. The study involved 335 fire incidents from eleven furisdictions, including the Cities of Baltimore, College Park and Annapolis, Maryland, and Alexandria, Virginia; with the Maryland and Virginia suburban jurisidictions of Arlington County, Falrfax County, Prince William County, Montgomery County, Howard County, Baltimore County, and Anne Arundel County. The fire incidents involved in the study occurred between January 15, 1975, and April 30, 1976.

The analysis and study of the interview data from the 584 participants, in the 335 fire incidents involved the determination of the critical variables relative to the fire incidents 1nvolving: The occupancy of the building; The number of previous alarms in the building; The amount of smoke spread in the bullding; The time of the fire incident, and the height of the bulldings involved in the fire incidents. 
The participant population parameters were determined relative to the following demographic and empirical variables: The participant's sex; The participant's age; The participant's occupation; Previous training relative to fire situations; Previous experience in fire incidents; The participant's location in the building at the time of the fire; The means by which the participants became aware of the fire incident; Persons with the participant; Time of the participant's presence in the bullding; and the belief of the participant in the safety of the building.

The first, second and third actions of the participants after becoming aware of the fire incident were analyzed and compared relative to third actions. The variables of the participants relative to their distance from the fire, their belief in the safety of the building, the number of previous alarms in the building, and the extent of smoke spread were all compared with the selection of first actions. The selection and utilization of first actions were also compared relative to the participant's previous fire experience, and their previous training for fire incidents. The first, second, and third actions of the participants were also analyzed relative to any differences in the actions of the participants according to the sexual distribution of the participant population.

The various aspects of the participants movements through the smoke in the fire incidents were analyzed and compared. The first actions of the participants were considered relative to the smoke spread in the fire incident building. The evacuation time and the distance of evacuation movement for the total participant population and the participants that moved through smoke were compared. The evacuation distance relative to the time of occurrence of the evacuation were also compared. The distance of the participants movements through smoke were compared for the participants with and without previous fire experience, the participants with and without 
previous training, and the sexual distribution of the participants. The number of the participants who were forced to turn back in their movement through the smoke were compared relative to the previous fire experience, the previous training and the sexual distribution of the population. The viaibility distance of the participants was also compared with the movement through smoke and the turned back behavior of the participants.

The critical aspects of this study were compared with aspects of Wood's study on the British population consisting of 952 fire incidents and 2193 participants. Data from both studies were compared relative to the characteristics of the fire incidents, the participant populations, and the actions of the participants. The occupancy of the fire incident bullding, the time of the fire incident, the floor of origin of the fire Incident, and the extent of the smoke spread within the building, were compared for both studies. The reported sexual distribution, age distribution, and the means by which the participants became aware of the fire incident were compared for both of the participant populations. The actions of the participant population were compared from both studies relative to the first, second and third actions of the respective population. The first actions of both populations were compared relative to the male and female members of the respective populations. The percentages of the populations relative to the reasons for reentry behavior were also compared. The occurrence of the reentry, fire fighting, evacuation, movement through smoke, and the turned back behavior for both populations were also compared. The visibility distance for both populations was compared relative to the movement through smoke and the turned back behavior. 


\section{Progress Report:}

Project has been completed, and final report submitted, June 30, 1977.

Accomplishments:

The study results and conclusions provide verification of previous Investigations, and differences between British and American populations.

The study has provided a basic format for the collection and analysis of behavioral information from participants in fire incidents in future studies. Potential Applications:

The questionnaires developed in the study and the computer analysis procedures should have application in other studies. The introduction of the sequential analysis of the behavioral actions of the participants with the technique of weighted diagraphs may be adapted to related projects.

Reports and Papers:

Bryan, John L., "The Determination of Behavior Responses Exhibited in Fire Situations," The Journal of Fire and Flammability, VII, (July, 1976), 319-336.

Bryan, John L., "Human Behavior in Fire Situations," Presented at the Second Jolnt Panel Meeting on Fire Safety and Research, UJNR; Tokyo, Japan, October 20, 1976 .

Bryan, John L., "Project People - A Study of Human Response in Fire Incidents," Presented at Fourth International Symposium on Flammability and F1re Retardants, Washington, D.C., May 20, 1977. 
Proceedings of a Conference Held at NBS, Gaithersburg, Md., August 3-5, 2977,

Institution: Fire Protection Curriculum

College of Englneering

University of Maryland

NBS Grant No.: $6-9008$

Title: The Examination of Selected Systemic Varlables Influencing the

Discharge Distribution Pattern from Automatic Sprinkler Heads.

Princ1pal Invest1gator: John L. Bryan

Fire Protection Curriculum

College of Engineering

University of Maryland

College Park, Maryland 20742

(301) 454-2424

Other Professional Personnel: Craig L. Beyler, Research Assistant, Fire Protection Curriculum.

James M. Thompson, Harry L. Bradley, Robert C. Beller, and Edward B. Douberly, Student Research Assistants, Fire Protection Curriculum.

Project Summary:

The effects of flow rate, supply pipe size, direction of supply, deflector to celling clearance, orlentation of sprinkler arms, angles of the sprinkler head, and sprinkler guards on the distribution of water from sprinkler heads have been studied. Implications for the design of sprinkler heads and systems have been 1dentified.

\section{Progress Report:}

Initial profect has been completed, and three volume final report submitted June 30,1977 . Additional analysis of related study data is to be completed in August, 1977.

\section{Accomplishments:}

The study reports and conclusions have provided some significant insights into the relationships of the flow from automatic sprinkler heads as follows:

1. Distribution patterns from upright and pendent heads are dissimilar.

2. The coverage area or area within a given isodensity line of both upright and pendent heads have a maximum which is approached asymptomatically. 
3. A minimum feasible coverage area can be defined given a required density. At flow rates below that ylelding the minimum feasible coverage area, the coverage area is not yet developed and could not provide adequate coverage regardless of sprinkler spacing.

4. Unsteadiness and turbulence in the nozzle stream improves the distribution pattern.

5. The Reynold's Number of the flow in the supply pipe has an important effect on distribution patterns.

6. Sprinkler arms are an important determinant of the distribution pattern.

7. Sprinkler guards reduce the area of coverage of sprinkler heads.

8. Sprinkler spacing rules should be derived from sprinkler distribution patterns to provide for optimum system performance.

Potential Applications:

The procedures from the measurement of the flow from the automatic sprinkler heads may be applicable to further studies with consideration of the following adaptations from this study:

1. The radial collection container array is an excellent method of collection for single heads. However, when superimposing patterns to generate multiple head distribution patterns, the rectangular arrays is far simpler.

2. Stopping test to empty containers directly below the sprinkler head and supply pipe should be avoided bacause the data points $103 t$ are not important and the practice of restarting tests may induce error.

3. Isodensity comparisons, numerical overaly comparisons, and side by side comparisons of distribution patterns are all useful analytic tools.

Reports and Papers:

Beyler, C. L., The Effect of Selected Enviromental Varlables on The Distribution of Water from a Sprinkler Head. Paper accepted for The Seventh CIB Congress and General Assembly, Fire and Bulldings: September 14-21, 1977, Ed1nburgh, Scot1and.

Beyler, Craig L. and Richard L. P. Custer, "An Engineering Analysis of Actual Discharge from Sprinkler Heads," presented at The National Fire Protection Association, 81st. Annual Meeting, Washington, D.C., May 17, 1977.

Beyler, Craig L., "An Evaluation of Sprinkler Discharge Calculation Methods," Fire Technology, XIII, 3, (August, 1977), accepted for publication. 


\section{FLAME SUPPRESSION}

BY

CHEMICAL INHIBITORS

INSTITUTION: University of Massachusetts

GRANT NO: $\quad$ G $7-9010$

SOURCE OF FUNDS: NBS

PRINCIPAL INVESTIGATORS:

Marce] Vanpee

Chemical Engineering Dept.

Univ. of Massachusetts

Amherst, MA 01003

$\mathrm{Tel}$ : (413) 545-0593
James C. W. Chien

Polymer Research Institute

Univ. of Massachusetts

Amherst, MA 01003

Tel : (413) 545-2704

\section{PROJECT SUMMARY}

GOALS

This research is a systematic search for better inhibitors than

those currently in use. The program primarily has implications for flame retardancy in polymer burning but, by nature, will also apply to the problem of fire suppression in general.

The work is clearly divided between the two principal investigators. Professor Vanpee will study the effect of inhibitors on the propagation of flame and chemical processes in the gaseous phase. Professor Chien will investigate the effect of inhibitors and pyrolysis, oxidative pyrolysis and charring of the polymers.

In an extended phase of the program, we envision studying in some depth the mechanism of flame inhibition of selected additives of particularly high efficiency. Examples of such types of inhibitors are the compounds of lead, alkali metals and transition elements. 


\section{APPROACH}

In the search for new inhibitors emphasis is put on devising new test methods for evaluation of flame inhibition efficiency. Two new approaches are summarized here.

\section{Atomizer Diffusion Burner}

Liquid fuel is dispersed through a nozzle in the form of a spray of finely dispersed droplets, and is ignited in an atmosphere of N2/02 of controlled oxygen index. The additive is dissolved in the fuel. Its efficiency is then measured by the oxygen index method.

\section{Counter diffusion liquid burner}

The special burner designed by F. Williams, et. al. (1) to study the burning of liquid fuel will be used also to assess the efficiency of flame inhibitors.

\section{PROGRESS REPORT}

This research is a continuation of an inhouse program. Our progress report will therefore not be limited to the work accomplished during the 2 month period that this grant has been effective, but will include our previous work. Also included will be unpublished results of the authors' (Vanpee) earlier research on flame inhibition of interest to this meeting.

\section{Earlier work in flame inhibition}

Earljer work on flame inhibition by the author had to deal with the suppression of afterburning in rocket exhaust by metal components. The experiments were carried out in the following way: The additives were

(1) Extinction of Laminar Diffusion Flames for Liquid Fuels - J.A. Kent and F.A. Williams, Fifteenth Symposium (International) on Combustion p. $315(1974)$. 
dispersed in a rich ethylene-oxygen-nitrogen mixture while it was undergoing explosion in a closed spherical vessel. A quick-opening valve released the fuel rich products to the atmosphere where they produced an afterburning flame. Reduction in afterburning flame duration by increasing amounts of powdered additive was used as the criterion for inhibition efficiency. A total of 40 additives were tested including many salts of the alkali metals. Potassium salts prove to be the best flame suppressants in general and were greatly superior to iodine, one of the best known inhibitors.

Lithium salts were normally less efficient than the potassium salts with one exception, $\mathrm{Li}_{3} \mathrm{~N}$, which was 5 times more efficient than $\mathrm{K}_{2} \mathrm{CO}_{3}$ the most efficient salt of the potassium series.

The effect of increasing amounts of additive on the afterburning flame is illustrated in Fig. I for $\mathrm{K}_{2} \mathrm{CO}_{3}$. This work was reported partially in Progress in Astronautics and Aeronautics(2).

2. Current Results

I. Tests with the atomizer diffusion burner

The work on afterburning leads us to pursue our investigations on the salt of the alkali. The candidate salts were dissolved in liquid fuels (methanol, ethanol and benzene) and the solutions were burned in an atmosphere of oxygen and nitrogen, in the form of a spray of fine liquid droplets, produced by an atomizing nozzle. The effectiveness of an additive salt was measured by the limiting oxygen index method. Typical results

(2) Inhibition of Afterburning by Metal Compounds - M. Vanpee , R. N. Tromans and D. Burgess. Progress in Astronautics and Aeronautics, 15, 419 (1964). 
obtained by this method are shown in Fig. 2 for various additives in a methyl alcohol flame. The best additives were: lead tetracetate, ferric acetylacetonate, benzene chromium tricarbonyl, rubidium hydroxide, potassium hydroxide and ferrocenes.

In the grouping of the alkali hydroxides, it was found that:

a) At low concentrations, the order of effectiveness was:

$$
\mathrm{Rb}>\mathrm{K}>\mathrm{Na}>\mathrm{Li}>\mathrm{Cs}
$$

b) At relatively high concentrations ( $>5 \% \mathrm{Wt}$ ), their effectiveness was

in the order of their atomic masses as follows:

$$
\mathrm{Cs}>\mathrm{Rb}>\mathrm{K}>\mathrm{Na}>\mathrm{Li}
$$

\section{Counter diffusion liquid burner}

During the first 2 month period that this grant has been effective we have built and tested a counter diffusion liquid burner similar to the one designed by $F$. Williams and Kent. $(1)$ A flow of oxidizer (air or $\mathrm{N}_{2} / \mathrm{O}_{2}$ mixtures of various compositions) of uniform velocity is directed toward a circular fuel surface and produces, when ignited, a flat diffusion flame close to the surface of the burning liquid. We intend to use this burner to investigate the effectiveness of inhibitors when added to the liquid fuel.

Limiting oxygen index (LOI) will be used to screen the various candidates. LOI is the mole fraction of 0xygen at the extinction of the flame. LOI will be determined for various additive concentrations in the 1 iquid fuel and the effectiveness will be determined by the slope of the plot of LOI versus the additive concentration. The flat flame geometry is particularly helpful because extensive mathematical modelling has been done on the extinction of flat laminar diffusion flames by Williams et al! (3) The analys is is based on (3) Krishnamwithy, L., Williams, F. A., and Seshadri, K., Combustion and Flame, 26, 363 (1976). 
the observation that extinction occurs when the Damkohler number is below a critical value. The method described will be used to determine the kinetic parameters of the fuel in the presence of the inhibitor. Thus a correspondence between flame inhibition and reduction in kinetic parameters could be sought.

\section{Test methods for the evaluation of pyrolysis inhibition efficiency}

The principal chemical events occurring in the solid polymer during combustion are thermal pyrolysis in regions devoid of oxygen and oxidative pyrolysis in regions containing dissolved oxygen. At the University of Massachusetts we have a unique thermoanalytical laboratory specially suited for such investigation.

The facility includes a CMEX MP-3 and a CDS 820 apparatus which permit the pyrolysis of polymer from $4 \%$ min to $20,000 \% \mathrm{sec}$ in inert or reactive atmosphere such as oxygen. The polymer sample is held at the reaction temperature for predetermined length of time. The products are collected in a liquid $\mathrm{N}_{2}$ trap, back-flushed into a master GC. The eluents from the master GC are on-line identified by a SPEX MC-2 Mass Chromatograph, a CDS 1200 peak identifier and a Perkin-Elmer Mass Spectrograph. The entire system is interfaced with a PDP II/IOE minicomputer for data acquisition. With the above system, the products of pyrolysis and oxidative pyrolysis can be identified, their abundance quantitatively analyzed, and the kinetics of their formation determined. The effect of an inhibitor on each product by either pyrolysis or oxidative pyrolysis can be individually evaluated. 
Figure 3 compares the product distributions of thermal pyrolysis of normal and transition metal inhibited polypropylene at $438^{\circ}$. Figure 4 compares the product distributions of oxidative pyrolysis of these materials at three temperatures. These figures show that most of the products are suppressed by the inhibitor at a very low level of $0.4 \%$.

\section{Reports}

N. X. Hung

A Study of Flame Retardation for Polymer Systems M.S. Dissertation, University of Massachusetts.

J. C. W. Chien and J. K. Y. Kiany

Pyrolysis and Oxidative Pyrolysis, To be Published in J. Polymer Sci. 

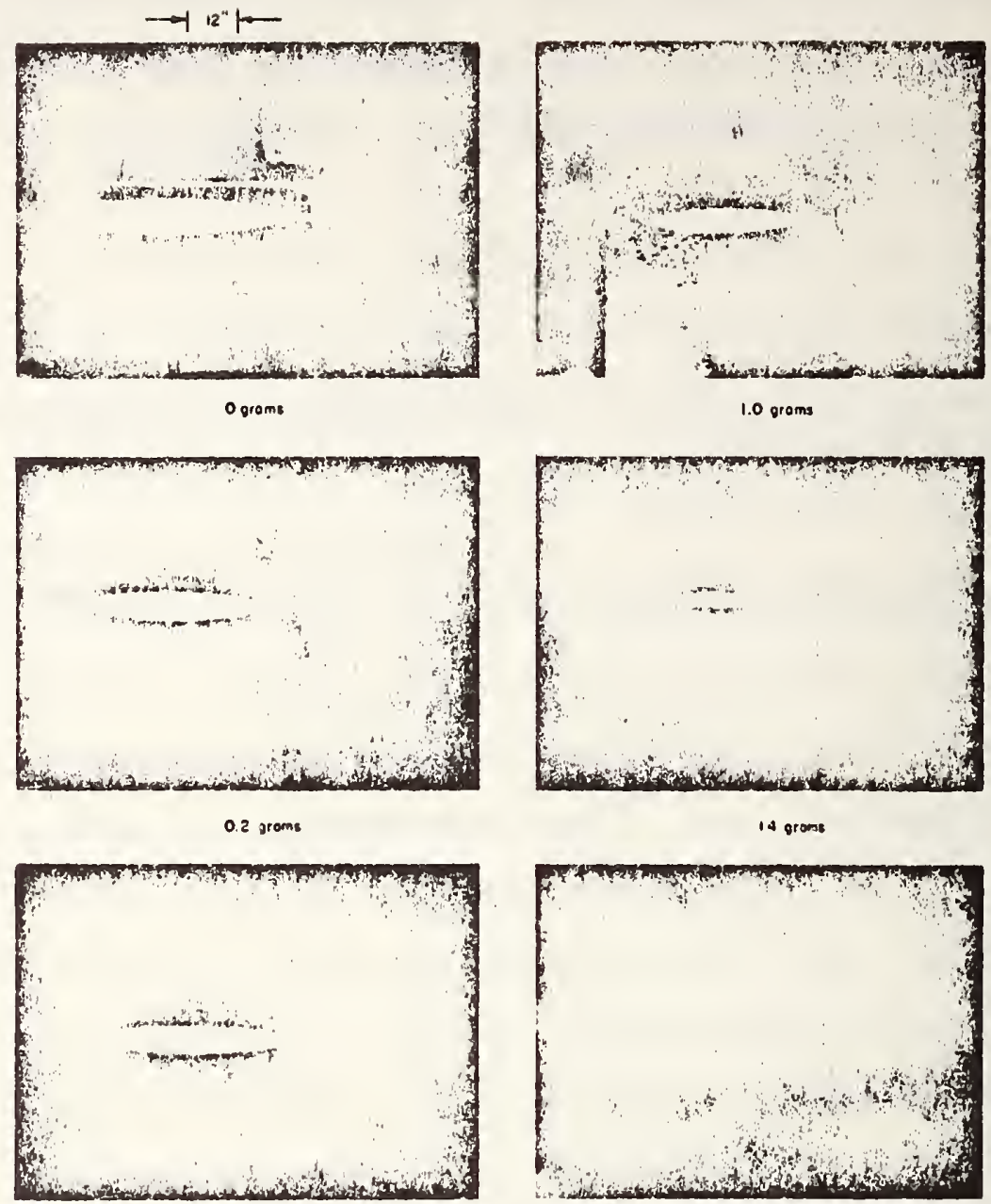

0.8 groms

2.0 gram

Fig. I Photographs of afterburning flames showing the effect of increasing amounts of $\mathrm{K}_{2} \mathrm{CO}_{3}$ additive. 
Figure 2. Linjiting Oxyren Index vs. Concentration

For Metallic Additives in Metharol

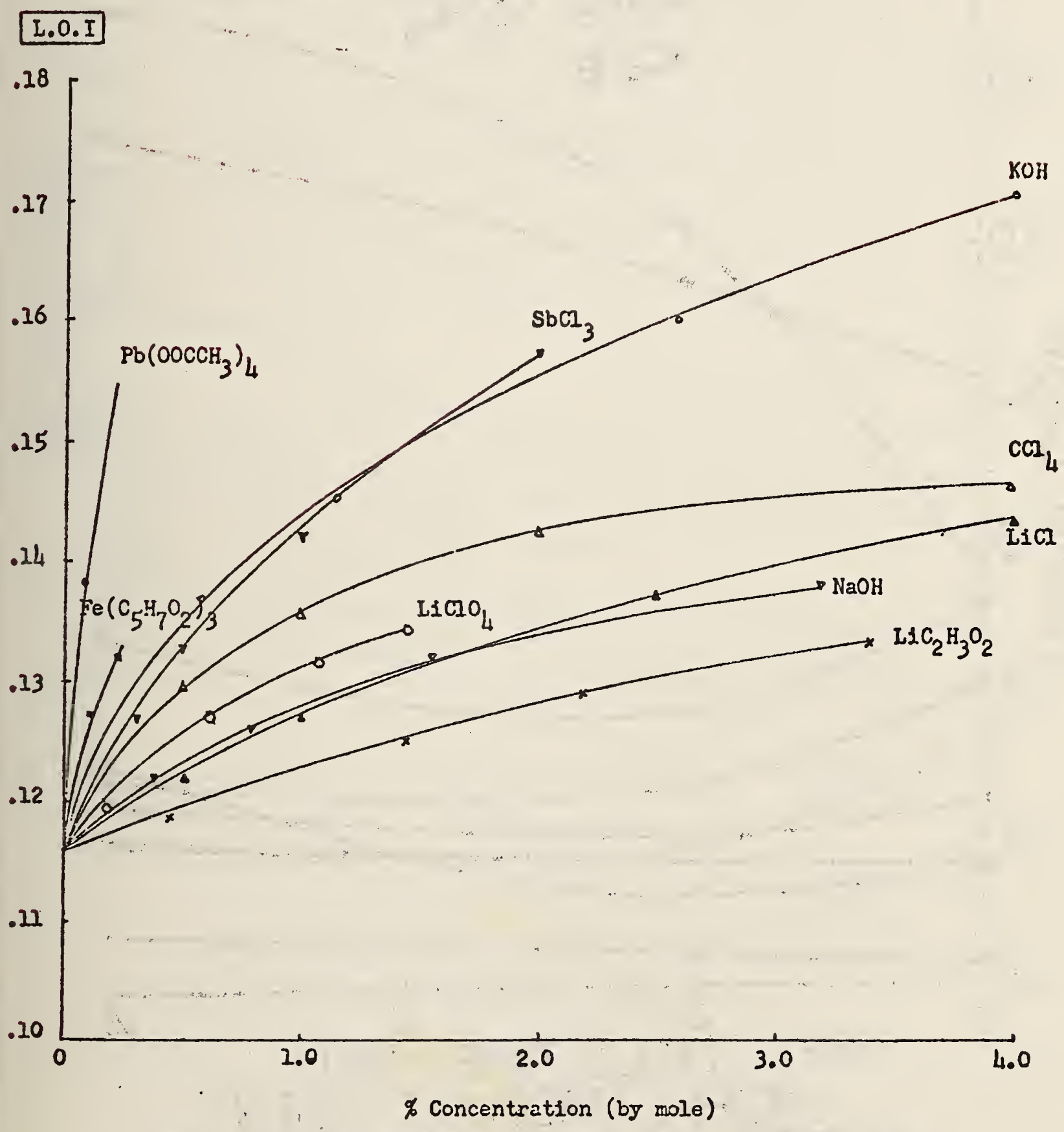




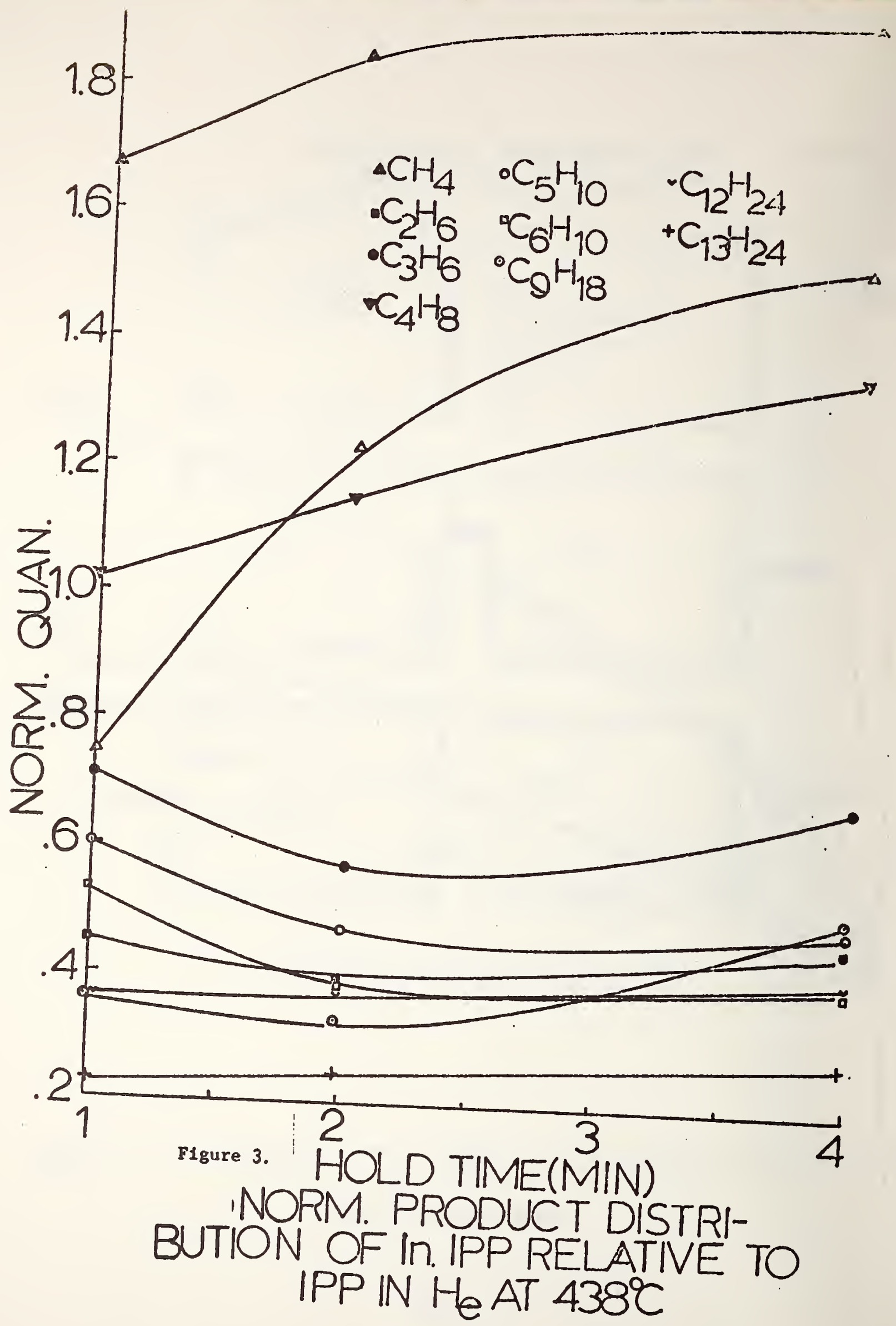




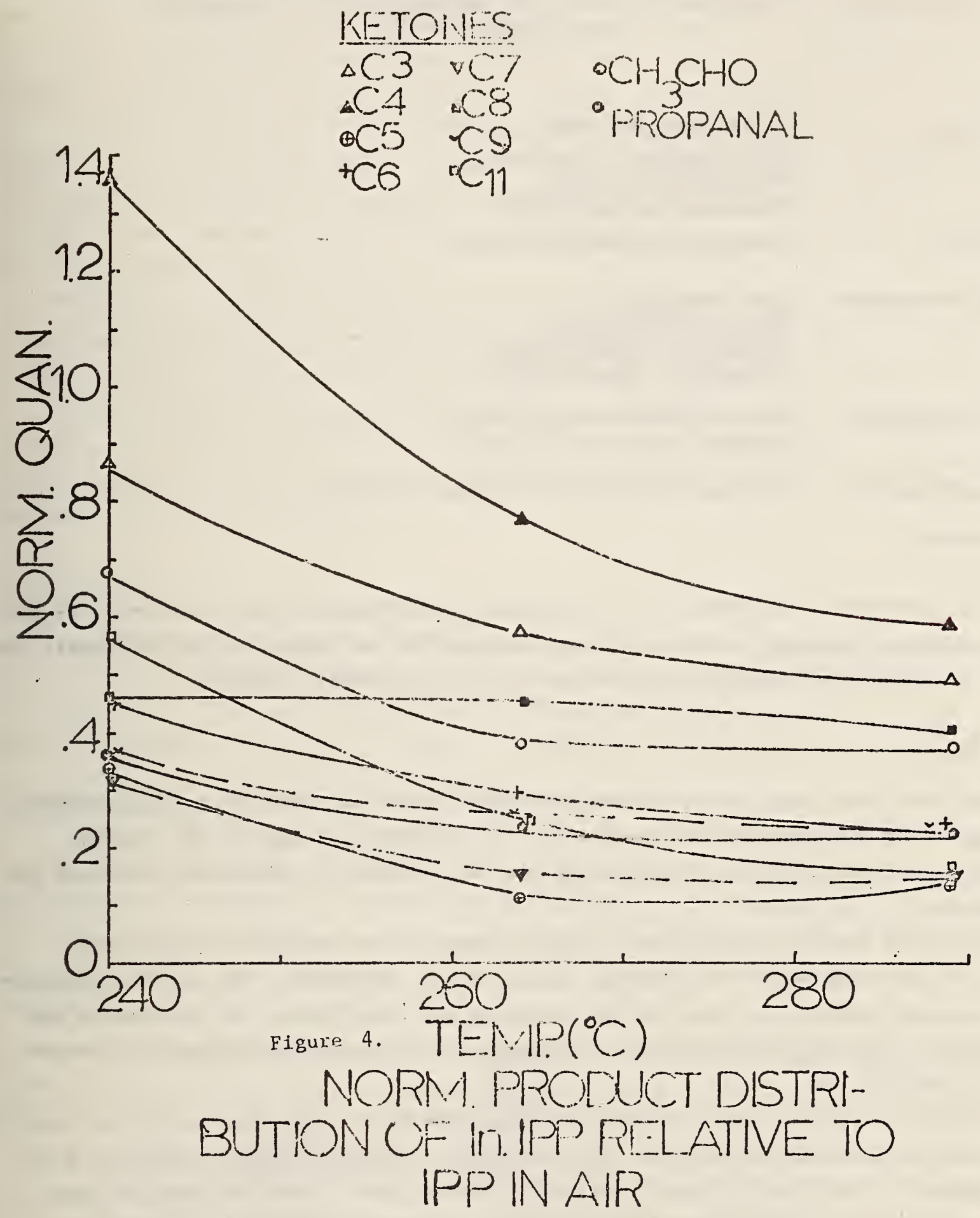


Institution:

Grant Title:

Principal Investigator: Fred Shafizadeh

Research Assoctates:

Research Assistants:

Project Summary:
University of Montana

Missoula, Montana 59812

Telephone: 406-243-6212

NFPCA Grant No. 76026

Wood Chemistry Laboratory

University of Montana

Missoula, Montana 59812

Chemistry of Cellulosic Fires

Peter P.S. ChIn, Allan G.W.

Bradbury and Peter J. Lieu

W1lliam F. DeGroot and Thomas W. Aanerud

The objectives of this project are to systematically determine the transformations and chemical reactions involved in the inftiation, propagation and suppression of cellulosic fires in order to provide a scientific basis for coping with the related problems.

\section{Progress Report:}

It has been shown that aclds or flame retardants, which can generate acldic compounds on heating, lower the decomposition temperature of cellulose and suppress the flaming combustion by reducing the rate of production and total amount of combustible volatiles and taxry products.

Chlorine and phosphate derivatives, whether present as an additive or substituent, mainly act in the same manner by releasing related acidic materials. The detailed mechanism of the reactions involved was shown by the synthesis and investigation of chlorinated and phosphorylated sugar derivatives as model compounds and cellulose derivatives with various degrees of substitution.

In view of the role of acid catalysis in flameproofing of cellulosic materials, these studies have been extended to wood and 1 ts other major components, mainly 11gnin and xylan (hemicellulose). The effect of zinc chloride on the pyrolysis of wood is shown in Table I.

It was found that on high temperature pyrolysis, dlammontum phosphate is much more effective than phosphoric acid in catalyzing the dehydration and charring reactions. Investigation of this synergistic effect indicate that at temperatures of more than $200^{\circ}$, diammonium phosphate decomposes to produce ammonia and phosphoric acid derivatives. The acidic products catalyze the breakdown of the cellulose macromolecule and its reaction with ammonia to produce ammoniated compounds; most likely glycosylamines and related derivatives formed by interaction of newly formed carbonyl compounds and ammonta. The ammonlated 
compounds on further heating dehydrate to produce a stable char as shown for glycosylamines. Analysis of cellulose samples heated at various temperatures in the presence of diammonium phosphate or ammonia and phosphoric acid demonstrated the production of ammoniated derivatives and the synergistic effect of nitrogen and phosphorus derivatives.

Addition of flame retardants not only results in partial combustion of cellulosic materials, but also decomposition at lower temperatures, which alters the rate of release of combustible volatiles and the heat of combustion as a function of temperature. Therefore, the rate of heat release could be used for evaluation of flame retardants and ignitability of cellulosic materials in general.

Originally, a flame ionization detector (FID) was used for thermal evolution analysis of cellulosic materials with or without flame retardants and the results were calibrated to provide the heat of combustion of the volatile pyrolysis products as a function of temperature.

In the subsequent experiments, reaction coulometer, which measures the amount of oxygen required for combustion, was adapted for measurement of the heat release. This system provides a reliable and unique method for analysis of various cellulosic fuels involved in propagation of hazardous fires.

Ac complishments :

1. The catalytic effect of common fire retardants in reducing flammability of the cellulosic materials by altering their pyrolysis products has been established.

2. A method has been developed for evaluating the flammability of cellulosic fuels by measuring their rate of heat release as a function of temperature.

\section{Potential Applications:}

The basic information developed in these studies provides a guideline for reducing the fire hazards by chemical treatments and measurement of the flammability of cellulosic fuels.

\section{Future Milestones:}

1. Analysis of wood products before and after treatment with commonly used flame retardants to determine their flammability and variation in production of smoke and toxic gases.

2. Determine a chemical description of the reactions involved in smoldering combustion of cellulosic materials. 
1. F. Shafizadeh, Y. Z. Lai and C. R. McIntyre, "Thermal Degradation of 6-Chloro Cellulose and Cellulose-Zinc Chloride Mixture," J.Appl. Polym. Sci., in press.

2. F. Shafizadeh and W. F. DeGroot, "Combustion Characteristics of Cellulosic Fuels," Therma1 Uses and Properties of Carbohydrates and Lignins, F. Shafizadeh, K. Sarkanen and D. Tillman, Editors, Academic Press, New York, 1976.

3. F. Shafizadeh and P. P. S. Chin, "Thermal Deterioration of Wood," ACS Symposium Series, No. 43, Wood Technology: Chemical Aspects, 1977.

4. F. Shafizadeh and P. P. S. Chin, "Preparation and Characterization of 1,6-Anhydro-3,4dideoxy-B-D-glycero-hex-3-enopyranos-2-ulose," ACS Symposium Series, №. 39, Snythetic Methods for Carbohydrates, 1976.

5. R. A. Susott, F. Shafizadeh and T. W. Aanerud, "Determination of Heat Release by Reaction Coulometry," manuscript prepared for publication.

6. F. Shafizadeh and P. P. S. Chin, "Effect of Phosphate Derivatives on Pyrolysis and Combustion of Ce11ulose: 1. Dipheny1 phosphate. 2. Diammonium phosphate," manuscript being prepared for publication.

7. F. Shafizadeh, "Combustion and Flameproofing of Cellulosic Materials," a paper presenter at the 172nd National American Chemical Society Meeting, San Francisco, California, August 30 September 3, 1976.

8. F. Shafizadeh, P. P. S. Chin, and W. F. DeGroot, "Application of TEA for Evaluation of Flammability and Flameproofing," a paper presented at the Fourth International Conference on Non-Flammability of Polymeric Materials," Bratislava, September 14-16, 1976 .

9. F. Shafizadeh, "Combustion, Combustibility and Heat Release of Forest Fuels," a paper presented at the 69 th Annual Meeting of American Institute of Chemical Engineers, Chicago, I1linois, November 28 - December 2, 1976. 
Table I. Pyrolysis Products of Cottoliwood at $600^{\circ}$.

\begin{tabular}{|c|c|c|}
\hline Product & Neat & $+5 \% \mathrm{ZnCl}_{2}$ \\
\hline Carbon monoxide & $4.0^{a}$ & 3.6 \\
\hline Carbon dioxide & 5.8 & 5.5 \\
\hline Acetal dehyde & 2.0 & 4.4 \\
\hline Furan & 0.7 & 7.9 \\
\hline $\begin{array}{l}\text { Acetone } \\
\text { Propionaldehyde }\end{array}$ & 1.5 & 0.9 \\
\hline Propenal & 2.9 & 0.9 \\
\hline Methanol & 1.4 & 2.7 \\
\hline 2-Methy? furan & $b$ & b \\
\hline 2,3-Butanedione & 2.4 & 1.0 \\
\hline 1-Hydroxy-2-propanone & 2.7 & $T$ \\
\hline Glyoxal & 2.2 & $\mathrm{~T}$ \\
\hline Acetic Acid & 5.7 & 5.4 \\
\hline 2-Furaidehyde & 1.3 & 5.2 \\
\hline Formic Acid & 0.9 & 0.5 \\
\hline 5-Methy $1-2$-fural dehyde & 0.3 & 0.9 \\
\hline 2-furfuryl alcohol & 0.6 & $T$ \\
\hline Guaiacol & 0.6 & $T$ \\
\hline Phenol & 1.2 & $T$ \\
\hline $\mathrm{p}$-Cresol & 0.5 & $T$ \\
\hline Water & 15.9 & 19.3 \\
\hline Tar & 27.9 & 19.6 \\
\hline Char & 17.3 & 53.6 \\
\hline
\end{tabular}

apercentage, yield based on the weight of the sample; $T=$ trace amounts. $b_{\text {Not clearly identifiable for wood. }}$ 
Institution

University of Notre Dame

Grant Title

Fire and Smoke Spread

Project Coordinator

Dr. K. T. Yang, Professor and Chairman, Department of Aerospace and Mechanical Engineering, University of Notre Dame, Notre Dame, Indiana (219) 283-7466

Principal Investigator

Dr. J. R. Lloyd, Associate Professor (219) 283-7198

Co-Investigators

Dr. A. M. Kanury, Associate Professor

Dr. S. T. McComas, Professor

Dr. V. W. Nee, Professor

Dr. A. A. Szewczyk, Professor

Consultant

Dr.E.W. Jerger, Professor and Associate Dean

Research Assistants

L. C. Chang, Graduate Student

H. C. Chiou, Graduate Student

V. K. Liu, Graduate Student

N. P. Lynch, Graduate Student

C. J. Tsu, Graduate Student

Project Summary

The purpose of this research is to develop an improved predictive method for describing the physical movement of fire and smoke in enclosures such as rooms, compartments and corridors. The long-term goal is the development of a numerical computer code (UNDSAFE, University of Notre Dame Smoke and Fire in Enclosures) capable of predicting the fire and smoke spread behavior in an enclosure as a function of geometry and materials content. It can be used to study a wide range of phenomena associated with fire in an enclosure, including the motion of hot gases generated by a fire, temperature build-up and distribution of products of combustion, ventilation of fire through windows and doorways, radiation from walls, soot and hot gases, and interactions among multiple fire plumes as well as between plumes and ceilings, walls and corners.

This numerical code is based on a finite difference representation of a set of first-principle differential field equations for unsteady turbulent recirculating flows including effects of strong buoyancy, compressibility, combustion, multiple species and wall, soot and gaseous radiation. The mathematical modeling of turbulence, radiation and combustion is based on phenomenological and physical principles, and the validity is established by comparison of the numerical calculations with experimental studies carried out at the University of Notre Dame and at the Center for Fire Research of the National Bureau of Standards. The complexity of the real fire and smoke spread phenomena dictates a step-by-step approach of developing the numerical model to insure that at each step the model is self-consistent physically and correct in terms of known results.

This project was originally initiated under NSF RANN Grant GI-37191, and has since been continued under Grants ATA73-07749A01, AEN-73-07749-A02 and NBS G7-9002. 
Progress Report

Two basic geometries are utilized in this study. One is a simple rectangular enclosure with a doorway on one end which is primarily used in the step-by-step development of the numerical code. The other is an interconnected room-corridor enclosure also with a door at the end of the corridor. The small-scale experiments, both at Notre Dame and at the NBS, deal specifically with the roomcorridor geometry to obtain needed data for evaluating the accuracy of the UNDSAFE code. A brief summary of the current progress being made in the various areas of development is given below:

\section{Computer Code Development}

Our current operational UNDSAFE code is capable of handling two-dimensional compartments, corridors and interconnecting enclosures involving turbulent compressible buoyant flows caused by simulated floor or elevated fires. Wall, soot and gaseous radiation in one-dimension, arbitrary thermal boundary conditions at the ceiling and the floor, and an extended region to include conditions outside the enclosure can all be taken into account. An error correction scheme, which has been found to be effective in controlling the accuracy of the numerical calculations in a variety of situations, is now fully incorporated into the working code. The documentation of a simplified version of this code, known as UNDSAFE I, which deals with a simple two-dimensional compartment with a floor source of arbitrary strength and location, a window or doorway, arbitrary ceiling and floor thermal boundary conditions, and no radiation effects, has now been issued as a Technical Report TR-79002-77-1, which is currently being distributed through NTIS.

2. Turbulence Modeling

The turbulent buoyant flow associated with fire and smoke spread in corridors and compartments is characterized by turbulent intensities ranging from that of almost laminar flows to that of very strong turbulent flows. The latest algebraic turbulence model for the eddy viscosity, which is an improved version of that reported in the last year's meeting, takes into account both local shear and stratification effects and is specifically formulated to accommodate the wide range of intensities mentioned above. A technical report describing the development of this algebraic model, its sensitivity, and its advantage over other existing models including phenomenological differential field models, is now being prepared. This model will be severely tested to determine its validity in the corridor problem as soon as the detailed transient temperature and velocity data, now being obtained in our laboratory, become available. From a basic fluid mechanics point of view, the algebraic model does have some inherent limitations concerning the transport of turbulence, the extent of which is difficult to assess at this time, but which can be determined by comparisons with the experimental data. Some preliminary study has been carried out to apply differential field turbulence models developed for simple turbulent shear flows to the present problem.

\section{Radiation Modeling}

Simulation studies using UNDSAFE and a one-dimensional radiation model for wall, soot and gaseous radiation are being conducted to determine the relative importance of these radiation quantities as function of the depth of the smoke layer, soot concentration, species concentrations of the participating gases, and boundary temperatures at the ceiling and the floor. Since the inclusion of radiation in UNDSAFE calculations greatly increases the computer CPU time, a systematic study has been carried out to explore the possibility of not updating radiation effects at every time step, but rather, updating the effects at regularly spaced time steps. The results show for the present calculations that radiation updating every 10 time steps provides very adequate results when compared to that when the updating is done every time step. This simplification is now incorporated in the UNDSAFE code for the radiation simulation studies. 
4. Experimental Studies

There are two currently active experimental studies. One deals with the measurement of transient temperature and velocity fields in a model corridor with strip heaters and methane burners to simulate floor fires. Temperature measurements in both heater cases have now been completed. We now also have corresponding steady-state velocity data. We have plans to use a laser Doppler velocimeter to map the complete transient velocity fields for the two simulated fire cases. A second experimental study deals with mean flow and turbulence measurements in a wind tunnel with an unstable temperature profile. The study will be used to provide direct experimental data on the effect of temperature stratification on the turbulence field which is needed to verify the effect of stratification as predicted by our latest algebraic turbulence model. The previously designed heater, which produces linear temperature profiles at the tunnel test section entrance, has been found to be inadequate to produce the level of Richardson number expected in the enclosure fire phenomena. Current effort is directed toward base plate heating in the wind tunnel to generate high Richardson numbers.

5. NBS Data Simulation

The validity of the UNDSAFE code can only be determined by comparing numerical results with appropriate experimental data. The transient velocity and temperature measurements in the Notre Dame model corridor will be used exactly for this purpose. Also, simulation studies have been in progress to generate numerical results which can be used to compare with the steady-state experimental data obtained in the NBS corridor facilities. This latter comparison is somewhat difficult to make at the outset because of unknown thermal boundary conditions in the experiments and the two-dimensional nature of the UNDSAFE code. One completed case is worth mentioning at this time. An attempt has been made to adjust the strength of the simulated floor fire for the case of having a soffet only at the corridor exit so that the resulting steady-state temperature profiles would match that of the NBS data. It is found that to do so requires a heater source of $150 \mathrm{KW}$, as compared to the experimental value of $210 \mathrm{KW}$. We feel that this comparison is satisfactory, particularly in view of the fact that heat losses in the experiment were not controlled. Other calculations for possible comparisons with the NBS data are now continuing.

6. Multiple Plume-Ceiling Interaction Study

In this study the UNDSAFE code is utilized to study the interaction between two adjacent plumes and the interaction of these plumes with floor and ceiling. The objective is to determine the plume merging time, the extent of the plume region that interacts with the ceiling, and the smoke layer thickness generated by the plumes as functions of heat source geometry relative to the ceiling height and heat source strengths. Several previously completed computer runs are now being repeated with the latest algebraic turbulence model. Results will be correlated on the basis of Grashof numbers and various geometrical ratios, and compared with data existing in the literature.

7. Combustion Modeling

The fire has so far been simulated in our study by volumetric heat sources with location and strength corresponding to those of the simulated fires. A program has been initiated to develop experimental data so that the combustion process in the fire can be modeled for incorporation into the UNDSAFE code. Fire testing facilities are now being fabricated in our laboratory for experimental studies on free burning fires as well as fires burning in the proximity of walls and ceilings. These fire tests will commence shortly.

8. Cinematics

A formal contract has been signed with the Argonne National Laboratory to provide movie-making services to convert computer output from UNDSAFE in transient velocity and temperature fields into movies. All the needed software has been 
debugged and we have established compatibility with the Argonne computer and movie-making system. A trial run shows very promising results, and a production run is scheduled.

\section{Accomplishments}

1. A computer code, UNDSAFE, for two-dimensional unsteady recirculating flows with turbulence, compressibility, strong buoyancy, combustion and radiation has been developed. The code is sufficiently flexible to incorporate any desirable phy sical models for turbulence, radiation and combustion as well as accommodate a wide variety of enclosure and corridor configurations.

2. The validity of UNDSAFE has been examined in detail regarding its numerical stability and accuracy, and also in terms of comparison with known results in several limiting cases. An error correction scheme has also been developed and incorporated into UNDSAFE, and is shown to be an effective tool to ascertain the numerical accuracy in a variety of enclosure fire problems.

3. This computer code also incorporates output in the form of CALCOMP plotted instantaneous velocity vector and temperature fields so that different recirculation zones and regions of high temperature can be readily discerned. This mode of output is also used as a data base to generate computer movies showing the detailed time responses of the flow and temperature fields.

4. The computer code UNDSAFE currently incorporates a new algebraic turbulence model for recirculation flow and wide ranges of turbulence levels, a radiation model which accounts for one-dimensional wall, soot and gaseous radiation, and a combustion model based on simulated volumetric heat sources valid throughout the corridor except in the immediate vicinity of the fire. These models are continually refined based on new experimental data.

5. Computer simulation runs have been carried out to support the ongoing corridor fire program at the NBS Cent er fof Fire Research. Many of the flow features and temperature field variations observed in the NBS experiments do agree with that from the computer calculations.

6. Two test facilities have been constructed at Notre Dame and are now in continuing use. One is a wind tunnel capable of burning gaseous fuels or employing strip heaters as simulated fires. The other facility is a model enclosure simulating a burn room with a corridor attached in line. Instrumentation includes probes for temperature, velocity, and gas concentration, as well as for flow visualization with smoke. Test results obtained so far include flow patterns from flow visualization, steady velocity profiles, and also detailed transient temperature profiles. Some of these results have already been utilized in the development of refined physical models in the computer code.

Potential Applications

Once the code UNDSAFE is developed to the extent that it adequately predicts the spread of real fire and smoke in any enclosure configuration, many potential applications can be identified. In the case of fire hazard testing of materials, applications of UNDSAFE can be found in the design and data interpretation of such tests as the tunnel tests, radiant panel tests, corner tests, and the like. The computer code can also be used in the support of large-scale fire tests in rooms or even in buildings in terms of pre-test simulation, instrumentation and data acquisition and post-test data reduction and analysis. Applications can also be found in architectural design in the generation of input data for the design of structure for fire integrity, escape routes in buildings, compartmentalization for fire containment, fire detection and fire fighting techniques, and also for the design of building codes. Lastly, this computer code can also serve as a vital simulation tool in the training of fire fighting personnel to show the importance of various physical effects on the spread of fire and smoke in rooms and corridors. 
Future Milestones

1. Finalization of the turbulence model based on the steady and unsteady velocity and temperature measurement in the Notre Dame model corridor.

2. Finalization of the combustion model.

3. Completion of basic studies on plume interaction and room ventilation.

4. Complete analysis of NBS small scale corridor test data.

5. Complete analysis of the E-84 tunnel test data of the Underwriters' Laboratory.

6. Development of the three-dimensional computer code and the associated physical models.

7. Utilization implementation.

Reports and Papers

1. K. T. Yang and J. R. Lloyd, "Fire and Smoke Spread," Technical Report ND-PR-07749-7, Department of Aerospace and Mechanical Engineering, University of Notre Dame, Notre Dame, Indiana, October 1, 1976, 37 pp.

2. A. C. Ku, M. L. Doria and J. R. Lloyd, "Numerical Modeling of Unsteady Buoyant Flows Generated by Fire in a Corridor, "Proceedings of the Sixteenth (International) Symposium on Combustion, Boston, Mass., August 15-20, 1976.

3. K. T. Yang and L. C. Chang, "UNDSAFE I. A Computer Code for Buoyant Flow in an Enclosure, "Technical Report TR-79002-77-1, Department of Aerospace and Mechanical Engineering, University of Notre Dame, Notre Dame, Indiana, March 1, 1977, 102 pp.

4. K. T. Yang and J. R. Lloyd, "Fire and Smoke Spread," Final Technical Report submitted to the National Science Foundation, ND-PR-07749-8, Department of Aerospace and Mechanical Engineering, University of Notre Dame, Notre Dame, Indiana, May 31, 1977. 
Institution: University of Pittsburgh

Grant No. :

$5-9005$

Grant Title:

Toxicity of Plastic Combustion Products

Principal Investigator: Yves Alarie, Ph.D.

Graduate School of Public Health

University of Pittsburgh

Pittsburgh, Pennsylvania 15261

(412) 624-3047

Other Professionals

and Students:

Dr. Magi11, Dr. Frohliger, Dr. Anderson, Dr. Lucia, Dr. Barrow, Mr. Dierdorf, Mr. Melnick, Mrs. Kane

Project Summary:

To develop toxicological methodologies to assess the hazards of thermal decomposition products from polymeric materials. The project is particularly oriented toward irritating gases and aerosols in the smoke produced.

Progress Report and Accomplishments:

In a special report to NBS dated February 1977 which consists of the doctoral thesis of C.S. Barrow our main progress to date is described in detai1. This report may be purchased directly from the National Technical Information Service, 5825 Port Royal Road, Springfield, Virginia 22151.

The order number is PB-267233. The cost of a paper copy is $\$ 9.75$; a microfiche copy costs $\$ 3.00$.

Our objectives are now expanding and are summarized on the following diagram. 


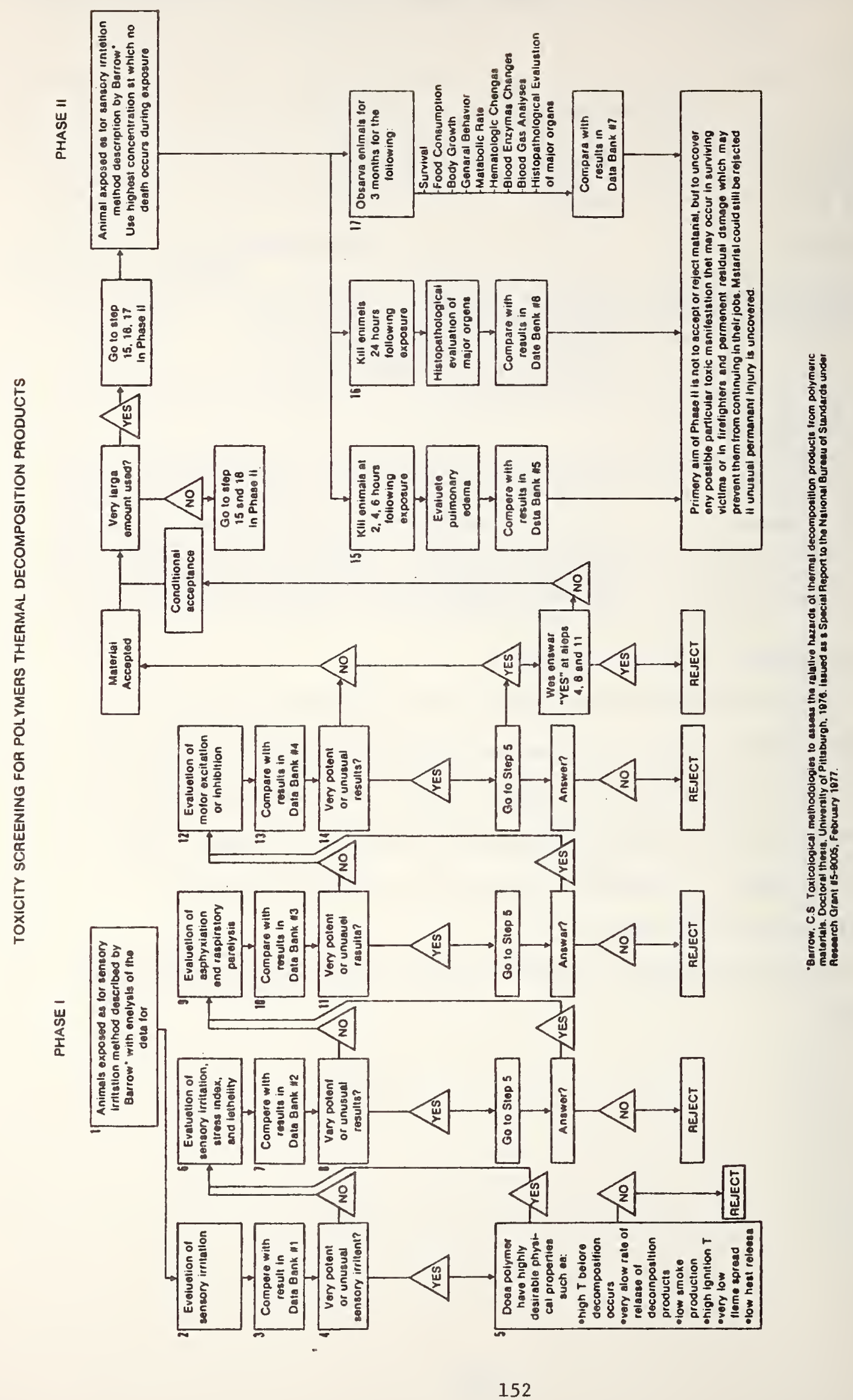




\section{INSTITUTION:}

GRANT NUMBER:

\section{GRANT:}

\section{PRINCIPAL INVESTIGATOR:}

\section{(CO-PRINCIPAL INVESTITATDRS):}

Prof. S. C. Israel Asst. Prof., Mat'ls Sci \& Enq., Panager Chemistry Division W. A. Galster Res. Assoc., Flammability Research Center, Manager Biomedical Division

\section{FACULTY:}

Prof. R. C. Baldwin Prof. D. A. Chatfield Prof. M. L. Grunnet Prof. B. M. Huqhes Prof. F. D. Hileman Prof. S. M. Moore

Prof. J. H. Petajan Prof. J. D. Seader

Prof. K. J. Voorhees

\author{
Flammability Research Center \\ University of Utah \\ P.0. $80 \times 80 B 9$ \\ Salt Lake City, Utah 84108 \\ Telephone: (801) 581-8431 \\ 7-9005-NBS
}

"The Physiological and Toxicolngical Aspects of Smoke Produced During the Combustion of Polymeric Materials"

Professor I. N. Einhorn

Professor, Materials Science and Engineering Adjunct Professor, Chemical Engineering Adjunct Professor, Biopharmaceutical Sciences Director, Flammability Research Center

INOUSTRIAL RESEARCH ASSOCIATES:

Dr. G. E. Hartzell

Dr. D. G. Farrar

\section{PROJECT STAFF:}

Mr. T. L. Blank

Ms. C. L. Fraley

Mr. A. P. Krensky

Mr. R. B. Jeppsen

Mr. J. B. McCandless

Mr. H. H. McClennen

$\mathrm{Mr}$. D. N. Osborne

Ms. S. B. Pedersen

$\mathrm{Mr}$. D. L. Pope

$\mathrm{Mr}$. R. F. Rose

Ms. A. A. Synder

Ms. P. L. Tadman

Mr. L. H. Wojcik

\section{GRADUATE STUDENTS:}

Mr. J. R. Angal

Mr. R. W. Darr

Mr. B. G. Dinger

$\mathrm{Mr}$. D. M. Hou

Mr. N. Igarashi

Mr. S. S. Ou

Mr. D. J. Wendel
Asst. Res. Prof., Mat'ls Sci \& Enq., Biomedical Division

Asst. Res. Prof., Mat'ls Sci'\& Eng., Chemistry Division

Assoc. Prof. Dept. of Neurol. \& Pathol., Manager Pathol. Section

Assoc. Res. Prof., Mat'ls Sci \& Enq., Manaqer Data Systems

Asst. Res. Prof., Mat'ls Sci \& Enq. , Chemistry Division

Clinical Assoc. Prof., Dept. of Pathol., Medical Examiner, State of Utah

Prof., 0ept. of Neurol., Manager Neurol. P Neurophysiology Section

Prof., Chairman, Dept. of Chemical Enq., Manager Smoke Research Section

Assoc. Res. Prof., Mat'ls Sci \& Eng., Senior Res. Fellow, Chemistry Division
Research Associate Research Associate

Research Specialist

Secretary

Business Manager

Research Assistant

Research Associate

Research Technician

Analytical Chemist

Laboratory Technician III

Junior Analytical Chemist

Medical Technologist III

Electron Microscope Tech.

Administrative Assistant

Data Analyst

\section{Chemical Engineering}

Bioengineering

Physiology

Materials Science \& Eng.

Materials Science \& Enq.

Chemical Engineering

Chemical Englneering
The Dow Chemical Company

Imperial Chemical Industries, Ltd.

Blomedical Division

Flammability Research Center

College of Enqineering

Biomedical Division

Biomedical Division

Chemistry Division

Chemistry Division

Biomedical Division

Chemistry Division

Biomedical Division

Biomedical Division

Flammability Research Center

Flammability Research Center

Ph.D. Candidate

(Society of the Plastics Industry Fellowship) (Forest Products Association Fellowship)

Ph. D. Candidate

(Society of the Plastics Industry Fellowship)

M.S. completed, Ph.D. Candidate

(Society of the Plastics Industry Fellowship)

Ph.D. completed June 1977

(Society of the Plastics Industry Fellowship) Ph.D. Candidate

(Society of the Plastics Industry Fellowship)

Ph.D. Candidate

(International Isocyanate Institute Fellowship) 
The Flammability Research Center of the University of Utah combines efforts of an extensive staff of personnel from the Colleges of Engineering, Medicine, and Science, together with significant participation from members of agencies actually involved in fire fighting and public safety. This multidisciplinary team is engaged in a three-part program aimed toward an indepth assessment of the basic hazards to human survival as a result of fire exposure.

TASK I - DEVELOPMENT OF PROTOCOL FOR ASSESSMENT OF RELATIVE TOXICITY OF MATERIALS UPON COMBUSTION

A. Evaluation of commonly employed combustion/exposure systems.

B. Development of analytical methodology necessary to monitor commonly encountered toxicants as well as to identify unusual toxicants that may be encountered during fire exposure.

C. Evaluation of behavioral and physiological responses of rats to selected toxicant systems in order to determine those parameters which are most meaningful, sensitive, and reproducible in evaluating toxicological hazards.

D. Histophathological evaluations to correlate potential tissue damage resulting from toxicant exposure with functional impairment observations.

E. Development of computerized data acquisition and reduction systems to handle the vast amount of analytical and physiological data resulting from animal exposure experiments. 
TASK II - SMOKE OPTICAL DENSITY STUDIES

Task II is a continuation of smoke optical density studies, with particular emphasis on an examination of the additivity of optical density produced from the burning of composites.

\section{TASK III - POLYMER DEGRADATION STUDIES}

Task III involves development and application of improved methodology for studying materials produced from burning materials. Research is being conducted within the scope of this task to aid in determination of the mechanics of polymer thermal decomposition of specific systems.

\section{POTENTIAL APPLICATIONS}

1. FIRST-TIER SCREENING PROTOCOL - COMBUSTION PRODUCTS TOXICITY

A first-tier screening protocol has been developed which will permit easy and reproducible assessment of the development of "unusually toxic" products in the complex mixtures of combustion products.

2. SECOND-TIER SCREENING PROTOCOL - COMBUSTION PRODUCTS TOXICITY

An indepth, or second-tier protocol which may be used to assess the physiological and toxicological responses to animals resulting from a single acute exposure to combustion products has been developed. Present research is designed to develop the specifications required for standards promulgation.

\section{FUTURE MILESTONES}

An intensive study of combustion product toxicology is in progress to determine the potential physiological and toxicological hazards 
resulting from combustion of natural and synthetic materials used in our "built environment." Analysis procedures are in the final stages of development which, when completed, should permit a premarket assessment of hazards relating to combustion product toxicity.

TASK I - DEVELOPMENT OF A PROTOCOL FOR ASSESSMENT OF RELATIVE TOXICITY OF MATERIALS UPON COMBUSTION

\section{A. Combustion Module Development and Evaluation}

An essential ingredient required for development of a screening protocol is an appropriate combustion device which would be interfaced with an animal monitoring/exposure chamber and analytical instrumentation.

Development of this aspect of research is difficult due largely to the unavalability of relevant combustion methodology which is meaningful, reproducible, and applicable to comparison of a variety of materials. There also exists considerable controversy surrounding utilization of radiant heat energy as compared to conduction heat, as well as flaming and nonflaming modes. The goal of this task was to resolve the significance of two important issues: (1) separation of pure flaming combustion from nonflaming oxidative decomposition; and (2) the question of radiant versus conductive energy input, i.e., heat flux versus sample temperature.

Laboratory evaluation of the tube furnace combustion device (e.g., DIN Combustion Apparatus), the static combustion furnace, and the Aminco NBS Smoke Density Chamber. A variety of reference materials (wood, cellular plastics, and solid polymers were selected and combusted under a variety of conditions. Performance of each system was judged using the analysis of combustion products as well as by the use of physiological and behavioral response of rats.

Based upon the results of such laboratory evaluation it has been possible to design, build, and evaluate a hybrid combustion device more 
suitable for screening applications of combustion toxicology than any currently available apparatus.

Protocol development has progressed through the experimental stage entering the evaluation of precision and accuracy of the method with some selected applications. A system capable of combusting materials in the flaming and nonflaming modes allowing animal exposure to toxic fumes without appreciable heat stress has been perfected. Rapid conductive heating to temperatures just below and above the flaming point is used for the two modes of combustion. Different amounts of the material sufficient to estimate the apparent dose $\left(\mathrm{g} / \mathrm{m}^{3}\right)$ for incapacitating $\left(\mathrm{EC}_{50}\right)$ and $\mathrm{killing}$ $\left(L_{50}\right)$ half of the animals is used. Head only exposures providing opportunities for close examination of animal responses, easy collection of blood samples, and observation of the lethal effects, improves the biological assessments of the animals' responses. Causality of these responses is also explored through correlation between behavioral responses, blood parameters, and analysis of respiratory and toxic gases in the chamber. Relative toxicity assessment is now envisioned as a determination of the material's flash point, $E_{50}, E_{50}$, toxic causality and emission of gases during both modes of combustion. Comparison of materials in these ways should provide a wider data base necessary for appropriate application by industry. The utility of this approach remains to be evaluated, especially in the precision and sensitivity of this method.

Simplified methods for identifying effects of asphyxia and other toxic interactions are being sought. Hopefully, this will provide an 
easier method for detecting the usual toxicity of combustion products, sorting out unusual problems with new materials. Recommended practices involving practical and economic evaluations of combustion toxicity of products in a first-tier screening are envisioned.

B. A computerized analytical system has been designed and assembled which is capable of monitoring, by batch processing, the combustion chamber environment. - Routine analysis of the concentration of respiratory gases, oxygen, and carbon dioxide are conducted every three minutes during the 30-minute exposure episode. Other analytical techniques have been developed to permit routine analysis, by batch processing of carbon monoxide, acetaldehyde, acrolein, hydrogen halides (chlorine or bromine), hydrogen cyanide, selective nitriles, styrene monomers, and total hydrocarbons, either individually or in selected combinations. A complete computerized assessment of the above information can be readily retrieved after a given exposure episode.

C. As mentioned previously, the combustion/exposure chamber has been designed, built, and used for assessment of toxicity of combustion products. Special monitoring devices have been designed and constructed to permit easy and accurate assessment of loss of avoidance using a leg-flexion paradigm. Techniques have been developed which have permitted assessment of $\mathrm{pH}$ homeostasis. Blood data measurements, $\mathrm{pH}, \mathrm{PO}_{2}, \mathrm{PCO}_{2}, \mathrm{HCO}_{3}$, hemoglobin, oxyhemoglobin, and carboxyhemoglobin, have been developed and a system designed and fabricated to permit rapid and accurate computerization of this information. 


\section{Histophathological Studies}

In studying the histopathology of animals exposed to the products of combustion from various materials, we have found that smoke from each material produces some unique effects that we had not expected. It has also become clear that smoke from a given material affects different organs and tissues differently. That is, smoke from different materials may produce uniquely different pathological patterns. These patterns may be helpful in allowing us to know what organs and tissues might be affected acutely by the inhalation of certain types of smoke by a patient. Patterns could also implicate the contribution of specific materials to the complex mixtures of smoke. It should be possible to anticipate what the delayed and sometimes fatal sequelae of some exposure to smoke of various types might be.

\section{Evaluation of Douglas Fir}

Animals exposed to wood smoke have shown an apparently unique pathological pattern. Wood smoke contains $\mathrm{CO}, \mathrm{CO}_{2}$, as well as aldehydes such as acrolein and acetaldehyde. The physiological and pathological effects of Douglas fir subjected to a variety of heat fluxes with and without a pilot flame have been studied, as well as the exposure chamber concentrations of $\mathrm{O}_{2}, \mathrm{CO}, \mathrm{CO}_{2}$, acetaldehyde, and acrolein.

Rats exposed for 20 minutes to smoke from $20 \mathrm{~g}$ of Douglas fir irradiated at 2.5-5.0 watts $/ \mathrm{cm}^{2}$ without pilot flame developed severe respiratory distress. Three to 24 hours later coagulation necrosis of epithalium of the trachea-bronchial tree with slough- 
ing and purulent exudate could be seen. The lungs showed congestion and atelectasis. The thyroid gland developed progressively increasing desquamation of epithelium into the follicular colloid with infiltration by inflammatory cells and macrophages. Other organs appeared normal. If the animal lived 7-.to 8 days the tracheobronchial tree was reepithelized by normal pseudostratified columnar epithelium and moderate to severe pneumonia was present. Animals which lived 30 days postexposure showed moderate pneumonia, flattened thyroid epithelium, and globules in thyroid colloid. Animals surviving 10 months after exposure showed similar changes. other organs, including the brain, appeared normal.

2. Evaluation of Polyvinyl Chloride Polymers

In studies of animals exposed to the combustion products of polyvinyl chloride polymers there was a significant mortality. The intoxication syndrome was characterized again by respiratory distress, but with the added effect of damage to the cornea. The mortality rate and severity of the pathology appeared to be related to the percent of vinyl chloride monomer in the original sample. Pathological changes in animals dying within 24 hours consisted of coagulation necrosis of tracheal and bronchial mucosd, with sloughing and purulent exudate. The lungs initially showed congestion, atelectasis, and edema. Later, pneumonia supervened. Eight to 16 days postexposure animals had abnormal re-epithelization of tracheal and bronchial 
mucosa with tall, columnar, mucous-secreting epithelium introbronchial exudate and pneumonia. That is, goblet-cell hyerplasin of the tracheobroncial tree developed after exposure. The thyroid glands in animals exposed to the degradation products of PVC polymers appeared normal. A number of animals showed small foci of necrosis in heart and liver. Other organs, including spleen, kidney, thyroid, and brain, showed no significant abnormalities. Thus, PVC smoke intoxication does differ from wood smoke intoxication. The abnormal cells produced as a consequence of exposure to the degradation products of PVC polymers may cause an individual exposed to PVC smoke to develop chronic bronchitis or other types of chronic pulmonary disease. It is possible that such individuals might later develop bronchial epithelial metaplasia and subsequent anaplasia.

\section{Other Studies}

Further studies have been conducted using pure gases commonly found in "real fires" such as carbon monoxide and hydrogen cyanide. The pathological effects of exposure to these gases has been defined.

\section{E. Computerization Related to NBS Research Programs}

Over the year, two major software projects originally begun in 1975 under RANN funding and designed to facilitate the studies into the toxicity of burning materials have been completed. The first involves the direct interface of our general laboratory computer with the gas chromatographic integrator to assist in the calculations and data storage of the concentra- 
tions of volatile gases present in exposure chamber atmospheres. Using the facilities of newly-purchased disc drives and using a disc-orientated operating system developed by Hewlett-Packard, files of data are received from the gas chromatographic integrator system and stored on magnetic tape. With operator interaction these files can be used as standards or unknowns to calculate concentrations of total hydrocarbons, organics, air species $\left(\mathrm{O}_{2}, \mathrm{~N}_{2}, \mathrm{Ar}, \mathrm{CO}\right.$ and $\left.\mathrm{CO}_{2}\right)$, and other species such as $\mathrm{HCN}$ and $\mathrm{HCl}$ present in the combustion atmospheres at various times.

The second software program involves development of a standard file structure in which to organize data from various exposures. This involves details of the exposure along with animal data such as loss of avoidance, death, and blood parameters measured at various times of exposure. A schematic representation of the file structure is shown in Figure 1. Using a specific data format, as that shown in the figure for storage of experimental results, permits detailed statistical evaluations of experiments with limited amount of operator interaction. This latter phase of the computerization program is envisioned to continue into next year's program.

A major achievement was also the design of a medical terminal which will allow direct input from our blood analysis equipment directly into the file structure mentioned above. While this $1 / 0$ device has not yet been incorporated into the existing software, it should be fully operational and integrated into the above software capabilities in next year's program. In addition, implementation of a real-time executive monitor system for 
our laboratory computer will allow multiple exposures to be monitored, while reducing the amount of manual data input, presently being required.

\section{TASK II - SMOKE OPTICAL-DENSITY STUDIES}

Smoke studies at the Flammability Research Center during the past few years have been directed toward development of a convenient and reliable method for predicting smoke development. In this regard theoretical studies have been supplemented by small-scale experimental work.

The method of Robertson can be used for estimating the potential hazard from smoke production in a room. However, rather than using naximum specific optical density, as obtained with the NBS chamber, the percentage of sinoke as measured with the Arapahoe flow-through chamber can be substituted. This method, as applied to all finishing and furnishing materials in a room, involves estimation of an effective light extinction coefficient from the equation:

$$
\bar{k}_{e f f}=\frac{(P 00) 2.303}{v_{r}} \sum_{i} \frac{(\% \text { Smoke })_{i} M_{m_{j}}}{100}
$$

where: $V_{r}=$ volume of the room

6 = a factor that accounts for expansion and loss of smoke from the room (Robertson suggests a value of 0.25 )

(\% Smoke) $=$ percentage of a material converted to particulates

$$
\begin{aligned}
& M_{m}=\text { Mass of material } \\
& P O D=\text { particulate optical density }
\end{aligned}
$$


Based on our experiments, the following values of POD have been determined:

$$
\begin{aligned}
& \text { POD }=19,000 \mathrm{~cm}^{2} / \mathrm{gm} \text { for the nonflaming or smoldering mode } \\
& \text { POD }=36,000 \mathrm{~cm}^{2} / \mathrm{gm} \text { for the flaming mode }
\end{aligned}
$$

These values are in good agreement with theoretical light scattering and absorption calculations made assuming absence of multiple scattering effects. This latter assumption we have recently verified in a separate study.

Values of $\bar{K}_{\text {eff }}$ from Eq. (1) are compared to limiting values of Jin to determine whether an occupant of the room can detect an exit. For a backlighted sign, Jin gives

$$
\left(\overline{\mathrm{K}}_{\text {eff }}\right)_{\max }=\underline{8}
$$

where: $L_{V}=$ visual distance.

For an illuminated wall, Jin gives

$$
\left(\bar{K}_{\text {eff }}\right)_{\max }=\underline{3}
$$

However, Eqs. (2) and (3) assume that the observer's eyes are not irritated.

The summation term in Eq. (1) is based on the assumption that the amount of smoke produced from two or more different materials is additive, irrespective of whether the materials are placed side-by-side or back-toback. Because experimental data to support this important assumption were lacking in the literature, a study was recently initiated at the Flammability Research Center using the NBS chamber in the non-flaming mode. The material combinations and other pertinent information are listed in Table 1. For these materials the data on $D / L$ and $C_{s}$ are well correlated by a POD of $19,000 \mathrm{~cm}^{2} / \mathrm{gm}$, which was determined by earlier experiments at the Flammability Research Center. 
The effect of time on the specific optical density for PVC, $\alpha$-cellulose, and their side-by-side combination was determined. When the pure material was tested two samples of it were placed side-by-side. Values of the specific optical density for the combination appear to be the summation of the values for separate materials after dividing by two. The additivity of results is also evident for the maximum specific optical density and for the mass loss. When these same materials are tested back-to-back results again demonstrate the validity of the additivity as sumption.

Results for maximum specific optical density and mass loss from sideby-side tests on all binary pairs of ABS, PVC, and Douglas fir (DF) were determined.

Based on studies made thus far it appears that Eq. (1), (2), and (3) provide an acceptable method for determining whether a room is optically safe or not in the event of a fire. However, supporting data in the flaming mode are needed as well as additional data in the non-flaming mode.

\section{TASK III - POLYMER DEGRADATION STUDIES}

\section{A. Effluent Gas Analysis (TGA/MS)}

A new effluent gas analysis system has been constructed and tested during the last six months. The system resembles the original design (1) with the exceptions of lower dead volumes in the furnace and shorter transfer lines between the furnace and the mass spectrometer.

A number of specific tests have been conducted to evaluate the system. These tests inciude: surface absorption characteristics of gases such as hydrogen chloride; convolution problems associated with diffusion; and rapid and reproducible heating of the sample to a preselected isothermal temperature. 
The heated Teflon $(R)$ lines and the entire system was pretreated with hydrogen chloride until a small continuous bleed was observed. At this point samples were injected at sizes representing increases of 2 , 4, 6 fold. A plot of how these materials interacted with the surface was obtained by monitoring $\mathrm{m} / \mathrm{e} 36$ with time and then mathematically fitting a function to the tail of the peak. It was found following pretreatment that the observed peak shape at the mass spectrometer was independent of sample size injected. It was concluded from this experiment that one could precondition the surface to prevent or minimize surface absorption.

Injection of any sample at the oven as a slug produced a gaussian peak as monitored by the mass spectrometer. Therefore, the specific ion plot of a given mass at the mass spectrometer did not represent the production of gases in the oven, rather an additive convolved function. Deconvolution procedures have become possible in recent years because of computers and a better understanding of Fourier transforms. A convolution can be written

$$
g(x) * f(x)=h(x)
$$

To deconvolve $g(x)$ one has to know or guess the $f(x)$, the convolution function. In our case this function can be obtained accurately by injecting a slug of compound at the oven and then obtaining diffusion curve at the mass spectrometer. After obtaining this function it can be fed into a computer along with the convolved data, followed by fast Fourier transform (FT), which then allows Eq. (1) to be written

$$
g(x)=\frac{h(x)}{f(x)}
$$

The function $g(x)$ can then be obtained by a reverse FT. Using this approach in a program written at the Flammability Research Center, it was deduced that the design of the system was adequate and only minor convolution was produced. 
In the past the sample was heated in the Mettler oven by heating at $70^{\circ} \mathrm{C} / \mathrm{min}$ to the isothermal temperature. At present the samples are placed in the oven below the heating zone while the oven is evacuated and flushed. At this point the sample crucible on the sensing stick is raised into the heating zone. Temperature rise times of $400-500^{\circ} \mathrm{C} / \mathrm{min}$ are obtained using this method.

\section{B. Polyurethane Polymers}

\section{Chemical Characterization of Polyurethane Foams. Four rigid} polyurethane foams, widely used in commerce, were hydrolyzed in aqueous base. This hydrolysis produced a mixture of the original polyols and polyomines corresponding to the raw materials used in foam production. These components were analyzed by chemical ionization mass spectrometry without prior separation. The chemical ionization produced mainly the protonated molecules in $(M+N)^{+}$. Ion assignments were made for each compound of each homologous series. Observed fragmentation was limited to the loss of aniline from certain polyomines and the loss of water from each polyol. The polyomines were analyzed further by high pressure liquid chromatography. These methods complement the classical methods of determining the chemical composition of polyurethane foams.

\section{Thermal Decomposition Mechanisms in Polyurethane Polymers}

Considerable progress has been made in development of analytical procedures which have been utilized in the study of polymer thermal decomposition mechanisms .

Products of pyrolys is in a helium atmosphere of a model urethane polymer were-investigated using GC/MS and GC/Cl-MS. Chemical-ionization mass spectrometry was used because it produces, primarily, protonated molecular ions $(M+1)$ with little fragmentation which facilitated the identification of the polyol decomposition products. Combining this information with results of the identification of volatile compounds, a detailed mechanism for urethane-polyol pyrolysis has been formulated. 


\section{Combustion of Douglas Fir}

A detached study of Douglas fir and $\alpha$-cellular was conducted utilizing newly developed analytical procedures. Attempts were made to separate the lignin from the Douglas fir with as little change to the lignin as possible.

Application of direct pyrolysis chemical-ionization mass spectrometry and the subtraction of spectra has provided a criteria for determining when lignin has been extracted in a form similar to that in wood.

The following of light gas decomposition products of Douglas fir in air and helium has provided new insight into the kinetics of decomposition. Faster and higher-resolution gas chromatographic techniques are being developed to follow an even greater number of products, many of which, due to conmon molecular weight or serious electron impact fragmentation, cannot be followed by a mass spectrometer. 
FRC/UU UTEC NO.

069

070

$76-213$

071

$76-221$

072

$76-227$

073

$76-228$

074

$76-229$

075
Title and Author(s)

"Some Physical, Chemical, Toxicological, and Physiological Aspects of Fire Smokes," J. D. Seader and I. N. Einhorn; paper presented at the Sixteenth International Symposium on Combustion of the Combustion Institute, Massachusetts Institute of Technology, Cambridge, Massachusetts, August 15-21, 1976. Proceedings 16th Combustion Institute (In Press).

"The Physiological and Toxicological Aspects of Combustion," I. N. Einhorn, M. L. Grunnet, J. H. Petajan, and R. C. Baldwin; paper presented at the Fifth International Fire Protection Seminar, Karlsruhe, West Germany, September 22-24, 1976.

"Flammability and Thermal Characteristics of a Urea Formaldehyde Foam," I. N. Einhorn, K. J. Voorhees, and D. A. Chatfield; an invited paper presented at the Fourth International Cellular Plastics Conference of the Cellular Plastics Division, Society of the Plastics Industry, Montreal, Canada, November 18, 1976.

"Thermal Degradation of Model Urethane Foams--An Analytical Study - I," I. N. Einhorn, M. S. Ramakrishnan, K. J. Voorhees, and R. W. Mickelson; invited paper presented at the Fourth International Cellular Plastics Conference, the Society of the Plastics Industry, Montreal, Canada, November 15-19, 1976; Polymer Science and Engineering (In Press).

"Thermal Degradation of Model Fire-Retarded Urethane Foams--An Analytical Study - II," I. N. Einhorn, M. S. Ramakrishnan, K. J. Voorhees, and R. W. Mickelson; invited paper presented at the Fourth International Cellular Plastics Conference, the Society of the Plastics Industry, Montreal, Canada, November 15-19, 1976; Polymer Science and Engineering (In Press).

"The Assessment of the Human Survival Response During Aircraft Accidents," I. N. Einhorn; invited paper presented at an International Seminar on Aircraft Rescue and Fire Fighting, National Fire Protection Association (International), Geneva, Switzerland, September 13-17, 1976.

"Pathology and Neuropathology of Fire Victims in Aircraft Fires," M. L. Grunnet; invited paper presented at an International Seminar on Aircraft Rescue and Fire Fighting, National Fire Protection Association (International), Geneva, Switzerland, September 13-17, 1976. 
"An Investigation of the Thermolysis Mechanism of Model Urethanes," K. J. Voorhees, F. D. Hileman, I. N. Einhorn, and J. H. Futrel1; paper presented at the Fourth International Cellular Plastics Conference of the Cellular Plastics Division, The Society of the Plastics Industry, Montreal, Canada, November 18, 1976; Joumal of Polymer Science (In Press).

"Chemical Characterization of Polyurethane Foams," N. A. Mumford, I. N. Einhorn, and D. A. Chatfield; paper presented at the Fourth International Cellular Plastics Conference of the Cellular Plastics Division, Society of the Plastics Industry, Montreal, Canada, November 18, 1976.

"The Physiological and Toxicological Aspects of Combustion," I. N. Einhorn, M. L. Grunnet, and J. H. Petajan; paper presented at the Second Joint Meeting, U. S. - Japan Panel on Fire Research and Safety, Tokyo, Japan, October 19-22, 1976.

"Physiological and Behavioral Responses to Fire Combustion Products," G. E. Hartzell, S. C. Israel, S. C. Packham, F. D. Hileman, M. L. Dickman, R. W. Mickelson, R. C. Baldwin; invited paper presented at the Fourth International Cellular Plastics Conference, The Society of the Plastics Industry, Nontreal, Canada, November 15-19, 1976.

"Fire Research and Public Safety," G. E. Hartzell; invited paper presented at the 64th National Safety Congress and Exposition, Chicago, Illinois, October $18-21,1976$.

"Combustion Products of Materials--Assessing the Toxicity Hazard," S. C. Israel; invited paper presented at the American Chemical Society 12th Midwest Regional Meeting, Kansas City, Missouri, October 28-29, 1976.

"Correlation of Gravimetric Smoke Measurement by the Arapahoe Chamber with Optical Smoke Measurement by the NBS Chamber for Flaming Combustion,". S. S. Ou, J. D. Seader, Fire Research (In Press).

"Prediction of the Smoking Tendency of Materials," J. D. Seader, S. S. Ou, paper presented at the Committee on Fire Research, National Academy of Sciences International Symposium on Toxicity and Physiology of Combustion Products, University of Utah, Salt Lake City, Utah (March 22-26, 1976).

"Correlation of the Smoking Tendency of Materials," J. D. Seader, S. S. Ou, paper presented at meeting of The American Chemical Society, September 1976; Fire Research (In Press). 
"The Physiological and Toxicological Aspects of Combustion," I. N. Einhorn, M. L. Grunnet, J. H. Petajan; paper presented at a Symposium and Workshop, The Polytechnic Institute of New York and U. S. Department of Transportation, April 1977.

088 $77-069$

"Component Analysis of Rigid Polyurethane Foams," N. A. Mumford, D. A. Chatfield, I. N. Einhorn, Fire Research (In Press).

089 $77-070$

"The Analysis of Rigid Polyurethanes by Chemical Ionization Mass Spectrometry," N. A. Mumford, D. A. Chatfield, I. N. Einhorn, submitted to Joumal of Applied Polymer Science.

Theses and Dissertations (1976-1977)

Hileman, F. D., New Techniques for the Analysis of Thermolysis Products. Ph.D. Dissertation, Department of Chemistry, College of Science, University of Utah (February 1977).

Hou, D. M., The Effect of Fire Retardant Concentration on the Flamabizity Characteristics of Rigid-Urethane Foam Polymers. M.S. Dissertation, Department of Materials Science and Engineering, College of Engineering, University of Utah (July 1977).

Igarashi, Nobuya, Studies Pertaining to the Mechanisms of Step-Growth Folymers -- Nyzon 6, Polyethylene Terephthalate, and Polycarbonate. Ph.D. Dissertation, Department of Materials Science and Engineering, College of Engineering, University of Utah (June 1977). 


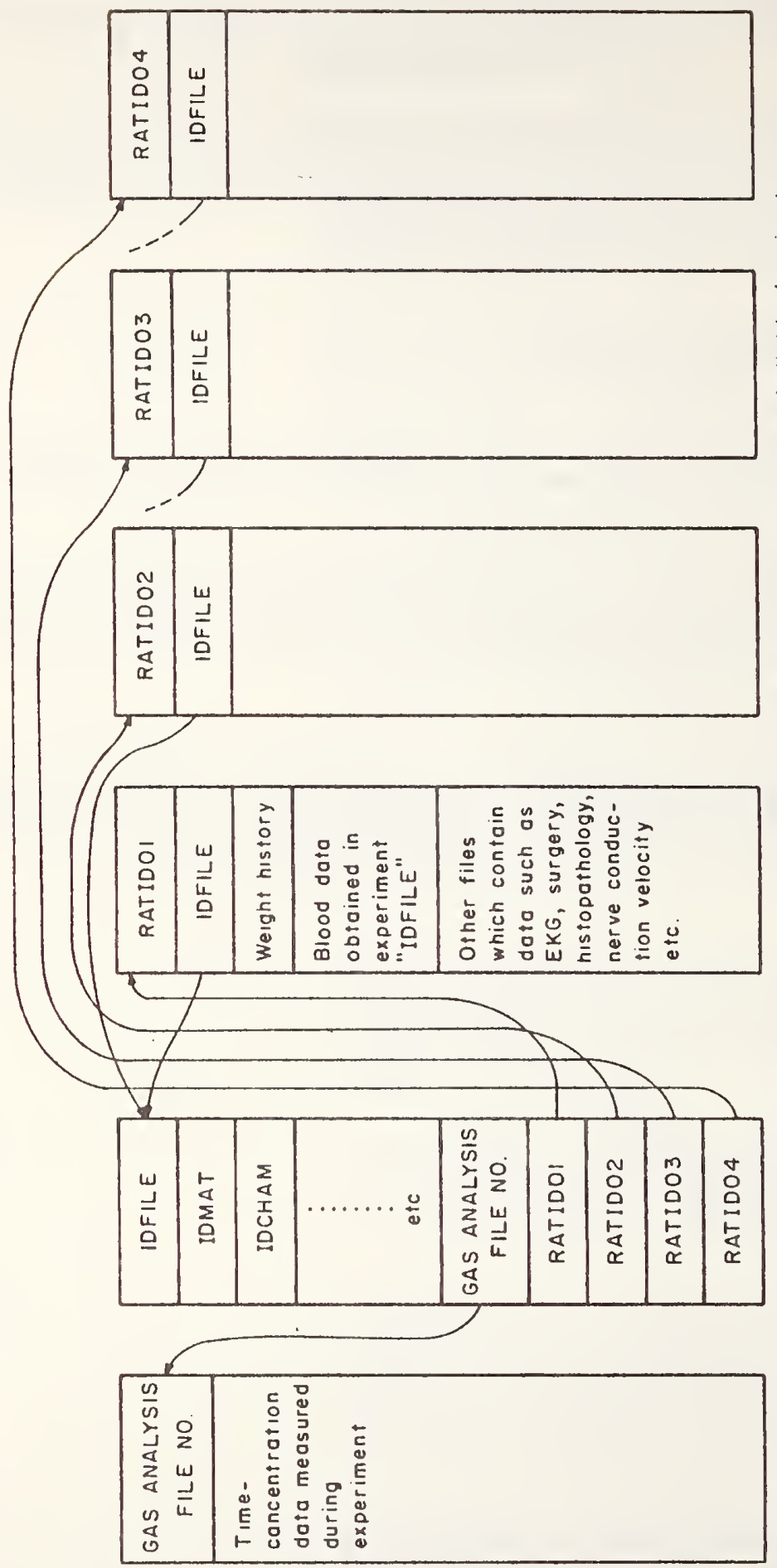

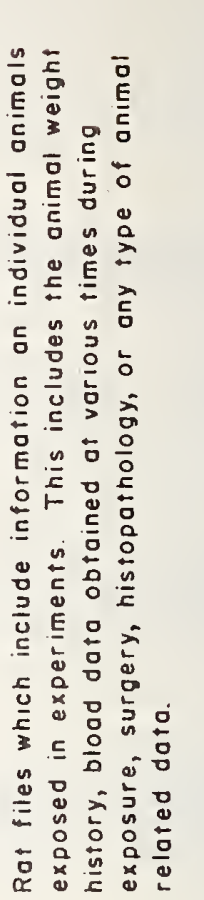

몬

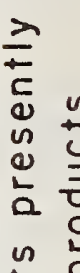

$\leftarrow 2$

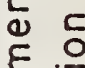

는

م

x

4

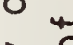

$\frac{\pi}{2} \frac{2}{0}$

둥

ᄃ $\stackrel{0}{\simeq}$

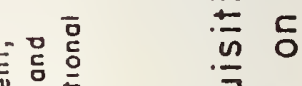

范

चु

O

o

등

言范管

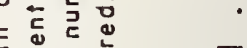

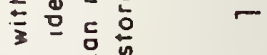

@ $\overline{0}$

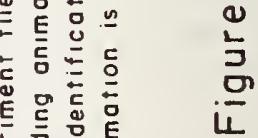

ํํำ 
Table 1

Tests with Material Combinations

Material

Combination

PVC/ $\alpha$-cellulose

PVC/ $\alpha$-cellulose

ABS/PVC

$\mathrm{DF} / \mathrm{PVC}$

DF/ABS

\section{Placement}

side-by-side

back-to-back

side-by-side

side-by-side

side-by-side
Dimensions, inches

$1-7 / 16 \times 11 / 16 \times 0.030$ each

$1-7 / 16 \times 11 / 16 \times 0.060$

$2-15 / 16 \times 2-15 / 16 \times 1 / 8$

$2-15 / 16 \times 2-15 / 16 \times 1 / 8$

$2-15 / 16 \times 2-15 / 16 \times 1 / 8$ 
Institution: University of Washington

Grant No. G6-9016

Grant Title: Development and Evaluation of Vocal Alarm Systems for Hospitals and Convalescent Homes

Principal Investigators: John P. Keating and Elizabeth F. Loftus

Department of Psychology

College of Arts and Science

University of Washington

Seattle, Washington 98195

Project Summary:

In 1973 the current research team (principal investigators Keating and Loftus) developed the messages used for emergency alarms in the Seattle Federal Building. These messages were designed using techniques of behavioral science research and subsequently experimentally evaluated to determine that they facilitated efficient, quick, and calm egress from affected areas during fire and other emergency situations. Subsequently, this system has been adopted by newly constructed federal high-rise buildings as well as copied by a variety of other high-rise structures.

The research team was asked to investigate the feasibility of developing such vocal alarm messages for health facilities (hospitals and convalescent homes). Since health care facilities posed a variety of problems not faced by high-rise structures, the investigation began by a careful review of all literature pertinent to emergency evacuation systems in such facilities. Convinced that the extant literature was almost nonexistent concerning this problem, the investigators initiated a program of research specifically aimed at development of emergency messages for use in health facilities.

The initial phase of this research entailed in-depth interviews with selected hospital and nursing home fire specialists. These interviews acquainted the investigators with problem areas specific to emergency evacuation in hospitals and nursing homes. Surprisingly varied approaches to emergency training and communication were reported during the interviews. While all institutions had some form of alarm signal whether it be vocal communication or simple bell alarms, the way such messages were communicated and alarms sounded dramatically differed between the institutions studied.

To verify this information and to help generalize to a broader hospital/ nursing home population, investigators conducted a mail interview survey concerning alarm procedures that was mailed to all hospitals and nursing homes in the State of Washington. The response to this survey was better than fifty percent. The investigators felt that an accurate representation from the variety of hospitals and nursing homes sampled was secured through the questionnaire format. Once again the variety in 
messages and emergency procedures in use throughout the hospitals and nursing homes in Washington was perhaps the most important finding from the survey.

Since the investigation team's particular mandate was to look at the feasibility of developing vocal alarm messages for health facilities, the focus of the research program was aimed directly at this problem. Relying on the information gained through the interviews and survey, the number one priority was defined as some kind of standardization in the construction of vocal alarm messages for health facilities. Such standard forms seemed essential given the transient character of many doctors who work several hospitals in a community as well as the nursing staff which frequently can be interchanged among cooperating hospitals. The problem of standardization may not be so critically important for nursing homes since nursing homes frequently do not have more sophisticated alarm delivery systems, and usually rely on some electronic alarm to signal an emergency.

The first issue addressed by the investigators was whether such vocal alarm systems should deliver coded messages to alert personnel to emergencies, or simply communicate to personnel as well as patients the fact that an emergency situation in the structure existed. Based partly on our interviews and partly on the written responses to the questionnaire, the investigators concluded that because of a variety of problems with differing patient populations (e.g., burn victims, mental patients), such vocal alarm messages in hospitals should be delivered in a coded format.

With this decision made, the next question addressed by the investigators was how might delivery of a coded message be easily recognized by targeted personnel while at the same time allowing the message to remain concealed from the patient population. Relying on the principles of cognitive experimental psychology, a program of studies was initiated to construct messages with high connotative meaning for informed and trained personne1 which at the same time would communicate relatively innocuous messages to the patients. To accomplish this purpose, a research paradigm was designed to identify words which directly connote fire and at the same time do not explicitly inform the entire population effected that there is a fire in the facility. It is our intent to recommend such words be used to introduce fire messages and at the same time establish a standard, coded format for such messages. For example, the introduction of a fire alarm message could begin with "Nurse Blaze 4 West, Nurse Blaze 4 West" signaling a fire situation on the fourth floor, west wing. The introduction of the message with the title nurse seemed optimal since from our interviews and questionnaire survey nurses seem to be the identified component of the personnel staff whose quick and meaningful response to emergency situations is crucial for successful fire response. The title "nurse" seems also preferable to other possible titles since nurses are seldomly solicited by name over hospital public address systems.

The data collected enabling us to properly identify words and messages for use in health facilities is currently being analyzed and will be available for presentation at the August NBS contractors meeting. At that time, messages will be recommended for use during emergencies in health facilities, and future direction of this research will be described. 
ANNUAL CONFERENCE ON FIRE RESEARCH, NBSIR 77-Z308

Proceedings of a Conference Held at NBS, Gaithersburg, Md., August 3-5, 2977, (Issued October 2977)

Institution:

Grant Title:

Grant No. :

Principal Investigator: John Fothergill

Integrated Systems Inc.

11880 Coakley Circle

Rockville, Ma. 20852

\section{Project Summary:}

Under Contract to the Center for Fire Research, Integrated Systems, Inc.

(ISI) has developed an improved version of a steady state air movement computer simulation program. This model has a much greater ability to represent a contemporary building system and is significantly more efficient than an earlier model completed in 1975. It also provides for horizontal movement and a much improved representation of HVAC systems. Under this same contract, ISI has also developed a new smoke transport computer simulation program which predicts smoke concentrations in a building based upon air movement data. This model is completely compatible with the latest air movement simulation program, including an ability to predict the movement of smoke through HVAC systems.

To provide a basis for testing these new simulation programs, trace gas field tests of three buildings have been and will be made. Trace gas concentration data, state data and pressure differential data has been and will be collected. Parametric models of these buildings are constructed and simulated to calibrate the models against field data. After calibration of the models, parametric variations are simulated to evaluate various smoke control hypothesis.

An unsteady thermal state smoke movement simulation program has also been developed and is being tested. Thermal effects, due to a hypothesized fire scenario, in air movement behavior and smoke transport can be simulated with this program.

An investigation of the practicality of modeling and simulating the effects of dispersion in the smoke transport program has been performed. Present simulation models assume instantaneous homogeneous mixing. This approach appears to be satisfactory for some structures but does not appear to be satisfactory for others. Straight forward treatment of dispersion in the classical form is not economically or practically feasible as an added simulation function to the smoke movement programs. Consequently, a pragmatic approach has been sought in this investigation.

A guideline for smoke control systems designers is also presently in preparation as a part of this effort. 


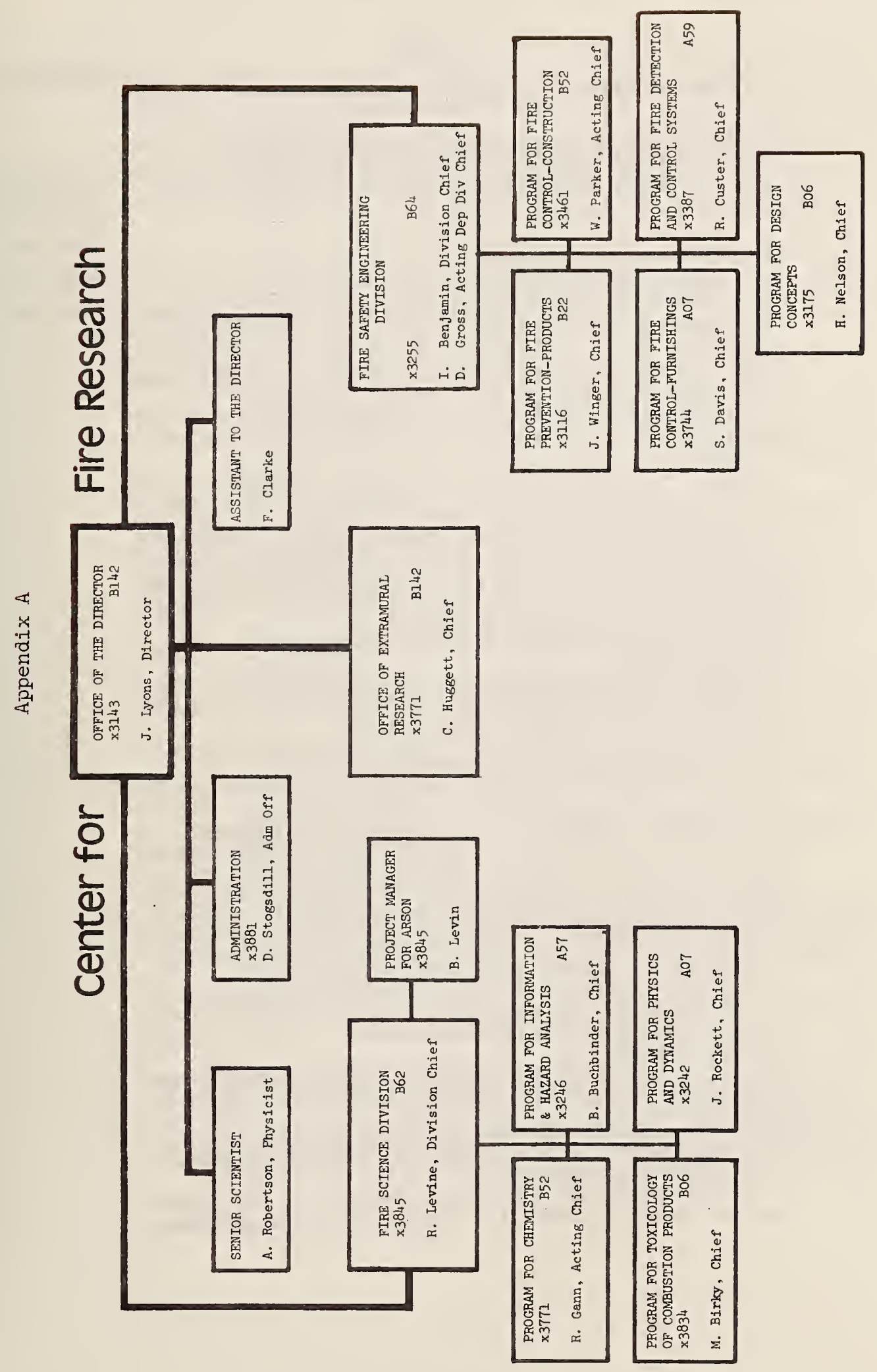




\section{An Alet}

To reduce losses of lift and property, through better fire prevention and control, and for other purposes.

Be it enacted by the Senate and House of Representatives of the United States of America in Congress assembled, That this Act may be cited us the "Federal Fire Prevention and Control Act of 1974".

\section{FINIINGS}

Sec: 2. The Congress finds that--

(1) The National Commission on Fire Prevention and Control, established pursuant to Public Iaw 90-259, has made an exhaustive and comprehersive examination of tlre Nation's fire problem, has made detailed findings as to the extent of this problem in terms of human suffering and loss of life and property, and has made ninety thoughtful recommendations.

(2) The United States today has the highest per capita rate of death and property loss from fire of all the major industrialized nations in the world.

(3) Fire is an undue burden affecting all Americans, and fire also courstitutes a pnblic health and safety problem of great dimensions. Fire kills 12,000 and scars and injures 300,000 Americans each year, including 50,000 individuals who require extended hospitalization. Ilmost $\$$ is billion worth of property is destroyed annually by fire, and the total economic cost of destructive fire in the United States is estimated conservatively to be $\$ 11,000,000,000$ per year. Firefighting is the Nation's most hazardous profession.

(4) Such losses of life and property from fire are unacceptable to tlre Congress.

(5) While fire prevention and control is and should remain a State and local responsibility, the Federal Government must help if a significant reduction in fire losses is to be achieved.

(6) The fire service arrl tlre civil defense program in each locality would both benefit from closer cooperation.

(7) The Nation's fire problem is exacerbated by (A) the indifference with which some Americans confront the subject; (B) the Nation's failure to undertake enough research and development into fire and fire-related problems; (C) the scarcity of reliable data and information; (D) the fact that designers and purchasers of buildings and products generally give insufficient attention to fire safety; (E) the fact that many communities lack adequate building and fire prevention codes; and $(F)$ the fact that local fire departments spend about 95 cents of every dollar appropriated to the fire services on efforts to extinguish fires and only about 5 cents on fire prevention.

(8) There is a need for improved professional training and education oriented toward improving the effectiveness of the fire services, including an increased emphasis on preventing fires and on reducing injuries to firefighters.

(9) A national system for the collection, analysis, and dissemination of fire data is needed to help local fire services establish research and action priorities.

(10) The number of specialized medical centers which are properly equipped and staffed for the treatment of burns and the rehabilitation of victims of fires is inadequate.

(11) The unacceptably high rates of death, injury, and property loss from fire can be reduced if the Federal Government establishes a

Federal Pire Prevention and Control Aot of 1974. 15 USC 2201 note.

15 USC 2201. 15 USC 278 P notes. 
coordinated program to support and reinforce the fire prevention and control activities of State and local governments.

PURPOSES

25 USC 2202.

Sec. 3. It is declared to be the purpose of Congress in this Act to-

(1) reduce the Nation's losses caused by fire through better fire prevention and control;

(2) supplement existing programs of research, training, and education, and to encourage new and improved programs and activities by State and local governments;

(3) establish the National Fire Prevention and Control Adrninistration and the Fire Research Center within the Department of Commerce; and

(4) establish an intensified program of research into the treatment of burn and smoke injuries and the rehabilitation of victims of fires within the National Institutes of Health.

\section{DEFINITIONB}

25 USC 2203.

Sec. 4. As nsed in this Act, the term-

(1) "Academy" means the National Academy for Fire Prevention and Control;

(2) "Administration" means the National Fire Prevention and Control Administration established pursuant to section 5 of this Act:

(3) "Administrator" means the Administrator of the National Fire Prevention and Control Administration;

(4) "fire service" means any organization in any State consisting of personnel, apparatus, and equipment which has as its purpose protecting property and maintaining the safety and welfare of the public from the dangers of fire, including a private firefighting brigade. The personnel of any such organization may be paid employees or unpaid volunteers or any combination thereof. The location of any such organization and its responsibility for extinguishment and suppression of fires may include, but need not bo limited to, a Federal installation, a State, city, town, borough. parish, county, fre district, fire protection district, rural fire district, or other special district. The terms "fire prevention", "firefighting", and "firecontrol" relate to activities conducted by a fire service;

(5) "local" means of or pertaining to any city, town, county, special purpose district, unincorporated territory, or other political subdivision of a State;

(6) "Secretary" means the Secretary of Commerce; and

(7) "State" means any State, the District of Columbia, the Commonwealth of Puerto Rico, the Virgin Islands, the Canal Zone, Guam, American Samoa, the Trust Territory of the Pacific Islands and any other territory or possession of the United States.

FSTARISHMENT OF THF NATIONAL FIRE PREVENTION AND CONTROL ADMINISTRATION

Sec. 5. (a) Establishment of Aduinistration.-There is hereby established in the Department of Commerce an agency which shall be known as the National Fire Prevention and Control Administration.

(b) Anministrator. - There shall be at the head of the Administration the Administrator of the National Fire Prevention and Control Administration. The Administrator shall be appointed by the Presi- 
dent, by and with the advice and consent of the Senate, and shall be compensated at the rate now or hereafter provided for level IV of the Executive Schedule pay rates (5 U.S.C. 5315). The Administrator shall report and be responsible to the Secretary.

(c) Deputy Administrator. - There shall be in the Administration a. Deputy Administrator of the National Fire Prevention and Control Administration who shall be appointed by the President, by and with the advice and consent of the Senate, and who shall be compensated at the rate now or hereafter provided for level V of the Executive Schedule pay rates (5 U.S.C. 5316). The Deputy Administrator shall perform such functions as the Administrator shall from time to tirne assign or delegate, and shall act as Administrator during the absence or disability of the Administrator or in the event of a vacancy in the office of Administrator.

\section{PUBLIC EDUCATION}

SEc. 6. The Administrator is authorized to take all steps necessary to educate the public and to overcome public indifference as to fire and fire prevention. Such steps may include, but are not limited to, publications, audiovisual presentations, and demonstrations. Such public education efforts shall include programs to provide specialized information for those groups of individuals who are particularly vulnerable to fire hazards, such as the young and the elderly. The Administrator shall sponsor and encourage research, testing, and experimentation to determine the most effective means of such public education.

NATIONAL ACADEMY FOR FIRE PREVENTION AND CONTROL

Sec. 7. (a) Egtablishment.-The Secretary shall establish, at the earliest practicable date, a National Academy for Fire Prevention and Control. The purpose of the Academy shall be to advance the professional development of fire service personnel and of other persons engaged in fire prevention and control activities.

(b) Superintendent. - The Academy shall be headed by a Superintendent, who shall be appointed by the Secretary. In exercising the powers and authority contained in this section the Superintendent shall be subject to the direction of the Administrator.

(c) Powers of Superintendent.-The Superintendent is authorized to-

(1) develop and revise curricula, standards for admission and performance, and criteria for the awarding of degrees and certifications;

(2) appoint such teaching staff and other personnel as he determines to be necessary or appropriate;

(3) conduct courses and programs of training and education, as defined in subsection (d) of this section;

(4) appoint faculty members and consultants without regard to the provisions of title 5, United States Code, governing appointments in the competitive service, and, with respect to temporary and intermittent services, to make appointments to the same extent as is authorized by section 3109 of title 5, United States Code;

(5) establish fees and other charges for attendance at, and subscription to, courses and programs offered by the Academy. Such fees may be modified or waived as determined by the Superintendent;

(6) conduct short courses, seminars, workshops, conferences, and similar education and training activities in all parts and localities of the United States; 
(7) enter into such contracts and take such other actions as may be necessary in carrying out the purposes of the Academy; and

(8) consult with officials of the fire services and other interested persons in the exercise of the foregoing powers.

(d) Program of the Academx.-The Superintendent is authorized

(1) train fire service personnel in such skills and knowledge as may be useful to advance their ability to prevent and control hres, inclnding, but not limited to-

(A) techniques of fire prevention, fire inspection, firefighting, and fire and arson investigation;

(B) tactics and command of firefighting for present and

future fire chiefs and commanders;

(C) administration and management of fire services;

(D) tactical training in the specialized field of aircraft fire control and crash rescue;

(E) tactical training in the specialized field of are control

and rescue aboard waterborne vessels; and

(F) the training of present and future instructors in the aforeinentioned subjects;

(2) develop model curricula, training programs, and other educational materials suitable for use at other educational institutions, and to make such materials available without charge;

(3) develop and adininister a program of correspondence courses to advance the knowledge and skills of fire service persommel;

(4) develop and distribute to appropriate officials model questions suitable for use in conducting entrance and promotional exarainations for fire service personnel; and

(5) encourage the inclusion of fire prevention and detection technology and practices in the education and professional practice of architects, builders, city planners, and others engaged in desigu and planning affected by fire safety problems.

(e) TECHNICAL AssistaNCE. - The Administrator is authorized, to the extent that he determines it necessary to meet the needs of the Nation, to encourage new programs and to strengthen existing programs of education and training by local fire services, units, and departments, Stato and local governments, and private institutions, by providing technical assistance and advice to-

(1) rocational training programs in techuiques of fire preven-

tion, fire inspection, firefighting, and fire and arson investigation;

(2) fire training courses and programs at junior colleges; and

(3) four-year degree progranıs in fire engineering at colleges and universities.

Piraccasa?

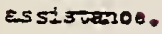

Pogte P. 1545.

(f) Assistance.-The Administrator is authorized to provide issistauce to State and local fire service training programs through grants, contracts, or otherwise. Such assistance shall not exceed 4 per centum of the amount authorizell to be appropriated in each fiscal year pursuant to section 17 of this Act.

(g) Sitr Selectron.-The Academy shall be located on such site as the Secretary selects, subject to the following provisions:

(1) The Secretary is authorized to appoint a Site Selection Board consisting of the Academy Superintendent and two other members to survey the most suitable sites for the location of the Academy and to make recommendations to the Secretary.

(2) The Site Selection Board in making its recommendations and the Secretary in making his final selection, shall give consideration to the training and facility needs of the Academy, environ- 
mental effects, the possibility of using a surplus Government facility, and such other factors as are deemed important and relevant. The Secretaly shall make a final site selection not later than 2 years after the date of enactment of this Act.

(h) Cons'riverrion Cosis.-() () the sums authorized to be appropriated for the purpose of implementing the programs of the Administration, not nore than $\$ 9,000,000$ shall be available for the construction of facilities of the Academy on the site selected under subsection (g) of this section. Such sunis for such construction shall remain available until expended.

(i) Educational and Professional Assistance.-The Administrator is authorized to-

(1) provide stipends to students attending Academy courses and programs, in amounts up to 75 per centum of the expense of attendance, as established by the Superintendent;

(2) provide stipends to students attending courses and nondegree training programs approved by the Superintendent at universities, colleges, and junior colleges, in amounts up to 50 per centum of the cost of tuition;

(3) make ol eliter into contracts to inake payments to institutions of higher education for loans, not to exceed $\$ 2,500$ per academic year tor any individual who is enrolled on a full-time basis in an undergraduate or graduate program of fire research or engineering which is certified by the Superintendent. Loans under this paragraph shall be made on such terms and subject to such conditions as the Superintendent and ench institution involved may jointly determine; and

(4) establish and maintain a placement and promotion opportunities center in cooperation with the fire services, for firefighters who wish to learn and take advantage of different or' better career opportunities. Such center shall not limit such assistance to students and graduates of the Academy, but shall undertake to assist all fire service persomnel.

(j) BoArd of Visirors.-Upon establishment of the Academy, the Secretary shall establish a procedure for the selection of professionals in the field of fire safety, fire prevention, fire control, research and development in fire protection, treatment and relabilitation of fire victims, or local government services management to serve as members of a Board of Visitors for the Academy. Pursuant to such procedure, the Secretary shall select eight such persons to serve as members of such Board of Visitors to serve such terms as the Secretary may prescribe. The function of such Board shall be to review annually the program of the Academy and to make comments and recommendations to the Secretary regarding the operation of the Academy and any improvements therein which such Board deems appropriate. Each member of such Board shall be reimbursed for any expenses actually incurred by him in the performance of his duties as a member of such Board.

(k) Accreditation.- The Siperintendent is authorized to establish Committeo on a Committee on Fire Training and Education which shall inquire into Fire Trainins and make recommendations regarding the desirability of establishing and Eduoation. a mechanism for accreditation of fire training and education programs Establishment. and courses, and the role which the Academy should play if such a mechanism is recommended. The Committee shall consist of the Superintendent as Chairman and eighteen other members appointed by the Administrator from among individuals and organizations possessing special knowledge and experience in the field of fire training and education or related fields. The Committee shall submit to the Adminis- Report to trator within two years after its appointment, a full and complete Administrator. 
report of its fundings and recommendations. Upon the subunission of such report, the Committee shall cease to exist. Each appointed menber of the Committee shall be reimbursed for expenses actually incurred in the performance of his duties as a member.

(I) Apurssiov.- The Superintendent is authorized to admit to the courses and programs of the Academy individuals who are members of the firefighting, rescue, and civil defense forces of the Nation and such other individuals, including candidates for membership in these forces, as lie determines can benefit from attendance. Students shall be admitted from any State, with due regard to adequate representation in the student body of all geographic regions of the Nation. In selecting students, the Supelintendent nay seck nominations and advice from the fire services and other organizations which wish to send students to the Academy.

\section{FIRE TECIYNOLOGY}

15 USC 2207.

Sec. 8. (a) Technology Ievelopment Program.-The Administrator shall conduct a continuing program of developuluent, testing, and evaluation of equipment for use by the Nation's fire, rescue, and civil defense services, with the aim of inaking available improved suppression, protective, auxiliary, and warning devices incorporating the latest technology. Attention shall be given to the standardization, compatibility, and interchangeability of such equipment. Sucl development, testing, and evaluation activities shall include, but need not be limited to-

(1) safer, less cunbel'some articles of protective c'othing. including helmets, boots, and coats;

(2) breathing apparatus with the necessary duration of service, reliubility: low weight, and ease of operation for practical use ;

(3) safe and reliable auxiliary equipment for use in fire prevention, detection, and control, such as fre location detectors, visual and audio communications equipment, and mobile equipment;

( $t$ ) special c'othing and equipment needed for forest fires, brush fires, oil and gasoline fires, aircraft fires and crash rescle, fires occnrring aboard waterborne vessels, and in other special firenghting situations;

(5) Fre detectors and related equipment for residential use with high sensitivity and reliability, and which are sufficiently inexpensive to purchase, install, and maintain to insure wide acceptance and use;

(6) in-place fire prevention systems of low cost and of incrensed reliabilicy and effectiveness;

(i) methods of testing fire a'arms and fire protection devices and systems on a non-interference basis;

(8) the development of purchase specifications, standards, and acceptance and validation test procedures for all such equipulent and devices; and

(9) operation tests, demonstration projects, and fire investigations in support of the activities set fortl in this section.

(b) Lisaratiov.-The Administration shall not engage il the manufactire or sale of any equipment or device developed pursuant to this section, except to the extent that it deems it necessary to adequately develop, test, or evaluate such equipment or device.

(c) Mavagesment STodres.- (1) The Administrator is authorized to conduct, directly or through contracts or grants, studies of the operations and management aspects of fire services, utilizing quantitative techniques, such as operations research, management economics, cost effectireness studies, and such other techniques and methods as 
may be applicable and useful. Such studies shall include, but need not be limited to, the allocation of resources, the optimum location of fire stations, the optimum geographical area for an integrated fire service, the manner of responding to alarins, the operation of citywide and regional fire dispatch centers, firefighting under conditions of civil disturbance, and the effectiveness, frequency, and methods of building inspections.

(2) The Administrator is authorized to conduct, directly or through contracts or grants, research concerning the productivity and efficiency of fire service personnel, the job categories and skils required by fire services under varying conditions, the reduction of injuries to fire service personnel, the most effective fire prevention programs and activities, and techniques for accurately measuring and analyzing the foregoing.

(3) The Administrator is authorized to conduct, directly or through contracts, grants, or other forms of assistance, development, testing, and demonstration projects to the extent deemed necessary to introduce and to encourage the acceptance of new technology, standards, operating methods, command techniques, and management systems for utilization by the fire services.

(4) The Adninistrator' is author'ized to assist the Nation's fire services, directly or through contracts, grants, or other forms of assistance, to measure and evaluate, on a cost-benefit basis, the effectiveness of the programs and activities of each fire service and the predictable consequences on the applicable local fire services of coordination or combination, in whole or in part, in a regional, metropolitan, or statewide fire service.

(d) Roral, Assisiance.-The Admiuistrator is authorized to assist the Nation's fire services, directly or through cont racts, grants, or other forms of assistance, to sponsor and encourage research into approaches, techniques, systems, and equipment to improve fire prevention and control in the rural and remote areas of the Nation.

(e) Coondination.-In establishing and conducting programs under this section, the Administrator shall take full advantage of applicable technological clevelopinents made by other departments and agencies of the Federal fovernment. hy State and local governments, and by business, industry, and nonprofit associations.

\section{NATIONAL FIRE DATA CENTER}

Sec. 9. (a) General. - The Administrator shall operate, directly or through contracts or grants, an integrated, comprehensive National Fire Data Center for the selection, analysis, publication, and dissemination of information related to the prevention, occurrence, control, and results of fires of all types. The program of such Data Center shall be designed to (1) provide an accurate nationwide analysis of the fire problem, (2) identify major problem areas, (3) assist in setting priorities, (4) deterınine possible solutions to problems, and (5) monitor the progress of programs to reduce fire losses. To carry out these functions, the Data Center shall gather and analyze-

(1) information on the frequency, causes, spread, and extinguishment of fires;

(2) information on the number of injuries and deaths resulting from fires, including the maximum available information on the specific causes and nature of such injuries and deaths, and information on property losses;

(3) information on the occupational hazards faced by firefighters, including the calses of deaths and injuries arising, directly and indirectly, from firefighting activities; 
(4) Information on all types of firefighting activities, mcluding inspection practices;

(5) techrival information related to building construction, fire properties of materials, and similar information;

(6) information on fire prevention and control laws, systems, methods, techniques, and administrative structures used in foreign nations;

(7) information on the causes, bohavior, and best method of control of other types of fire, including, but not limited to, forest fires, brush fires, fire underground, oil blow-out fires, and waterborne fires; and

(8) such other information and data as is deemed useful and applicable.

(b) Merryons.-In carrying out the program of the Data Center, the Administrator is authorized to-

(1) develop standardized data reporting methods;

(2) encourage and assist State, local, and other agencies, public and private, in developing and reporting information; and

(3) make full use of existing data gathering and analysis organizations, both public and private.

Insormation dis(c) Disseminatron.- The Administrator shall insure disseminasomination. tion to the maximum extent possible of fire data collected and developed by the Data Center, and shall make such data, information, and analysis available in appropriate form to Federal agencies, State and local governments, private organizations, industry, business, and other interested persons.

MABTER PLANB

25 usc 2209.

Repart to

Sec. 10. (a) General - The establishment of master plans for fire prevention and control are the responsibility of the States and the political subdivisions thereof. The Administrator is authorized to encourage and assist such States and political subdivisions in such planning activities, consistent with his powers and duties under this Act.

(b) REPORr.-Four years after the date of enactment of this Act, the Secretary shall submit to the Congress a report on the est :blishment and effectiveness of master plans in the field of fire prevention and control throughout the Nation. Such report shall include, but need not be limiter to-

(1) a summary of the extent and quality of master plauning activities;

(2) a summary and evaluation of master plans that have been prepared by States and nolitical subdivisions thereof. Snch summary and evaluation shall consider, with respect to each such plan (A) the characteristics of the jurisdiction adopting it, including, but not limited to, density and distribution of population; ratio of volunteer versus paid fire services; geographic location, topography, and climate; per capita rate of death and property loss from fire; size and clinracteristics of political subdivisions of the governmental units thereof; and socio-economic composition; and (B) the approach to development and implementation of the master plans;

(3) an evaluation of the best approach to the development and implementation of master plans (e.g., central planning by a State agency, regionalized planning within a State coordinated by $n$ State agency, or local planning supplemented and coordinated by \& State agency);

(4) an assessment of the costs and benefits of master plans;

(5) a recommendation to Conoress on whether Federal financial assistance should be authorized in order that master plans can be developed in all States; and 
(6) a model master plan or plans suitable for State and local implenientation.

(c) Definition.--For the purposes of this section, a "master plan" is one which will result in the planning and implementation in the area involved of a general program of action for fire prevention and control. Such master plan is reasonably expected to include (1) a survey of the resources and persomnel of existing fire services and an analysis of the effectiveness of the fire and building codes in such area; (2) an analysis of short and long term fire prevention and control needs in such area; (3) a plan to meet the fire prevention and control needs in such area; and (4) an estimate of cost and realistic plans for financing the implementation of the plan and operation on a continuing basis and a summary of problems that are anticipated in implementing such master plan.

\section{REIMBURSEMENT FOR COSTS OF FIREFIGHTING ON FEDERAL PROPERTY}

Sec. 11. (a) Claim.--Each fire service that engages in the fighting 15 USC 2210. of a fire on property which is under the jurisdiction of the United States may file a claim with the Administrator for the amount of direct expenses and direct losses incurred by such fire service as a result of fighting such fire. The claim shall include such supporting information as the Administrator may prescribe.

(b) Determination.- Upon receipt of a claim filed under subsection (a) of this section, the Administrator shall determine-

(1) what payments, if any, to the fire service or its parent jurisdiction, including taxes or payments in lieu of taxes, the United States has made for the support of fire services on the property in question;

(2) the extent to which the fire service incurred additional firefighting costs, over and above its normal operating costs, in connection with the fire which is the subject of the claim; and

(3) the amount, if any, of the additional costs referred to in paragraph (2) of this subsection which were not adequately covered by the payments referred to in paragraph (1) of this subsection.

(c) Payment.--The Secretary shall forward the claim and a copy of the Administrator's determination under subsection (b) (3) of this section to the Secretary of the Treasury. The Secretary of the Treasury shall, upon receipt of the claim and determination, pay such fire service or its parent jurisdiction, from any moneys in the Treasury not otherwise appropriated but subject to reimburseinent (from any appropriations which may be available or which may be made available for the purpose) by the Federal department or agency under whose jurisdiction the fire occurred, a sum no greater than the amount determined with respect to the claim under subsection (b) (3) of this section.

(d) Adjudication.- In the case of a dispute arising in connection with a claim under this section, the Court of Claims of the United States shall have jurisdiction to adjudicate the claim and enter judgment accordingly.

\section{REVIEW OF CODES}

SEc. 12. The Administrator is authorized to review, evaluate, and suggest improvements in State and local fire prevention codes, building codes, and any relevant Federal or private codes and rogulations. In evaluating any such code or codes, the Administrator shall consider the human impact of all code requirements, standards, or provisions

State-looal fire provention oodes, roviow.

15 USC 2211. 
in terms of comfort and habitability for residents or einployees, as well as the fire prevention and control value or potential of each such requirement, standard, or provision.

\section{FTRE BAFETY EFTLCTIVENESS BTATEMENTS}

15 USC 2212.

SEc. 13. The Administrator is authorized to encourage owners and managers of residential multiple-unit, commercial, industrial, and transportation structures to prepare Fire Safety Effectiveness Statements, pursuant to standards, forms, rules, and regulations to be developed and issued by the Administrator.

\section{ANNUAL CONFERENCE}

15 USC 2213

Src. 14. The Administrator is authorized to orgunize, or to participate in organizing, an unnual conference on fire prevention and control. He may pay, in whole or in part, the cost of such conference and the expenses of some or all of the participants. All of the Nation's firc services shall be elicrible to sewd representutives to ench such conference to discuss, exchange ideas on, and participate in educational prograns on new techniques in fire prevention and control. Such conferences shall be open to the public.

PUISLIC SAFETY AW.RDS

25 USC 2214.

Sec. 15. (a) Estanushment.-There are hereby established two classes of howornry awards for the recognition of ontstanding and distinguished service by public safety officers-

(1) the President's Award For Outstanding Public Safety Service ("President's $\Lambda$ ward") ; and

(2) the Secretary's Award For Distinguished Public Safety Service ("Secretary's Award").

(b) Descration.- (1) The President's Award shall be presented by the President of the United States to public sa fety officers for extraordinary valor in the line of duty or for outstanding contribution to public safety.

(2) The Secretary's A ward shall be presented by the Secretary, the Secretary of Defense, or by the Attorney General to public safety osicers for distinguished service in the field of public safety.

(c) SEr.ection.-The Secretary, the Secretary of Defense, and the Attornev General shall advise and assist the President in the selection of individuals to whom the President's Award shall be tendered and in the course of performing such duties they shall seek and review nominations for such awards which are submitted to them by Federal, State, county, and local government officials. They shall annually transmit to the President the names of those individuals determined by them to merit the a ward, together with the reasons therefor. Recipients of the President's A ward shall be selected by the President.

(d) Lrmtation.-(1) There shall not be presented in any one calendar vear in excess of twelve President's A wards.

(?) There shall be no limitation on the number of Secretary's A rards presented.

(e) AwaRD.-(1) Fach President's Award shall consist of-

(A) a medal snitably inscribed, bearing such devices and emblems, and struck from such material as the Secretary of the Treasury, after consultation with the Secretary, the Secretary of Defense, and the Attomey General deems appropriate. The Secretary of the Treasury shall cause the medal to be struck and furnished to the President; and

(B) an appropriate citation. 
(2) Each Secretary's Award shall consist of an appropriate citation.

(f) Regula'trons.-The Secretary, the Secretary of Defense, and the Attorney Gencral are authorized and directed to issue jointly such regulations as may be necessary to carry out this section.

(g) Derinitions.-As uscd in this section, the term "public safety "Publio safety officer" means a person serving a public agency, with or without offloer." compensation, as--

(1) a firefighter;

(2) a law enforcement officer, including a corrections or court officer; or

(3) a civil defense officer.

\section{INNUAL, RFEOKT}

SEc. 16. 'The Secretary shall report to the Congress and the President Report to not later than June 30 of the year following the date of ellactment of Congress and this Act and each year therea fter on all activities relating to fire prerention and control, and all measures taken to implement and carry out this Act during the preceding calendar year. Such report shall include, but need not be limited to-

(a) a thorough appraisal, including statistical analysis, estimates, and long-term projections of the human and economic losses duc to fire;

(b) a survey and summary, in such detuil as is deened advisable, of the research and technology program undertaken or sponsored pursuant to this Act;

(c) a summary of the activities of the $\Lambda$ cademy for the preceding 12 months, including, but not limited to-

(1) an explanation of the curriculum of study;

(2) a description of the standards of admission and performance ;

(3) the criteria for the a warding of degrees and certificates; and

(4) a statistical compilation of the number of students attending the Academy and receiving degrees or certificates;

(d) a sunmary of the activities undertaken to assist the Nation's fire services;

(e) a summary of the public education programs undertaken;

(f) an analysis of the extent of participation in preparing and submitting Five Safety Effcctiveness Statements;

(g) a summary of outstanding problems confronting the administration of this Act, in order of priority ;

(h) such recommendations for additional legislation as are deemed necessary or appropriate; and

(i) a simmary of reviews, evaluations, and suggested improvements in State and local fire prevention and building codes, fire services, and any relevant Federal o: private codes, regulations, and fire services.

\section{AUTHORIZATION OF APPROPRIATIONS}

SEC. 17. There are authorized to be appropriated to carry out the 15 USC 2216. foregoing provisions of this Act, except section 11 of this Act, such sums as are necessary, not to exceed $\$ 10,000,000$ for the fiscal year ending June 30, 1975, and not to exceed $\$ 15,000.000$ for the fiscal year ending June 30, 1976.

FIRE RESEARCH CENTER

SEc. 18. The Act of March 3, 1901 (15 U.S.C. 278), is amended by striking out sections 16 and 17 (as added by title I of the Fire Preven- 
tion and Control Act of 1968) and by inserting in liel thereof the

"SEc. 16. (a) There is hereby established within the Department of Commerce a Fire Researcl Center which shall have the mission of performing and supporting resenrch on all aspects of fire with the ain of providing scientific and technical knowledge applicable to the prevention and control of fires. The content and priorities of the research program shall be determined in consultation with the Administrator of the National Fire Prevention and Control Administration. In implementing this section, the Secretary is authorized to conduct,

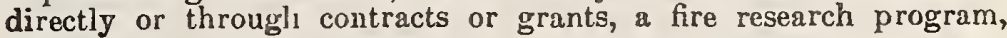
including-

"(1) basic and applied fire resentch for the purpose of arriving at an understanding of the fundamental processes underlying all aspects of fire. Such research shall include scientific investigations of -

"(A) the physics and chenistry of combustion processes;

"(B) the dynamics of flame ignition, flame spread, and flame extinguishment;

"(C) the composition of coinbustion products developed by various sources and under various environmental conditions;

"(D) the early stages of fires in buildings and other structures, structural subsystems and structural components in.all other types of fires, including, but not limited to, forest fires, brush fires, fires underground, oil blowout fires, and waterborne fires, with the aim of improving early detection capability;

"(E) the behavior of fires involving all types of buildings and other structures and their contents (including mobile homes and highrise buildings, construction materials, floor and wall coverings, coatings, furnishings, and other combustible materials), and all other types of fires, including forest fires, brush fires, fires underground, oil blowout fires, and waterborne fires;

"(F) the unique fire hazards arising from the transportation and use, in industrial and professional practices, of combustible gases, fluids, and materials;

:(G) design concepts for providing increased fire safety consistent with habitability, comfort, and human impact in buildings and other structures; and

"(H) such other aspects of the fire process as may be deemed useful in pursuing the objectives of the fire research program;

-(2) research into the biological, physiological, and psychological factors affecting human victims of fire, and the performance of individual members of fire services, including-

"(A) the biological and physiological effects of toxic substances encomtered in fires;

(B) the trauma, cardiac conditions, and other hazards resulting from exposure to fire;

"(C) the development of simple and reliable tests for determining the cause of death from fires;

"(D) imploved methods of providing first aid to victims of fires;

"(E) psychological and motivational characteristics of persons who engage in arson, and the prediction and cure of such behavior;

"(F) the conditions of stress encountered by firefighters, the effects of such stress, and the alleviation and reduction of such conditions; and 
"(G) such other biological, psychological, and physiological elfects of fire as have significance for purposes of control or prevention of fires; and

“(3) operation tests, demonstration projects, and fire investigations in support of the activities set forth in this section.

"The Secretary shall insure that the results and advances arising from the work of the researcli program are disseminated bioadly. He shall encourage the incorporation, to the extent applicable and practicable, of such results and advances in building codes, fire codes, and other relevant codes, test methods, fire service operations and training, and standards. The Secretary is anthorized to encourage and assist in the development and adoption of uniform codes, test methods, and standards aimed at reducing fire losses and costs of fire protection.

"(b) For the purposes of this section there is authorized to be Appropriation. appropriated not to exceed $\$ 3,500,000$ for the fiscal year ending June 30,1975 and not to exceed $\$ 4,000,000$ for the fiscal year ending June 30, 1976."

\section{VICTIMS OF FIRE}

Sec. 19. (a) Procmanr.-The Secretary of Health, Education, and 42 uSc 290a. Welfare shall establish, within the National Institutes of Health and in cooperation with the Secretary, an expanded progran of research on burns, treatment of burn injuries, and rehabilitation of victims of fires. The National Institutes of Health shall--

(1) sponsor and encourage the establishment throughout the Nation of twenty-five alditional bnrn centers, which shall comprise separate hospital facilities providing specialized burn treatment and including research and teaching programs, and twenty-five additional burn units, which shall comprise specialized facilities in general hospitals used only for burn victims;

(2) provide training and continuing support of specialists to staff the new burn centers and burn units;

(3) sponsor and encourage the establishment of ninety burn prograns in general hospitals which comprise staffs of burn injury specialists;

(4) provide special training in emergency care for bnrn victims;

(5) augment sponsorship of research on lonrus and burn treatment;

(6) administer and support a systematic program of research concerning smoke inhalation injuries; and

(7) sponsor and support other research and training programs in the treatment and rehabilitation of burn injury victims.

(b) Authorization of Aprropriation.-For purposes of this section, there are authorized to be appropriated not to exceed $\$ 5,000,000$ for the fiscal year ending June 30,1975 and not to exceed $\$ 8,000,000$ for the fiscal year ending June 30,1976 .

\section{PUBLIC ACCESS 'TO INFORMATION}

SEc. 20. Copies of any document, report, statement, or information 15 USC 2217. received or sent by the Secretary or the Administrator shall be made available to the public pursuant to the provisions of section 552 of title 5, United States Code: Provided, That, notwithstanding the provisions of subsection (b) of such section and of section 1905 of title 18, United States Code, the Secretary may disclose information which concerns or relates to a trade secret--

(1) upon request, to other Federal Government departnients and agencies for official use; 
(2) upon reguest, to any conmittee of Congress having jurisdiction over the subject niatter to which the information relates;

(3) in any judicial proceeding under a court order formulated to preserve the confidentiality of such inforuation without impairing the proceedings; and

(4) to the public whenl he determines such disclosure to be necessary in order to protect liealth and safety after notice and opportunity for conmucnt in writing or for discussion in closed session within fifteen days by the party to which the information pertains (if the delay resulting from such notice and opportunity for consment would not be detrimental to health and safety).

\section{ADMINISTRA'TIVE PROVISIONS}

25 USC 2218.

ScEmiviar Gerera?, cess to $=90-$ xds.

Piblieation in Fed 파리 Rog1s ter.

Sec: 21. (a) Assistance.-Each department, agency, and instrumentality of the executive brauch of the Federal Governinent and each independent regulatory agency of the United States is authorizcd and directed to furnish to the Administrator, npon written request, on a reimbursable basis or otherwise, such assistance as the Administ rator deems necessary to carry ont his functions and duties pursuant to this Act, including, but not linited to, transfer of personuel with their consent and withont prejudice to their position and ratings.

(b) Powers.-With respect to this Act, the Administrator is nuthorized to -

(1) enter into, without regard to section 3709 of the Revised Statutes, as amended ( 41 U.S.C. 5) such contracts, grants, leascs, cooperative agreements, or other transactions as may be necessary to carry out the provisions of this Act;

(2) accept gifts and voluntary and uncompensated services, notwithstanding the provisions of section 3679 of the Revised Statutes (31 U.S.C. $665(b)$ ) ;

(3) purchase, lease, or otherwise acquire, own, hold, improve, use, or deal in and with any property (real, personal, or mixed, tangible or intangible), or interest in property, wherever situated; and sell, convey, mortgage, pledge, lease, exchange, or otherwise disoose of property and assets;

(4) procure temporary and intermittent services to the sume extent as is authorized under section 3109 of title 5 , United States Coce, but at rates not to exceed $\$ 100$ a day for qualified experts; and

(5) establish such rules, regulations, and procedures as are uecessary to carry out the provisions of this Act.

(c) ACJIT.-The Secretary and the Comptroller General of the Unized States, or any of their duly authorized representatives, shall have access to any books, documents, papers, and records of the recipients of contracts, grants, or other forms of assistance that are pertinent to its activities under this Act for the purpose of audit or to determine if a proposed activity is in the public interest.

(d) INVENTTONS AND Discoveries. - All property rights with respect to inventions and discoveries, which are made in the course of or under contract with ally government agency pursuant to this Act, sliall be subject to the basic policies set forth in the President's Statement of Government Patent Policy issned August 23, 1971, or such revisions of that statement of policy as may subsequently be promulgated and published in the Federal Register.

(e) Coondination.- - To the extent practicable, the Administrator siall utilize existing programs, data, information, and facilities already available in other Federal Government departments and agencies and, where appropriate, existing research organizations, centers, 
and universities. The $\Lambda$ duministrator shall provide liaison at an appropriate organizational level to assure coordination of his activities with State and local govermment agencies. departments, bureaus, or offices concerned with any matter related to programs of tire prevention and control and with private and of her Federal organizations and oflices so concerned.

ASSISTANCE TO CONSUMFR PRODUÜI SAFETY COMMISSION

Sec. 22. Upon request, the Administrator shall assist the Consmmer 25 USC 2219. Product Safety Commission in the derelopinent of fire sa fety standards or codes for consumer uroducts, as defined in the ('onsumier Product Safety Act (15 U.S.C. 21051 et seq.).

\section{CONFORMING AMENDMENTS}

Sec. 23. Section 12 of the Act of February 14, 1903, as amended (15 U.S.C. 1511), is amended to read as follows :

\section{"BUREAUS IN DEPARTMENT}

"SEc. 12. The following named bureaus, administrations, services, offices, and programs of the public service, and all that pertains thereto, shall be under the jurisdiction and subject to the control of the Secretary of Commerce:

"(a) National Oceanic and Atmospheric Administration;

"(b) United States Travel Service;

“) Maritime Administration;

“(d) National Bureau of Standards;

"(e) Patent Office;

"(f) Bureau of the Census;

"(g) National Fire Prevention and Control Administration; and

"(h) such other bureaus or other organizational units as the Secretary of Conmerce may fron time to time establish in accordance with law."

Approved October 29, 1974.

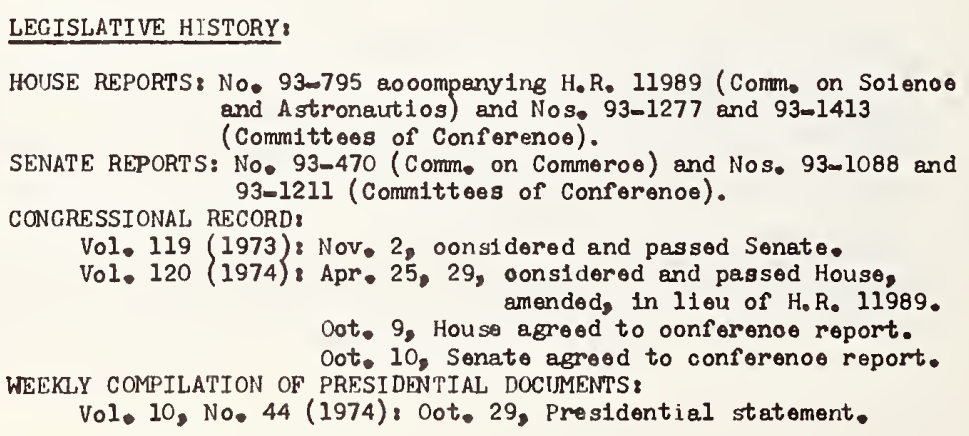


NBS-114A IREV. 7-73)

\begin{tabular}{|c|c|c|}
\hline $\begin{array}{l}\text { 1. PUBLICATION OR REPORT NO. } \\
\text { NBSIR } 77-1308\end{array}$ & $\begin{array}{l}\text { 2. Gov't Accession } \\
\text { No. }\end{array}$ & 3. Recipient's Accession No. \\
\hline \multirow{2}{*}{\multicolumn{2}{|c|}{$\begin{array}{l}\text { 4. TITLE AND SUBTITLE } \\
\text { Annual Conference on Fire Research }\end{array}$}} & $\begin{array}{l}\text { 5. Publication Date } \\
\text { October } 1977\end{array}$ \\
\hline & & 6. Performing Organization Code \\
\hline 7. AUTHOR(S) Clayton Huggett, Editor & & 8. Performing Organ. Report No. \\
\hline \multirow{2}{*}{\multicolumn{2}{|c|}{$\begin{array}{l}\text { 9. PERFORMING ORGANIZATION NAME AND ADDRESS } \\
\text { NATIONAL BUREAU OF STANDARDS } \\
\text { DEPARTMENT OF COMMERCE } \\
\text { WASHINGTON, D.C. } 20234\end{array}$}} & $\begin{array}{l}\text { 10. Project/Task/Work Unit No. } \\
4900900\end{array}$ \\
\hline & & 11. Contract/Grant No. \\
\hline \multirow{2}{*}{\multicolumn{2}{|c|}{ 12. Sponsoring Organization Name and Complete Address (Street, City, State, ZIP) }} & $\begin{array}{l}\text { 13. Type of Report \& Period } \\
\text { Covered } \\
\text { Final Report }\end{array}$ \\
\hline & & 14. Sponsoring Agency Code \\
\hline
\end{tabular}

15. SUPPLEMENTARY NOTES

16. ABSTRACT (A 200-word or less factual summary of most significant information. If document includes a significant bibliography or literature survey, mention it here.)

This report contains extended abstracts of grants and contracts for fire research sponsored by the Center for Fire Research, National Bureau of Standards and descriptions of the internal programs of the Center for Fire Research. It was prepared as a preprint for use at a conference of contractors and grantees held at NBS on August 3-5, 1977.

17. KEY WORDS (six to twelve entries; alphabetical order; capitalize only the first letter of the first key word unless a proper name; separated by semicolons) Combustion products; fire hazards; fire modeling; fire research; human behavior in fires.

$$
\text { X Unlimited }
$$

[ For Official Distribution. Do Not Release to NTIS

[ Order From Sup. of Doc., U.S. Government Printing Office Wa shington, D.C. 20402, SD Cat. No. C13

[X] Order From National Technical Information Service (NTIS) Springfield, Virginia 22151

\begin{tabular}{|l|c|}
\hline $\begin{array}{l}\text { 19. SECURITY CLASS } \\
\text { (THIS REPURT) } \\
\text { UNCL ASSIFIED }\end{array}$ & 198 \\
\hline $\begin{array}{l}\text { 20. SECURITY CLASS } \\
\text { (THIS PAGE) }\end{array}$ & 22. Price \\
UNCLASSIFIED & $\$ 9.00$ \\
\hline
\end{tabular}



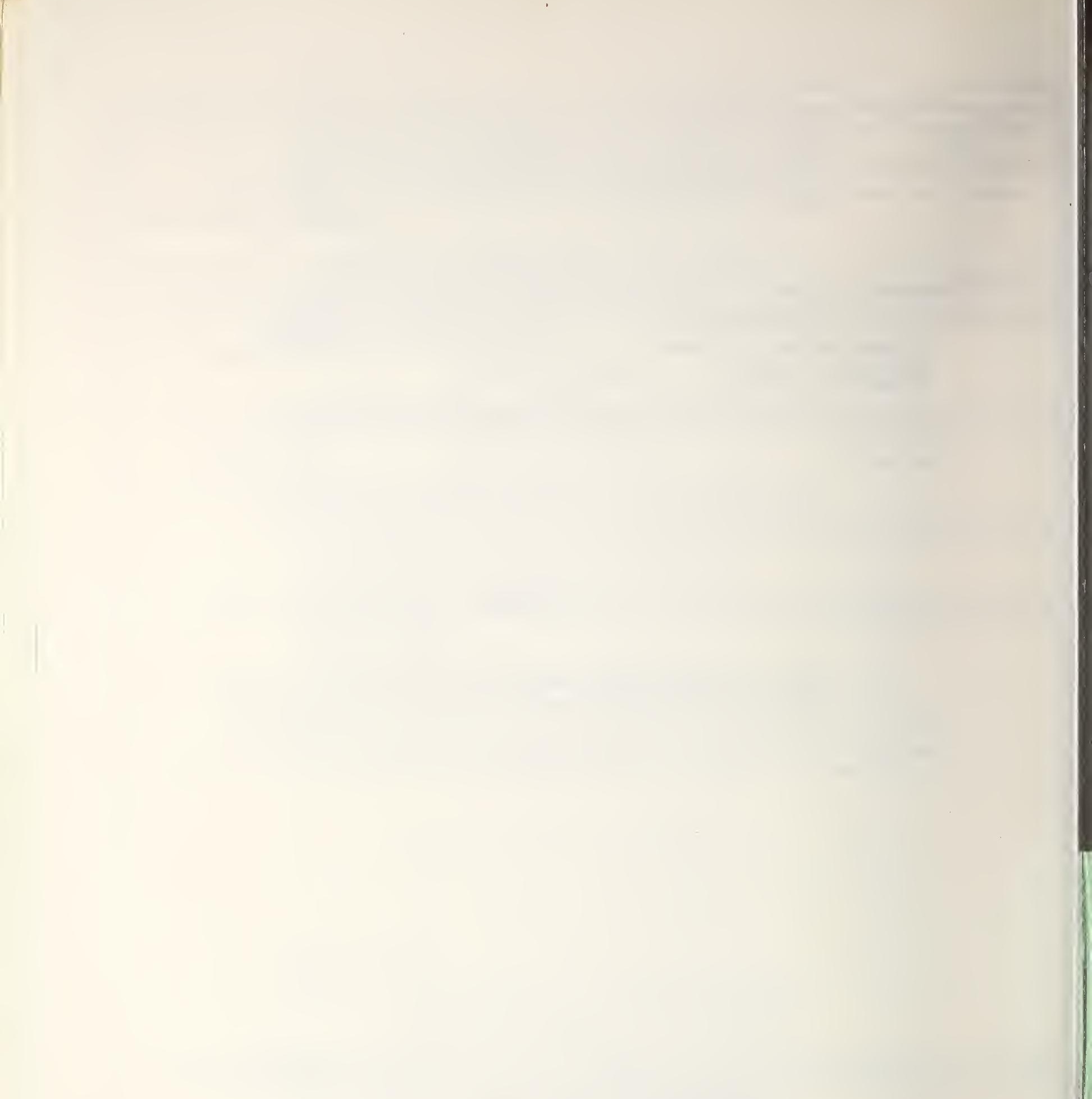